


\section{DELICACY}

by

Jaimee Morley

A thesis submitted to the Victoria University of Wellington in fulfilment of the requirements for the degree of Master of Architecture (Professional)

Victoria University of Wellington School of Architecture 


\section{ABSTRACT}

A new acceptance of aesthetics, technological advancements and current trends of slenderness and lightness have encouraged contemporary society towards the delicate. Delicacy is a notion within the aesthetic concept of beauty. To explore this shift towards the delicate in this portfolio, I explore the potential of delicacy within architecture through shifting scales. The design-led methodological framework pursues an iterative approach of exploration. To aid in generative and reflective discovery this research is structured to address three different scales: a 1:1 installation, mid-scale project and a public-scale project. The three scales increased in architectural complexity whilst testing the proposition. Literary context, projects and design precedents fed into the design process, further refining the proposition as it shifted. Scale, materiality, and colour and whiteness were developed as an evaluative framework throughout the entire research. An installation investigating the 'vast and the intimate' highlighted the importance of the human scale and considering materiality and construction techniques. The next experiment tested the proposition at an architectural scale and, through evaluation, refined the proposition to focus on delicacy. The final design investigation considers the perception of delicacy through a seemingly effortless architectural outcome through multiple scales. To conclude, the research considers the overarching typology down to the detail. Structure, materiality and detailing can all positively inform and enrich architectural aesthetic possibilities in favour of the delicate, where complexities are hidden within the appearance of effortlessness. 


\section{Acknowledgements}

Firstly, to my supervisor Jan Smitheram thank you for your endless support, encouragement and guidance.

To my quirky and loving family, thanks for the five years of enthusiasm, support and personal tutoring.

Joe, thanks for the best year yet.

Lastly thank you to the studio of 2017, the last five years have been unforgettable. 


\section{CONTENTS}

Abstract

01 Introduction

01

02 Literature Context

03 Design Precedents 26

04 Installation

05 Mid-Scale

06 Public-Scale

07 Conclusion

Reference List

Figures List

366 
01

INTRODUCTION 


\section{Background}

Contemporary life revolves around slenderness, not just architecture. As Mark Wigley argues, "to incessantly see, feel, hear, tap and stroke thin planes has become as vital as breathing. Our phones, tablets, laptops, and screens keep getting thinner" (2015, p. 27). A new acceptance of aesthetics, technological advancements and current trends of thinness and slenderness has encouraged contemporary society towards the delicate. Mosco argues in recent times "slenderness has regained its expressive context" (2012, p. 140). The current technological advancements toward delicacy (thinness and slenderness) is a conversation continuing in architecture. As Wigley argues, "thin has become the very image of connectivity and interactivity... Yet we hear so little about thinness in architecture, what it is, has been or could be" (2015, p. 27). Additionally, Mostafavi argues that investigating architecture with delicacy as the driver pushes for new possibilities of pure lightness, through re-thinking construction methods, scale and materials (2011, p. 247). This research is positioned within that context as it aims to investigate the potential of delicacy in architecture. Key words associated with delicacy and beauty both in traditional and contemporary society are; smooth, light, slender, thin, fragile, graceful (Burke, 1958, p. 96; Mattick, 2003, p. 48).

The exploration of delicacy comes from the lightness with materials, construction and making users aware of the fragility of architecture and weight of the building. Nishizawa confirms that "many young architects are now exploring this feeling of lightness and transience" (cited in Mostafavi, 2010, p. 11). Through the rise in trending popularity and consumer aesthetics, the notion of delicacy is well suited for analysis and investigation. Re-considering standard architectural elements such as a column can critique standardisation in favour of the delicate. 


\section{Scope}

This research recognises contemporary trends shifting towards the notion of delicacy and continues a discussion within the subjective nature of aesthetics.

The research operates primarily through a 'design as research' methodology rather than a research for design. Because the research is design-led, it does not attempt to provide a conclusive architectural solution for delicacy in architecture. Rather it explores and investigates the potential to evoke delicacy in architecture through three specific design enquires at three different scales. The research is investigated through a 1:1 installation, mid-scale design of a café pavilion and a public-scale design of a gallery and community centre over a time period of 8 months. The pace at which the installation and mid-scale design tests operated meant that the development was limited.

The proposition of this research changed and, as a result, this impacted on the scope. It was narrowed from exploring how to operate the vast and the intimate scale simultaneously at the installation and mid-scale stage, to the notion of delicacy for the public-scale. Direct discussion of delicacy within architecture is minimal. Through literature reviews and theoretical context, three essential elements of architecture have been aligned with evoking delicacy. As a result this research explored delicacy through an evaluative framework of three key themes; scale, materiality, and colour and whiteness. 
The research portfolio is comprised of $75 \%$ design and $25 \%$ designintegrated critical explanation and written theory. This document specifically is the $25 \%$ written contribution to the whole portfolio as per the course outline (Marques, 2017).

Despite the scope's continual refinement throughout the course of the research, certain areas of design and research could not be fully addressed. Such examples include:

- Detail development at the mid-scale

- Wider discussion about aesthetics and beauty

- Wider discussion and exploration of delicacy outside the scope of scale, materiality and colour and whiteness

- Working with timber as a delicate material

- Developing delicacy through techniques such as 3D printing

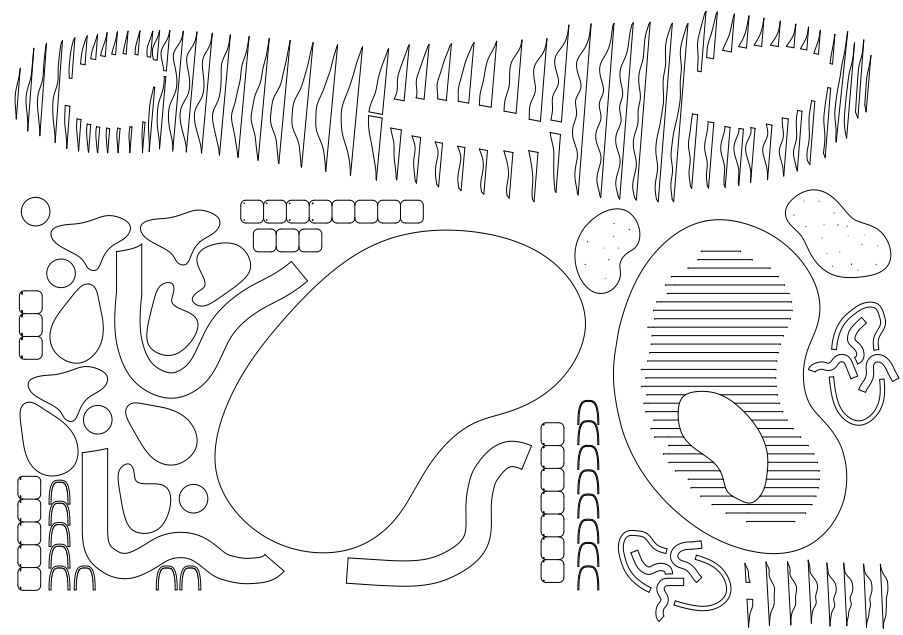

$\wedge$ 02. Design process making 
Proposition

How can architecture explore the notion of delicacy through a shift in scales? 


\section{Methodology}

This thesis focused on design-led research, where investigative and explorative design is the research. Following Murray Fraser's design methodology, alongside Jane Rendell's and Peter Downton's, “design research can be described as the processes and outcome of inquiries and investigations in which architecture use the creation of projects, or broader contributions towards design thinking" (Fraser, 2013, p. 1). Design-led research is an iterative methodology that is continually and critically analysed and reflected upon, whilst constantly progressing forward. Rendell argues, "instead of posing research question and then finding answers, in much design research the process operates through generative modes, producing works at the outset that may then be reflected upon later" (2013, p. 117). Following Rendell's argument, this thesis immediately started with design, and, upon critical reflection at each stage, discoveries were made that triggered external research and theoretical context. This way of researching allowed the proposition to develop throughout the investigation, creating a dynamic relationship between design and the disciplinary body of knowledge.

To clarify, due to the nature of the methodology, I was testing through design to refine the research proposition. Because of this, the proposition initially began investigating the beautiful sublime through focusing on the vast and the intimate scale simultaneously. However, upon critical reflection within the design process, the proposition evolved and refined towards investigating the notion of delicacy. This shift is clearly noted in chapter five. Due to the nature of the methodology the literary context 
was developed, as the research was refined, through the process of design. For the purpose of the course outline and clarity, the literary context is placed at the front of the document rather than distributed throughout.

A central method in this portfolio was shifting scales (and was a requirement of the stream). The research was explored at three different scales: a 1:1 scale installation, mid-scale design and a public scale. The tests and experiments from each scale helped inform the next, as they developed towards the final public scale design. As each stage increased in scale, the design's complexity also increased. Albena Yaneva considers shifting scales to be a strong method of design. She argues that "the tiny material operations of 'scaling up', 'jumping the scale', 'rescaling', and 'going down in scale' enable architects to think of the building and to gain new knowledge about it. Knowing through scaling is an integral aspect of architectural practice" (2005, p. 870). Yaneva's method of jumping in scale accelerates the design's concept and understanding, and continues the awareness of the human scale throughout the design process.

Within the three design projects, key methods used included: analogue drawing, physical and digital modelling, photography, diagramming and other means of graphic representation. Shifting through mediums these methods of designing enabled an iterative, extractive and reflective approach in relation to the scope of the research. 

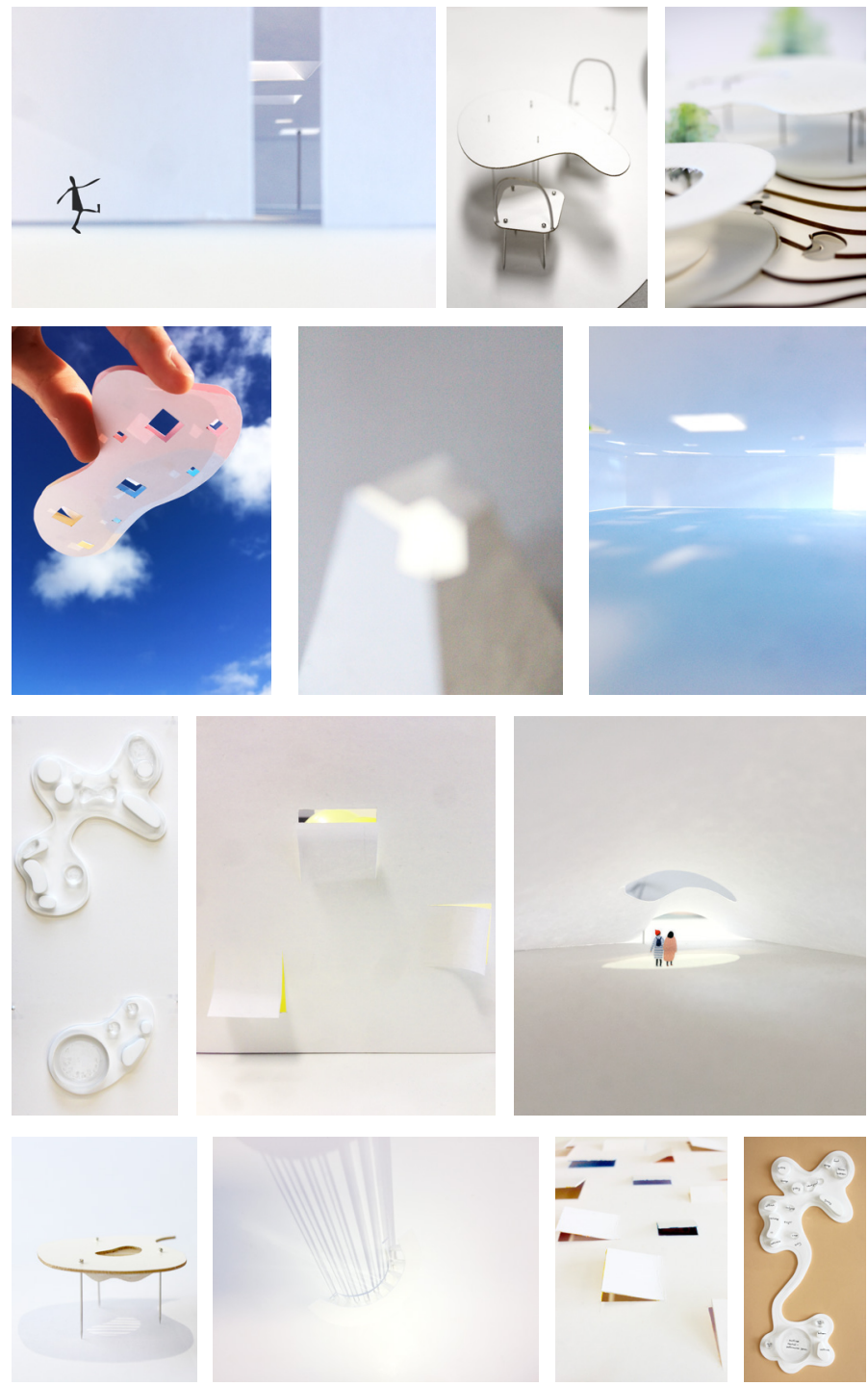

$8 \wedge$ 03. Design process matrix 


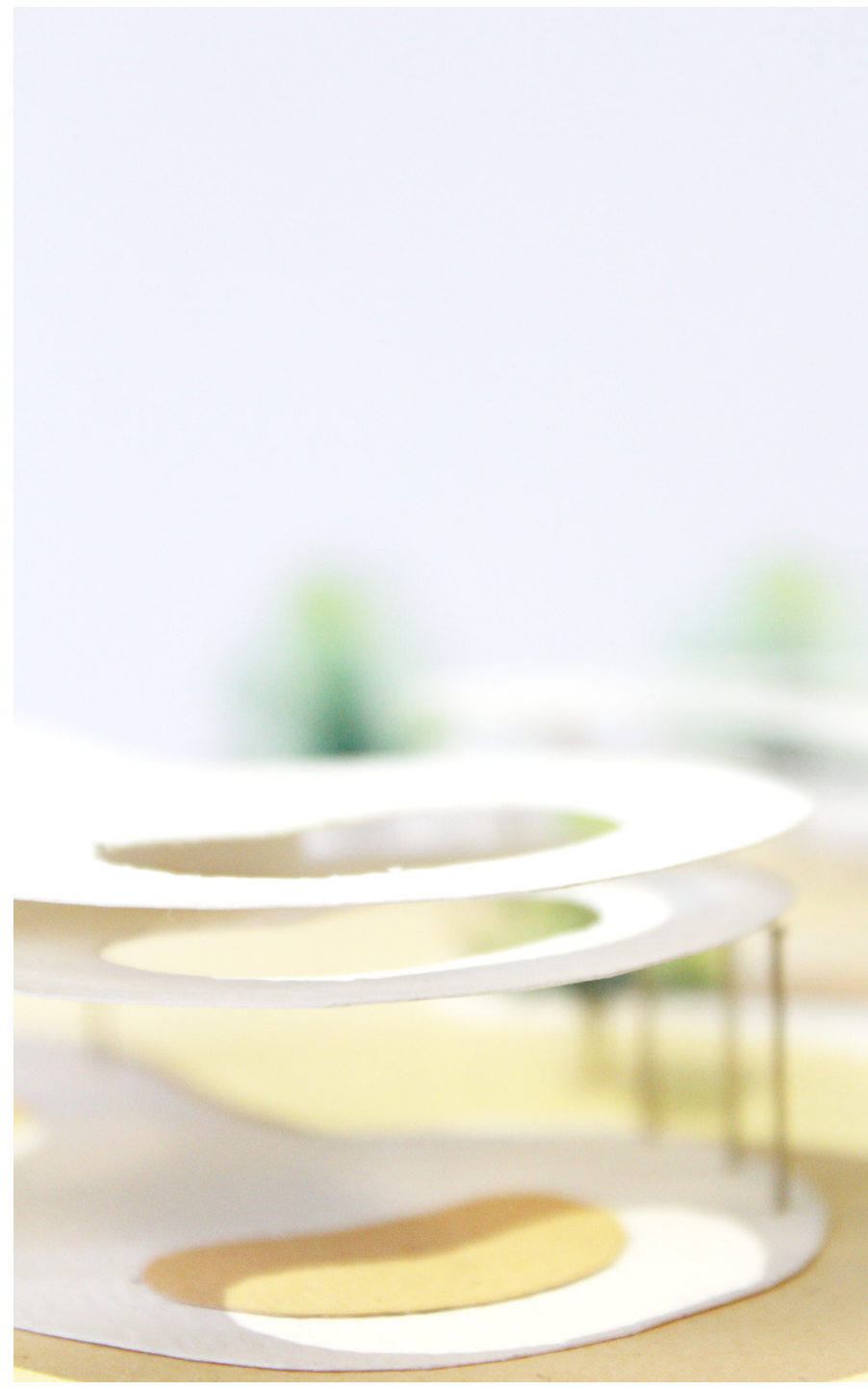

$\wedge$ 04. Iteration example 


\section{Research Structure}

This research portfolio is structured into 7 chapters

\section{Introduction}

The first chapter identifies the scope of the research. It is articulated through the background, proposition, scope and methodology. The thesis structure is also outlined.

\section{Literature Context}

The second chapter provides the theoretical, literature and precedential context relevant to the scope of the research. Aesthetic theory and Edmund Burke's concept of beauty provide the background to which the notion of delicacy is packed with both traditional and contemporary relevance. Mies and SANAA are highlighted as the traditional and contemporary figure. Delicacy is also discussed in relation to scale, materiality and colour and whiteness. The context chapter was developed in relationship to the design chapters as the proposition refined through design. This is not a traditional approach; however it is one that fits a design-as-research methodology.

\section{Design Precedents}

The third chapter analyses and critiques three key design precedents through an evaluative framework that is relevant to the scope of the research. Each precedent is evaluated against scale, materiality, and colour and whiteness. 


\section{Installation}

Installation is the first of three design chapters. It attempts to evoke the beautiful sublime, by focusing on engaging the vast and the intimate scale simultaneously through the design of an installation. Each design enquiry is critically reflected upon, regarding strengths and weaknesses, which led to the final design of the installation.

\section{Mid-Scale}

The second design experiment attempts to develop an architectural solution of a café pavilion that explores the vast and the intimate scale simultaneously. It develops upon what was learnt in chapter four, shifting towards an architectural language. The jump in scale accelerates the research and explores it with new complexities of site and programme. Chapter five concludes with a critical reflection where the proposition was refined towards the notion of delicacy.

\section{Public-Scale}

The public-scale is the final design chapter and investigates delicacy within architecture through the design of a gallery and community centre. It develops upon what was discovered and experimented in chapter four and five, providing critical reflections on each design test. The strengths from each design test were developed into a final design. Chapter six concludes with a critical reflection on the design where the notion of delicacy was explored through scale, materiality, and colour and whiteness in pursuit of the appearance of delicacy.

\section{Conclusion}

The final chapter concludes the research by providing a final critical reflection on the designs, process, successes and failures in relation to the scope of the research and the disciplinary body of knowledge. The potential for further research in this subject is provided within the discussion. 
02

\section{LITERATURE CONTEXT}


Introduction

This chapter provides the literature review and locates key precedential projects and critiques relevant to the scope of the research. Delicacy is within the discussion of aesthetic theories such as the beautiful and sublime. However, with limited literature discussions, arguments and references on delicacy within architecture specifically, this chapter pieces together an argument about delicacy. Due to the brevity of this portfolio document, the literary review discusses key authors, figures and ideas, as it cannot cover the same scope a full literature review considers. This literature chapter was developed alongside the design chapters, as the proposition was refined. This is not a traditional approach, however it aligns with the design-as-research methodology. Moreover, the limited scope of this chapter, due to brevity, means that although delicacy is part of many different concepts such as taste, this chapter focuses on delicacy in the context of architecture and Edmund Burke's concept of beauty ([1773] 1958). Focusing on Burke's theory of the sublime and the beautiful will firstly be briefly discussed, where the concept of delicacy is unravelled with both traditional and contemporary relevance. The absence of discussion around beauty and its subjective nature is also acknowledged, highlighting the emergence of the minor concept, delicacy. Secondly, delicacy will be briefly recognised alongside minimalism and two key figures in architectural development towards the delicate: Mies van der Rohe and SANAA as the traditional and contemporary figure of delicacy. Delicacy will then be unpacked through three key themes: scale, materiality, and colour and whiteness, essential qualities of architecture. This chapter concludes by addressing the three key themes as an evaluative framework to which the following chapters critique, discuss and explore delicacy. 


\section{Aesthetics and Beauty}

Delicacy is a situated within the prestigious aesthetic concept of beauty. Immanuel Kant acknowledged, "beauty, whether it be beauty of nature or of art, is the expression of aesthetic ideas" (Kant \& Meredith, 1911, p. 183). Philosopher Edmund Burke, a central figure in aesthetic judgements published a comprehensive and influential examination on the theory of the sublime and the beautiful. Burke gathered a lot of data and aligned the beautiful with the small, delicate, clear, smooth and light. His framework rejected Vitruvius's ideas of proportion and symmetry as essential signifiers of beauty (Burke, [1773] 1958, p. 96). As a result of Burke's influence "the experience of beauty would still today likely to be typed as 'feminine: smallness, smoothness, curviness, delicacy, cleanliness, soft coloration, lack of resistance, quietness" (Mattick, 2003, p. 48). Two hundred and fifty years later, the components that Burke outlined and discussed, such as delicacy are still relevant however due to a troubled relationship, are absent from discussion.

Aesthetics and beauty lost status within discussions due to its subjective nature. Simon O'Sullivan discusses the cause of aesthetic blindness and argues there were at least two factors, Marxism and deconstruction (2001, p. 125). Both of these factors placed an importance on theory, which in turn lead to a disinterest in beauty as aesthetics is "less involved in knowledge and more involved in experience" (O'Sullivan, 2001, p. 130). O'Sullivan argues "first aesthetics fell foul of Marxism A disinterested beauty?... Then it fell foul of deconstruction" (2001, p. 126). This disabled aesthetic discourse continued and the lack of discussion was due beauty being viewed as a superficial concern rather than critical, progressive or intellectual (Scruton, 1979, p. 25; Meyer, 2008, p. 6; Reisner \& Watson, 2010, p. 15). Reisner and Watson argue how "architectural discourse has been dogged by the Modernist ambition to avoid being driven by aesthetics" (Reisner \& Watson, 2010, p. 16), thus also contributing to the loss of discussion around aesthetics and beauty losing status. The subjective nature of aesthetic theory and the concept of beauty are 
discussed by many. Reisner argues, "for many, beauty is a concept that does not hold any value within architecture, while for others it has regained its importance and relevance" such as Frank Gehry who finds beauty to be "pretty and soft" (cited in Reisener \& Watson, 2010, p. 12). Odile Decuq believes that "to be in denial of the importance of beauty is the rejection of a basic human right" (cited in Reisner \& Watson, 2010, p. 13). These positions showcase a continually developing troubled relationship with aesthetics, beauty and architecture. Reisner and Watson highlighted the late 1970s generally to have provided an encouraging change "for aesthetically driven design to achieve positive status" as emotional content re-emerged (2010, p. 18), thus placing the discussion around beauty in a more favourable light, returning to the importance of aesthetics.

In recent times minor concepts within beauty such as delicacy are reemerging with value. To counter common tendencies, philosopher J. $\mathrm{L}$ Austin posed the question "how much it is to be wished that similar fieldwork will soon be undertaken in, say, aesthetics; if only we could forget for a while about the beautiful and get down instead to the dainty and the dumpy" (1956-1957, p. 9). Although Austin discusses this to insist that philosophers should clearly understand minor contexts before heavily investigating large-scale academic theories; it is directly relevant to this discussion. Austin highlights an interest in aesthetic concepts but more importantly draws attention to the minor concepts, the ones that are situated beneath the prestigious concepts such as the sublime and beautiful (Ngai, 2005, p. 811). Ngai also argues for the importance of aesthetic concepts that have been neglected by traditional theory. Concepts that are considered minor, however, are vital towards contemporary trends, culture and practice (Ngai, 2015). Ngai sheds light of the focus on this research, the notion of delicacy, a small concept within the beautiful one that lacks direct discussion. Despite architecture's resistance to acknowledging aesthetics, minimalism and delicacy contain strong links to one another. 


\section{Minimalism and Delicacy}

Parallels can be drawn between minimalism and delicacy due to their similar architectural language. Rather reviewing the entire history of minimalism, two key figures are discussed with traditional and contemporary relevance. With technological advancements in material and structure, minimalism and delicacy could be considered close companions. Despite the simple connotations, like delicacy, minimalism in architecture is complex and broad. It is considered an aesthetic condition, a cultural definition, a technique and an expression amongst many others (Vasilski, 2015; Ruby, Ruby, Sachs, \& Ursprung, 2003; Bertoni, Minimalist Architecture, 2002; Spector, 2006/2007). Both delicacy and minimalism are commonly associated with embracing the complexities of architecture with solutions that appear for be deceptively simple. According to Frampton, minimalism is the result of "maximum effect with the minimum expenditure of means" (1980, p. 163). Frampton discusses how minimalist architects express their maximum efforts of material, abstract and interpersonal relations with the minimum means of simplicity where the complexities are hidden.

Mies is the traditional figure discussed in this literature review regarding minimalism and delicacy. Mies was "an architect with the ability to reduce every problem to a kind of essential simplicity" (Colquhoun, 2002, p. 170). He had the ability to design a building with many technical complexities to appear pure, simple and clear, visually capturing the essence of the building where everything else is hidden or non-apparent. This also links to Bertoni's ideas describing minimalism, Mies and the ability to capture the essence (2002, p. 16). The Neue National Gallery breaks traditional ideas about museums with closed exhibitions spaces, and Mies creates an open plan, flexible space. "The building appears light and delicate and does not betray the great effort required to achieve this impression" (Krohn, 2014, p. 211). The attention to details and structure makes it feel as though the roof is floating out across each corner effortlessly. 


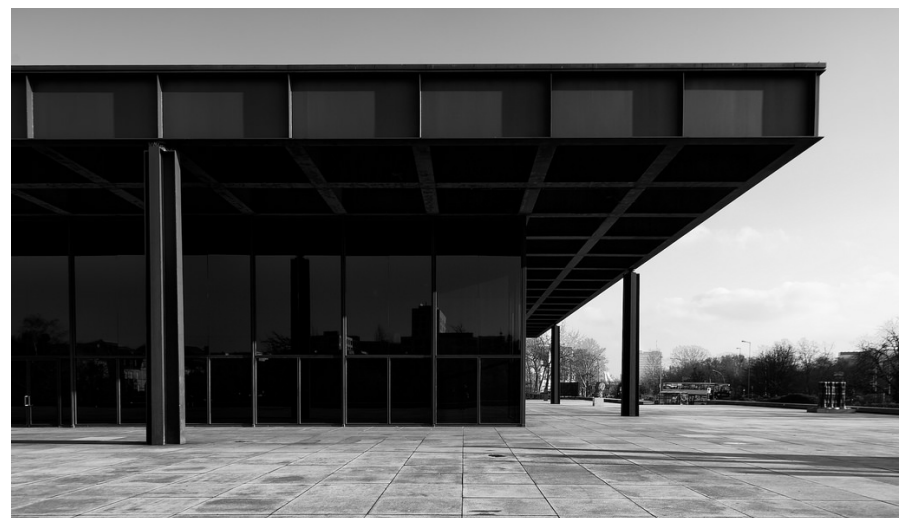

$\wedge$ 05. Mies van der Rohe, Neue National Gallery (lietz.photo, 2011)

The contemporary figure in minimalism and delicacy is the Japanese architecture firm, SANAA. SANAA has a portfolio of work that "appears effortless, but we should not be deceived. They strip things down...to construct a new form of complexity" (Allen cited in Kirk, 2012, p. 106). Linking Mies and SANAA, Stan Allen aligns directly with Frampton's theory of complexity in simplification, the perception of effortlessness. Although SANAA does not question delicacy directly, however they are continually aligned with it. Their work has been argued as "refined, pristine reductive and minimal. Delicate and white" (Allen, 2010, p. 58) and "optimistic and delicately simple" (Moreno \& Grinda, 2004, p. 31). In summary, the relationship between delicacy and minimalism has been investigated through the common link of creating an appearance of effortlessness when in fact the complexities are high. Both SANAA and Mies have shown the ability to create deceptively simple and delicate buildings. 


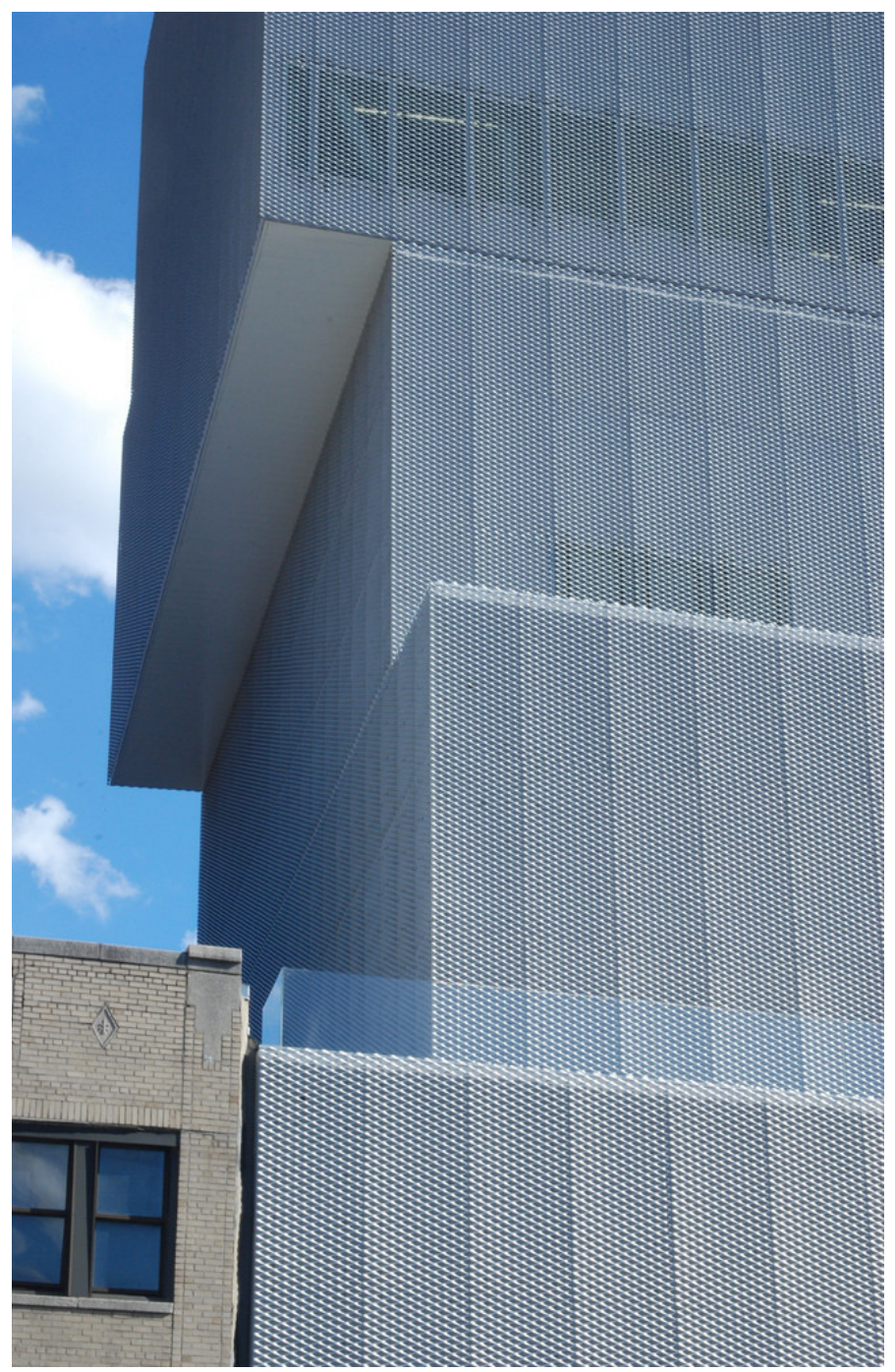

$\wedge$ 06. SANAA, The New Museum (Teer, 2010) 


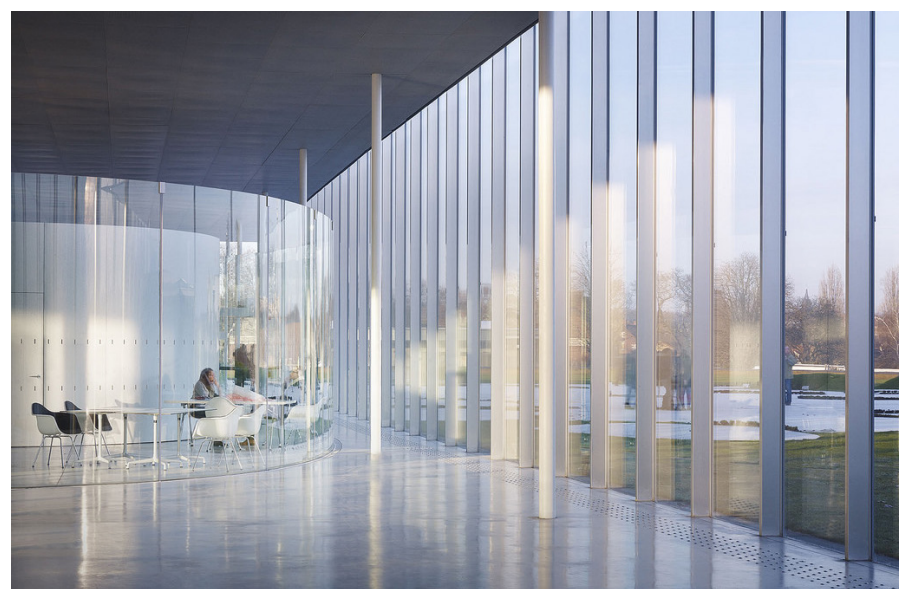

^ 07. SANAA, Lourve Lens (Lanoo, 2012)

The chapter now transitions into discussing delicacy through three key themes; scale, materiality, and colour and whiteness. Due to limited discussion on delicacy directly, this structure does not follow a traditional chronological literature review, but approaches it thematically, through essential architectural elements. Holl argues, "we must consider space, light, colour, geometry, detail and material as an experimental continuum. Though we can disassemble these elements and study them individually during the design process, they merge in the final condition" (Holl, 2000, p. 62). From Holl's argument and the initial research into delicacy three essential elements; scale, materiality, and colour and whiteness were evaluated as the key themes. Their purpose is to unpack delicacy in both this context chapter, and used as an evaluative framework throughout the design process. The three themes are essential qualities of architecture that shape space, structure and design dealing with both architectural aesthetics and construction. Mies and SANAA, the two key figures, are continued throughout the themed sections as exemplars. The following paragraphs clearly deal with my proposition. 


\section{Scale}

Scale is undoubtedly an important matter in architecture, despite its rejection by many practitioners today who view it as outdated (Adler, 2012, p. 6). It is a universal term, which architects discuss constantly through drawings, regulations, proportions and representations, providing boundaries, however it lacks experimentation. Burke poses two scales when regarding the sublime and the beautiful: the intimate and the vast. He argues, "greatness of dimension, is a powerful cause of the sublime... greatness of dimension, vastness of extent, or quantity, has the most striking effect" (Burke, [1773] 1958, p. 72). A vast height, length or depth pursues the sublime and in contrast the beautiful is small and delicate. Burke provides two ends of the scalar spectrum to reflect upon, the momentous and the miniature, the sublime and the beautiful. However, after discussing the distinctive separation between the two Burke states, "if the qualities of the sublime and beautiful are sometimes found united, does this prove, that they are the same, does it prove, that they are any way allied, does it prove even that they are not opposite and contradictory?" ([1773] 1958, pp. 124-125). Burke opens up the question as to how these two concepts and their descriptive elements could operate at the same time.

Could the vast and the intimate-scale work simultaneously to accentuate delicacy? To which Kirk argues, "the delicacy of details reveals its grandeur next to broad flat expanses, lacking it. Adjacent the coarse and the plain, the fine becomes finer" (2007, p. 26). The contrast of the vast against the intimate heightens the appearance of delicacy, which can be accentuated through the human scale. Architecture shifts towards the intimate scale when the human body is engaged (Kirk P. J., 2007, p. 49). Key contextual precedents, Mies (traditional) and SANAA (contemporary), both explore scale through their architecture. "Mies's architectural system also employs 
analogous proportions at large and small scales (Krohn, 2014, p. 219) and SANAA argues, "we play with light and dimensions more than anything" (cited in Sudjic, 2006, p. 54). SANAA acknowledges the relationship between architecture and humans. They argue, "The scale of the architecture is larger than that of the body, but I think about how to make a closer relationship" (cited in Brownell, 2011, p. 105). Mies considered similar propositions that shift between scales while SANAA focused on the details and human occupancy in relation to space.

The consideration of large and small simultaneously is essential as they are relative. Japanese architect Junya Ishigami also investigates this through operating multiple scales together. Ishigami's work pushes architecture physically to its limits, combining the greatness of dimension and delicacy. The installation 'Architecture as Air', for example, "combats themes of fragility and transparency" (Holt \& Looby, 2010, p. np) and is an "experiment in formal and aesthetic minimalism" (Kirk J. , 2012, p. 90). The lightness, transparency and miniature size of the columns embrace delicacy and physical fragility. As a result of this Holt and Looby argue, 'Ishigami challenges the understanding of what constitutes 'beam' and 'column', 'wall' and 'floor' (2010, p. np). It is the occupation of the installation and interaction with the body that enhances the spatial experience through shifting scales. Within the "intricacy and its delicacy the user is forced to become acutely aware of their own proximity to the structure...It defies weight, scale, boundary opacity and in effect becomes infinitely transparent" (Holt \& Looby, 2010). Playing with scale in pursuit of the delicate is broad and could be investigated in various directions. Such explorations may consider thick and thin, large and small, heavy and light, and intimate and vast. The following section discusses delicacy through a consideration of materials within project and literature reviews. 
Materiality

Technology has allowed materials to become slimmer while still maintaining its strength, creating the appearance of lightness. SANAA for example stands in favour of the "delicate and lightweight" (Sudjic, 2006, p. 50). Industrial materials such as glass, steel and even concrete can be considered delicate. They have the ability to be slender, fluid, smooth and transparent. Burke highlights the importance of smoothness when considering beauty. "A quality so essential to beauty, that I do not now recollect anything beautiful that is not smooth" ([1773] 1958, p. 114). Smooth slopes, smooth landscapes, smooth water, smooth edges and smooth polished surfaces all contribute towards beauty and more specifically, delicacy. Aligning with Burke's concept of smoothness and the properties of industrial materials, SANAA's work is seductive and fluid. SANAA is a part of a small collection of designers that "explore like few others the phenomenal properties of continuous spaces, lightness, transparency, and materiality to create a subtle synthesis" (Kazuyo Sejima \& Ryue Nishizawa 2010 Laureates: Jury Citation). The seamless totality builds upon the appearance of effortlessness as smooth materials and edges blend one space into another. Wilkinson argues, "curved surfaces deal with light in an appealing way and a curved form will generally appear lighter than a corresponding square or rectangular form of the same volume" (2001, p. 34). Within his essay discussing delicacy and lightness, Wilkinson argues that when regarding 'lightness' appearance is just as significant as weight. Alongside the smooth and slender materiality, transparent materials are strongly aligned with delicacy and lightness.

To create the appearance of smoothness through materiality, glass is used in multiple ways in architecture due to its transparent properties. Both Mies and SANAA heavily experiment with glass to produce different minimalist effects. Mies was primarily interested in the literal transparent 
glass. SANAA however, "represent both a critique of social norms and, through their re-thinking of materials and methods of construction, an exploration of the possibilities for an architecture of utter lightness unlike the modernist concept of transparency" (Mostafavi, 2011, p. 247). Mostafavi highlights that architects like SANAA experiment with materials, differing from the literal transparent effects that modernists indulged in. SANAA is interested in the manipulation and optical effects produced as they layer materials and blur boundaries. Colomina argues that SANAA's "architecture is much lighter than Mies, Johnson or even Eames. It is as if the architecture wants to disappear, to evaporate" (2015, p. 395). The effect of SANAA's interest and focus on materiality, alongside form and detailing "create[s] an architecture that is light and ephemeral, and continually changing with different situations of perception" (Allen cited in Kirk J. , 2012, p. 18). These discussions highlight SANAA's ability to capture delicacy and an ephemeral quality in their buildings through a concentration on, and commitment to, materiality. Minimising material systems and integrating techniques such as thickness and thinness drive design in a direction that evokes utter lightness. Colour is another element that can contribute to the experience of delicacy and lightness (Wilkinson, 2001, p. 42). The consideration of colour through natural materials or artificial application is another essential element in architecture that can explore the potential of delicacy. 


\section{Colour + Whiteness}

Colour and whiteness has the ability to aid in exploring delicacy within buildings. In architecture, colour and whiteness is either an artificial application or embedded in the material. It has the ability to activate occupants, enhance volumes, organise space, generate an ethereal effect, flatten or increase hierarchies, amongst many others (Brownell, 2011, p. 16; Safont-Tria, Kwinter, \& Holl, 2012, p. 20; Twose \& Smitheram, 2009, p. 58; Wigley, 1995). Holl argues for and experiments with colour relentlessly. Colour can be associated with delicacy as it "floats freely in space, in an intangible area at the boundary between the physical and the abstract" (Safont-Tria, Kwinter, \& Holl, 2012, p. 24). As colour is situated within a visible and invisible domain, it has the ability to produce an ethereal effect (Safont-Tria, Kwinter, \& Holl, 2012, p. 54). While bright colours create exciting and curious environments, whiteness has the ability to soften spaces.

The consideration of whiteness shifts toward soft, delicate and incredibly light environments. White, as argued by Nickelsen, "is really a delicate explosion of colour" (2010, p. 34). The notion of white space can be linked back to the aesthetic concept of beauty. According to Till, "modernist beauty is so often associated with pure forms, elimination of decoration and white walls" (cited in Kirk J. , 2012, p. 21). Mattie highlights white to be "modern and therefore progressive" as "the other dogma, of ethereal white façades... has never really disappeared" (2015, pp. 228-229). The ethereal effect from whiteness develops brighter spaces where light is diffused and hierarchies are dismissed. Twose and Smitheram argue for the effects of whiteness as an exploration of colour where "this treatment of the surfaces and objects gives an immaterial soft fog to the spaces. Hierarchies between elements are reduced by the flat whiteness and there is a sense of merging of things which normally have a discrete identity" 
(2009, p. 58). The softening and blurring effect of whiteness links with the materiality and perception of delicacy, and spaces are able to have a "scaleless characteristic" (Twose \& Smitheram, 2009, p. 58) and appear much lighter and more effortless than they actually are. Twose and Smitheram consider how the "conventions of orientation and weight are softened by the velvet white" (2009, p. 58). Whiteness has the ability to create a softer environment where mass and weight is diffused. The differentiation between structural elements and surface is dissolved, and everything appears thinner and lighter, thus considerably more delicate. The enquiry into colour and whiteness highlights its ability to create contrasting environments that both have the potential to evoke delicacy. Bright colours can communicate curious and ethereal environments, however whiteness creates soft, light and ethereal spaces, highlighting the notion of delicacy through another element.

\section{Conclusion}

Despite delicacy in architecture lacking obvious discussion and critiques, the writers, theorists and architects discussed in this chapter all contribute towards an understanding of delicacy. This chapter located delicacy within the aesthetic concept of beauty, and highlights some of the traits that could be aligned with delicacy, such as smooth, light, soft and clean. Some of these traits and more were unpacked further through analysing literature and architects that discuss minimalism, scale, materiality, and colour and whiteness in relation to delicacy. All of these themes begin to highlight the investigation of the appearance of effortless and delicacy where, in fact, the effort and complexity is quite the opposite. 
03

DESIGN PRECEDENTS 


\section{Introduction}

This chapter locates and critiques three key design precedents relevant to the scope of the research. Each design precedent was explored chronologically in relationship to the three design experiments. They grow in size and architectural complexity relevant to the three design scales. Each case study will be briefly described and then analysed and critiqued against the evaluative framework: scale, materiality, and colour and whiteness. Japanese architecture is briefly introduced before the final design precedent, locating SANAA within a community of designers that explore delicacy.

Mairin Hartt

Grafton Architects

Japanese Architecture

SANAA 


\title{
MAIRIN HARTT
}

\author{
The Miniature Sublime
}

\section{Description}

Visual artist and art educator Mairin Hartt explored the sublime in her 2010-2011 installation series, The Miniature Sublime. Hartt's work attempts to capture the elusive qualities of the sublime, where size loses significance. A continuing interest throughout her work is looking at delicate cellular patterns and the tension between growth and decay, existence and nonexistence, all working towards capturing the sublime (Hartt, 2008, p. np). To explore these ideas she pressed and set ink onto glass, producing abstract images of microscopic cells. The ink abstractions were viewed through eight black boxes elevated at eye level, engaging the viewer at a miniature scale. The next section addresses how Hartt's work investigates a shifts in scale between the vast and the intimate, directly relating to the first design experiment investigation in chapter four.

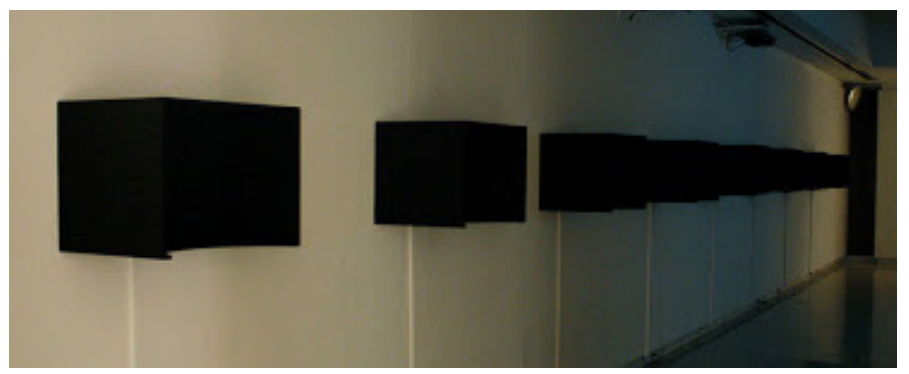

^ 08. Installation View 1 (Hartt, 2012) 


\section{Scale}

Challenging the historical notion of the sublime, Hartt removes the bodily perception of scale through the use of the viewing devices which then encompass the viewer's experience entirely. Looking through the viewport, the subject is disconnected from any sense of place or context, the micro cells become macro landscapes. Rather than the traditional response to the sublime, with physical vastness, Hartt opposes it with an intimate engagement where "the infinite within the miniscule is revealed" (Hartt, 2008, p. np). This ambiguous distinction between the macro and micro liberates the sublime experience from the vast.

Materiality

The fragility of the impermanent material enhances the ephemeral quality of Hartt's work. The ink abstractions delicately 'float' freely within the glass, generating an ethereal effect.

\section{Colour + Whiteness}

Through the use of light and colour, Hartt transforms the darkness, allowing the miniature to be visible. Hartt opposes whiteness with blackness, a traditional response to evoke the sublime. Backlighting the glass creates a strong contrast between the intense blue hues and white earthy tones within the blackness. 

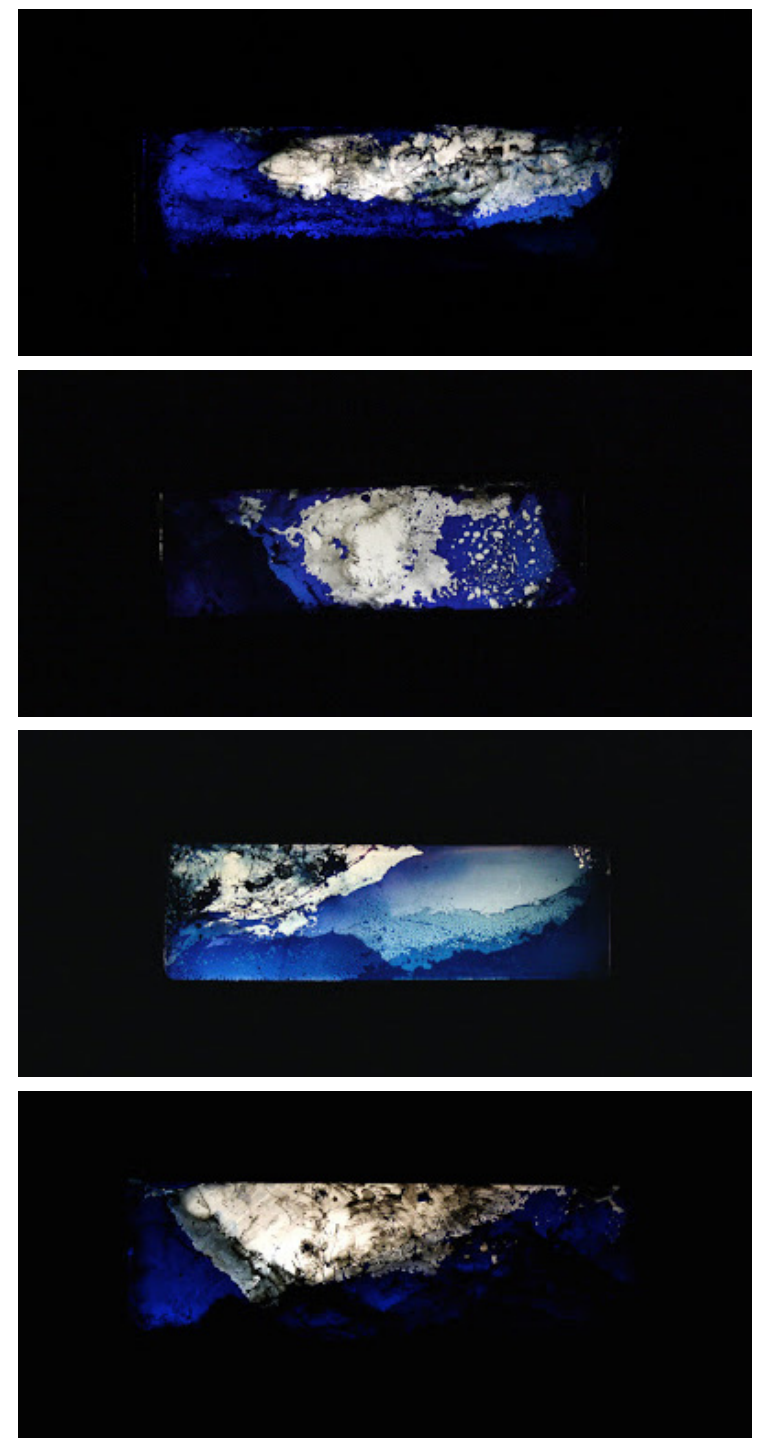


\section{Conclusion}

Hartt is able to establish a contradiction between the vast and the intimate scale. The loss of perception enables the viewer to experience the vast sublime within the delicate microscopic ink abstractions. Hartt is able to capture an uncomfortable tension between fragility and sublimity, and challenge the meaning of the sublime linked to the large scale.

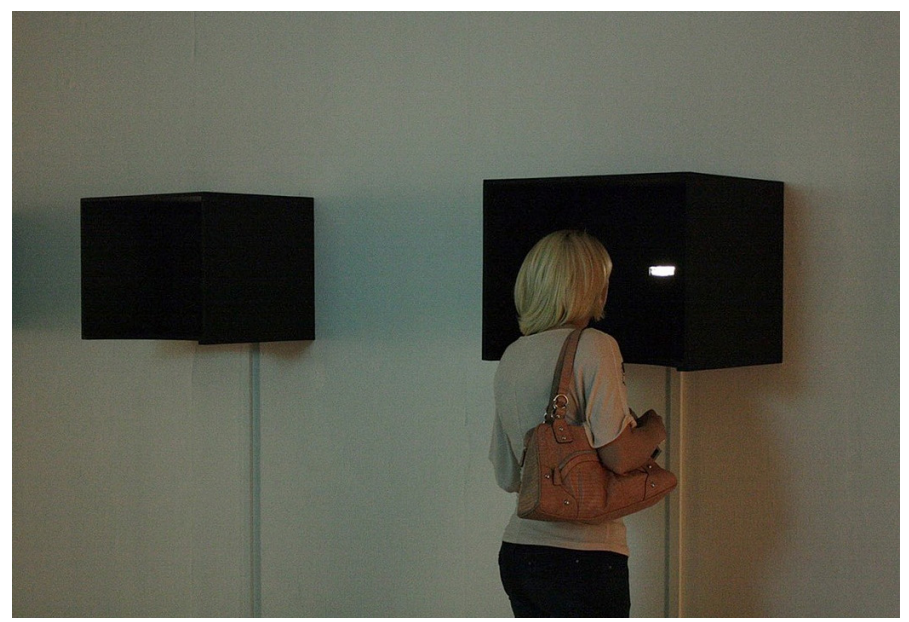

^ 10. Installation View 3 (Hartt, 2012) 


\title{
GRAFTON ARCHITECTS
}

Sensing Space

\begin{abstract}
Description
The Irish firm's installation in the Royal Academy's Sensing Space exhibition reimagined the most essential elements of architecture and space. Grafton Architects' installation was designed to recreate the opposing experience of lightness and darkness through suspended structures where the light is sourced from the roof (Goodwin, 2013). The dark space focused on weight and mass, while the light space evoked lightness. Together these spaces heightened the awareness of light as an essential component in experiencing space. The installation is designed with an architectural intent and language that addresses space, structure, surface, light and weight. These elements relate to the mid-scale design in chapter five as it explores the vast and the intimate scale through an architectural solution.
\end{abstract}

\section{Scale}

Both parts to the installation focus on scale, however the scale in the dark room is dramatically accentuated through the heavy suspended mass shaping the space through a large volume. The architects have considered how the user experiences the space, acknowledging the human scale within the heavy hanging mass (Goodwin, 2013). In the light section large panes hang just above head height, heightening the awareness of the human scale but in a different way. Light is delicately modulated across the ceiling surface. The contrast between the vastness of the structures and the intimate scale of the body engagement is highlighted in Grafton's installation through an awareness of scale. 
This content is unavaliable

Please consult the print version for access 


\section{This content is unavaliable}

Please consult the print version for access

^ 12. Grafton Architects, 'Sensing Space' dark space detail (De Arriba, 2014)

\section{This content is unavaliable}

Please consult the print version for access

$\bigwedge$ 13. Grafton Architects, 'Sensing Space' light room (Carl Court/Getty Images, 2014) 


\section{Materiality}

Visually the installation in both sections appears to be very heavy masonry planes, however are actually large wooden and steel frame structures. The appearance of a heavier mass accentuates the weight of the suspension. Grafton Architects use materiality to manipulate shadow and light and play with elements like weight and surface to communicate a sense of heaviness highlighting the distinct contrast between the heavy mass and the human scale. The experience of contrast between the two rooms, as intended by the exhibition, makes people aware of how architecture is able to frame space. Light and surface materiality are interrelated elements as they play off one another.

\section{Colour + Whiteness}

The installation has no reference to colour, however the use of light and white was essential in evoking lightness. Light was a driving force in the design of the installation and the 'light' space was designed bright and white to accentuate the soft shadows and vast whiteness of the space as it modulates the ceiling surface. The use of white in the dark room is through the glare of light accentuating the heavy mass. This project explores how to shape space and accentuate mass through channelling light. Channelling light and using it shape space was further explored within chapter five's design experiments.

\section{Conclusion}

Grafton Architects' installation Sensing Space focused on the experience of light and using light to shape space. They highlight the effect of light on surfaces and the way it breaks up light and reflects it, accentuates the weight, mass, lightness or enclosure (Goodwin, 2013). Grafton uses these and other perceptive tools to create two powerful spaces where the interaction and experience of space is essential to the human scale: large and small, light and dark, delicate and heavy. 


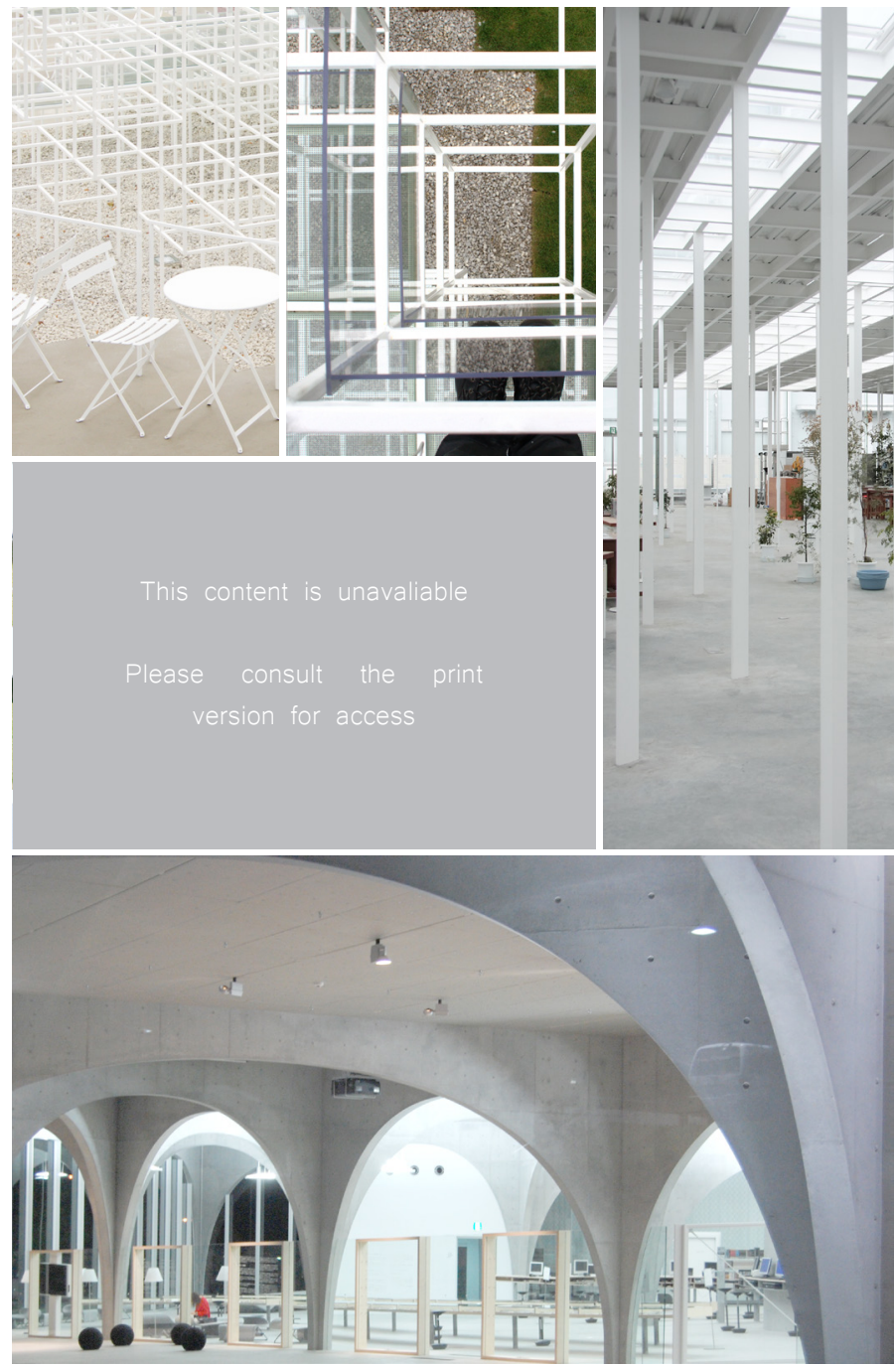




\section{JAPANESE ARCHITECTURE}

There are clear precedents of Japanese architecture both traditional and contemporary that seek light, slender and delicate architecture. For Mosco this has resulted in Japanese architecture "proposing some of the most interesting works of naked slender architecture" (2012, p. 140). Toyo Ito acknowledged that his "early work was about lightness and delicacy" intertwining the two words as the essence of his architecture (cited in Brownell, 2011, p. 206). It was in the 1980s when Ito communicated how architecture must be light. He carried this idea through to 2007 when he designed the Tama Art University Library. The attention to detail, structure and materiality created extremely slender arches shaping the interior. Mosco describes Ito's buildings as "of absolute clarity and essentialness" (2012, p. 148), the same terminology described when discussing delicacy and minimalism. SANAA who learnt from Ito "are part of a small and influential group of Japanese architects who tend to make their marks on paper lightly - and in their case, even lighter than most" (Mostafavi, 2011, p. 245). Such architects include Junya Ishgami, Sou Fujimoto, Tetsuo Kondo and Studio Velocity. Due to its climate and earthquake-prone location, architecture in Japan must be light. Ruye Nishizawa from SANAA confirms, "Architecture in Tokyo is really light. Because of the climate, we appreciate inside/outside in a kind of even way. Then we also have earthquakes, so our buildings must be very light to withstand them" (cited in Mostafavi, 2010, p. 245). With such a similar building climate (earthquakes and temperature) how can New Zealand's building industry explore delicacy similar to Japanese architecture? The extended introduction to this section is to acknowledge the community of designers that have also influenced this portfolio, which SANAA is a part of. 


\section{SANAA \\ Cafe J Terrace}

\section{Description}

Designed by Kazuyo Sejima and Ryue Nishizawa (SANAA) the Junko Fukutake Terrace Café (J Terrace) at Okayama University is a delicate architectural structure composed of a sinuous steel roof that is supported by a multitude of slender columns. The café is sheltered by a glass envelope. $\mathrm{J}$ Terrace is an open space for people to gather, sit, visit and relax in the exterior environment beneath the steel canopy that sweeps between the surrounding trees (Stevens, 2015, p. np). The boundary between interior and exterior is dissolved creating a direct relationship between inside and outside. The final design experiment in chapter six directly relates to this design precedent's consideration of scale, materiality and whiteness.

\section{Scale}

The contrast between the sweeping steel canopy and the forest of columns accentuates the importance of scale. Although the roof is as thin as possible, it meanders in all directions spreading across the landscape. The flexible open plan does however create a lot of unusable space that has no function other than a sheltered paving. The café is an intimate space beneath the large canopy shaped by the surrounding glazing. The overall design oscillates between large and small through structure, spaces and connections. 
This content is unavaliable

Please consult the print version for access

$\wedge$ 15. SANAA, J Terrace Overview (Okayama University, 2015) 
This content is unavaliable

Please consult the print version for access 
This content is unavaliable

Please consult the print version for access 
Materiality

SANAA has a strong relationship with materials. Grinda and Moreno argue, the "role of structure and material determination in the spatial organisation suddenly becomes a central theme of Sejima and Nishizawa's architecture" (2004, p. 31). SANAA's commitment to materials is essential in evoking delicacy and transparency hence the relevance of Grinda and Moreno's discussion. J Terrace is composed of concrete, glass and steel. These industrial materials are able to accentuate delicacy through smoothness and slenderness, shaping the spaces with lightness.

\section{Colour + Whiteness}

$\mathrm{J}$ Terrace is absent of bright colour, however whiteness is a consistent theme in SANAA's projects to evoke lightness and delicacy. Sejima from SANAA comments that they "try to create very white spaces - white ceiling, white floor - that would create a very non-hierarchical, brightly transparent space" (cited in Obrist, 2012, p. 71). SANAA aims to use white to make the space feel free of structure and as light and bright as possible.

\section{Conclusion}

$\mathrm{J}$ Terrace is composed of a sweeping roof plane and a series of columns designed with the theme of "a place where people gather and dialogue is generated” (Okayama University, 2015, p. np). The delicately designed building blurs the boundary between inside and outside through a flexible open space. SANAA plays with scale through material, structure and spatial definition. Beneath the large canopy are a series of intimate spaces oscillating between big and small. The J Terrace is a perfect example that communicates SANAA's interest in materiality, structure, whiteness and flexible space. 
This content is unavaliable

Please consult the print version for access

$\wedge$ 17. SANAA, J Terrace Flexible Space (Okayama University, 2015) 


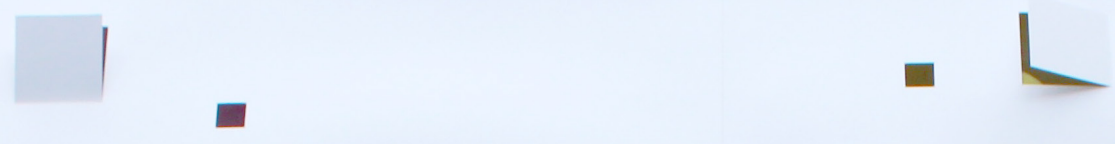

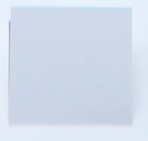

\section{-}
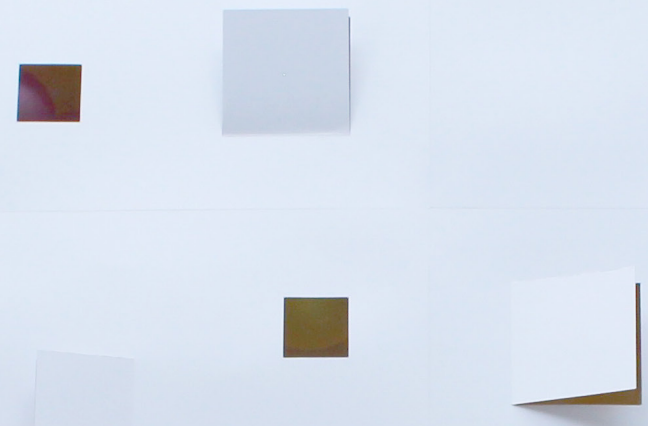

■
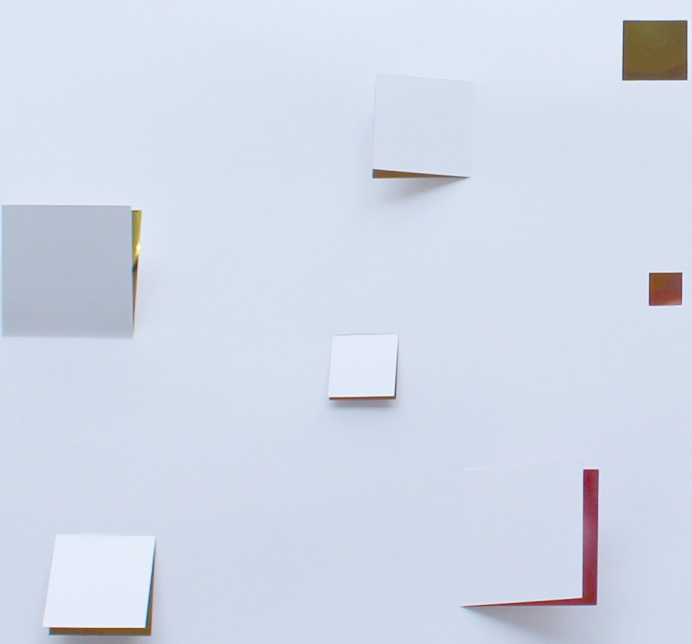
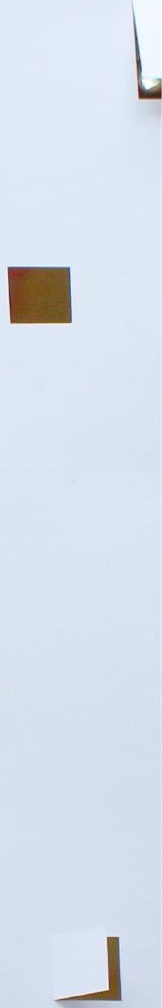
04

INSTALLATION 


\section{Introduction}

The installation is the first design experiments that investigates shifting scales. Operating at a 1:1 scale, the investigation enhances the awareness of the human scale and prompts interaction, whilst testing opposite conditions of the vast and the intimate. This chapter introduces the aim and method specific to this design experiment and then discusses and evaluates each investigation within the design process. The final design is analysed in regards to scale, materiality, and colour and whiteness before concluding with a critical reflection on the design, and moving forward to the next scale.

Aim

To test and investigate engaging both the vast and the intimate scale simultaneously through the design of an installation.

\section{Method}

Following the design-led methods as outlined in the introduction, an iterative and continual testing of ideas is undertaken through drawing, physical model-making and photography. The visual representations are a way to view the design progression through the weaknesses and successes, which are critically analysed and reflected on. 


\title{
Design Process Overview
}

\author{
non-linear
}

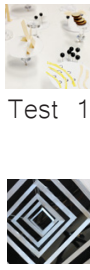

Test 2

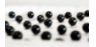

Test 3

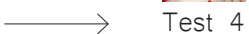

X
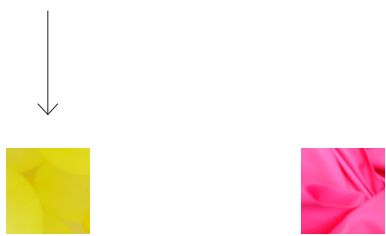

Test 5

Test 6

$x$
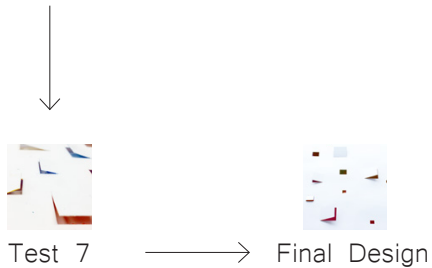

Test 8 $\mathrm{X}$ 


\section{Test One}

\section{Aim}

Analyse nature as a source of vast and intimate scales and translate into an image extraction.

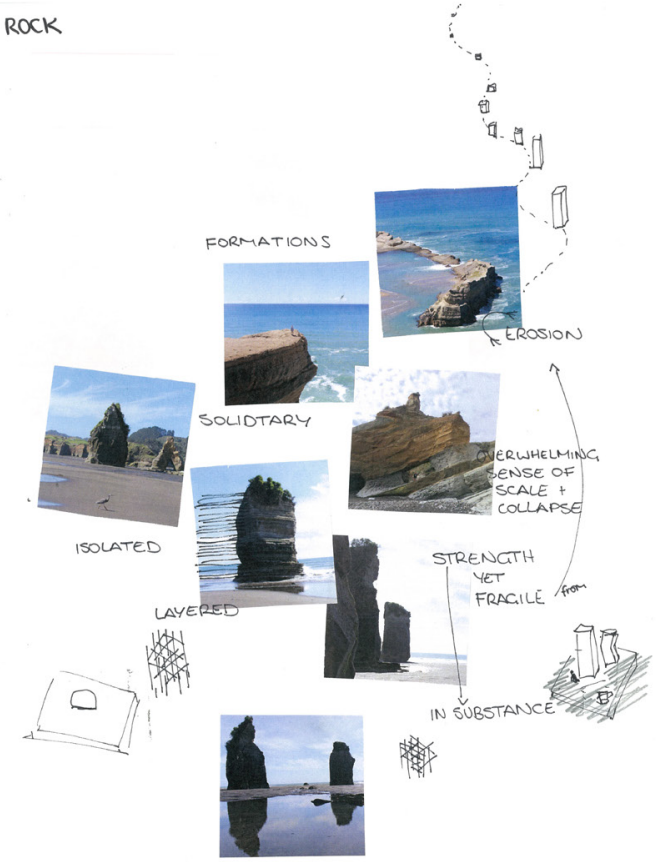

$\wedge$ 20. Experiential analysis of rock in nature 


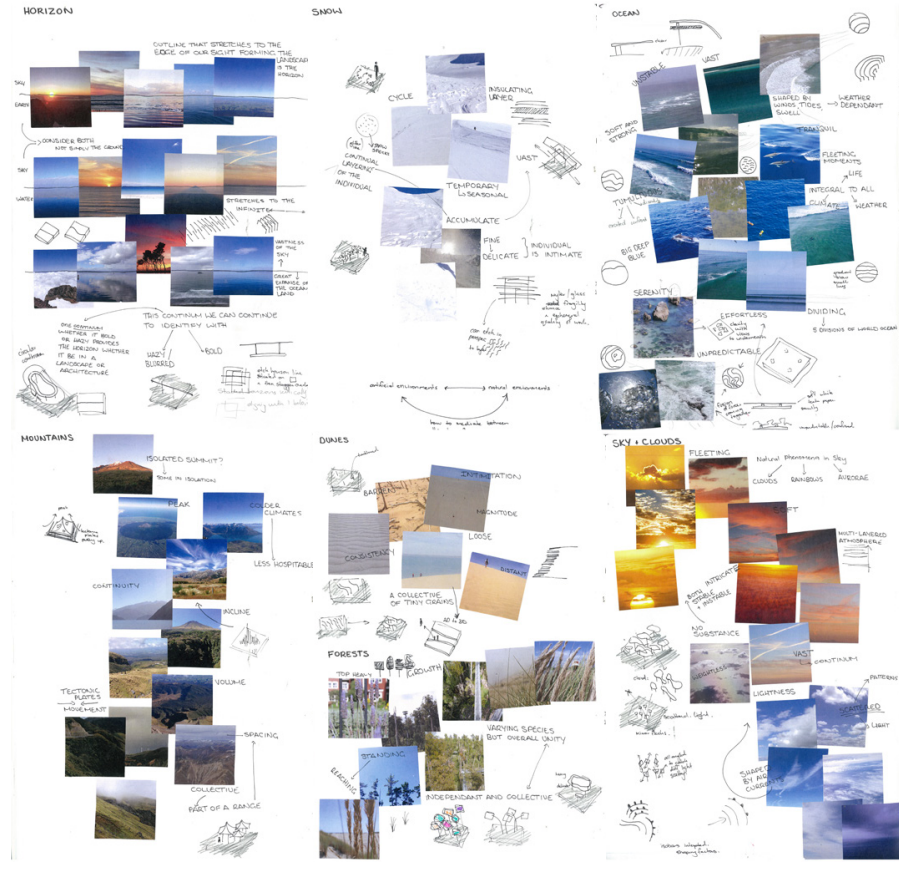

$\wedge$ 21. Experiential analysis of nature's elements 


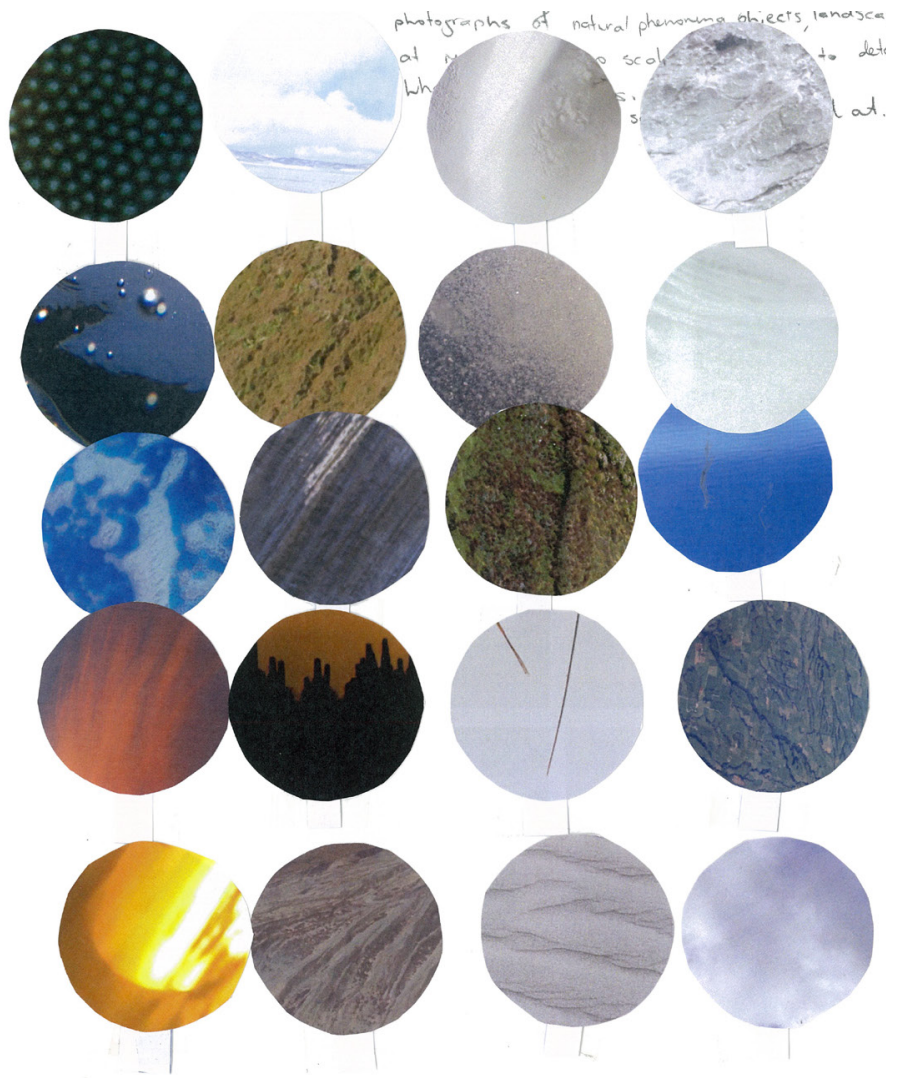

$\wedge$ 22. Image extraction

\section{Evaluation}

On reflection it created a static representation of personal experiential findings from nature's ephemeral qualities rather than investigating the 'vast and the intimate.' This test also does not address or engage the viewer through the design of an installation. 


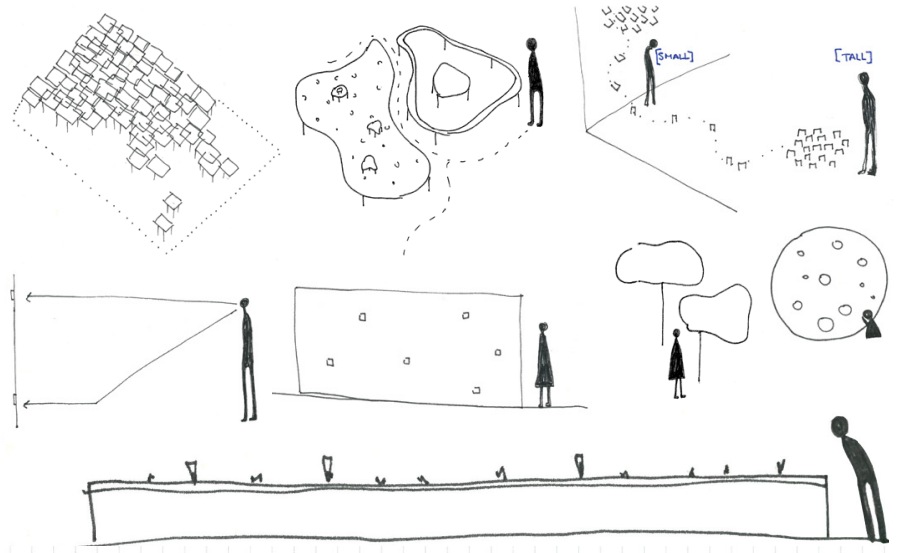

LIGHT

SCALE

MATERIAL

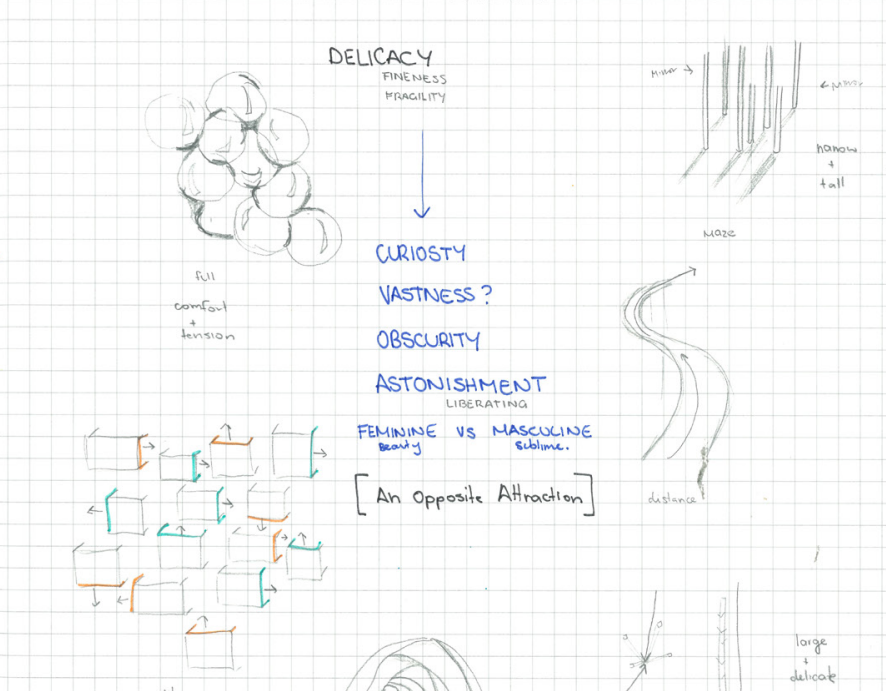

$\wedge$ 23. Sketchbook scans 


\section{Test Two}

\section{Aim}

Actively engage the subject through the use of paper and thread.

\section{Evaluation}

The creation of a viewport result was extremely successful in initiating engagement.

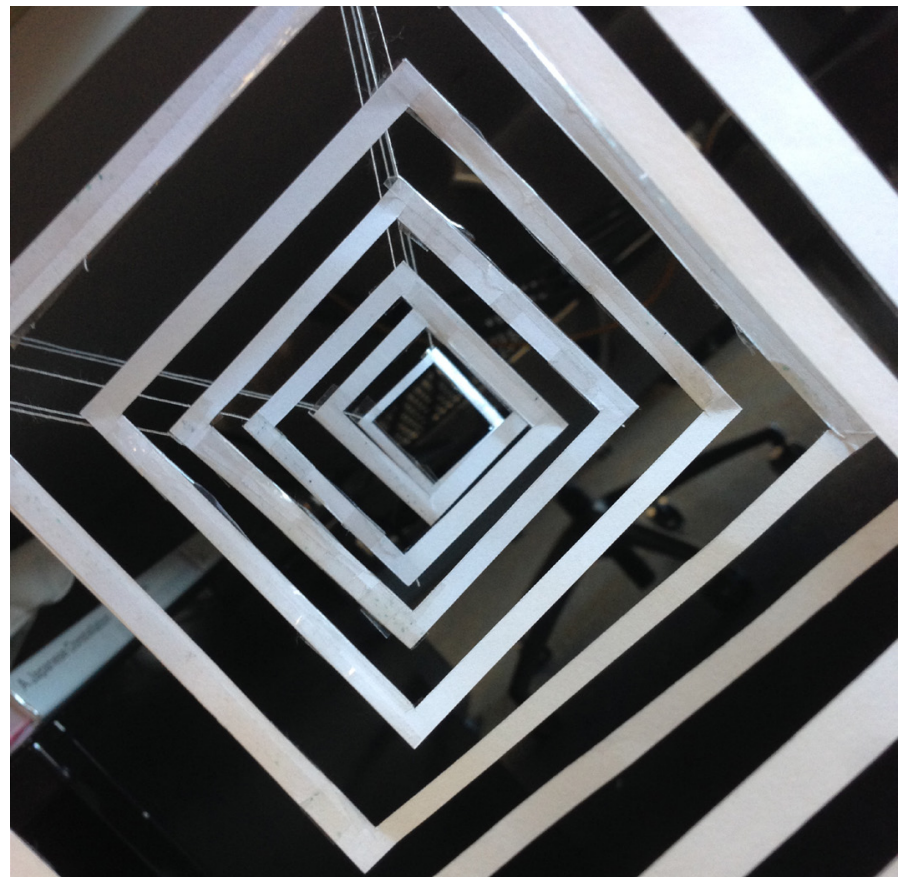




\title{
Test Three
}

\begin{abstract}
Aim
Develop upon the viewport and how it might obscure perception and experience of scale through two approaches. The first, to create a sense of vastness with repetition of dots through a tiny viewport. The second attempt aimed to evoke the vast within a small space by creating a floating continuum of objects that continue into the distance, testing the experience of vastness within a contained space.
\end{abstract}

\section{Evaluation}

On reflection the first approach was successful in terms of manual manipulation of controlling what the viewer sees. The second approach was not as effective as envisioned because the material was too large for the space. This reduced space for the layers, which diminished the 'vast' distance visible from the viewport. At a larger scale it would potentially be more successful. The design precedent for this test, Mairin Hartt was successful in creating a vast expanse within an intimate viewport. Her success in relation to this test is the execution of the material and working at a larger scale.
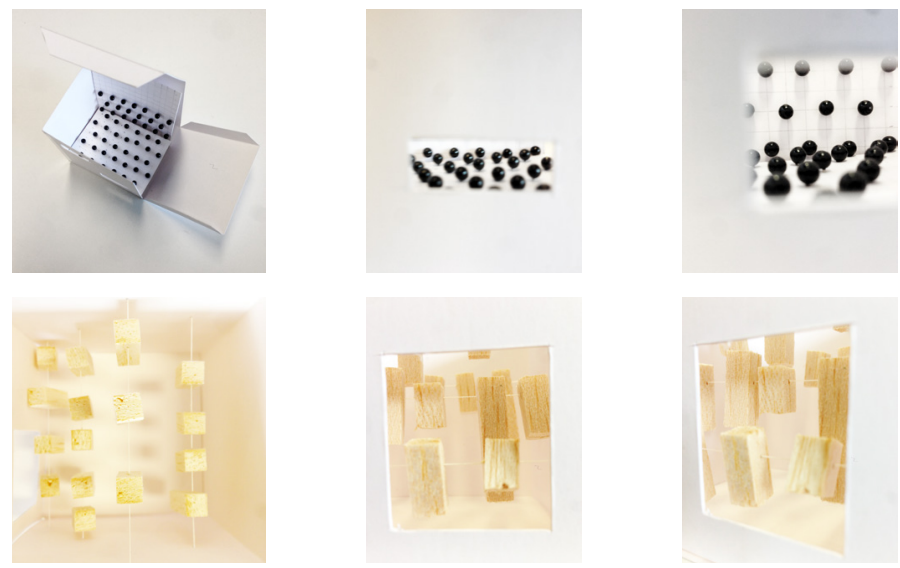


\section{Test Four}

\section{Aim}

Develop on the ideas in test three and precedent Mairin Hartt to create a small space that produces the experience of the vast through the use of an overwhelming repetition of dots. This test was also influenced by artist, Yayoi Kusama and her ability to create an immersive experience with intense repetition.

\section{Evaluation}

Due to the scale this exploration was not successful in the form of a small box and viewport. On reflection if it were to occupy an entire room it would be more successful. There would be an initial subliminal reaction as the dots overwhelm the viewer and then the curved disruptions create spaces that the subject could engage with at the human scale.

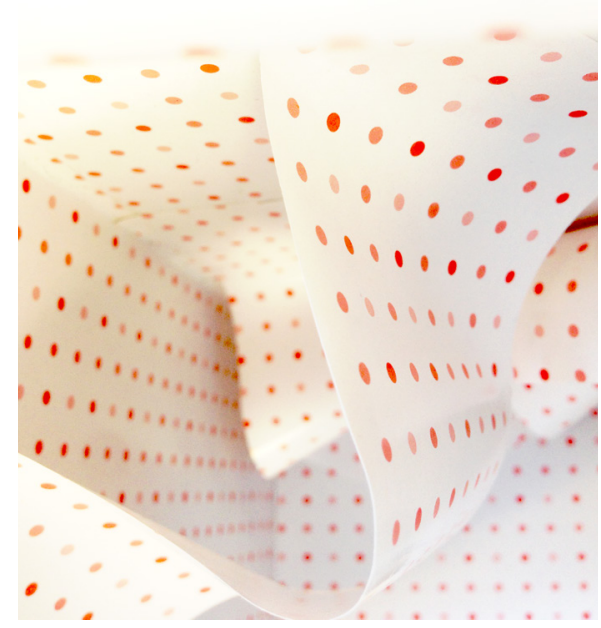

$\wedge 26$. Overwhelming repetition 


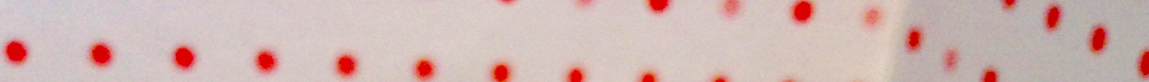

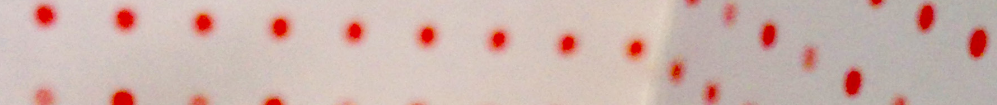

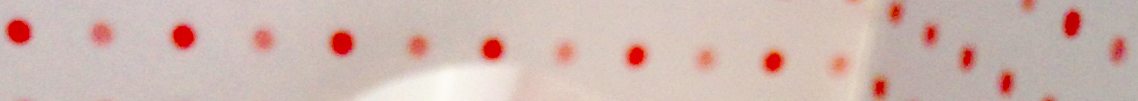

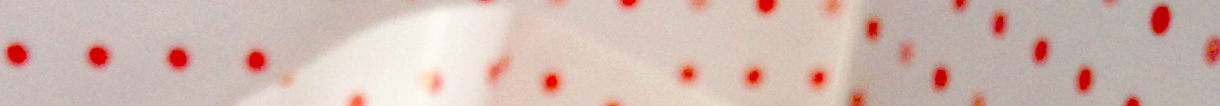

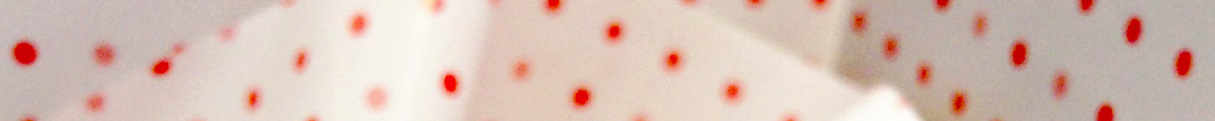

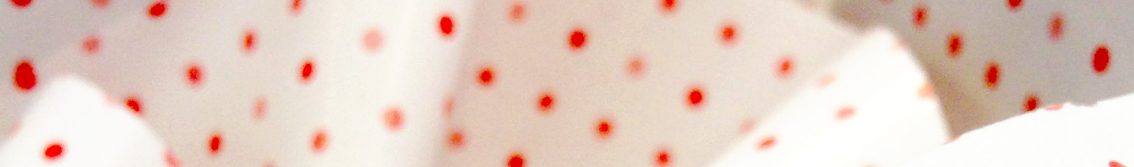

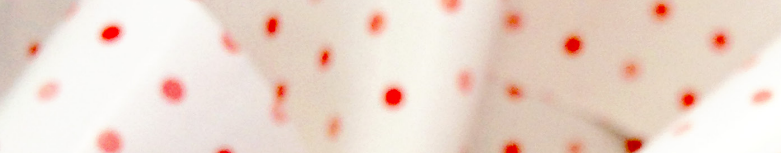

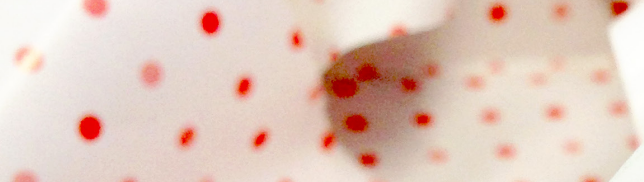
$+2$ ○ e $+2+\infty+\infty+\infty$ - $\rightarrow+*^{2}+$
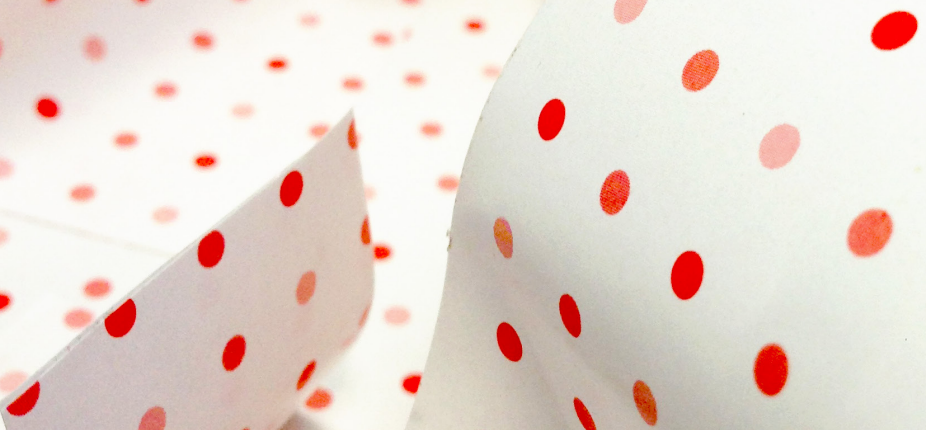<smiles>c1ccccc1</smiles><smiles>[CH]1[CH]CC1</smiles><smiles>[C+]1CCCC1</smiles><smiles>[131IH]</smiles><smiles>[CH]</smiles><smiles>[O]</smiles>
68

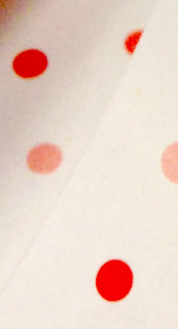

등

-

11
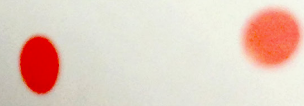

18

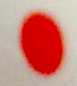

O

O<smiles>CC(C)(C)O</smiles>

(1) 1<smiles>C=C</smiles>

1<smiles>[AlH2]</smiles> 

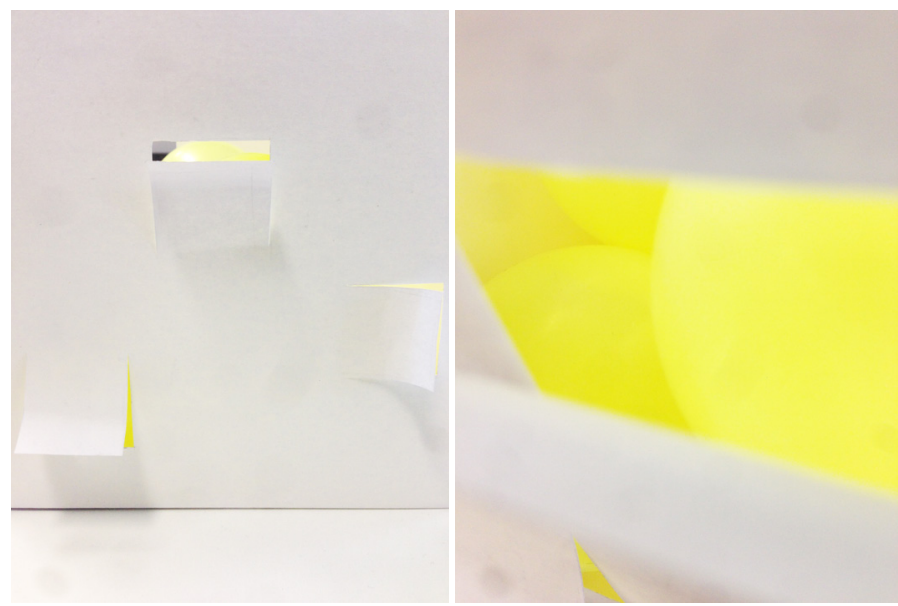

$\wedge$ 28. Viewport three

\section{Aim}

Use the viewport to engage the subject with the interior material and explore a contrast between intimacy and vastness. Link to precedent, Mairin Hartt and engage with her successes of achieving this.

\section{Evaluation}

Due to the translucent properties of the balloons, light travels through the layers positively attempting to create the vast within the intimate. This produced a successful result in terms of the interior experience and engagement, because, similar to Hartt's ink abstractions, the material is shaping the experience. However, on reflection, Hartt is able to control and manipulate the viewers experience whereas this test lacks the same level of control. 


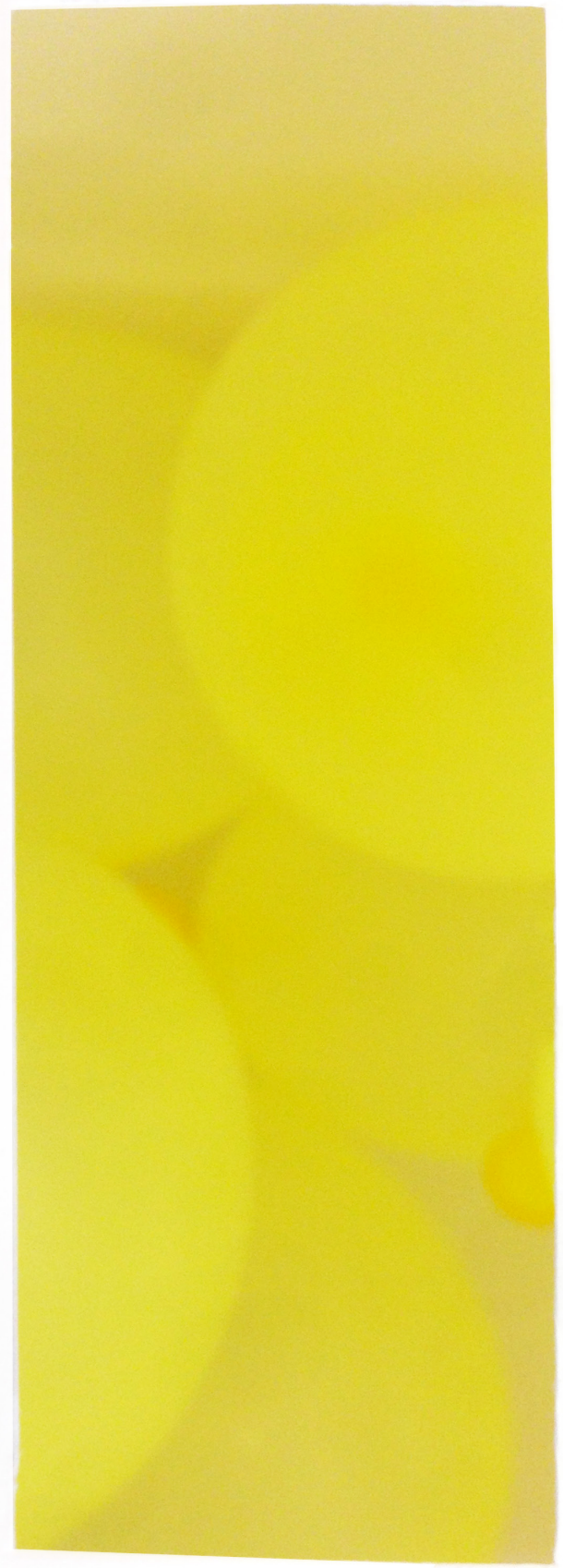




\section{Test Six}
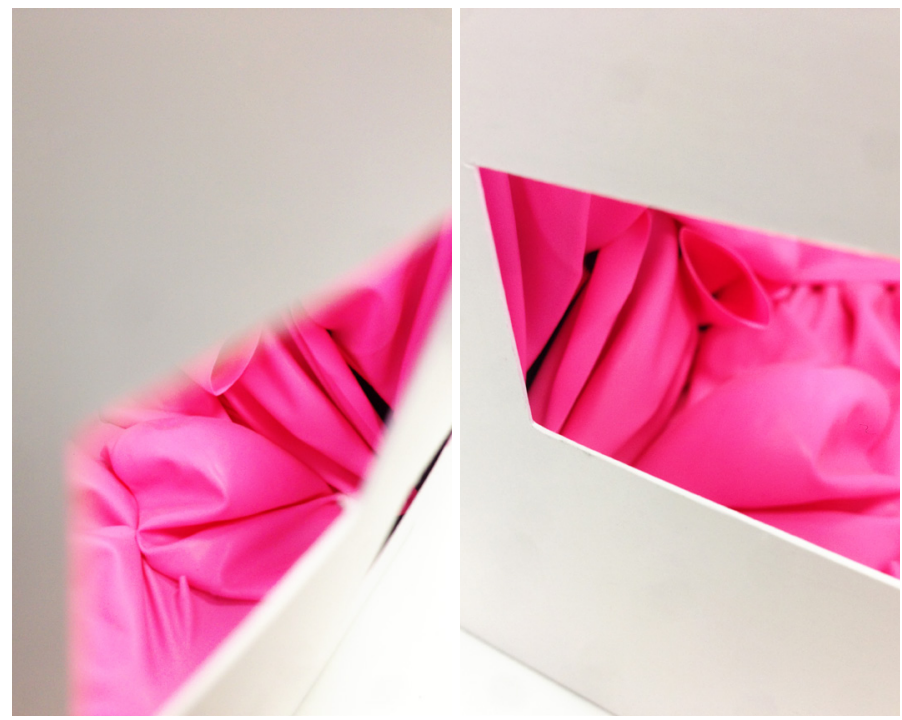

$\wedge$ 30. Viewport four

\section{Aim}

Manipulate the material from the previous test and explore the effects it could create.

\section{Evaluation}

Although the weakness from test five was its lack of manipulation, this test which focused on material manipulating was not successful. There was no engagement with exploring the vast or the intimate, even through the use of the viewport. The result within the box was flat and lacked depth, unlike the earlier tests. 


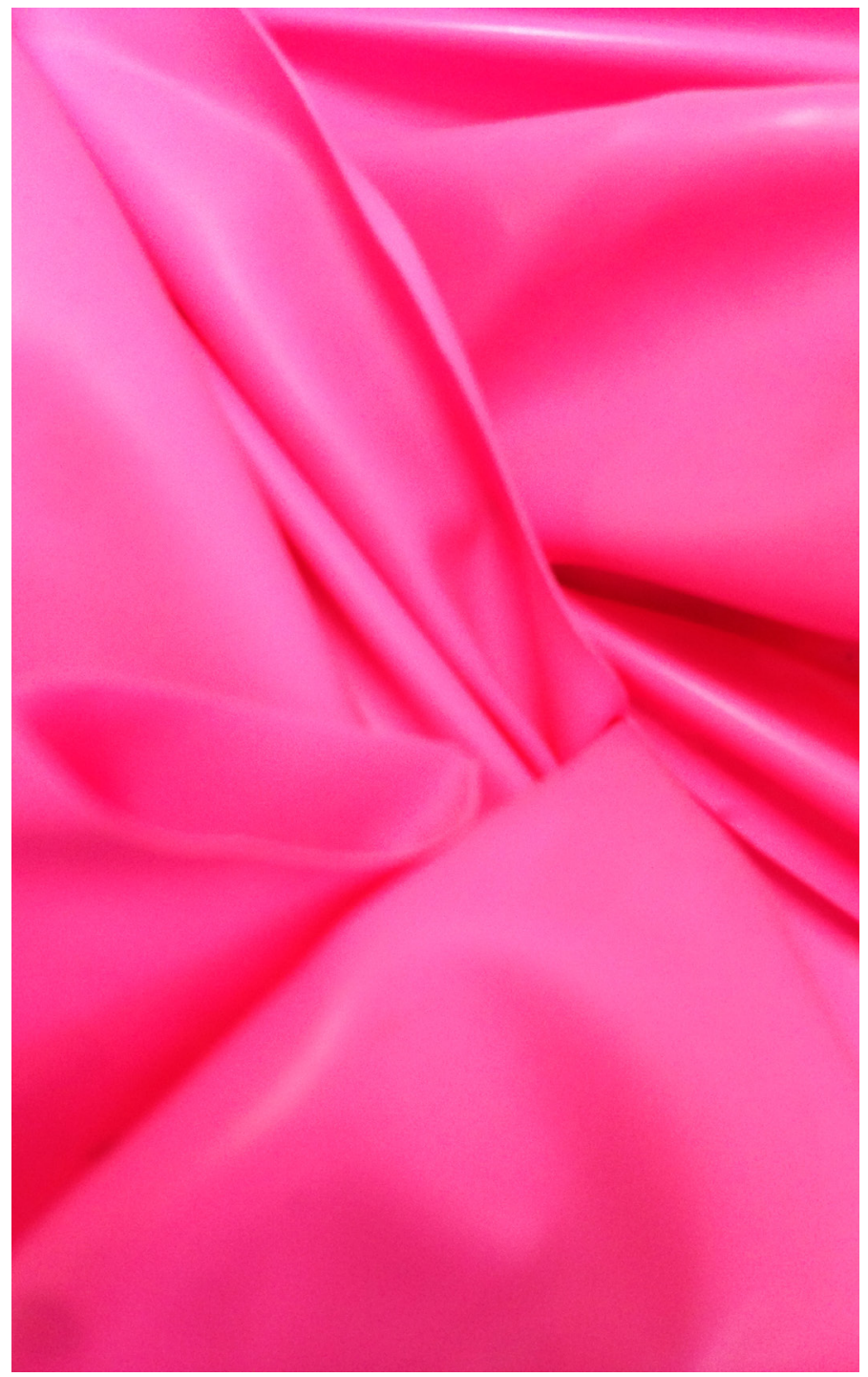

$\wedge$ 31. Pink tension 


\section{Test Seven}

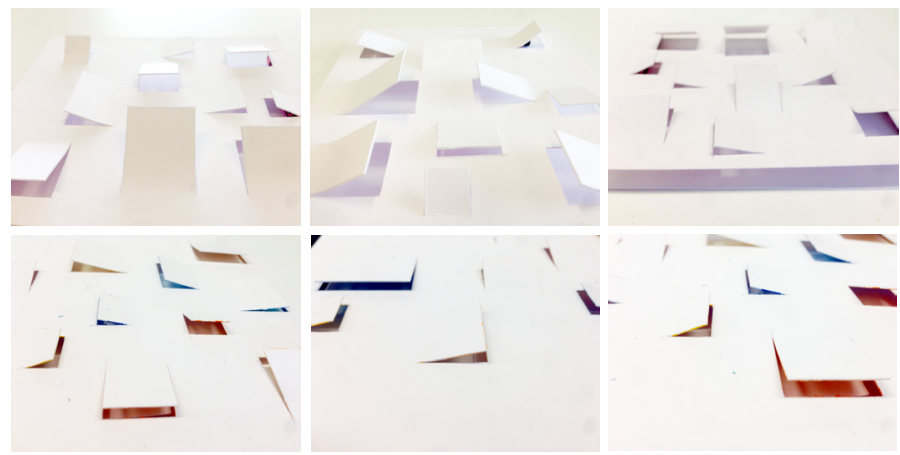

$\wedge$ 32. Physical testing of open and closed

\section{Aim}

Evoke the vast and the intimate through a contrasting environment between open and closed.

\section{Evaluation}

On reflection this test begins to explore the ideas of the vast and the miniature scale, however at such a small scale it needs to be developed further because it is difficult for the human body to engage with. The slits develop upon the concept of a viewport and evoke intimate moments while the smooth white surface of the paper begins to evoke vastness. The use of colour was successful with its ability to intrigue and engage the subject. 

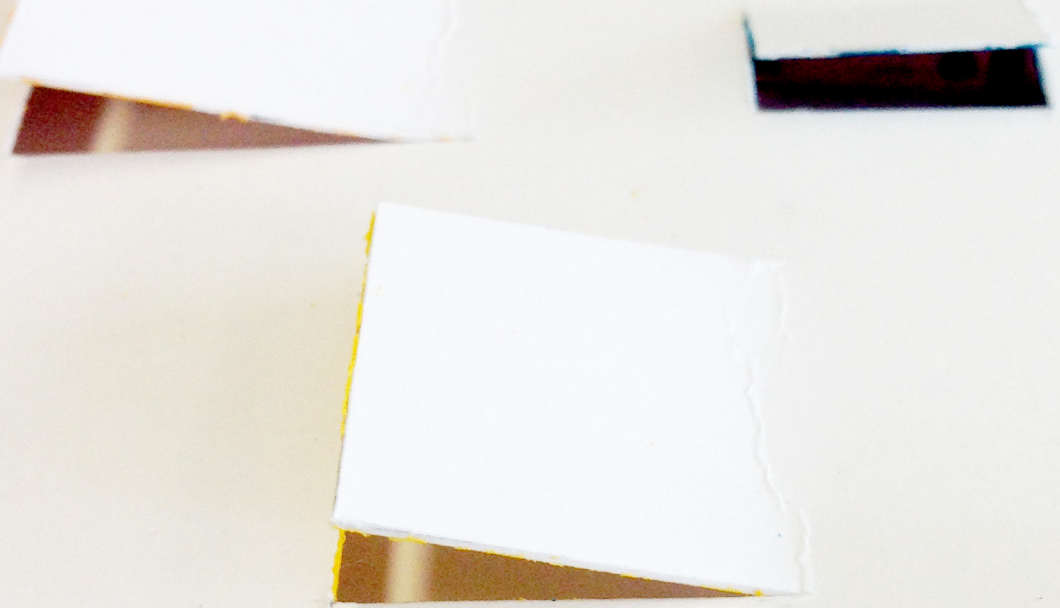


\section{Test Eight}
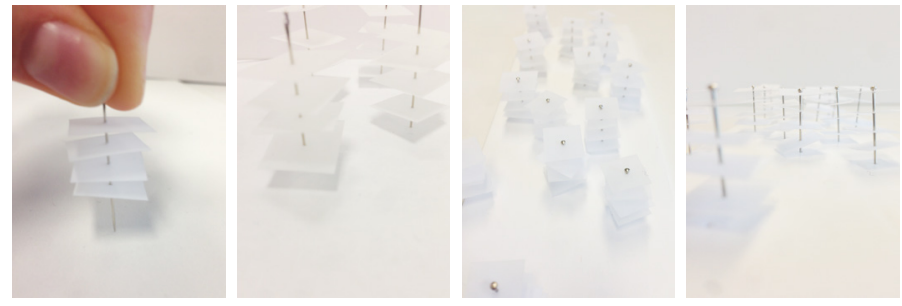

$\bigwedge$ 34. Material study

\section{Aim}

Attempt to create a contrast between vastness and delicacy using paper, pins and transparent film.

\section{Evaluation}

The use of transparent film attempted to blur boundaries and dissolve into one soft colour or disappear altogether. On reflection, the curved paper is far more successful through photographic representation. It is able to communicate a soft, vast surface and a delicate structure where boundaries begin to blur. However, neither led to further development for the installation as it was not as successful compared to test seven. This is because test seven develops a solution to actively engage the occupant as well as exploring the ideas of the initial aim. 

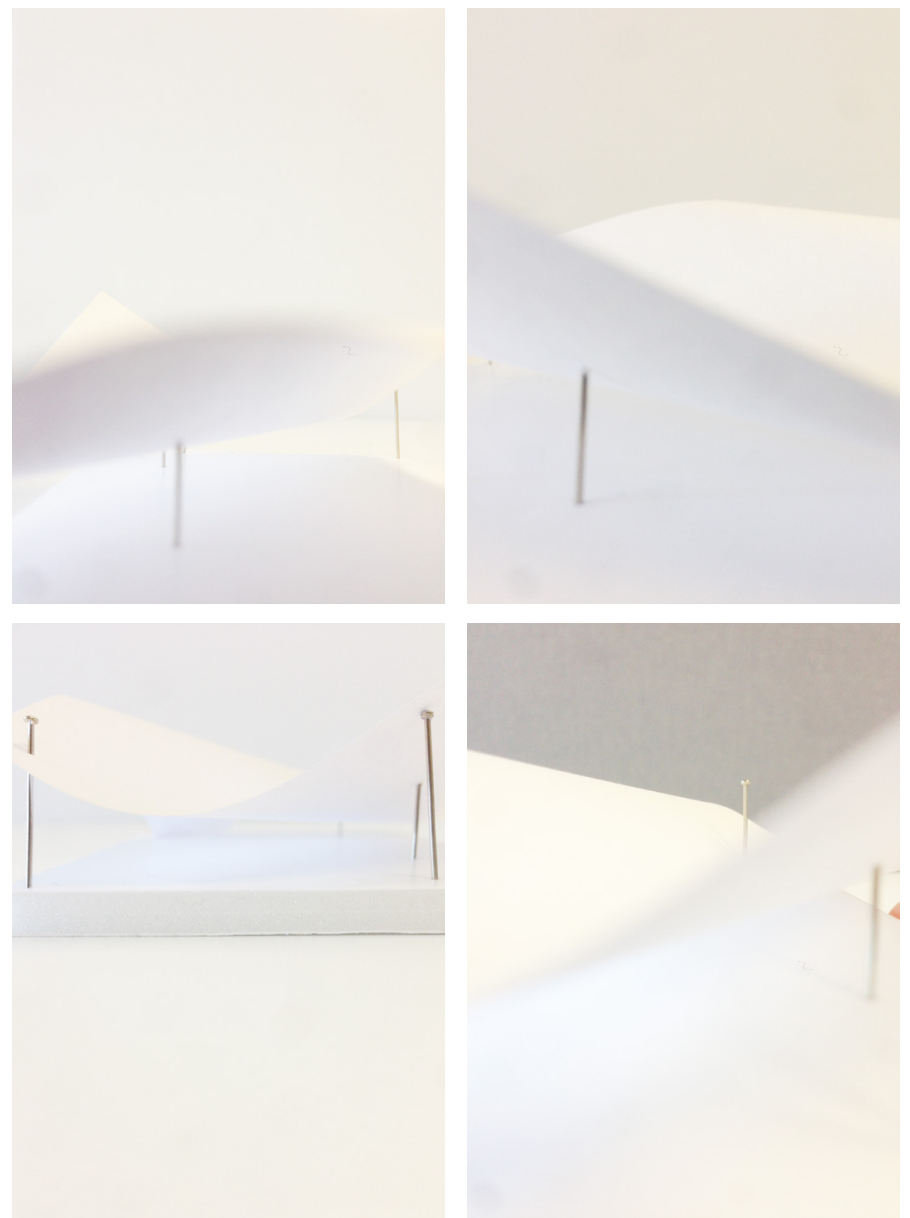

$\wedge$ 35. Blurring boundaries material test 

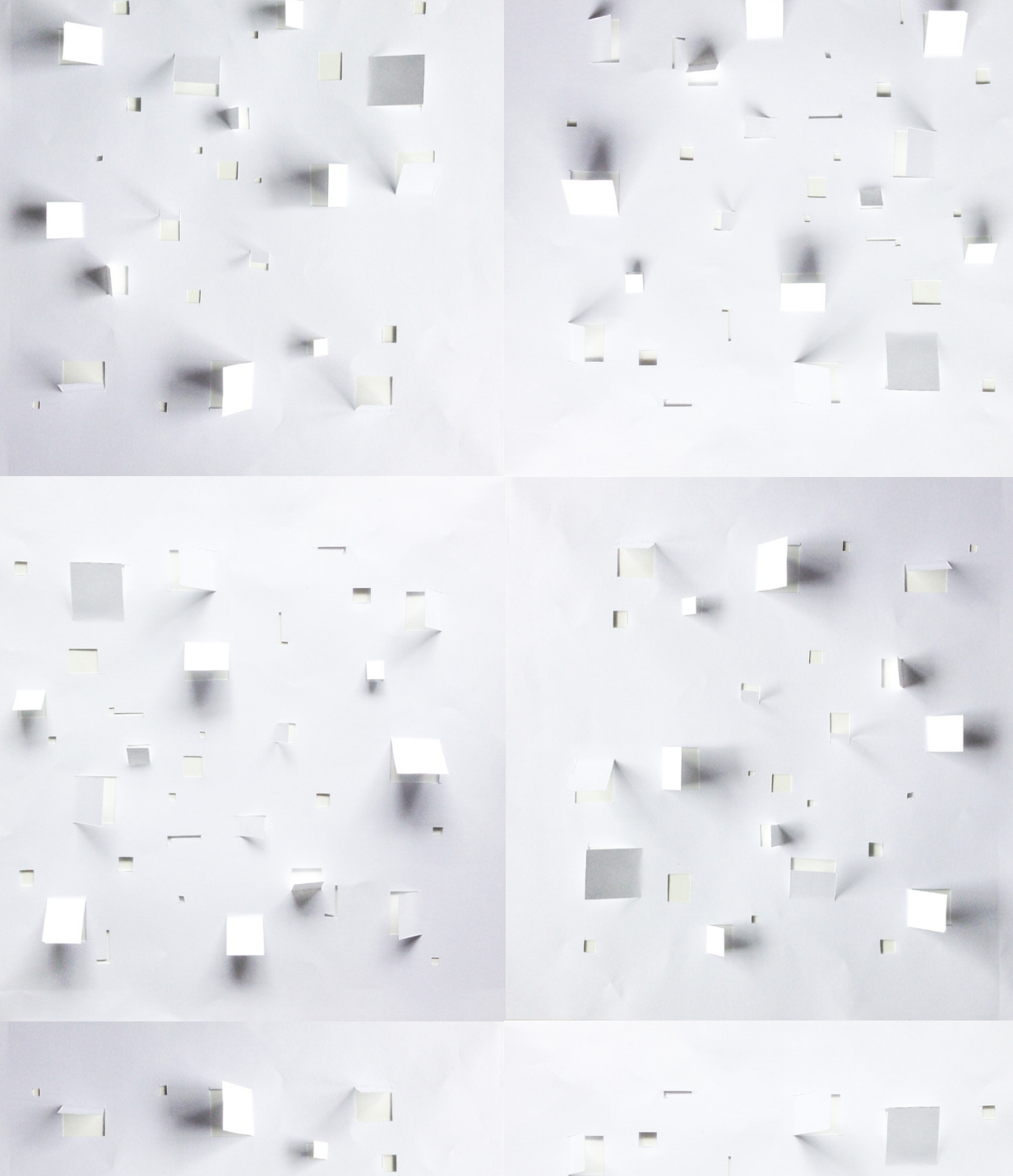

4
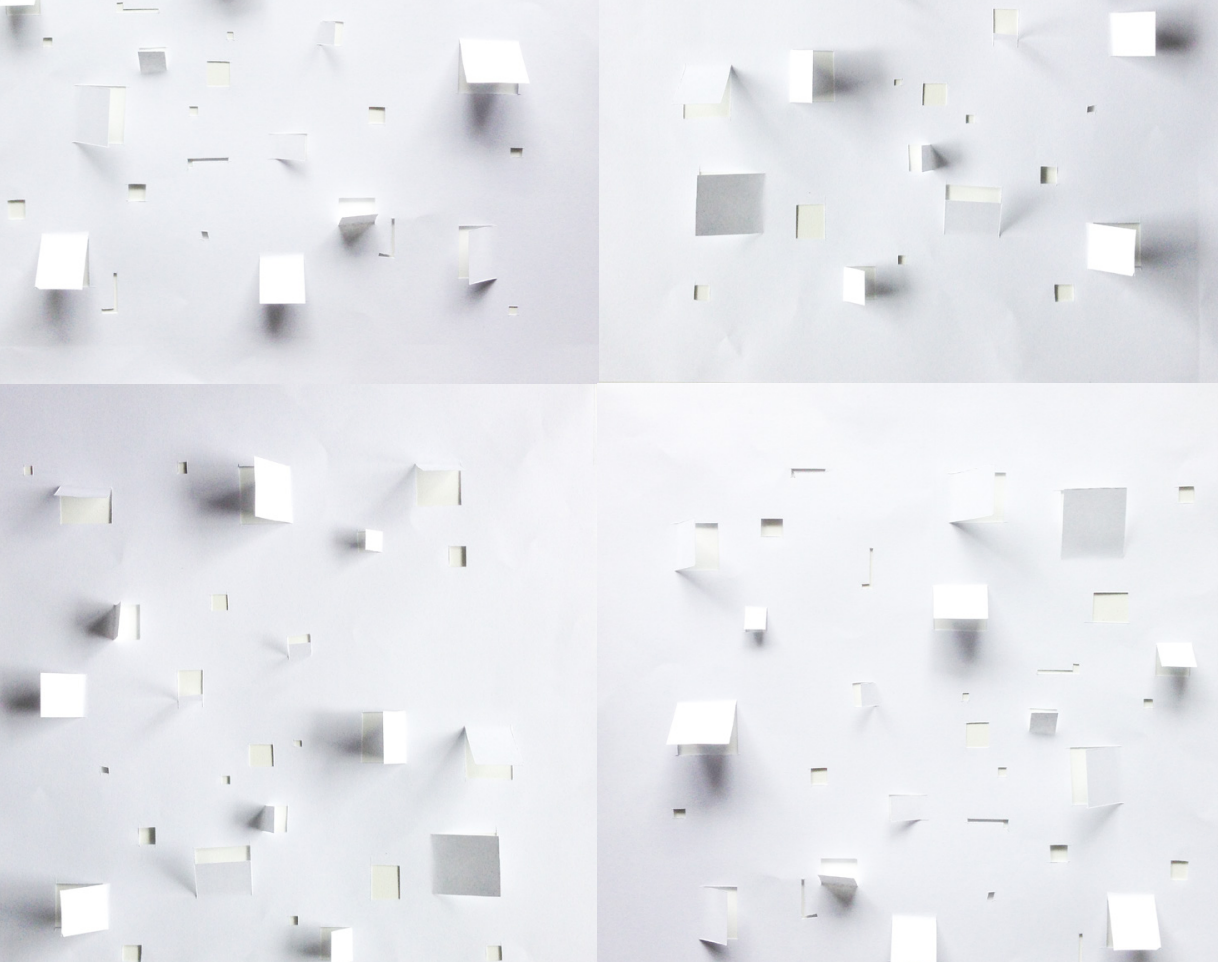


\section{Reflection}

After working at a smaller scale was a quick and efficient process to develop the final installation. Engaging the subject though a viewport was successful in activating the occupant and acknowledging the human scale. The earlier tests also signified the success of paper as a material. The use of paper was fundamental because of its fragile and delicate appearance. Wigley's argument towards thinness and its potential outlined in chapter one directly relates to the discoveries made in developing the final design.

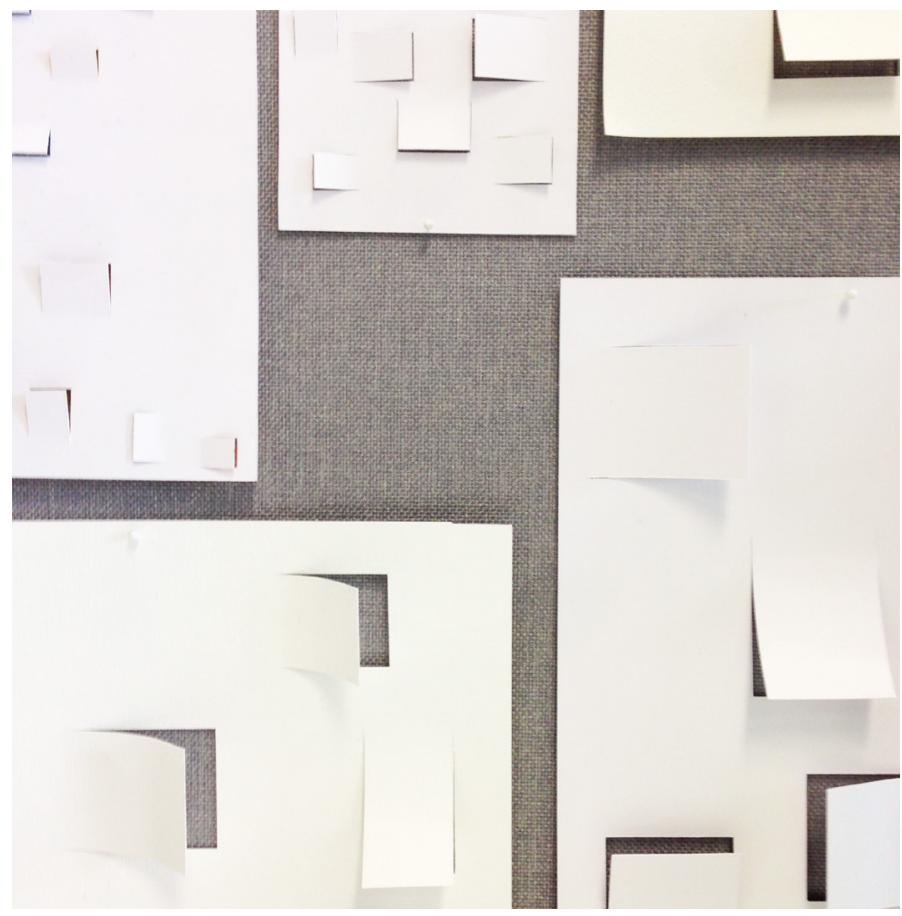

$\wedge$ 36. Different paper tests 


\section{FINAL DESIGN}

\section{Making}

The installation was designed through physical modelling and drawing. A box base was designed out of MDF to contain and define the interior material and support the paper. Clear acrylic supports were inset and cantilevered around the entire box perimeter. This supported the paper, but remained hidden, allowing the paper to float. To support the paper from within the box base and aid in sectioning the interior material, standing supports were created. Everything apart from the interior material was either clear acyclic or MDF spray-painted white to ensure the interior material's colours would act as features against the pure white paper.

The paper design was created through developing a square ratio of $20 \mathrm{~mm}$ for the viewports that scale up to provide four different sizes, based on earlier tests. The overall composition was essential to the design, therefore a few layouts and types of paper were tested. A grid of the same ratio provided a uniform and ordered layout, which the square viewports informally break up. The design included slits, orientated in every direction, and perforations. 

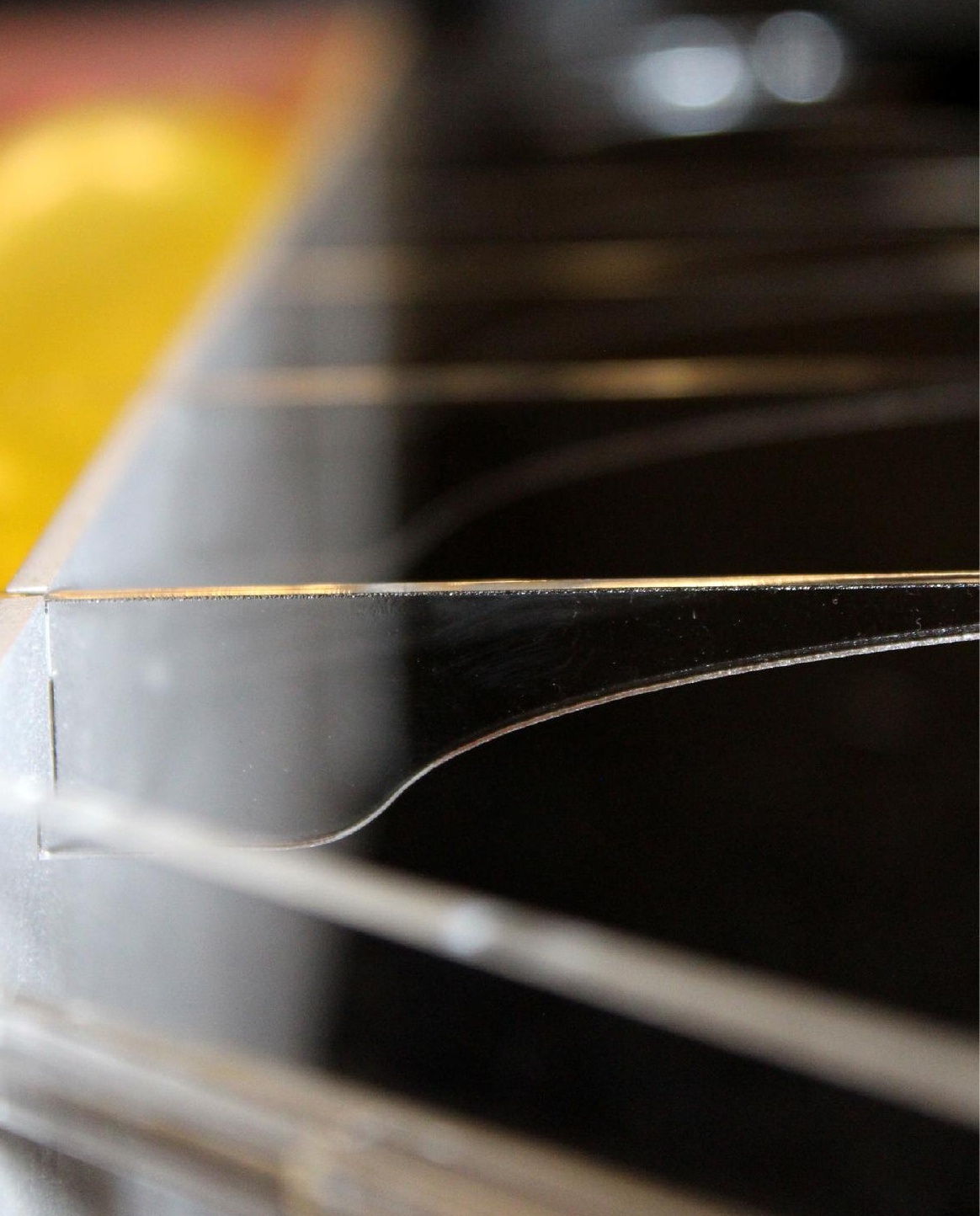


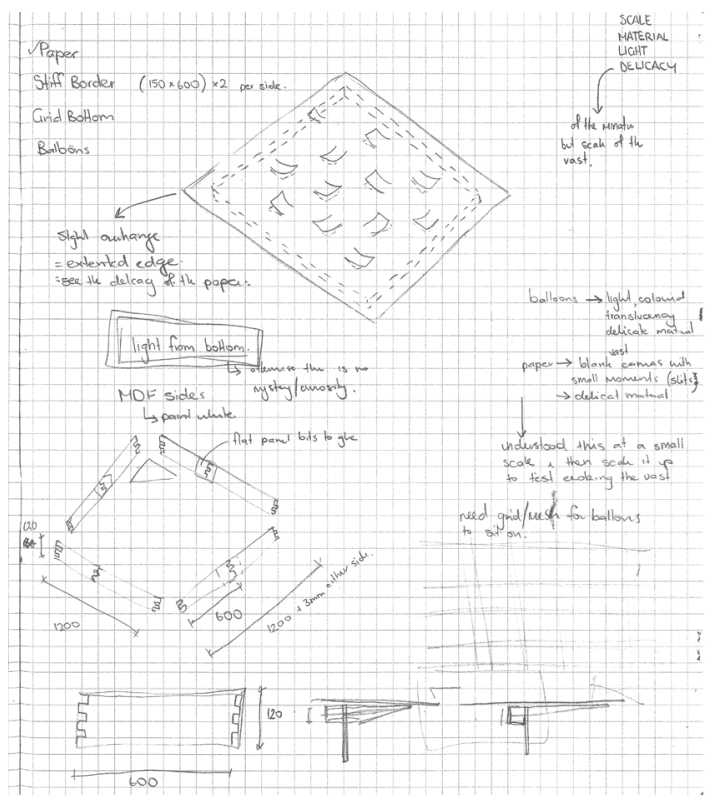

$1 /$
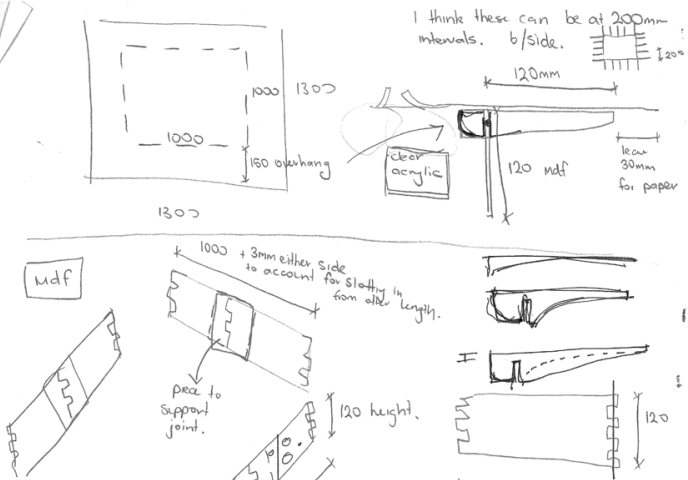

$k 1000+3 m m$ either side
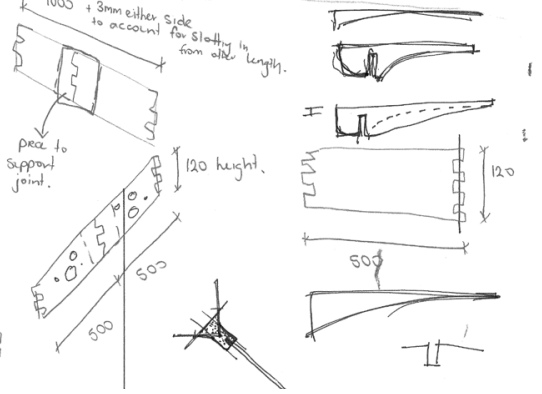


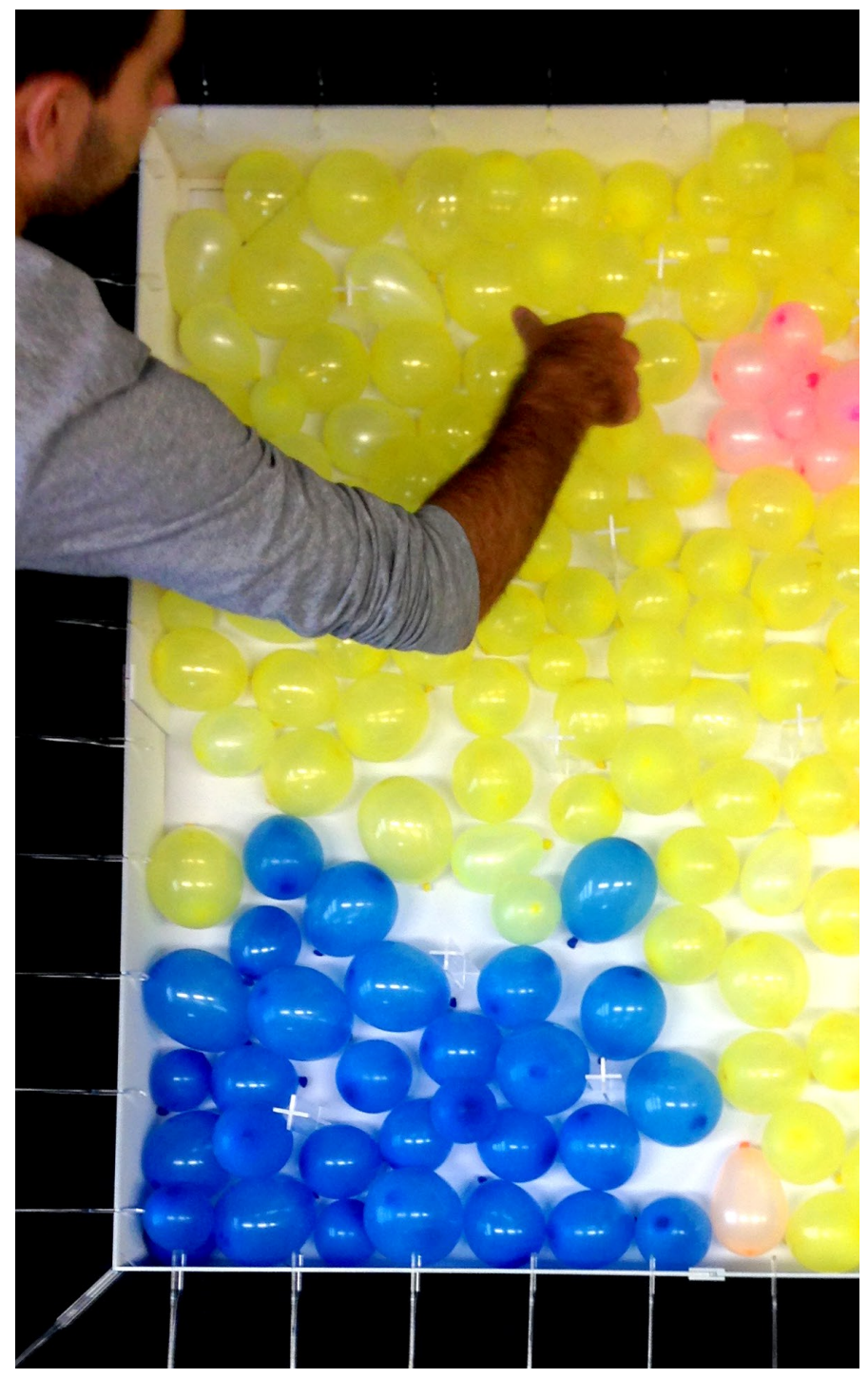

$\wedge$ 40. Making 69 


\section{FINAL DESIGN}

The installation is composed of a vast plane of paper that appears to float above the ground at ankle height with small perforations and lifts of the paper. When engaged at a more intimate level, the perforations and slits reveal soft and colourful moments hidden beneath. The interior material is defined by the volume of the box and colours are sectioned specifically to draw the viewer towards the design. At such a low level to the ground, the subject is encouraged to lower themselves and orientate around to engage with the installation. 

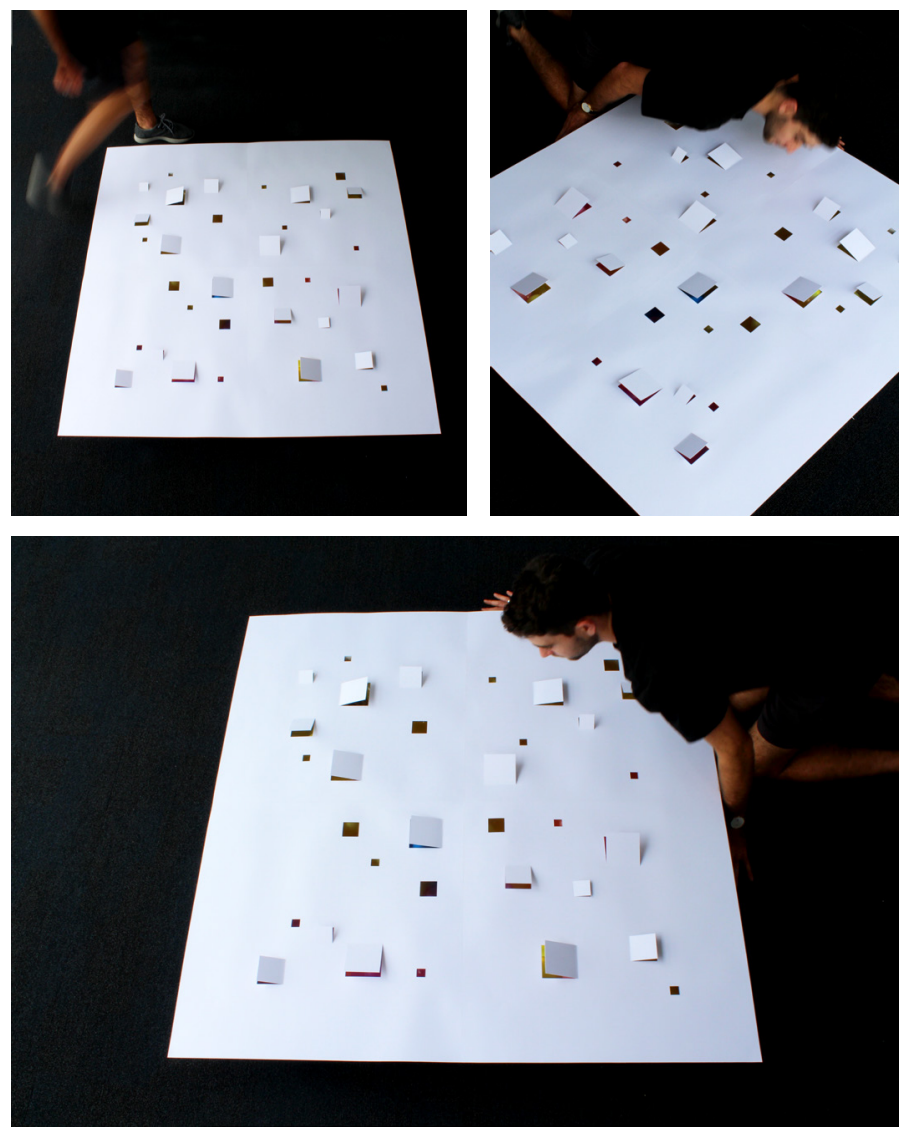

$\wedge$ 41. Subject engaging with installation 


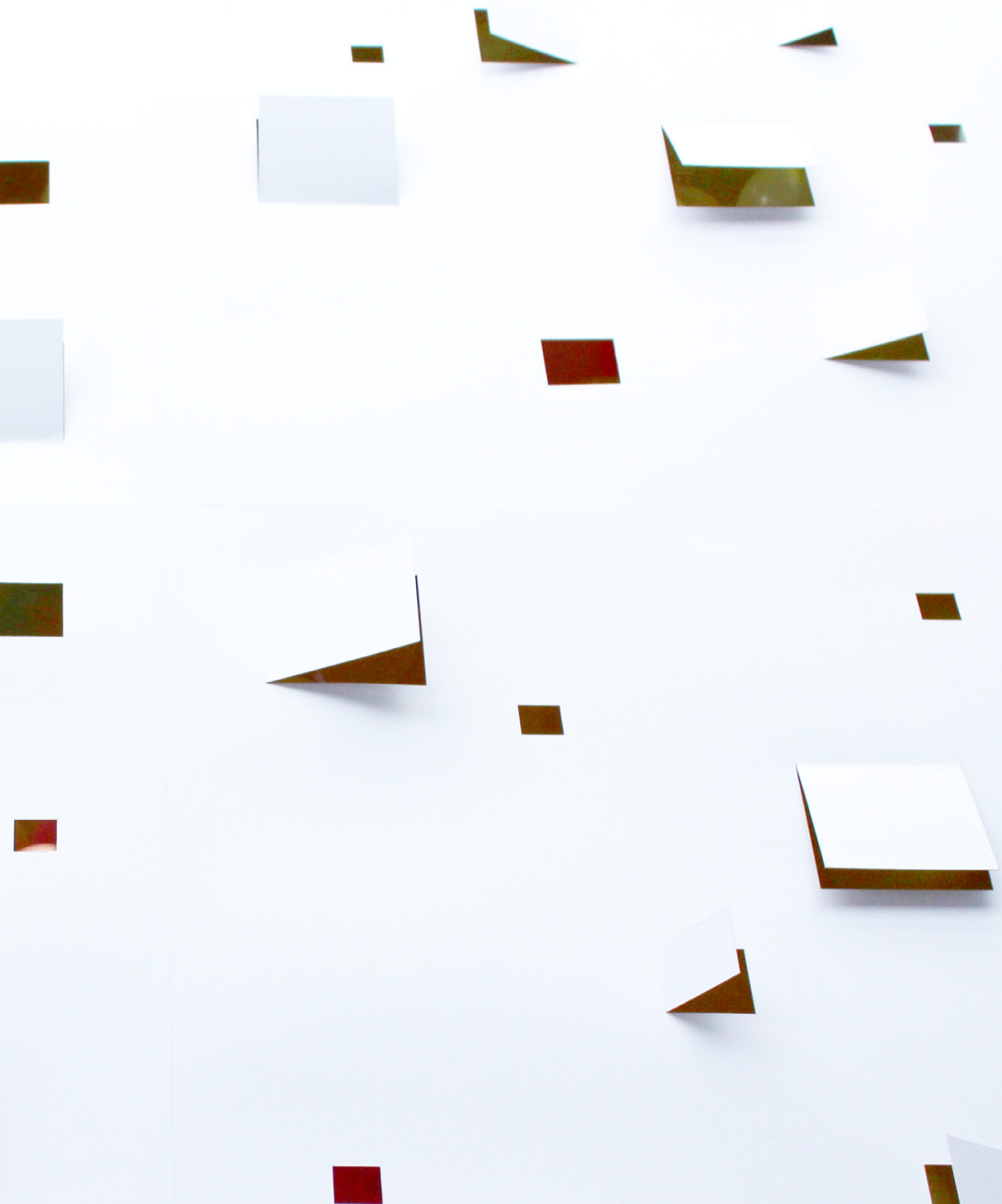


\section{Scale}

The large scale of the installation was essential to evoke the vast. Because of the measurement, the square shape enables the paper to feel wide and unreachable in the centre, thus extending its perception of size. The change in scale between the vastness of the paper and the intimacy of the moments revealing the interior, heighten the contrast between the two. Human interaction is essential in experiencing the shifting scales.

\section{Materiality}

The choice of materials became a key driver with their fragile appearances. The paper had to require enough strength and thickness to ensure it would not be entirely translucent when illuminated with colour, but thin and delicate enough to float. The balloons as the interior material were chosen for their delicate and fragile properties. When layered upon one another, they generate soft gradients of light.

\section{Colour + Whiteness}

The installation explores Kant's perception of the sublime and the beautiful where, "the night is sublime, the day beautiful. The sublime moves us, the beautiful charms" (Kant \& Meredith, 1911, p. lxxi). The contrast between the interior colour illumination and the surface create different experiences during the day and night. In daylight the soft translucent colours against the stark white setting draws the subject in for a closer look. The intensity of the whiteness evokes a subliminal element through its glare-like effect. At night the installation is transformed. The pure white paper disappears within the vast darkness, and the delicate moments are bold, with colour evoking the sublime at a miniature scale. 


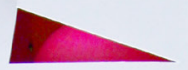

N
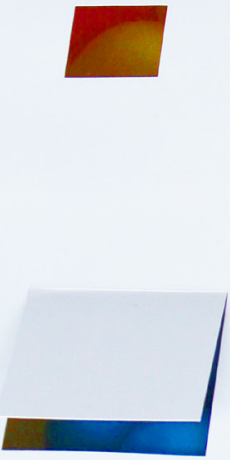

$\square$

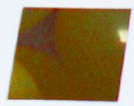

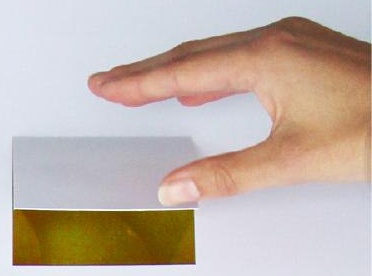
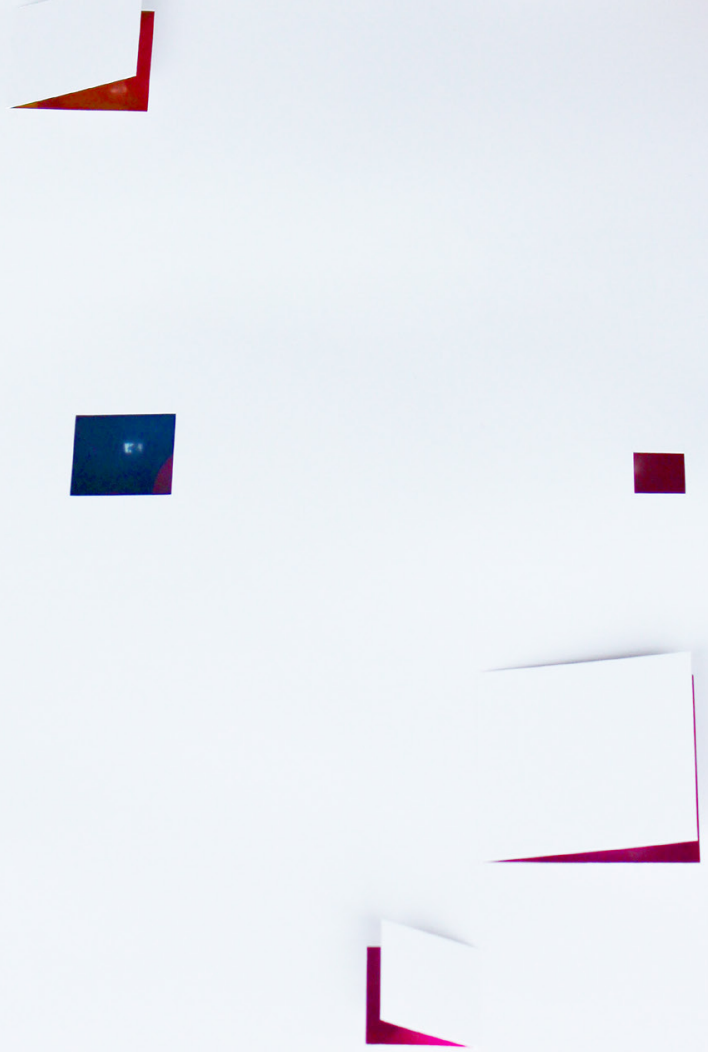

ㅁ

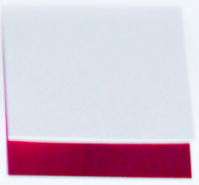




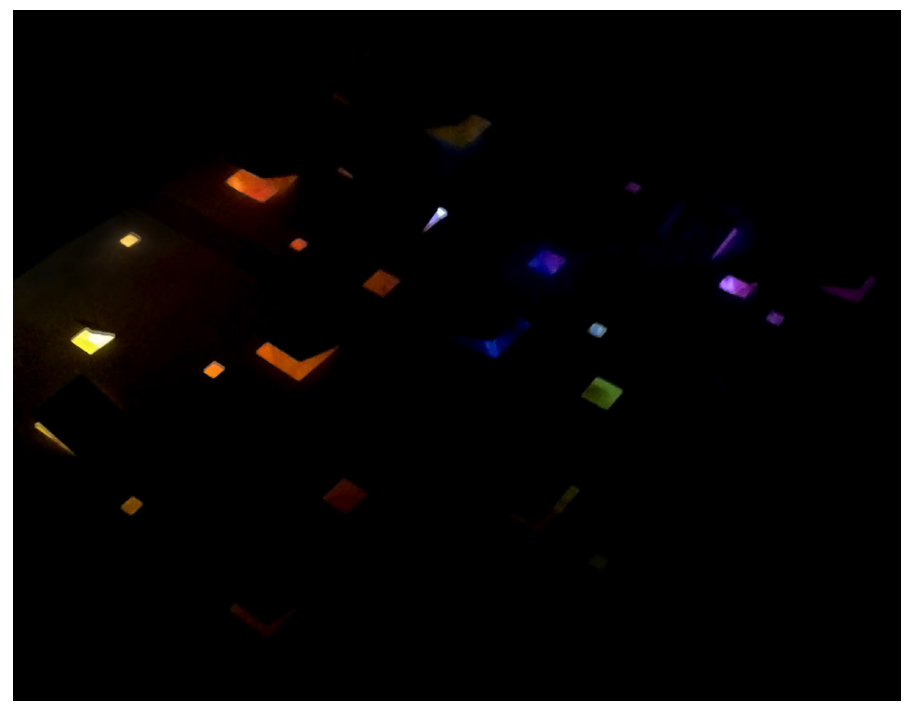

$\wedge$ 44. Night effect 


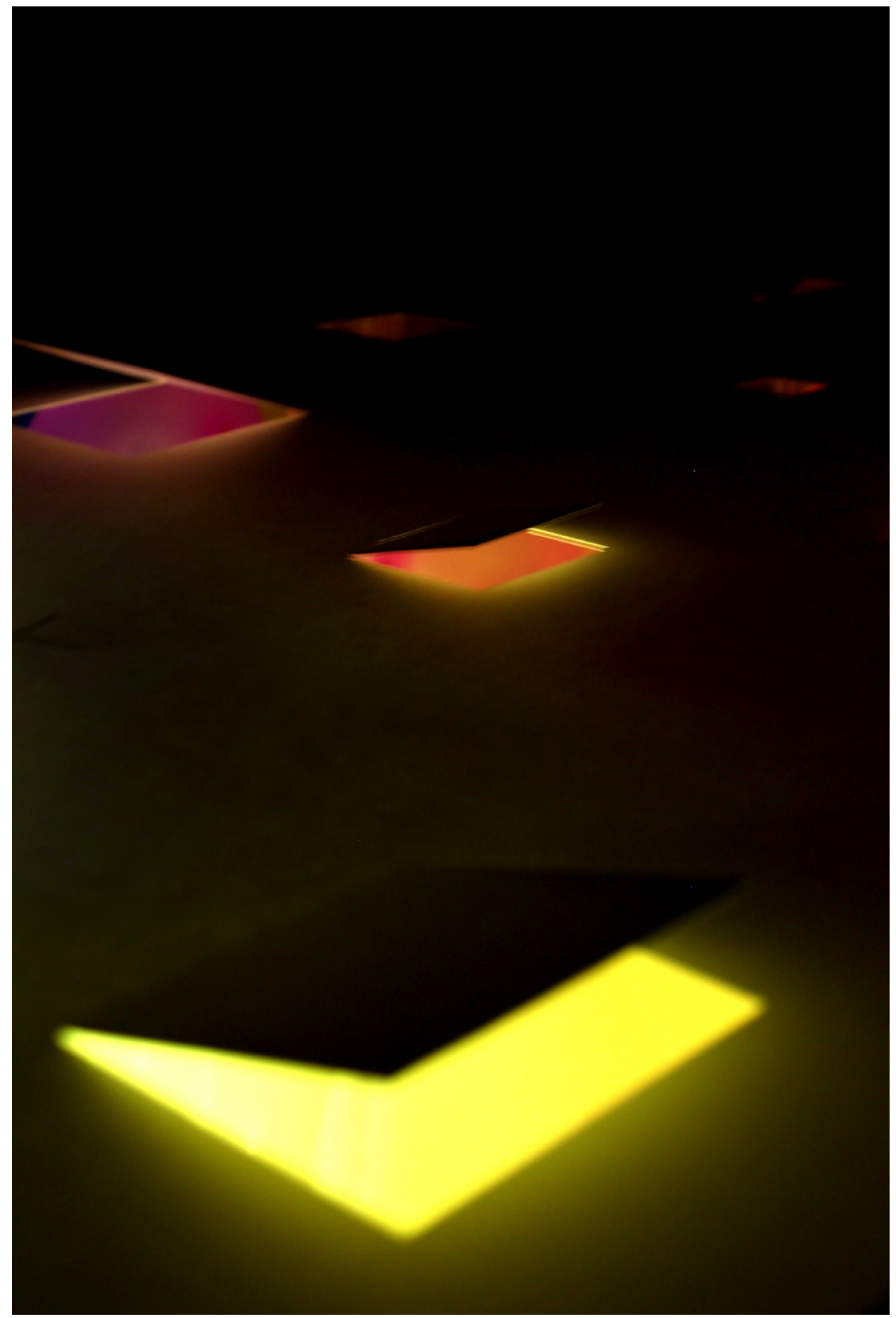




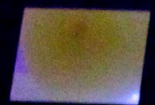



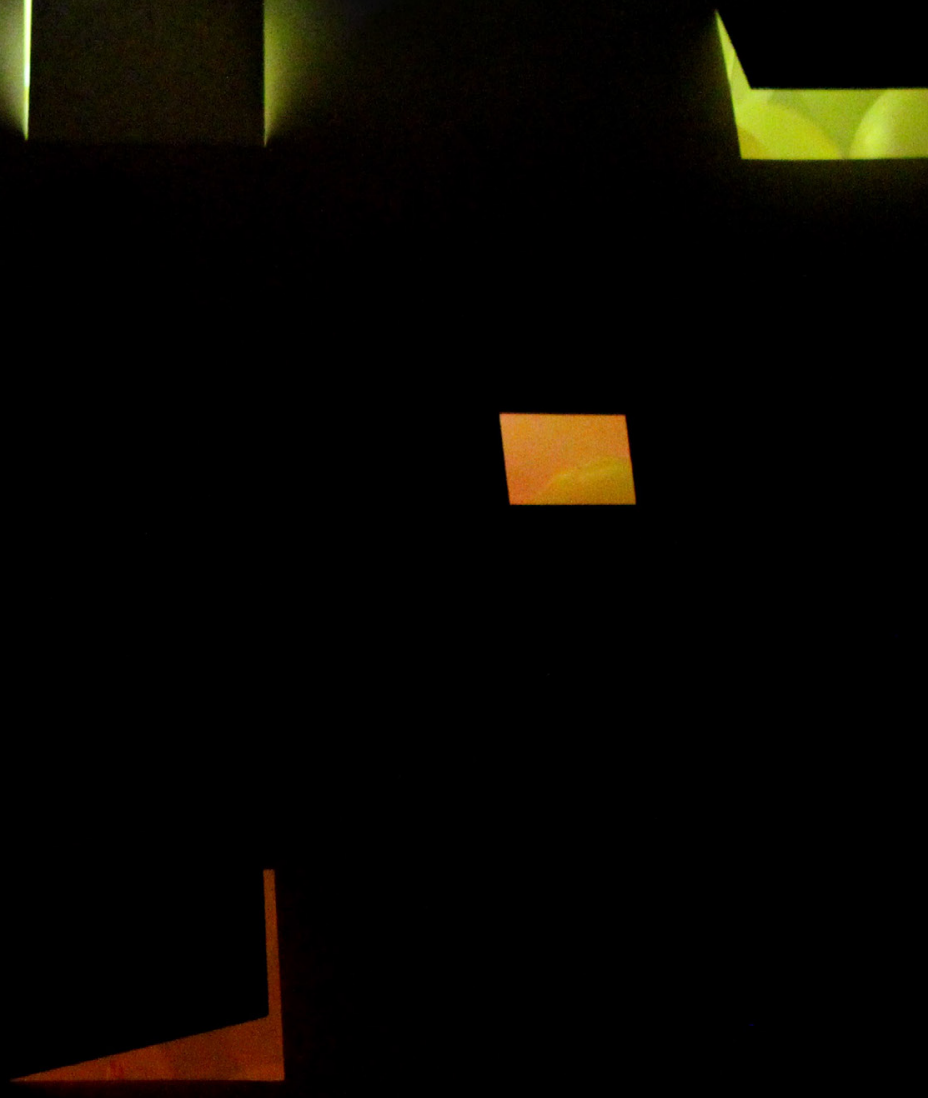


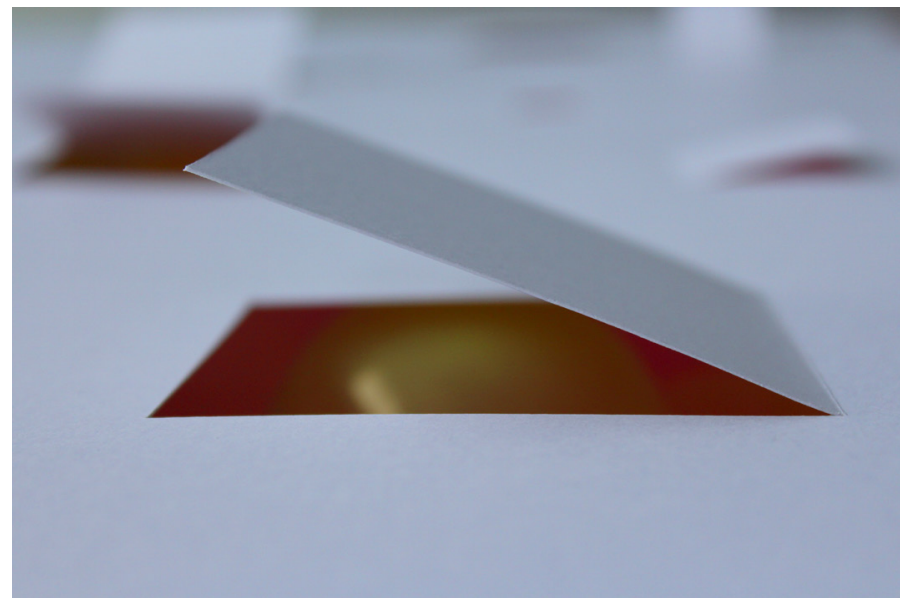

$\wedge$ 47. Opening detail

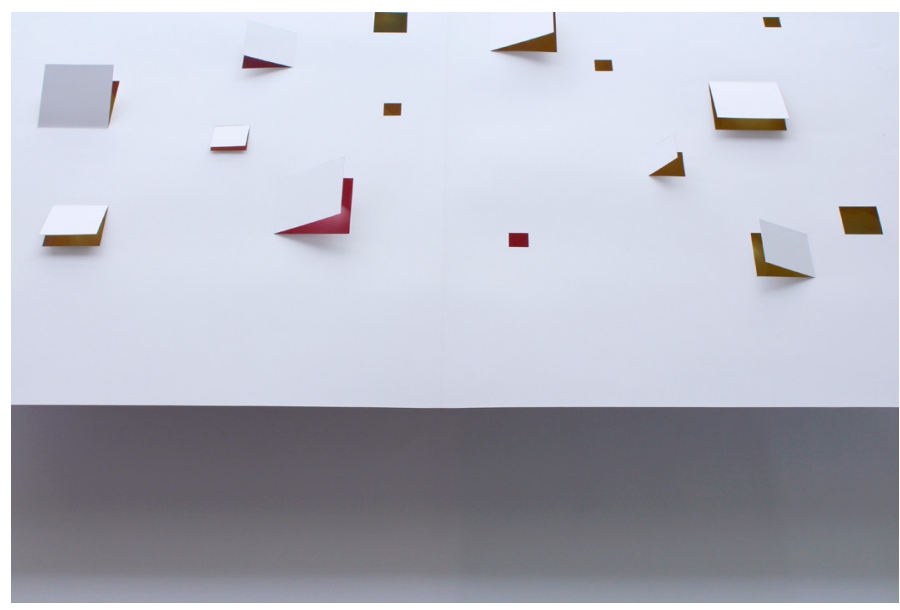

$\wedge$ 48. Floating effect 


\section{REFLECTION}

The installation set out to engage both the vast and the intimate scale through a series of trials and explorations. The tests that lead to failures were an integral part of the design process (O'Gorman \& Werry, 2012, p. 2). Their strengths and weaknesses were evaluated which lead to further developments in other directions. The final design is a successful development of the original idea of connecting the vast and the intimate through scale, materiality, and colour and whiteness.

Two key design iterations; test five and seven were combined, developed upon, and scaled up into the final design. The importance of these two tests was the development of intimate moments across a plane of white paper and the contrasting colours between the exterior and interior. The increased scale for the final design is larger than people might expect due to it still inheriting its delicate and minute qualities. The change in colour of the interior material and size of the perforations aid in creating variety and uniqueness to the design without losing sight of the design intent.

As an installation it relies on activating and engaging people. Hiding the interior material and reducing its visibility allows the material to remain a mystery, and the viewers are able to focus on the experience as a design strategy. The final design highlighted to me the importance of the human scale and working down to the detail. Considering the construction of the installation, materiality and moments of intrigue were all successful contributing factors. The following design chapter explores how to translate these ideas into an architectural solution. 

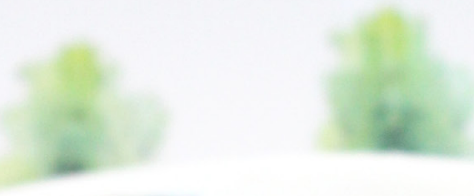

(6)
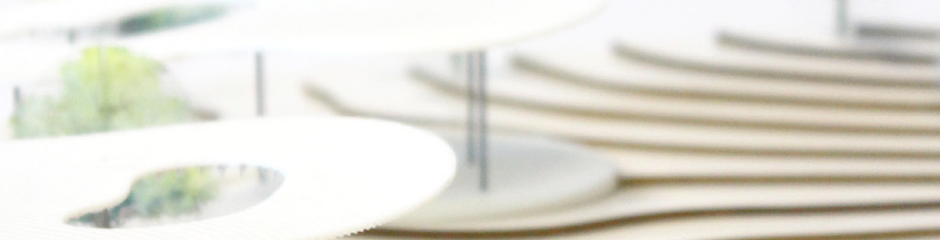

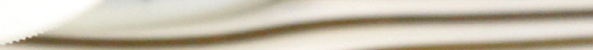

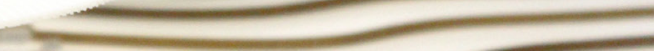

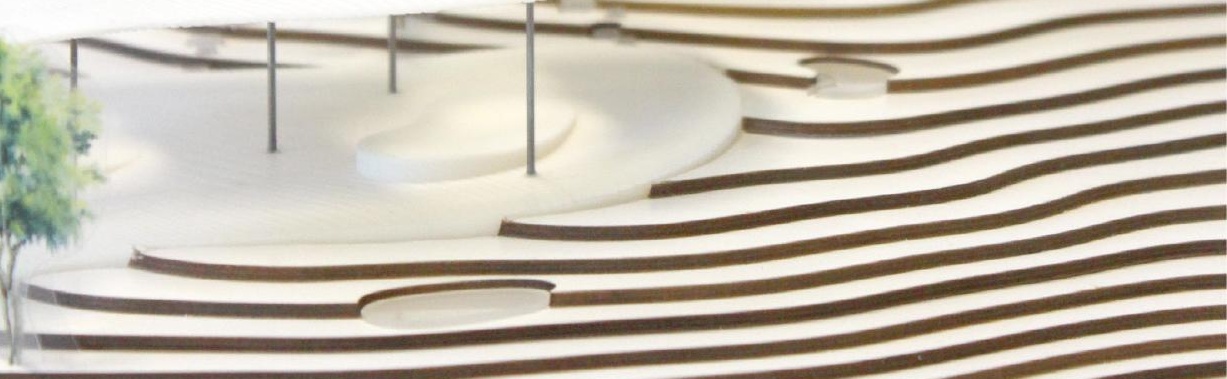

(2)

W Te Thes

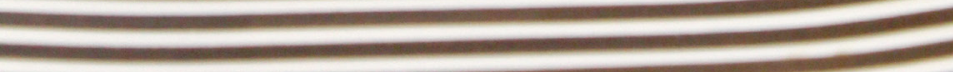

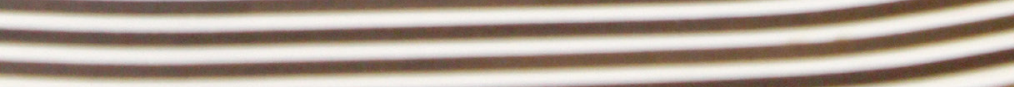

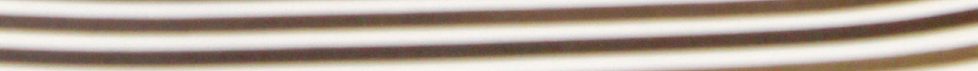




\section{4 \\ MID-SCALE}




\section{Introduction}

The opposing scalar conditions, the vast and the intimate are tested through the design of a café pavilion. This second design experiment translates the ideas from the installation with the added complexities of site and programme. Firstly this chapter outlines the aim and methodology, before scaling up the installation through the design process. The vast and the intimate scale are explored through various tests before site and programme are introduced. Once the café pavilion's site was established in the Wellington Botanical Gardens, the design process continued to explore the ideas of the vast and the intimate scale alongside strategies where site shaped and informed the design. To conclude the chapter, the final design is reflected upon. This scale signalled a shift toward focusing on the notion of delicacy. The shift is then addressed in the following public-scale chapter. 


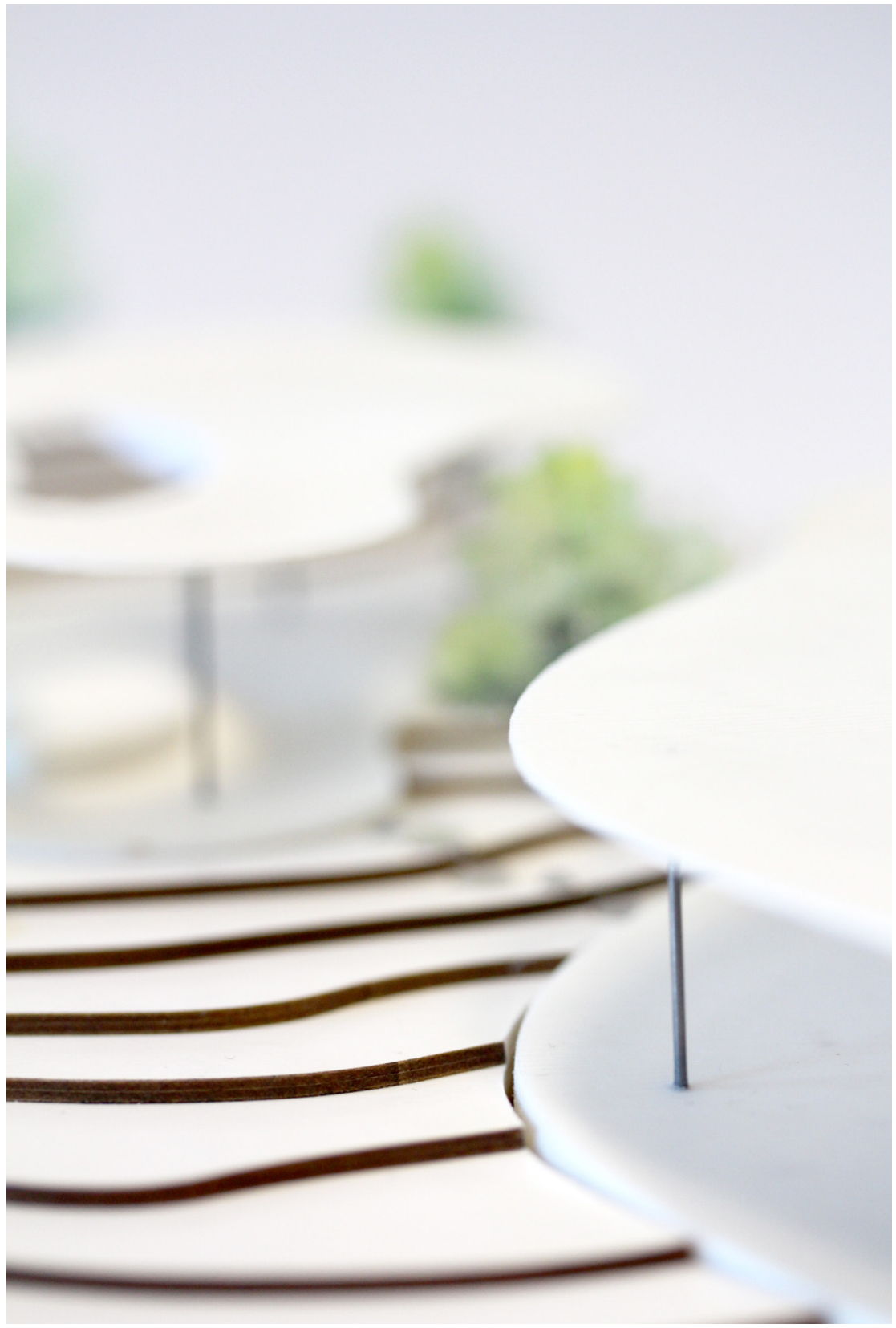


Investigate the vast and the intimate scale simultaneously through the design of a café pavilion, considering occupation and a jump in scale.

\section{Method}

The overarching methodology followed design-led research. Iterative and fast paced explorations test the aim through physical and digital modelling, photography and drawing. Like the installation, scale, materiality, and colour and whiteness are explored throughout the design process and all reflected upon in the final design. Although the methods are the same as the first design experiment the design intent has shifted from an installation to architectural solution, therefore produced different results. Mapping and drawing were new methods engaged to generate form from site. The explorations are continually reflected upon whilst moving forward as the design moves from the installation to the midscale. Yaneva's method of scaling is fundamental to the research. The 'jump' in scale from the installation to the mid-scale as argued by Yaneva, "accelerates the visualisation process" (2005, p. 880). New knowledge is quickly gained informing aspects that lack clarity in the design, through the visibility of a higher scale, which is evident in this design chapter. 


\title{
Design Process Overview
}

\author{
non-linear
}
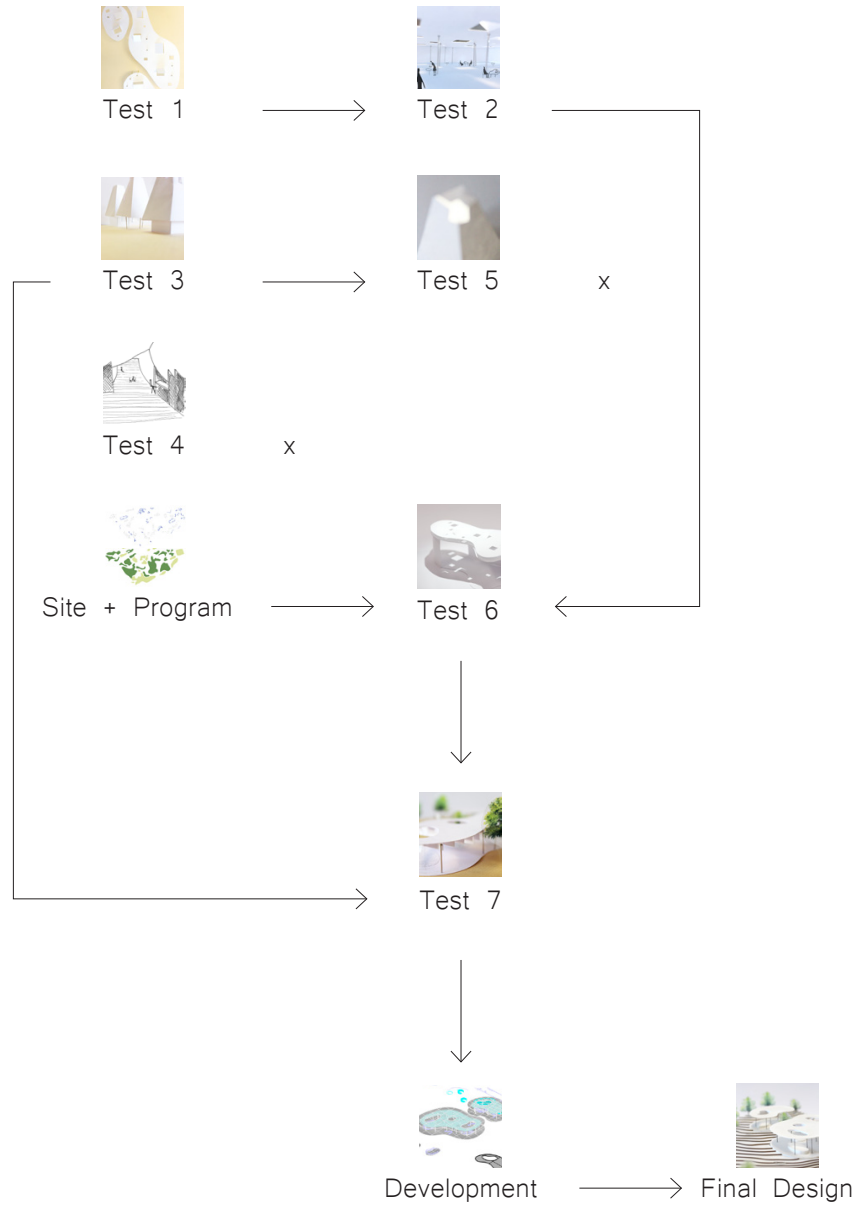


\section{Test One}

Rather than starting with site or programme the design process follows Yaneva's method of scaling up as the initial driver in this design process. The aim is initially investigated through a formal enquiry into space and occupation through architectural considerations before investigating site and program.

\section{Aim}

Scale up the installation in parts, dissect the most successful qualities and how one might occupy these spaces. I focused on using the same material whilst fluctuating the scale through the explorations.

\section{Evaluation}

Although an interesting test, on reflection by breaking up pieces and shifting scales, the models lose the sense of vastness that was evident in the installation. The more effective tests show the 'floating' roof or a greater sense of space. 
Test Two

\section{Aim}

Scale up the installation as a whole and consider occupation.
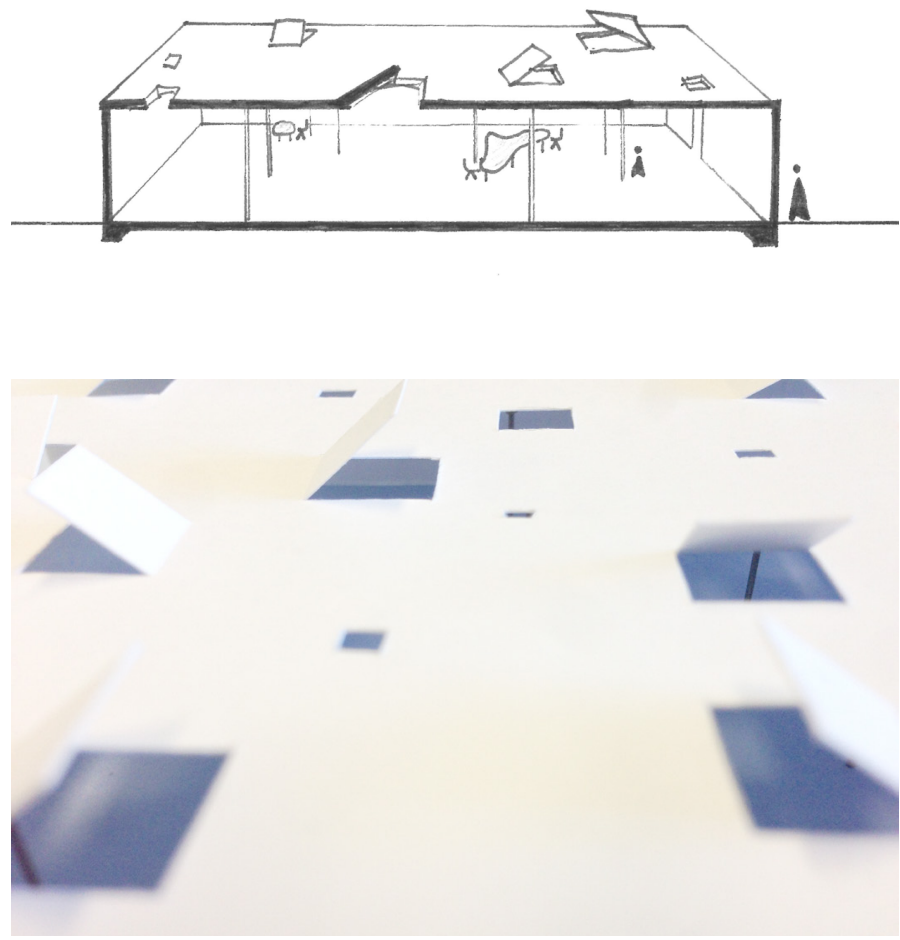


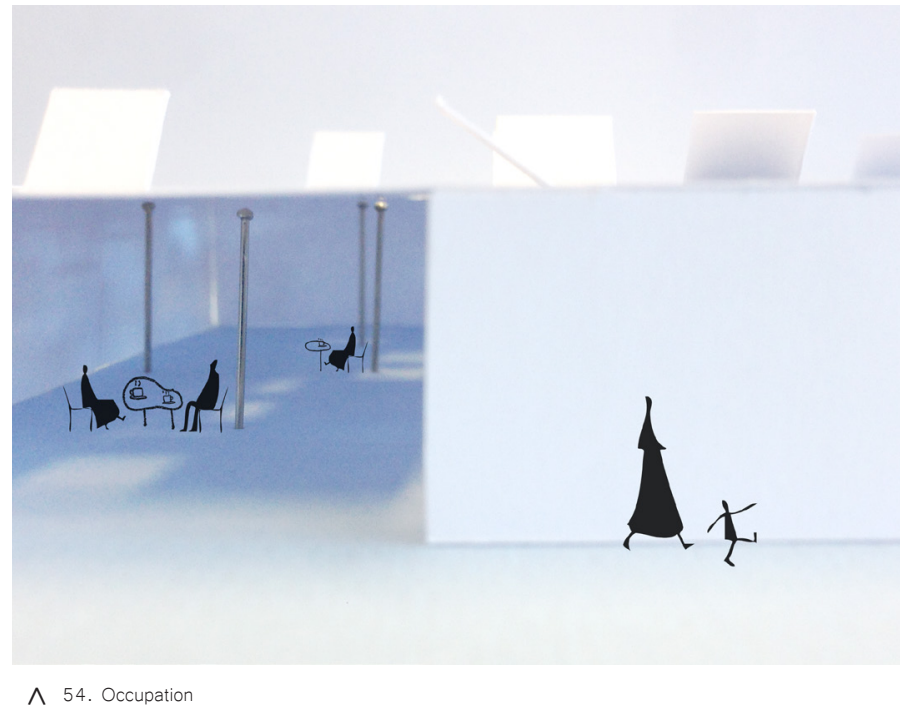





\section{Evaluation}

The space created by scaling up the installation was successful and has potential to develop upon with response to site. The interior is left flexible and circulation becomes free flowing whilst hidden from the exterior. The spatial envelope tests the vast and the interior structure, and moments in the roof test the miniature. However the roof lost its sense of delicacy as it does not appear to float like the installation.

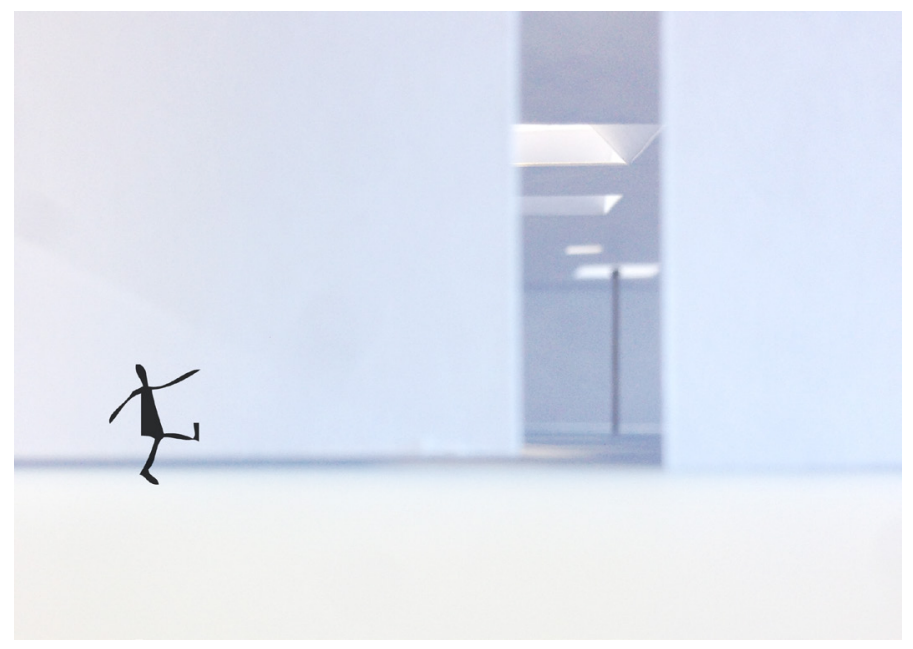

$\wedge$ 56. Interior moment 


\title{
Test Three
}

Test three shifts in direction linking to the second design precedent, Grafton Architects. This shift is due to research wanting to explore multiple ways to address the aim rather than following a linear format.

\begin{abstract}
Aim
Explore vastness through a series of hollow volumes and an intimate engagement with the structural relationship to the ground.
\end{abstract}

\section{Evaluation}

Overall the study predominantly focused on the roof shaping space. The appearance of 'floating' with minimal structural support enhances an intimate engagement with the occupants as it contrasts with the large volume. I tested different ways to channel lights and engage with the ground.
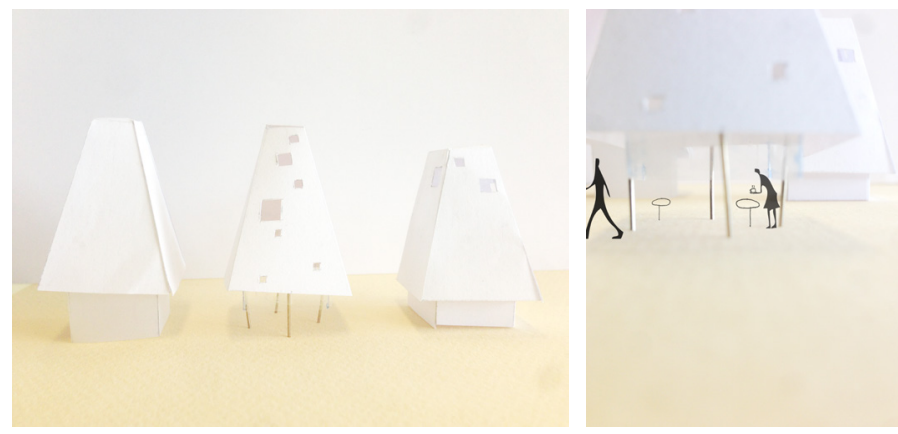

$\wedge$ 57. Test three 


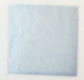

$\operatorname{sese}$

曾

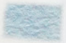

towe

saseses:

$$
\text { Pres }
$$$$
8^{2}=\frac{1}{25}
$$ 


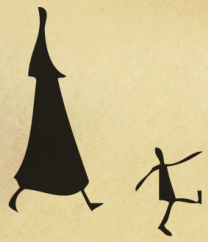




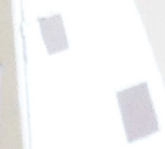
4<smiles>[Te]C1=[13C]=CC1</smiles> 
Part two in the series follows the same idea with tapering structural base and a top heavy design however the shape draws away too strongly from previous experiments by turning the vast into discrete elements, and as a result are no longer vast.

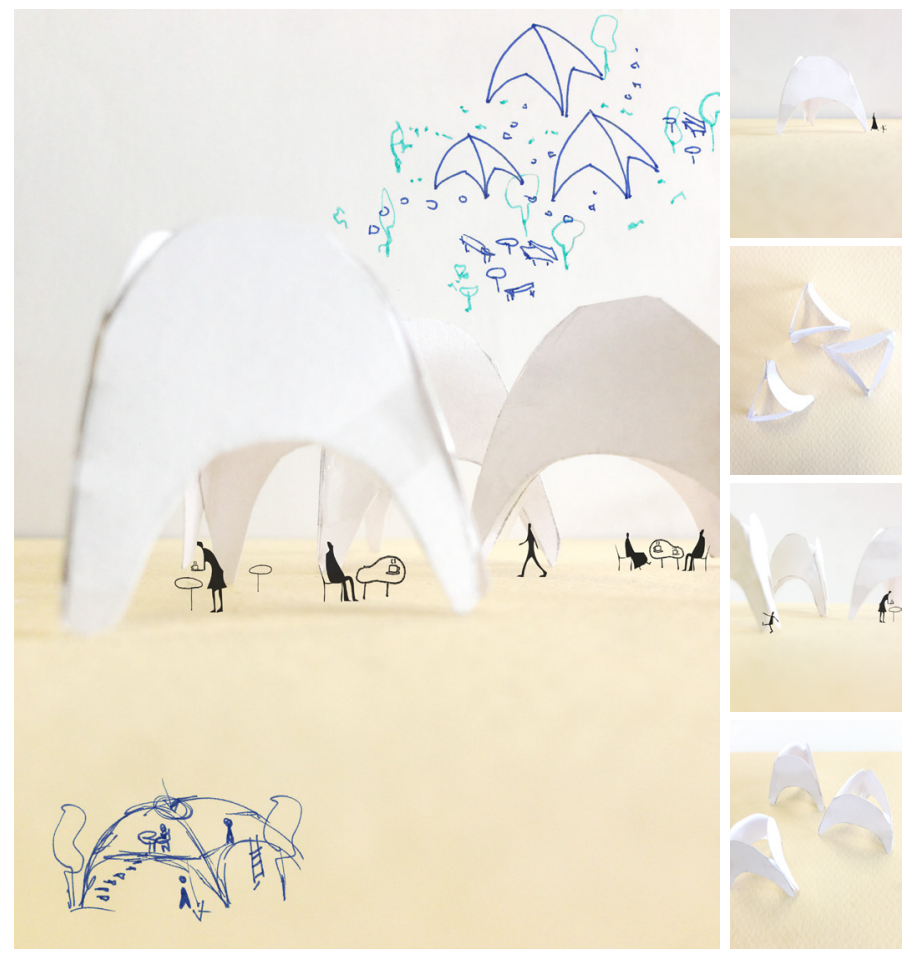

$\wedge$ 60. Test three part two 

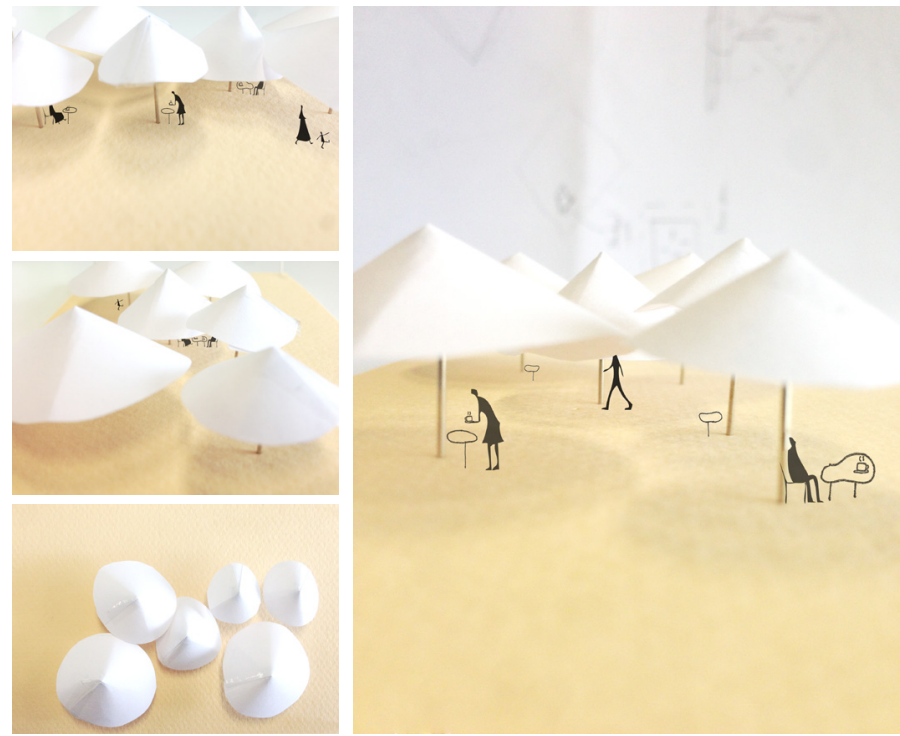

$\wedge$ 61. Test three part three

The layering circular rooftops attempt to read as one vast plane whilst remaining structural individual. However, on reflection, the shape struggles to read uniformly and does not have the same contrasting effect as the heavier volumes previously explored. As a result the test fails to explore the vast and intimate scale simultaneously. 


\section{Test Four}

\section{Aim}

Explore how to extend the perception of space through 'borrowed scenery'. This could also be achieved through the exploration of curves and floating planes. Borrowed scenery is a technique of design which engages with creating a continuity between the interior and exterior, a topic that was conceptualized in the 1960's in modernist architectural theory, however was evident long before that (Wybe, 2015, p. 32).

\section{Evaluation}

A quick exploration that used a path to act as a continuous line, drawing the eye's direction into the vast as it appears to disappear into the horizon. In response to the vast the smaller spaces created an intimate engagement for occupants within the design. These smaller spaces employed techniques adopted from the installation such as using light to engage the subject as a smaller scale. Despite the attempt this exploration was underdeveloped and unsuccessful. The consideration of light and volumes shaping space was more successful in the previous experiment as it has more potential for development working with the Grafton Architect design precedent.

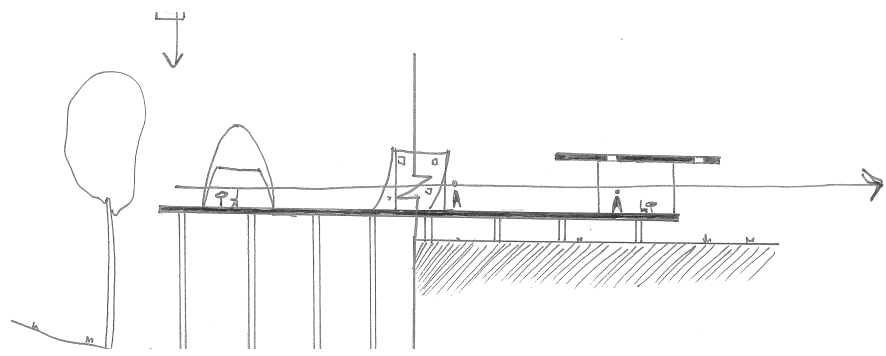

$\wedge$ 62. Test four section 

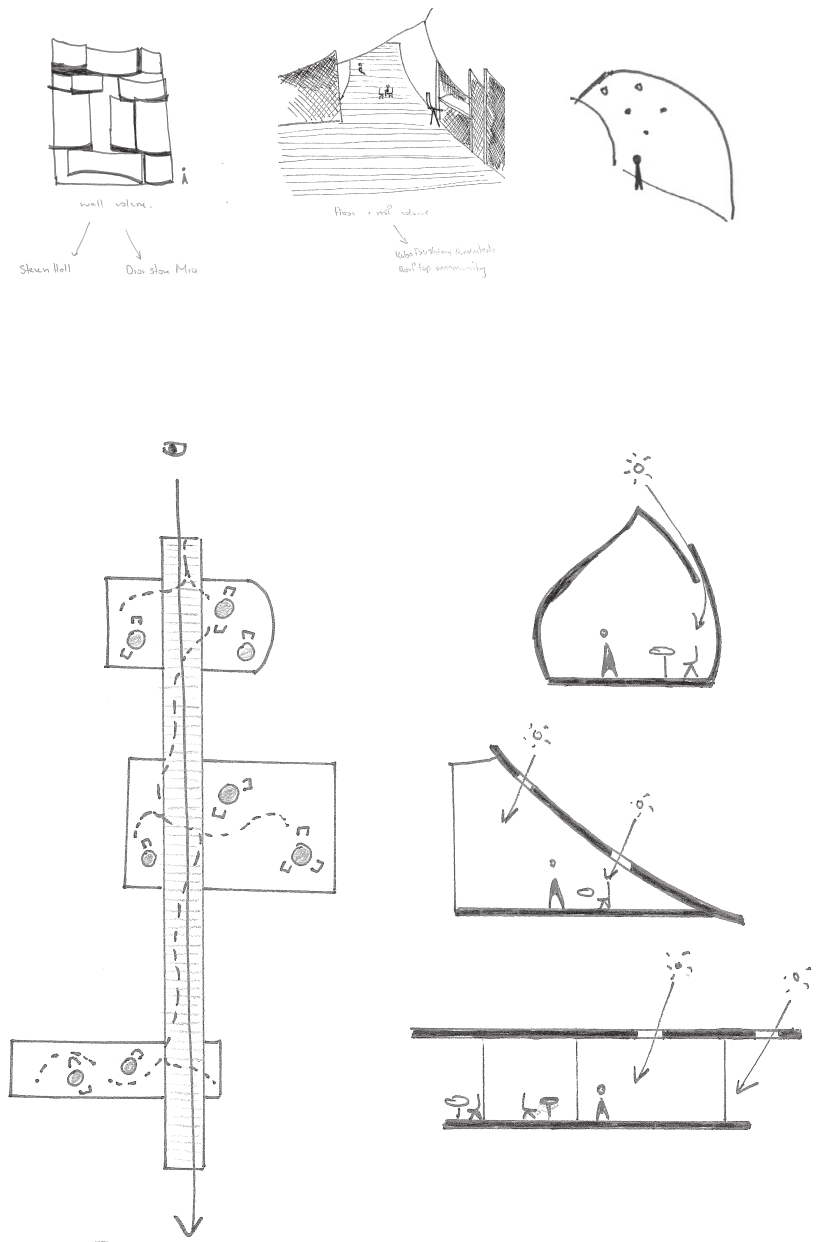

$\wedge$ 63. Drawings exploring spatial experiences 


\title{
Test Five
}

\begin{abstract}
Aim
Return to the volume in test three and exploit it further to explore shaping and experiencing light through different perforations. Due to the nature of the methodology the design process is non-linear. Because of this investigations may lead to dead ends which then enables the design process to back track and develop in another direction. This process is clearly evident here in test five.
\end{abstract}

\section{Evaluation}

The blurred lens allowed the eye to focus on the overall effect and not the details. Although this test specifically did not lead to further development it was an effective exploration that sparked the development of using light to shape space.
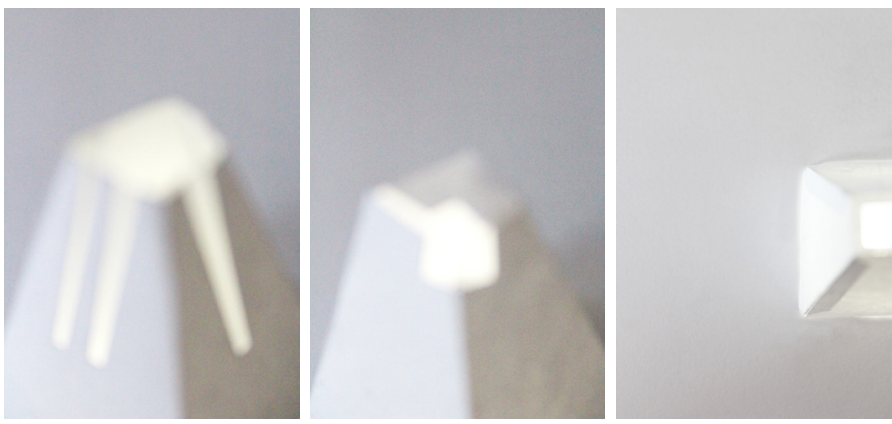

$\wedge$ 64. Volume exploration series 



\section{SITE}

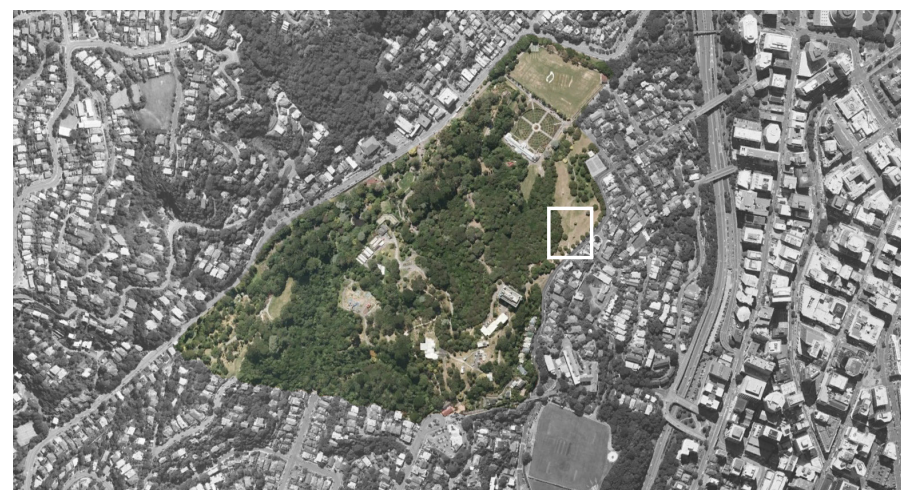

$\wedge$ 67. Site location (Google, 2017)

After rigorous design testing site and program were introduced to offer depth and complexity to the project. The Wellington Botanical Gardens was the selected site for this mid-scale exploration, providing a testing ground for the research. Throughout the botanical gardens natural elements shape circulation, dictate viewports and create relationships of movement and position. The formulation of nature use light and shadow to shape space and varying levels of density. The man-made elements oppose the natural with more solidity. Upon site evaluation, I engaged with the organic free forms of nature in both the vertical and horizontal direction. These qualities were mapped following Perry Kulper's methods of drawing as a visual way of thinking and engaging with site and understanding its qualities (2012, p. np).This investigation was explorative and speculative and could be critiqued as subjective, however in this case it produced a successful outcome. 
Drawing and mapping were used as analytical tools to represent active and static conditions on site. The site analysis is composed of a series of layered drawings that communicate different site qualities. Such qualities include circulation, vegetation densities and contours.

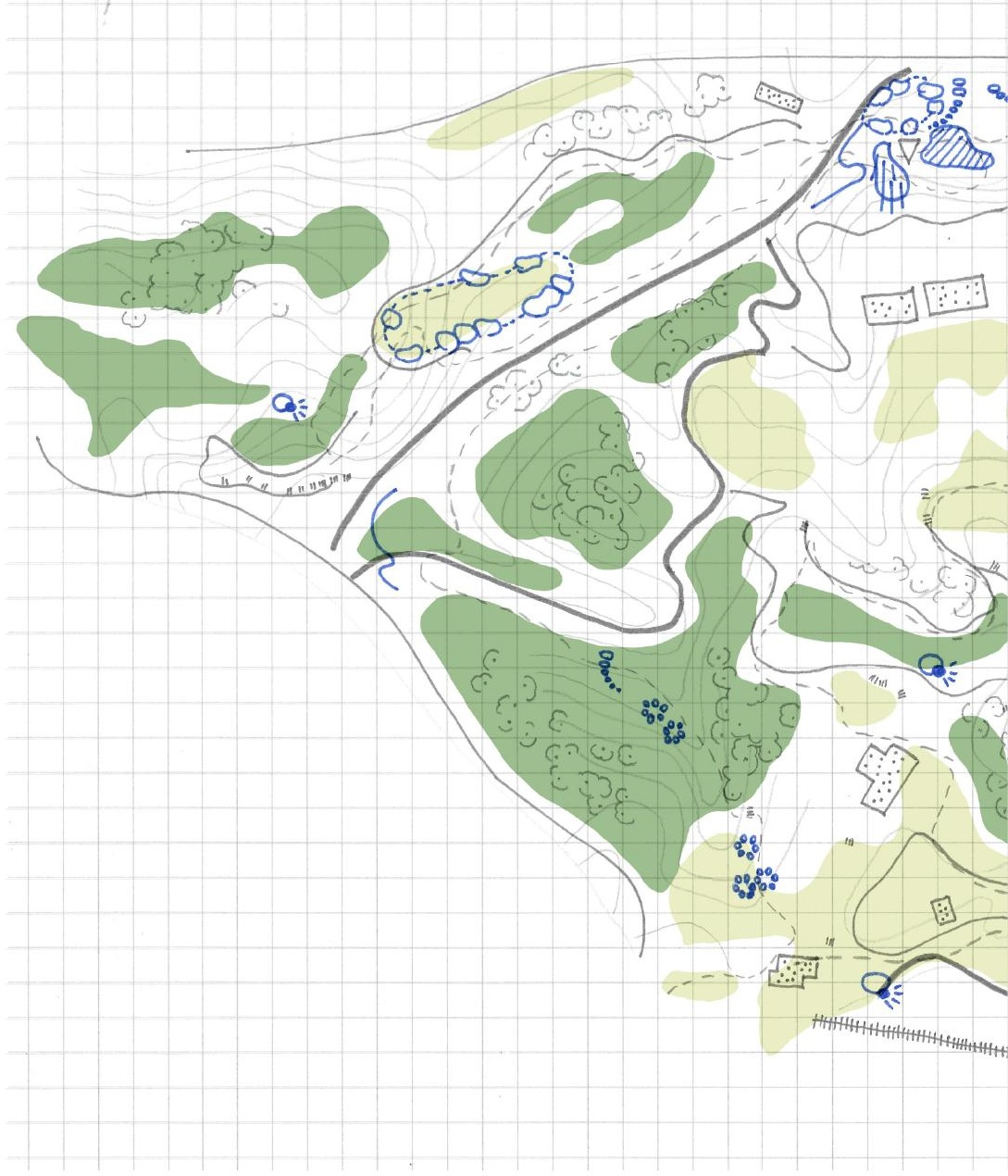




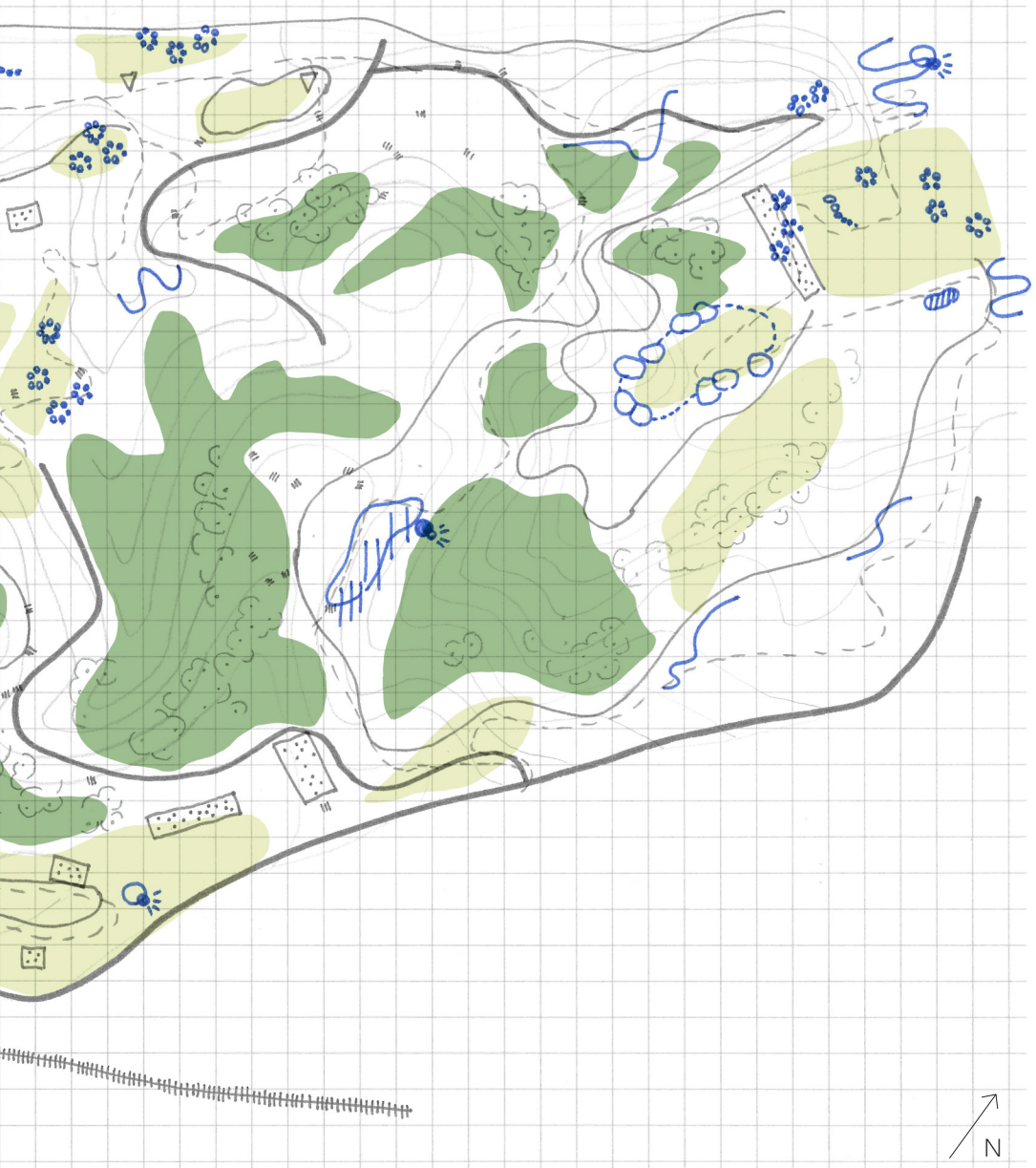


$\therefore: \because$ Buildings

$\triangle$ Small landmark stwetures

IIII Stairs

HWllt Cable car

Man-made

$\checkmark$ Main paths

$\checkmark$ secondary paths

$\int$ contours $5 \mathrm{~m}$

$\because \quad$ ciroulation

Q. .3 trees - dense vegetation

(10) lakes

$\therefore 8$ detail moments in nature

No strongly shaped path

io viewports

itt light shaping space

hidden arved paths

品

o. space shaped by trees

dense vegetation

light vegetotion

Natural

$108 \wedge$ 69. Site analysis key 


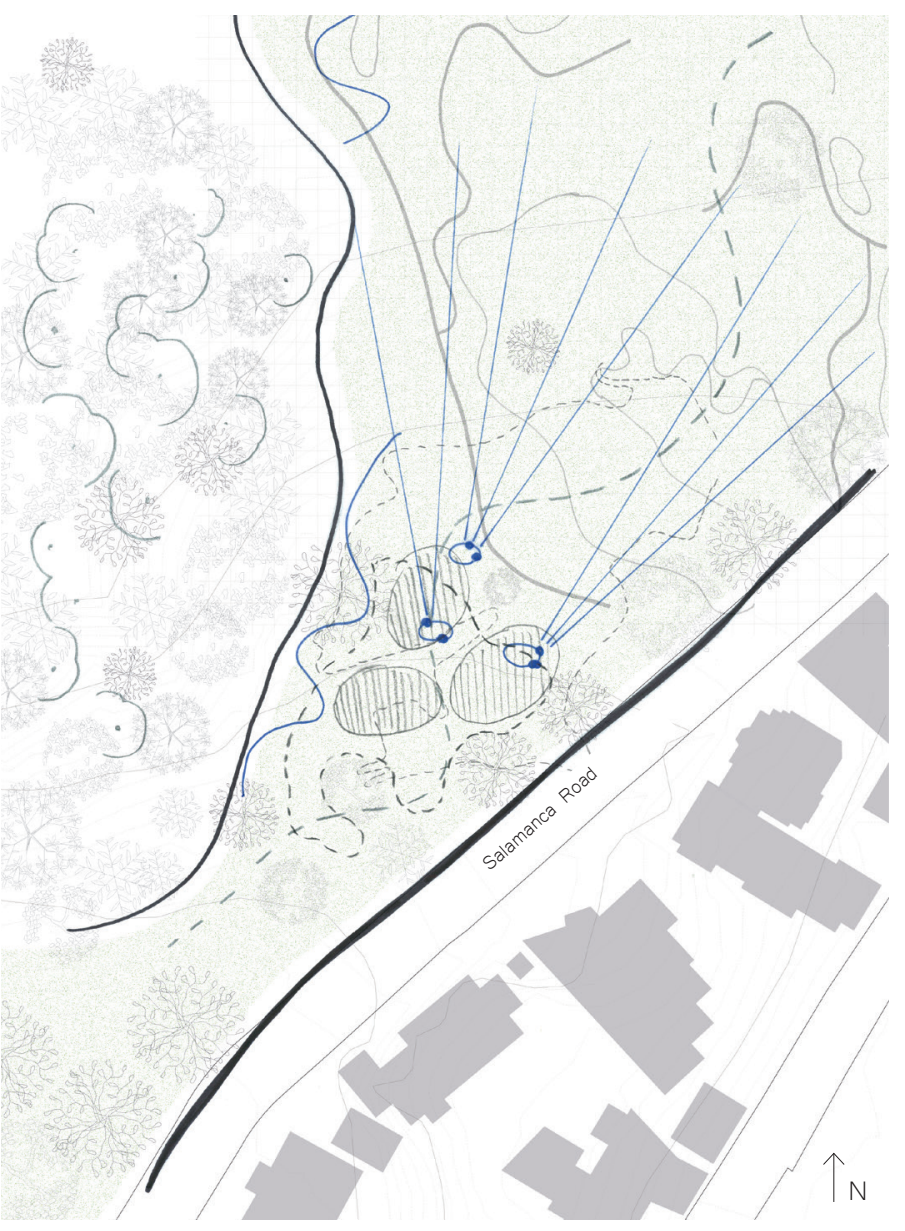

The same level of analysis was applied to the specific site location within the gardens. Through plotting conditions and layering information, I used the site's qualities to help derive form, viewports and location. 


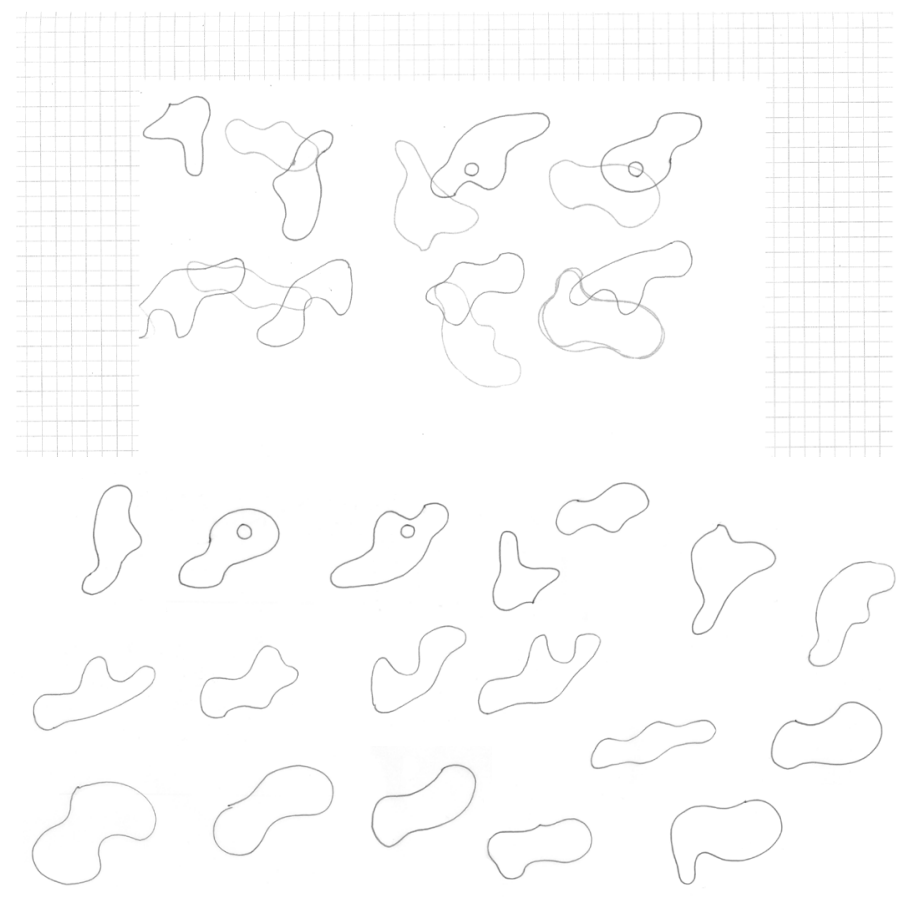

$\wedge$ 71. Deriving form

Multiple forms were generated through shaping spaces, focusing on engaging with the organic free flowing curves. These curves continue to meander through the site in different directions. The vegetation was hugely influential as the site's trees informed the shapes. The areas of openness on site were potential view shafts that were acknowledged. The forms were then layered upon one another, derived and developed upon in relation to points of interest and circulation to finalise the form. 

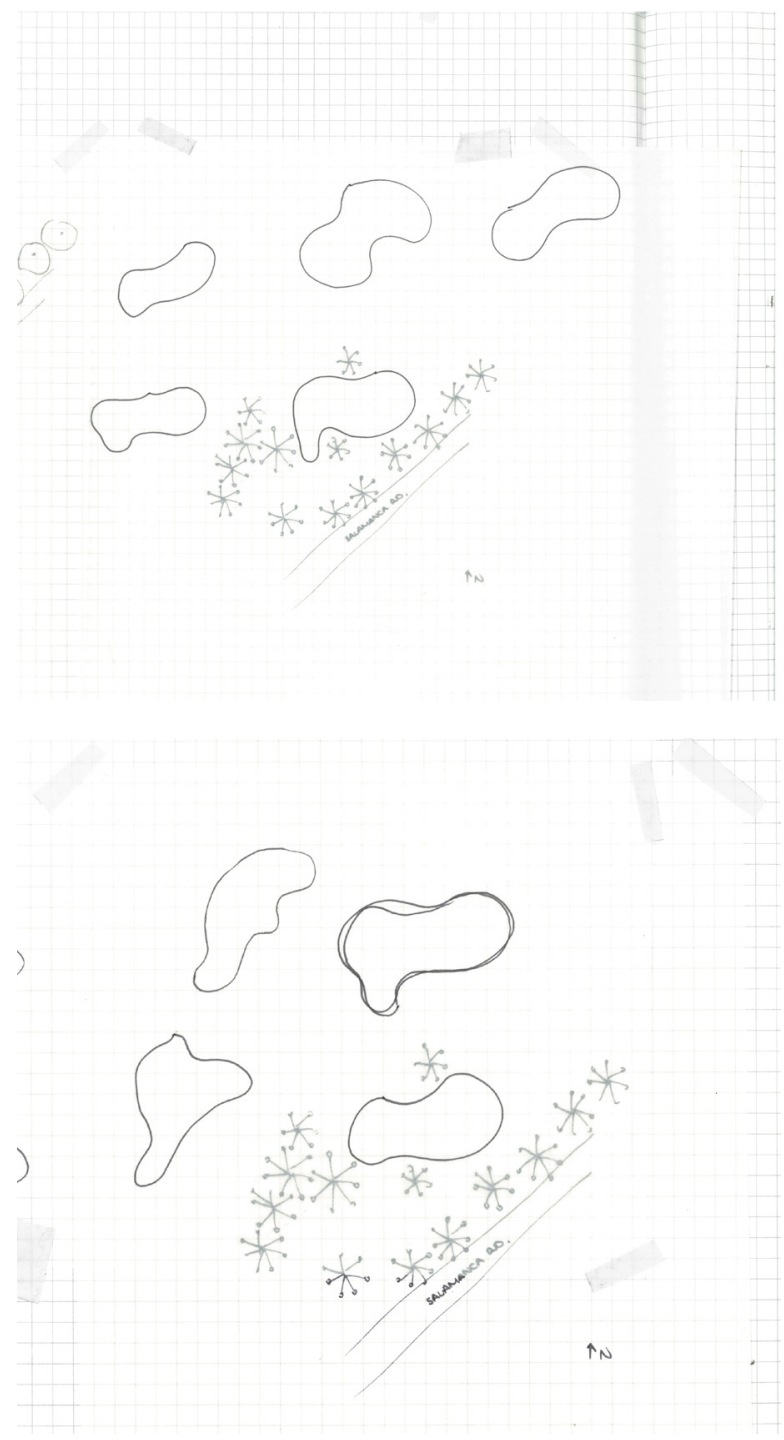

$\wedge$ 72. Using site to generate form 111 


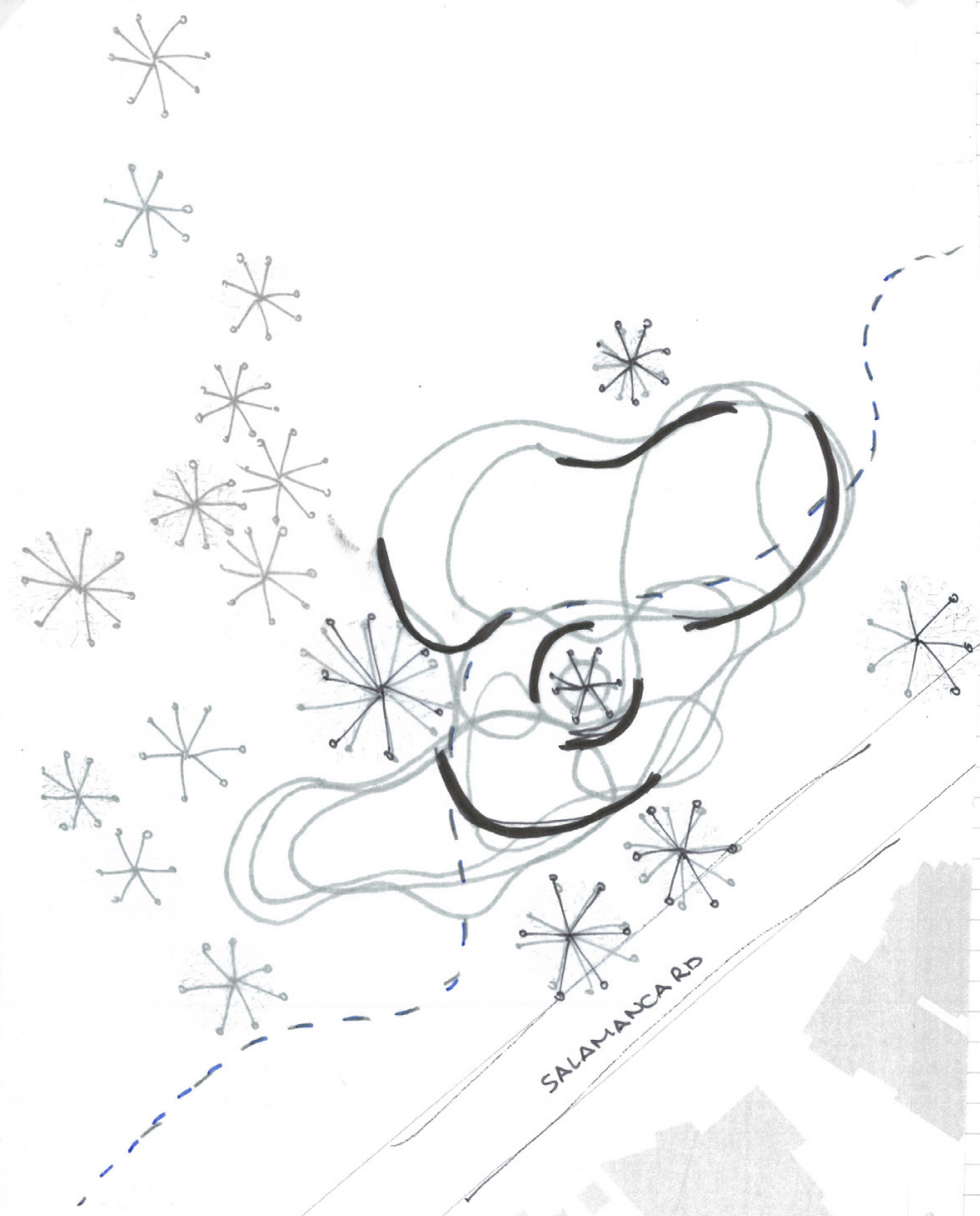




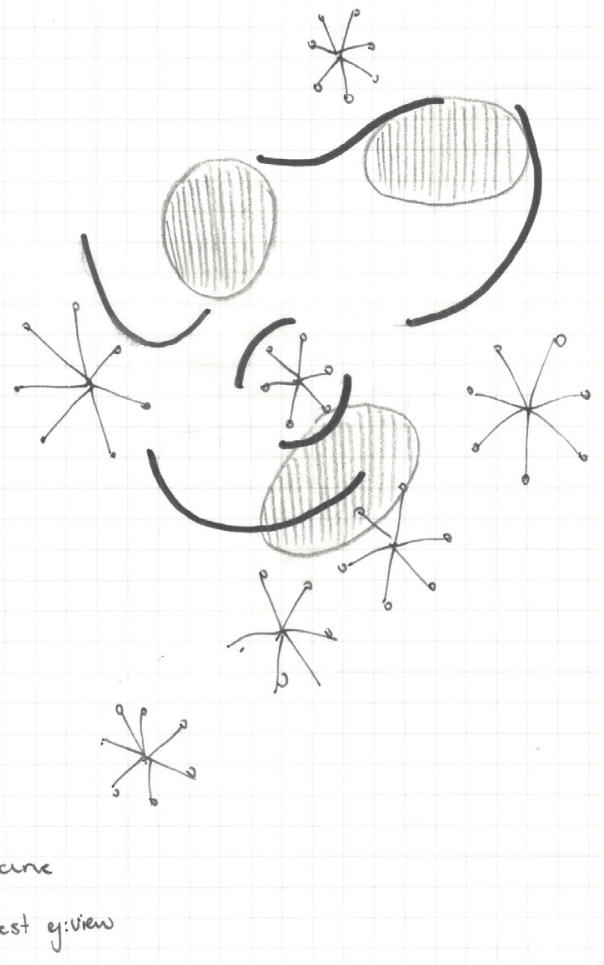



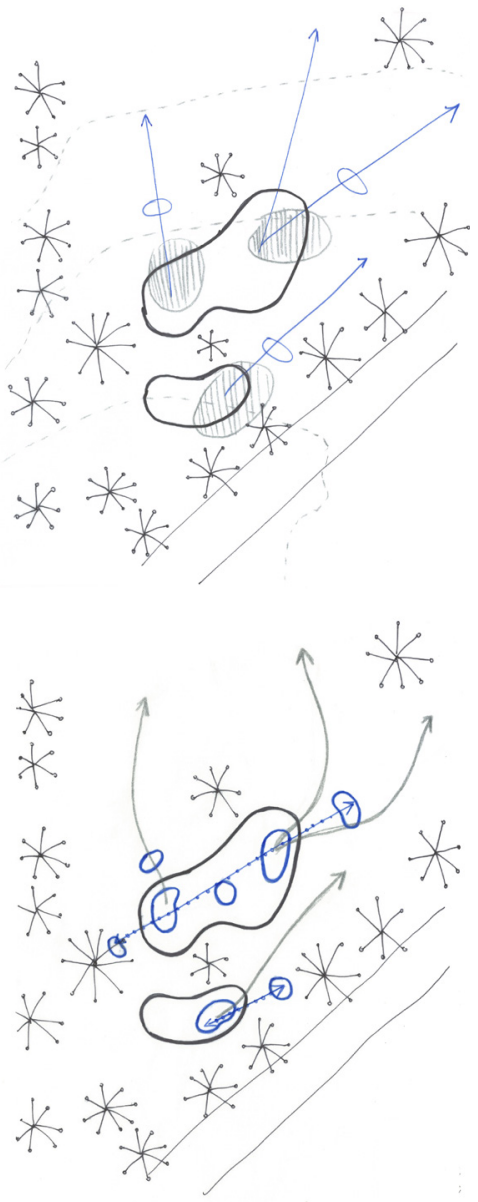


\section{PROGRAMME}

A programme with simple spatial implications has been selected. Wigley argues how SANAA's "pavilions and café with minimal programmatic and technical demands radicalise the aspiration" of the design, which in SANAA's case was thinness (2015, p. 37). To ensure the design is not overwhelmed with programmatic demands, Wigley's argument forms the programmatic framework and rational for the mid-scale. A pavilion with seating area and kiosk to form a café.

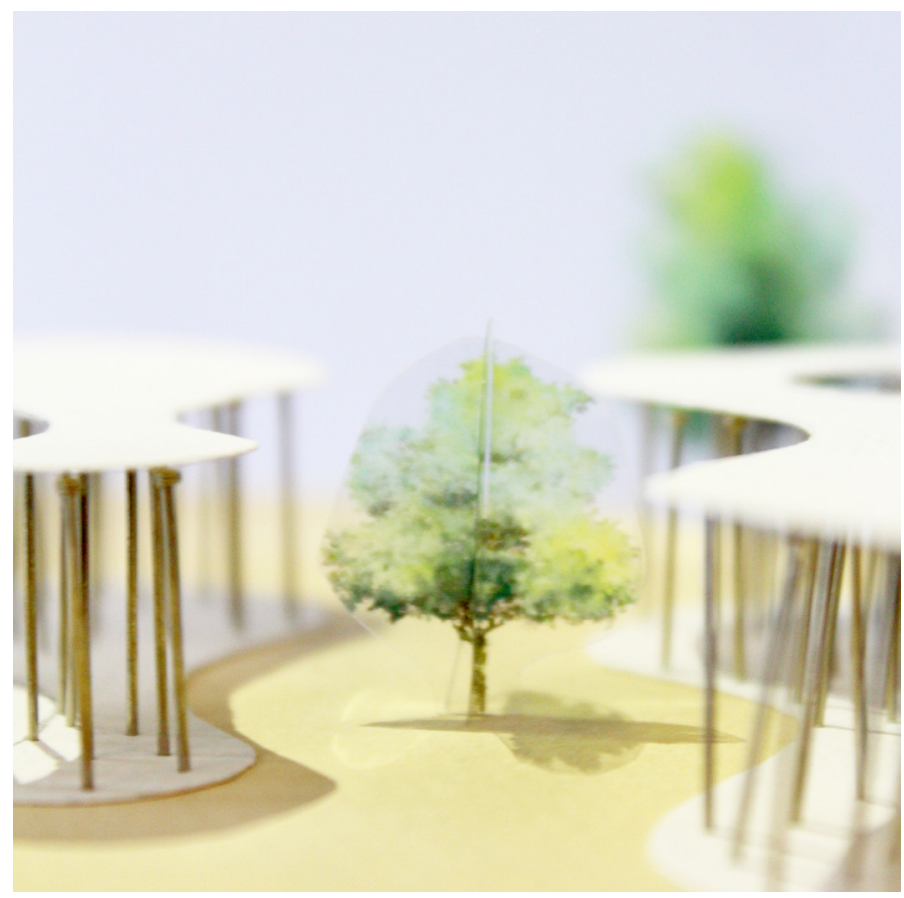




\title{
Test Six
}

\begin{abstract}
Aim
Following a non-linear methodology the design process then jumps back to the weakness of test two, which was the lack of engagement with the 'floating' plane. Thus, the aim of this exploration is to test the success of the floating plane from the installation evoking the vast and explore different ways of channelling light and colour through a doubled layered roof. Combining with earlier experimentation, consider how it might affect the interior and intimate experience.
\end{abstract}

$\wedge$ 77. Layered roof 

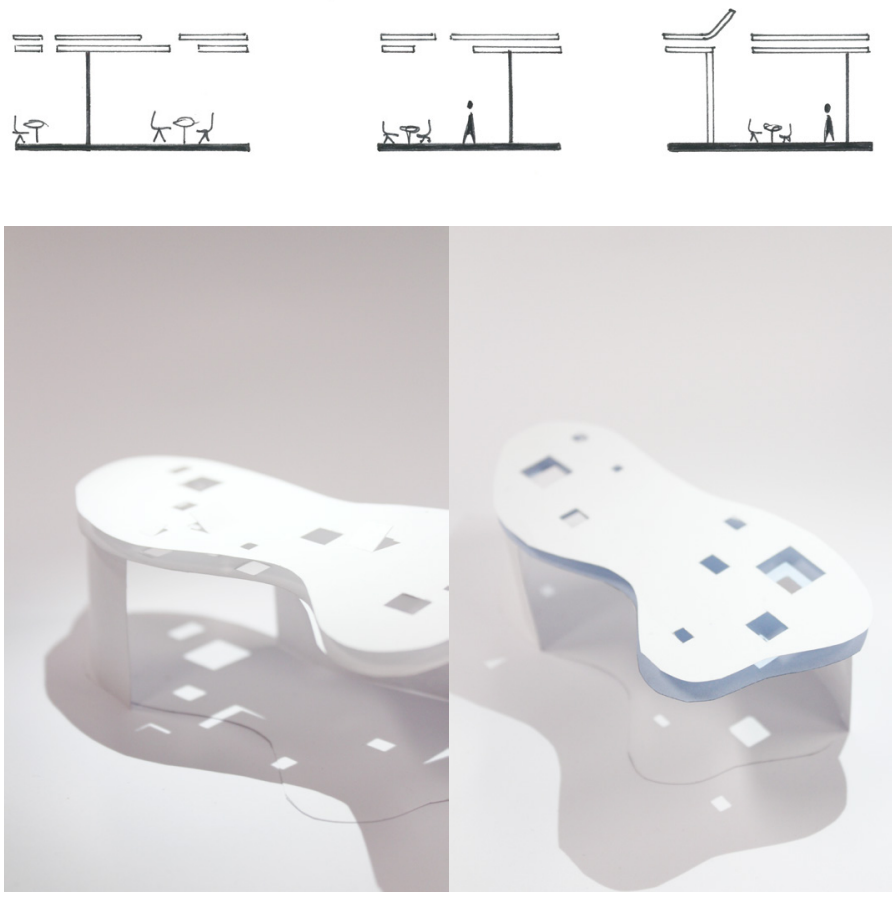

$\wedge$ 78. Roof perforations

Colour was investigated and three architectural precedents were quickly analysed through drawing on how they successfully generate colour whilst hiding the source. 
Colour Precedent Analysis
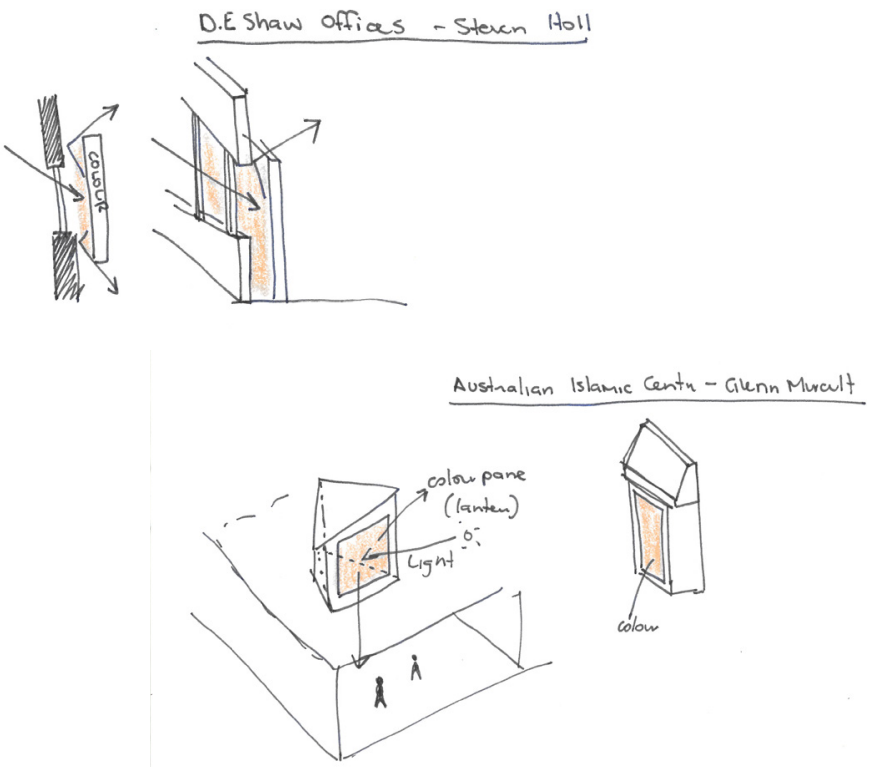

Achiering colom.

Rambow Chapel -kubo Tsushima Architeds
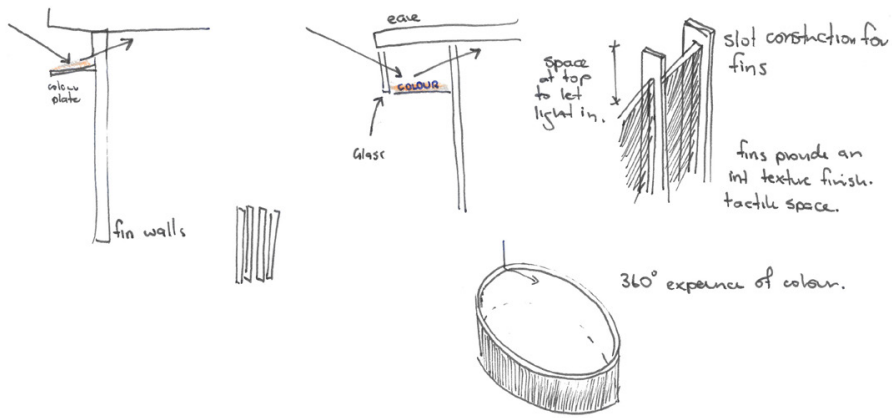


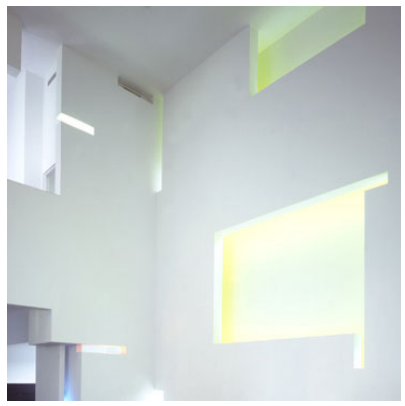

$\wedge$ 80. Steven Holl, D.E Shaw Offices (Warchol, 1992)

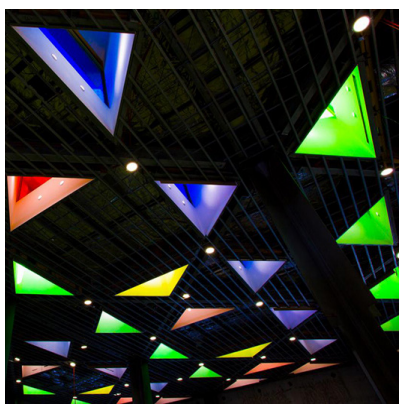

$\wedge$ 81. Glenn Murcutt, Australian Islamic Centre (Titz, 2016)

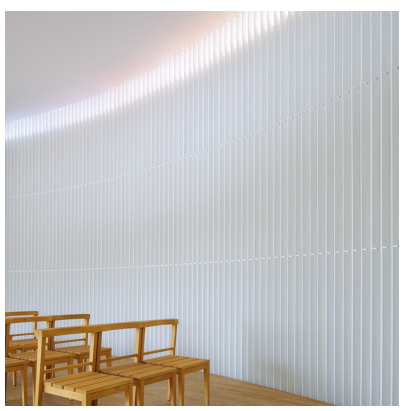

$\wedge$ 82. Kubo Tsushima Architects, Rainbow Chapel (Koji Fujii / Nacasa and Partners, 2015) 


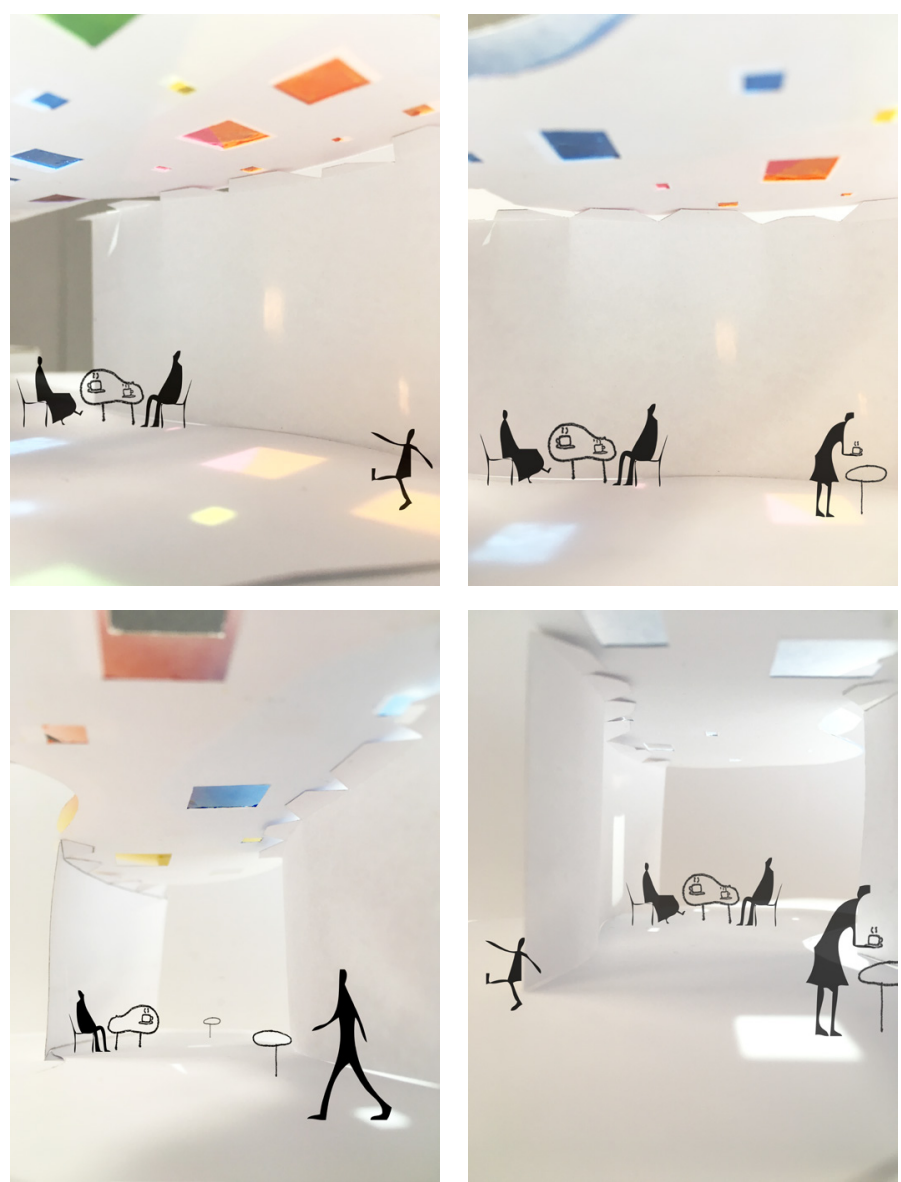

$\wedge$ 83. Interior experience with colour 


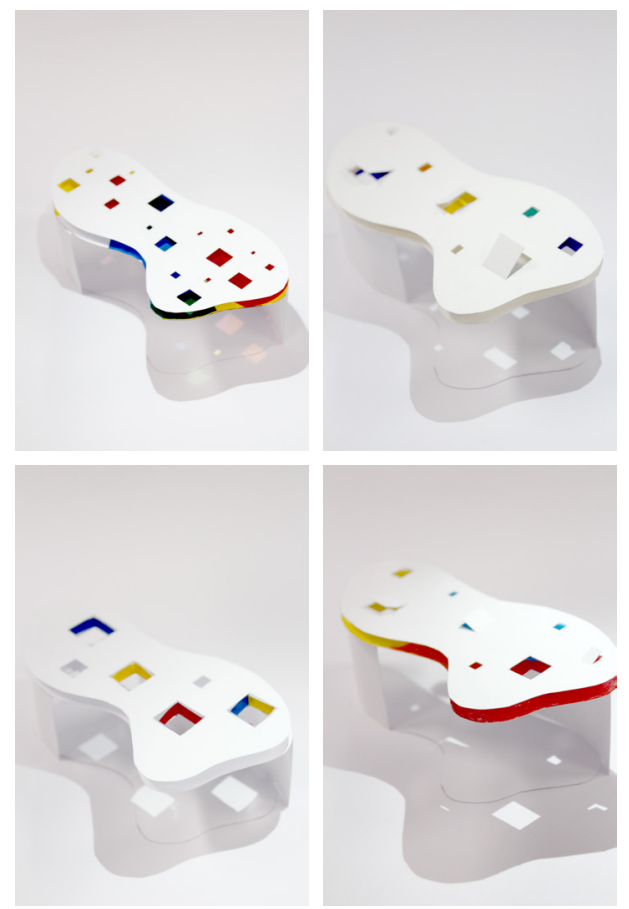

$\wedge$ 85. Colour integrated perforations

\section{Evaluation}

The thin roof floats above ground, shaped by sweeping with the landscape. An interesting discovery from this exploration was layering the roof to channel light and colour. This was successful through the use of both hidden colour and offsets, which add to the interior experience engaging the subject at an intimate scale, much like the installation. This test needs to be developed further, as it currently does not engaging with both the horizontal and vertical conditions of site. Test six was successful in testing preliminary ideas of shaping space. 


\section{Test Seven}

\section{Aim}

Test how light, colour and materials can shape the intimate internal spaces underneath the 'floating' roof without the use of standard walls. Combine the ideas from test three and six. How can this communicate intimacy, transparency and lightness?

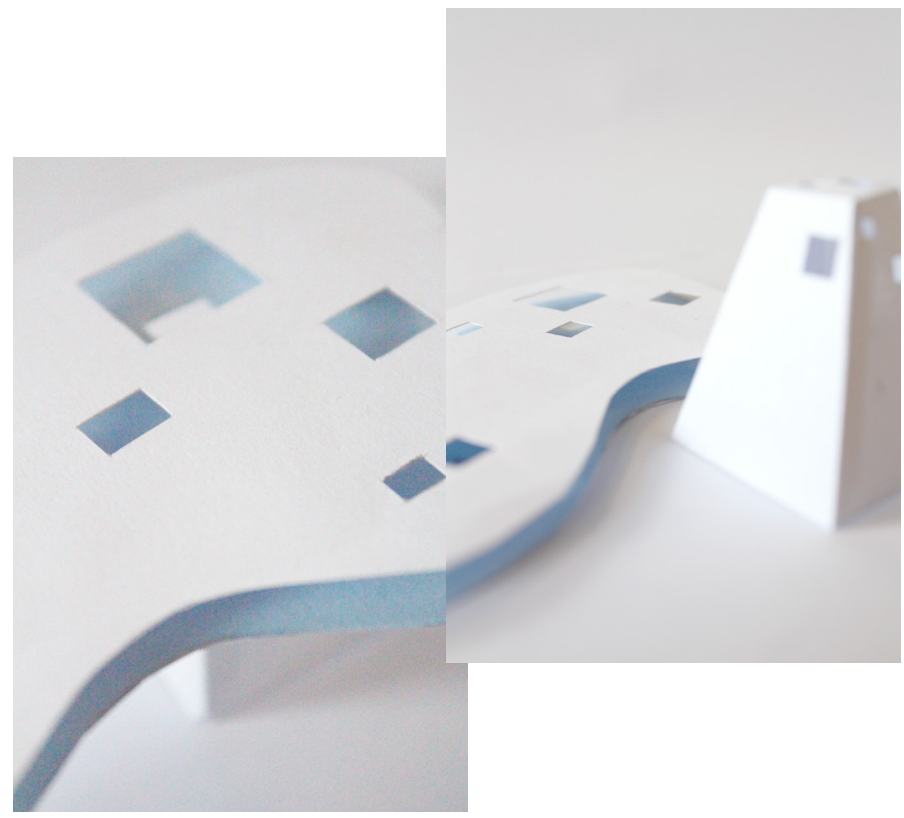




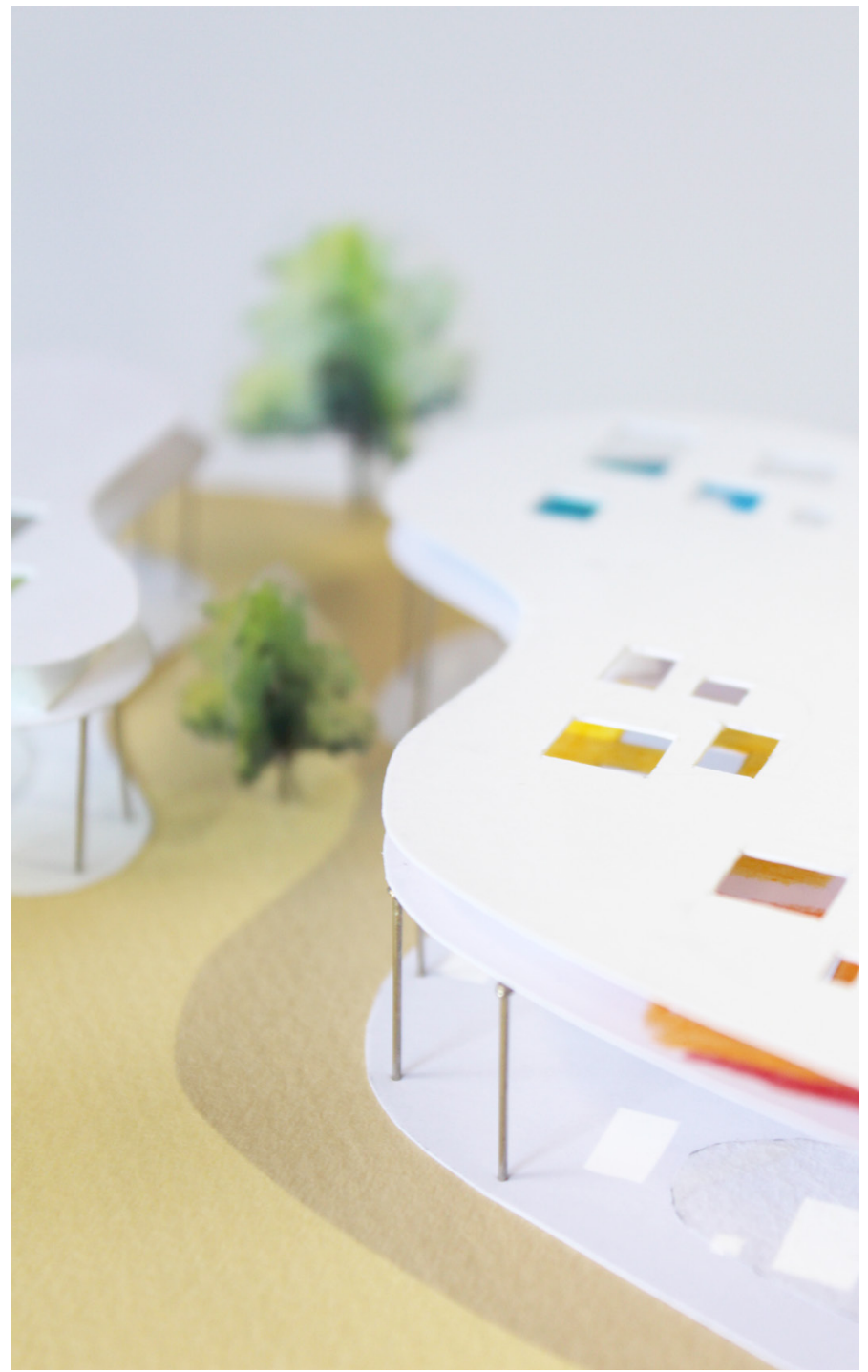

$124 \wedge 87$. Shaping through specific perforation and colour 

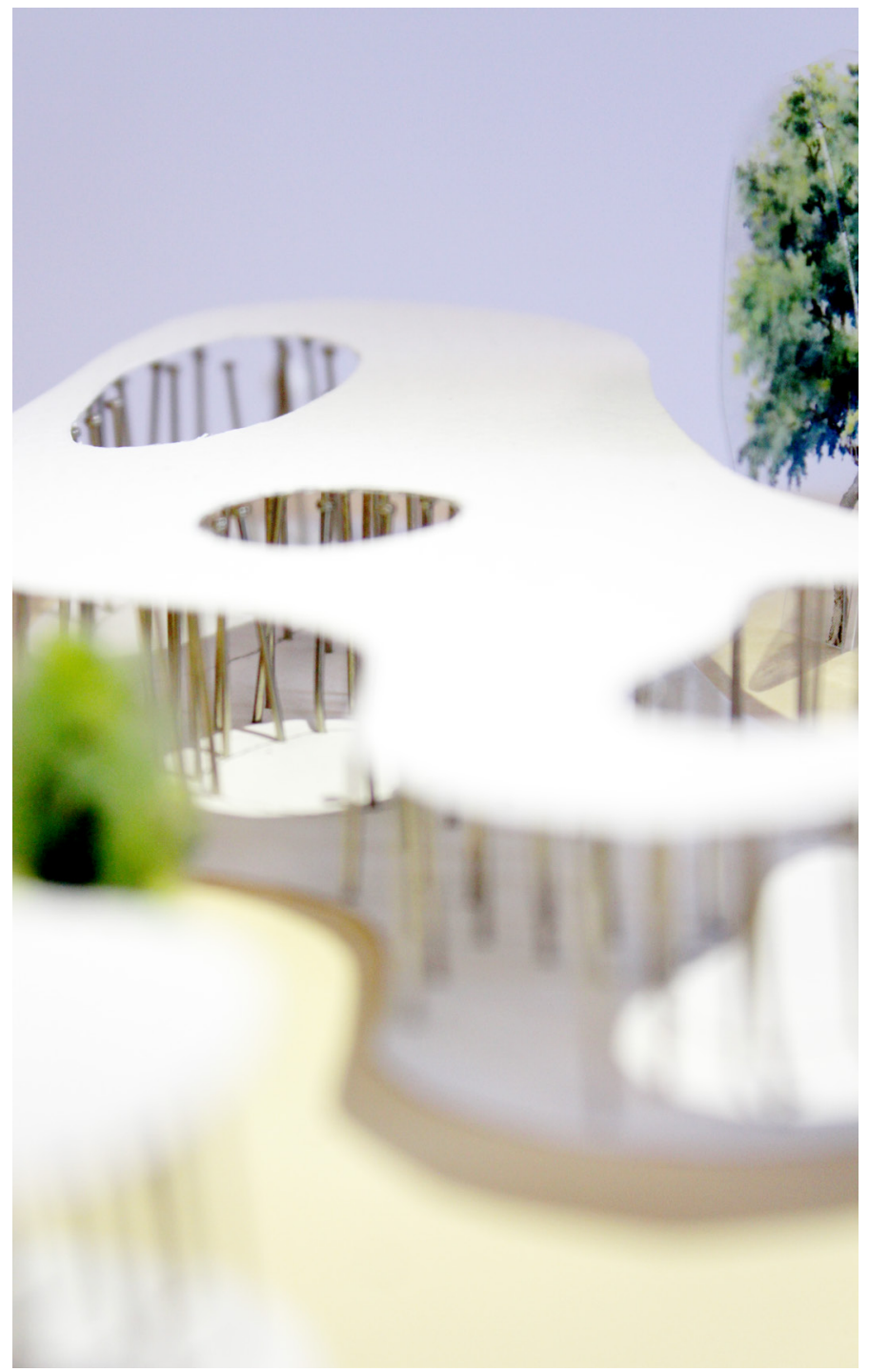


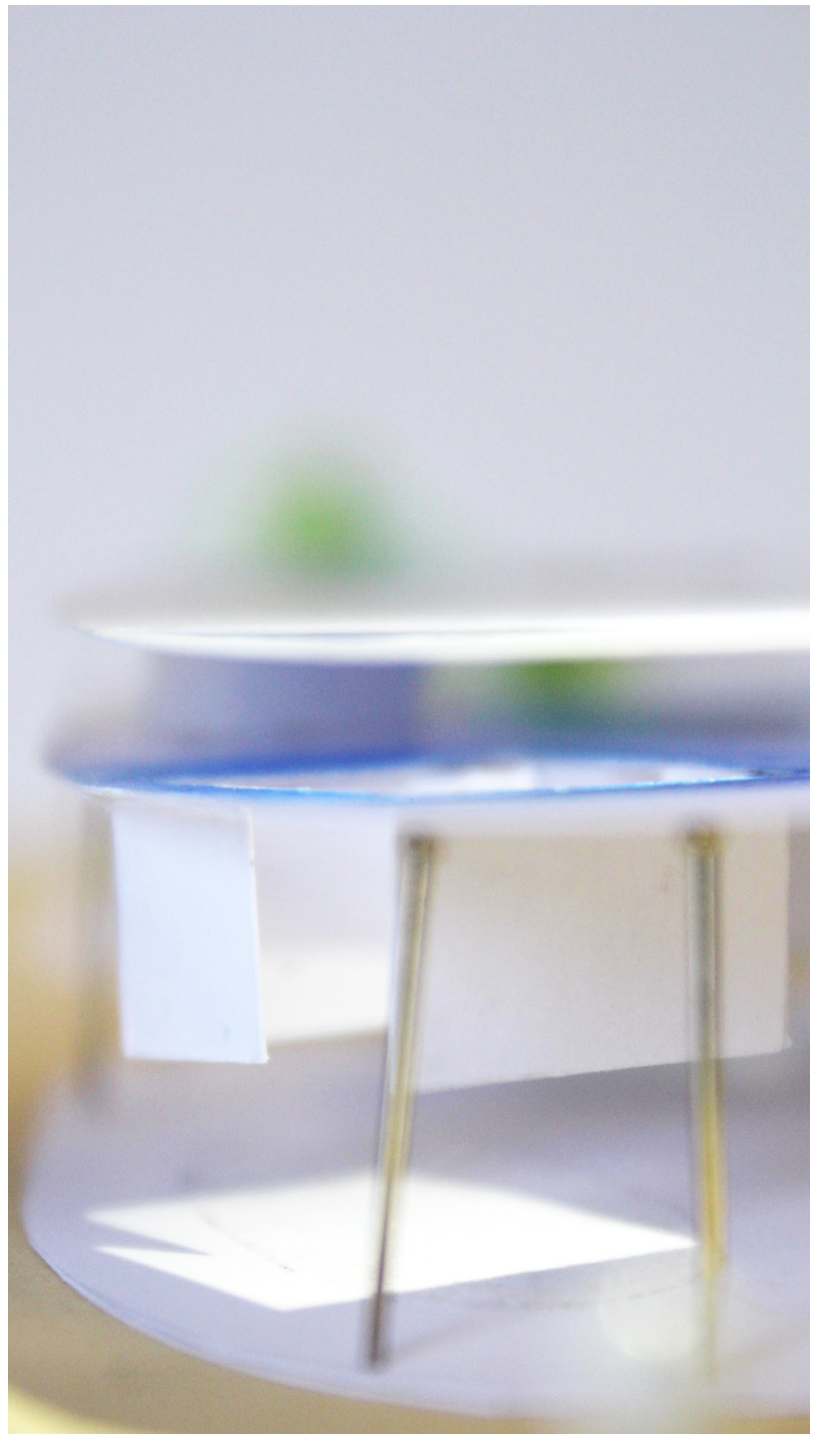

$126 \wedge$ 89. Shaping through large volumes 


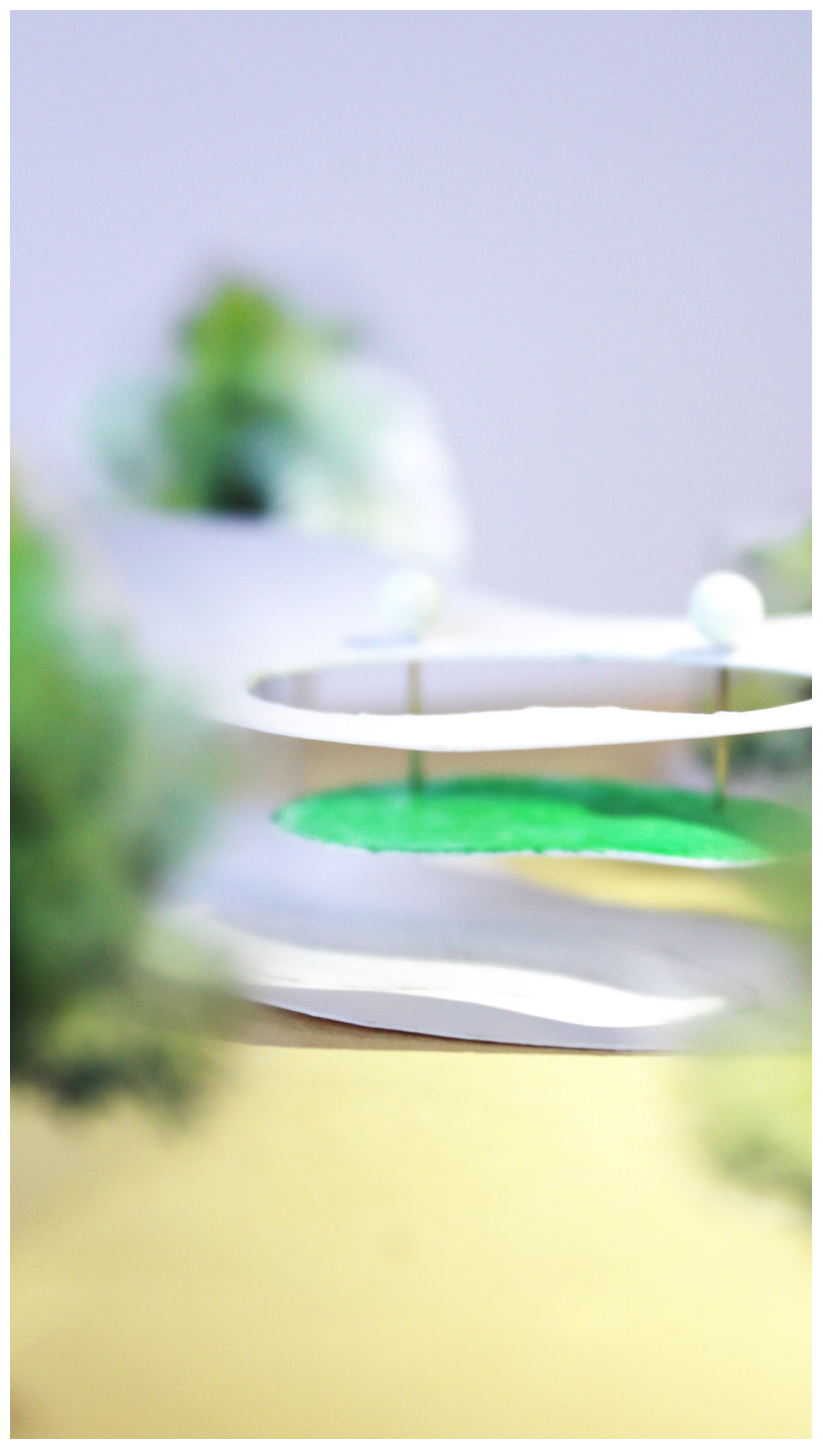


.

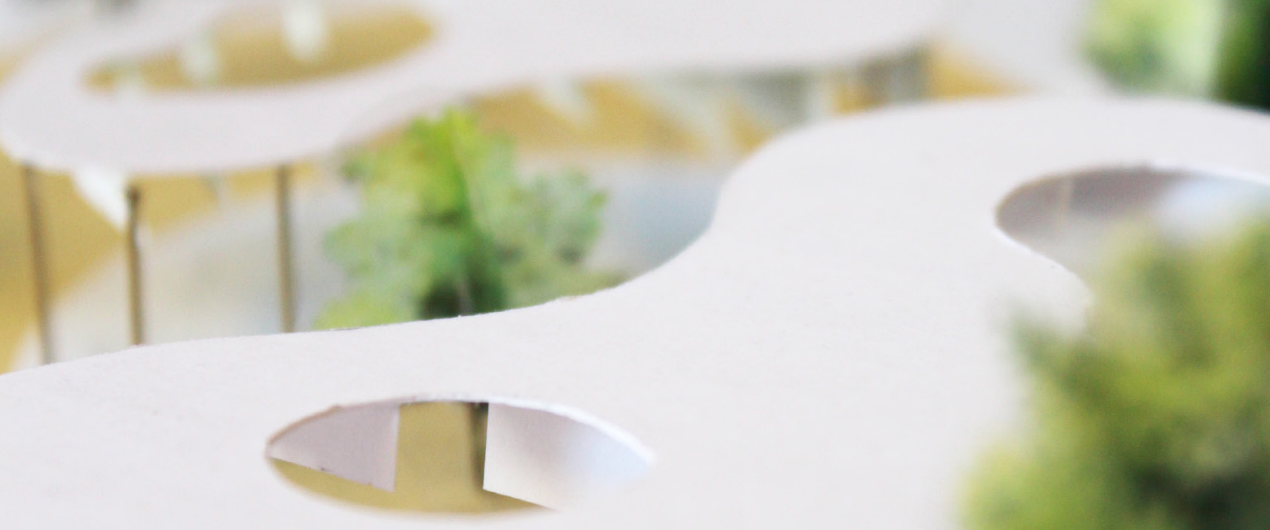



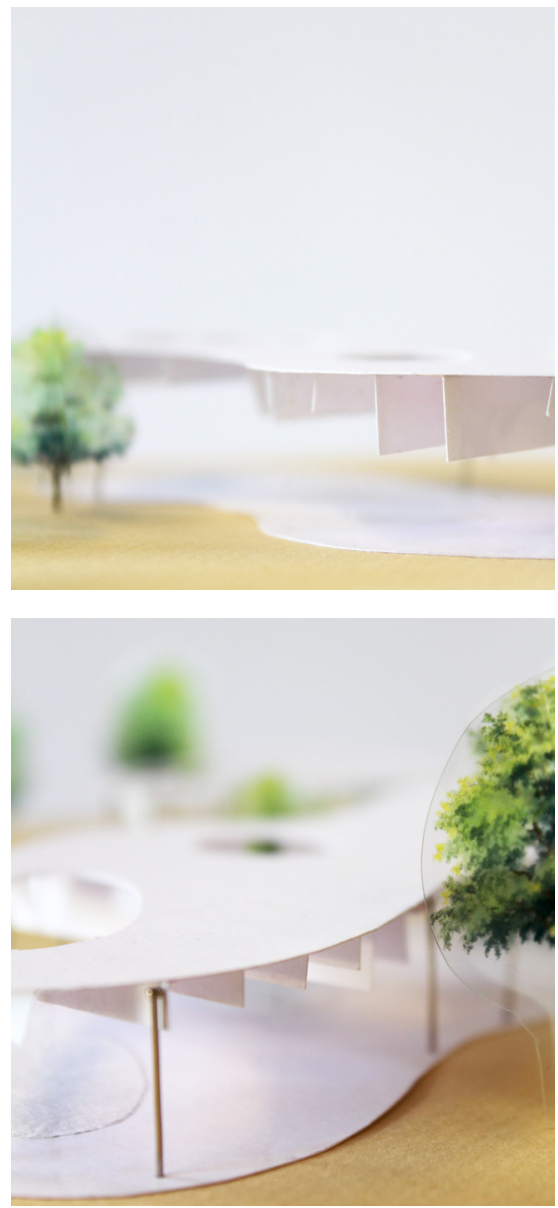

$\wedge$ 92. Hanging fins 

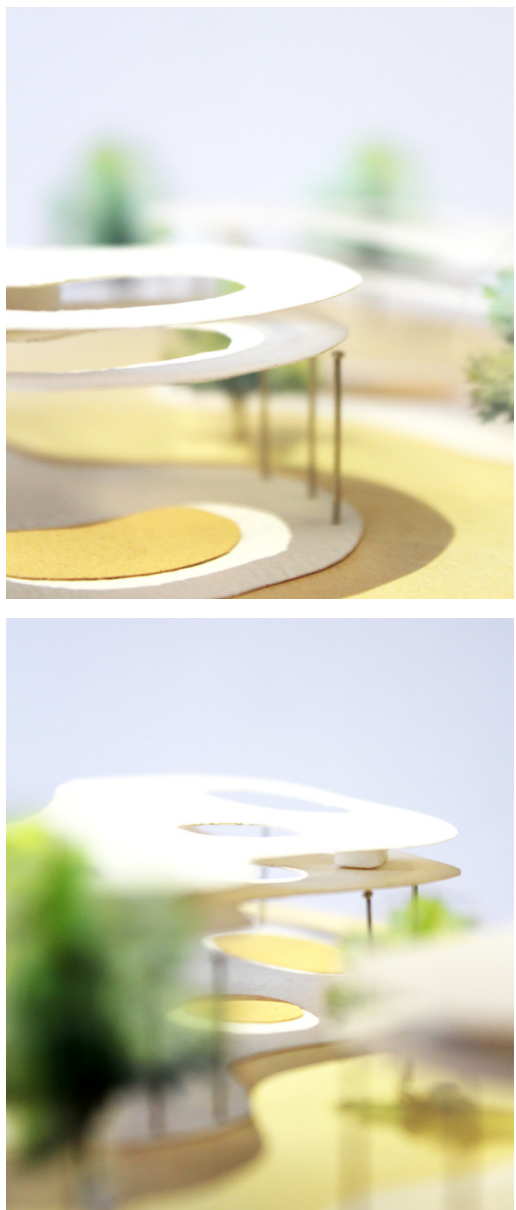

$\wedge$ 93. Shaping through colour 



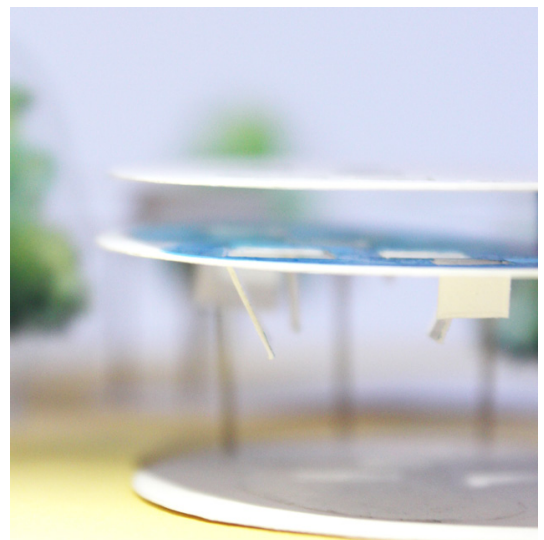

$\wedge$ 95. Shaping through hanging panes

\section{Evaluation}

This was an effective iterative series that investigated shaping space. The floating roof was explored both as single and double layered. Upon reflection, the single plane was most effective in evoking delicacy and vastness. Although the double layered roof was successful in hiding colour source and providing interesting perforations it does look heavier than the single plane. Perforations, colour, materiality and negative detail were all trialled and tested to evoke intimacy through delicacy, transparency and lightness. The photographs evoke a compelling vision in representing the overall design and spaces within. The most successful iteration integrated fins and negative detailing to shape space. 


\section{Development}

An organic form, a thin roof and negative detailing were the key ingredients that were developed upon and refined for the final design. The sense of 'floating' was also dependant on the context and location of interior spaces.

\section{Negative Detail}

The fins that shape the spaces underneath the roof through negative detailing were trialled and tested in terms of size, spacing, order, relationship to roof and repetition. The success came from exploring undulations rather than a uniform and rigid order. The development was important in defining the interior experience, visibility from the exterior and how could colour be integrated to activate the inhabitants. The interior spaces were centrally located in the building to ensure the roof did not lose its vast floating appearance.

\section{Thin Roof}

Maintaining a thin and delicate roof was essential in evoking the vast floating plane that is shaped by site. Rather than the fins all matching in height, they undulate the ceiling texturising the surface. However, most importantly, they taper in all directions to accentuate the thinness of the roof.

\section{Organic Form}

In the plan the building was shaped to sweep through the site; this language was then translated vertically as the floor plan undulates with the landscape's gentle slope. 

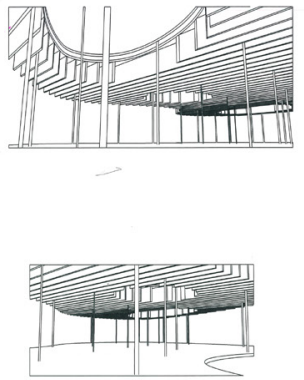

IIfHIIIIIIII
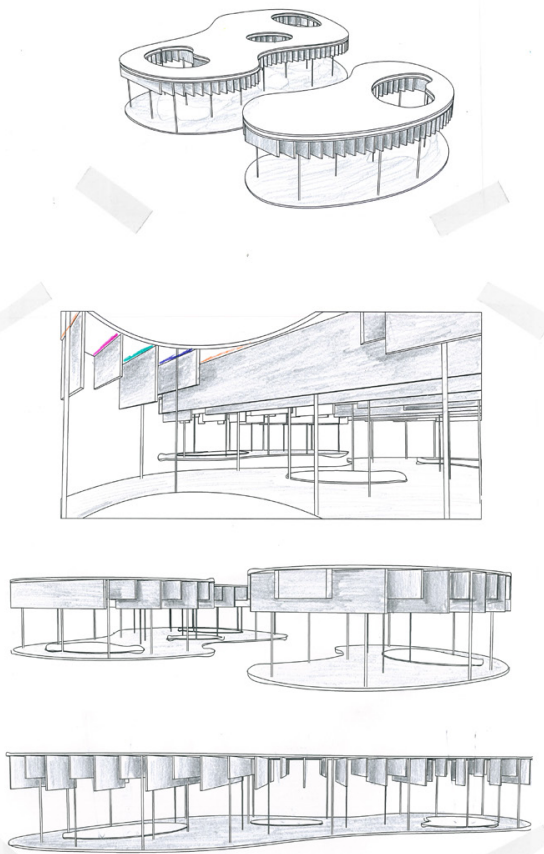

Mपगयणफ

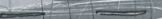

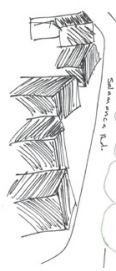
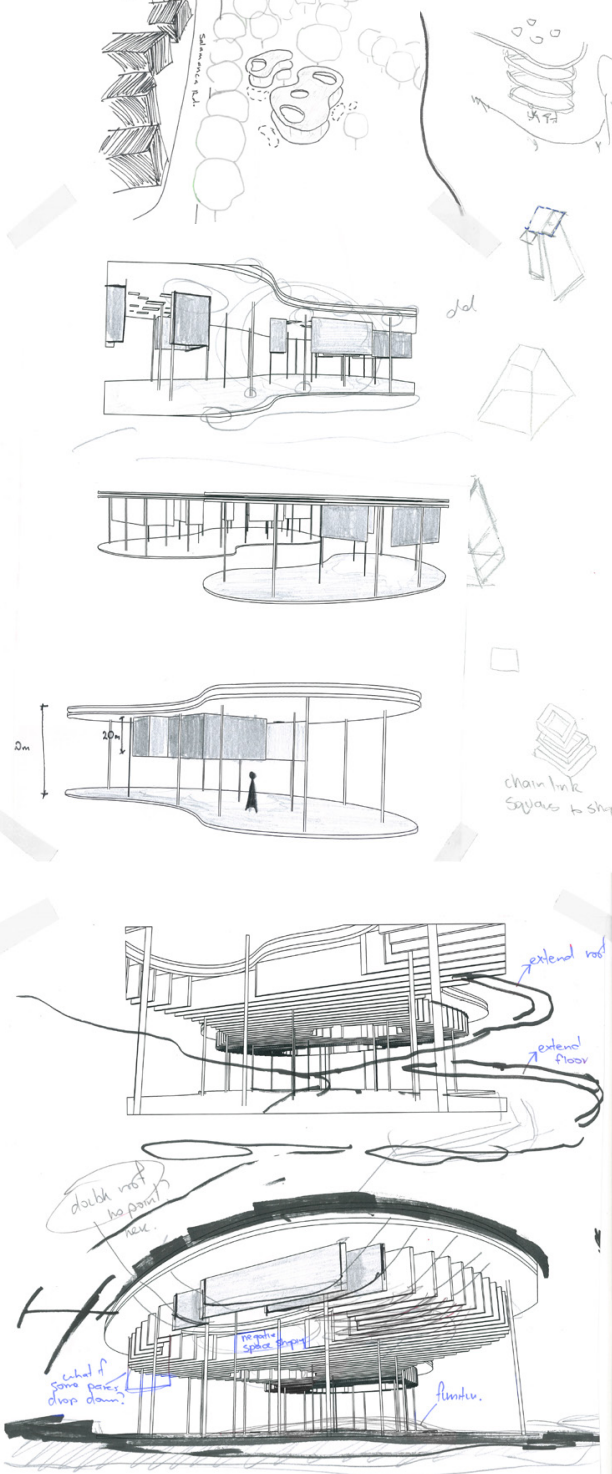

oat in the

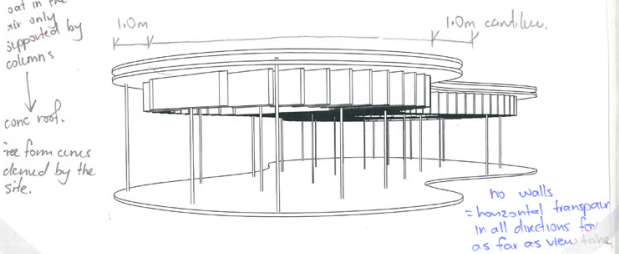




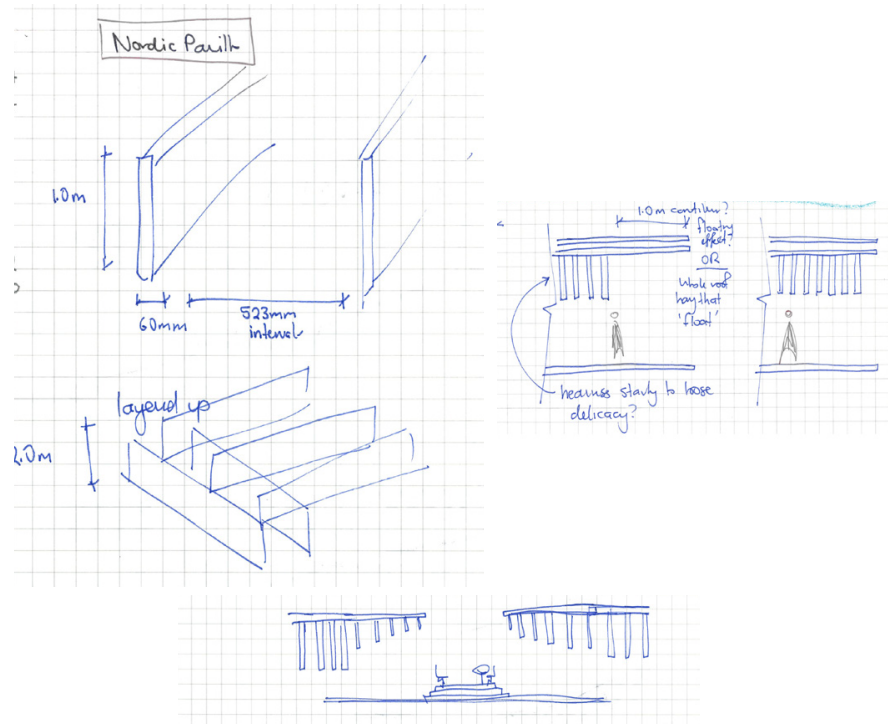

$1.5 \longrightarrow 0.5 ? \quad 0.1 ? \mathrm{~m}$
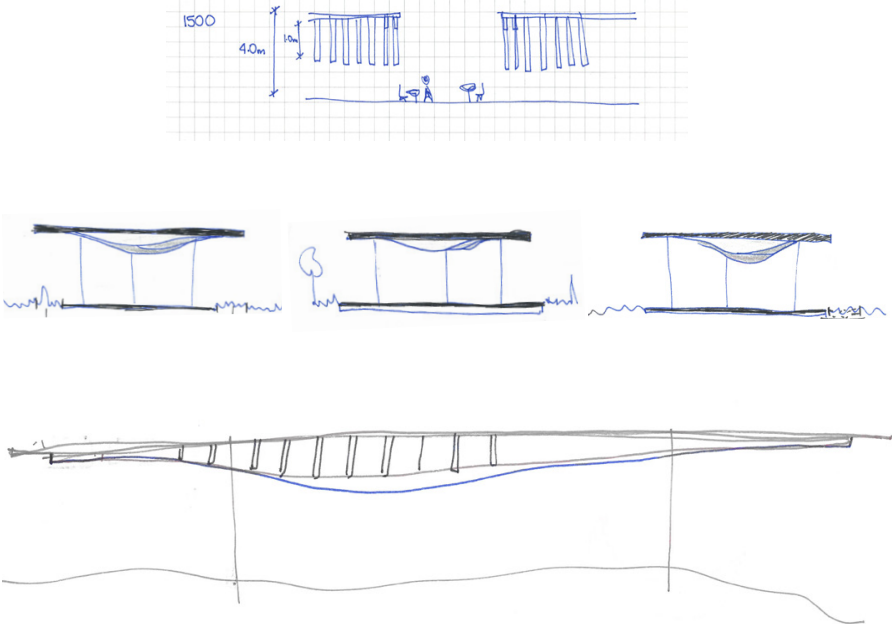

$\wedge$ 97. Shaping space with fins, analysis and development drawings 
FINAL DESIGN

Making
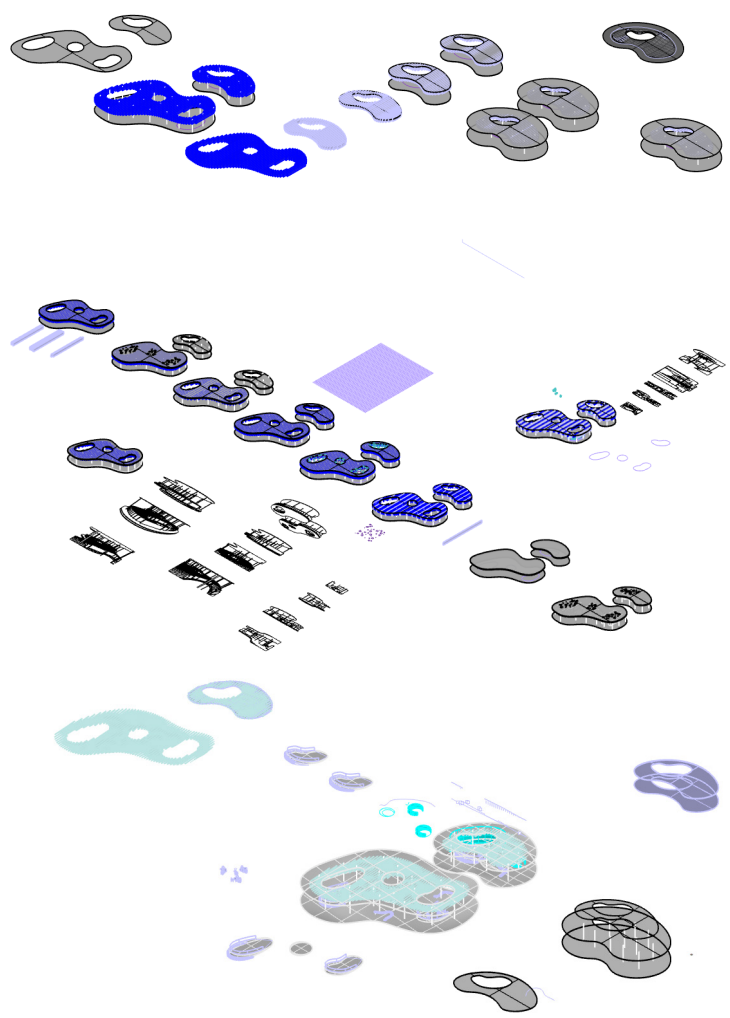

$\wedge$ 98. Digital model screenshots 


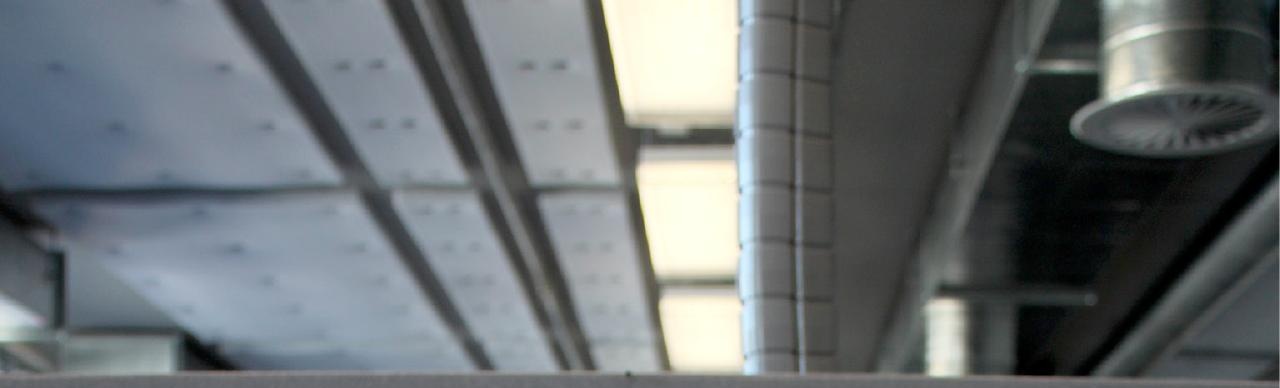




\section{FINAL DESIGN}

Test Nine

The café pavilion is located on the gentle slope alongside Salamanca Road in the Wellington Botanical Gardens. The design attempts to capture both the vast and the intimate scale through contrasting a vast sweeping roof plane and intimate interior spaces below. There are three designated interior spaces orientated and shaped by the site where people can enjoy a cup of tea or coffee as they enjoy the view down the sloping landscape. The rest of the pavilion is left for the subject to engage with and move down the slope.

The final design is composed of two floating roof planes that sweep down and across the landscape. The thin and delicate roofs are shaped by the free form curves derived from site, engaging with the landscape rather than opposing it. A lack of walls activates horizontal transparency in all directions encouraging a continuity between the interior and exterior. Delicately hanging fins undulate across the ceiling's surface, shaping intimate spaces through a negative detail. They taper outwards to ensure the roof retains its delicacy. The perforation in the roof mirrors the level surfaces below, creating a volume of space without walls. 

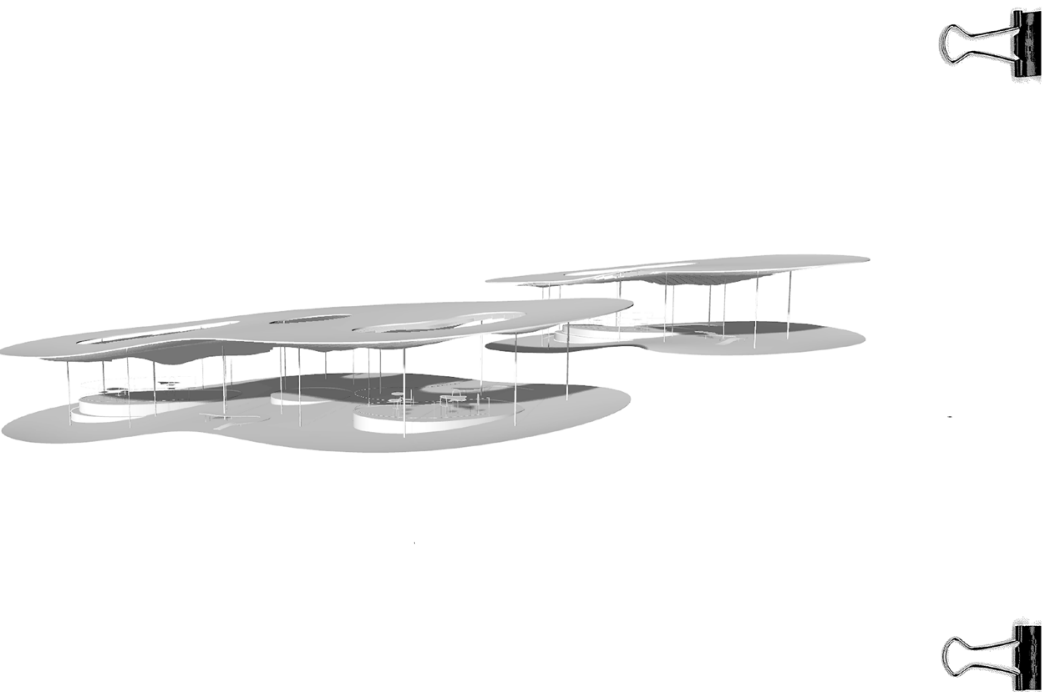


\section{Scale}

Opposing scales manifest within the design of the café pavilion. The thin roof stretches across the landscape in contrast to the delicate structure holding it up. Contrasting the vast roof with the appearance of fragility in its supporting structure heightens the awareness of scale. Seating and paving are shaped by the site, expanding the language of engaging the vast and the intimate beyond the scale of the building's structure and interior environment. Considering the large building scale alongside the human scale and engagement was important.

\section{Materiality}

Structural elements were reduced to a minimal dimension to evoke delicacy, which in turn intensified the vastness of the roof plane as it appeared to float. The multitude of columns were as thin and as delicate as possible with hidden connections, to look as though they are merely resting on the floor and touching the ceiling. The material palette is reduced both in size and colour to make everything appear as light and white and provide the contrast against the generation of colour. 


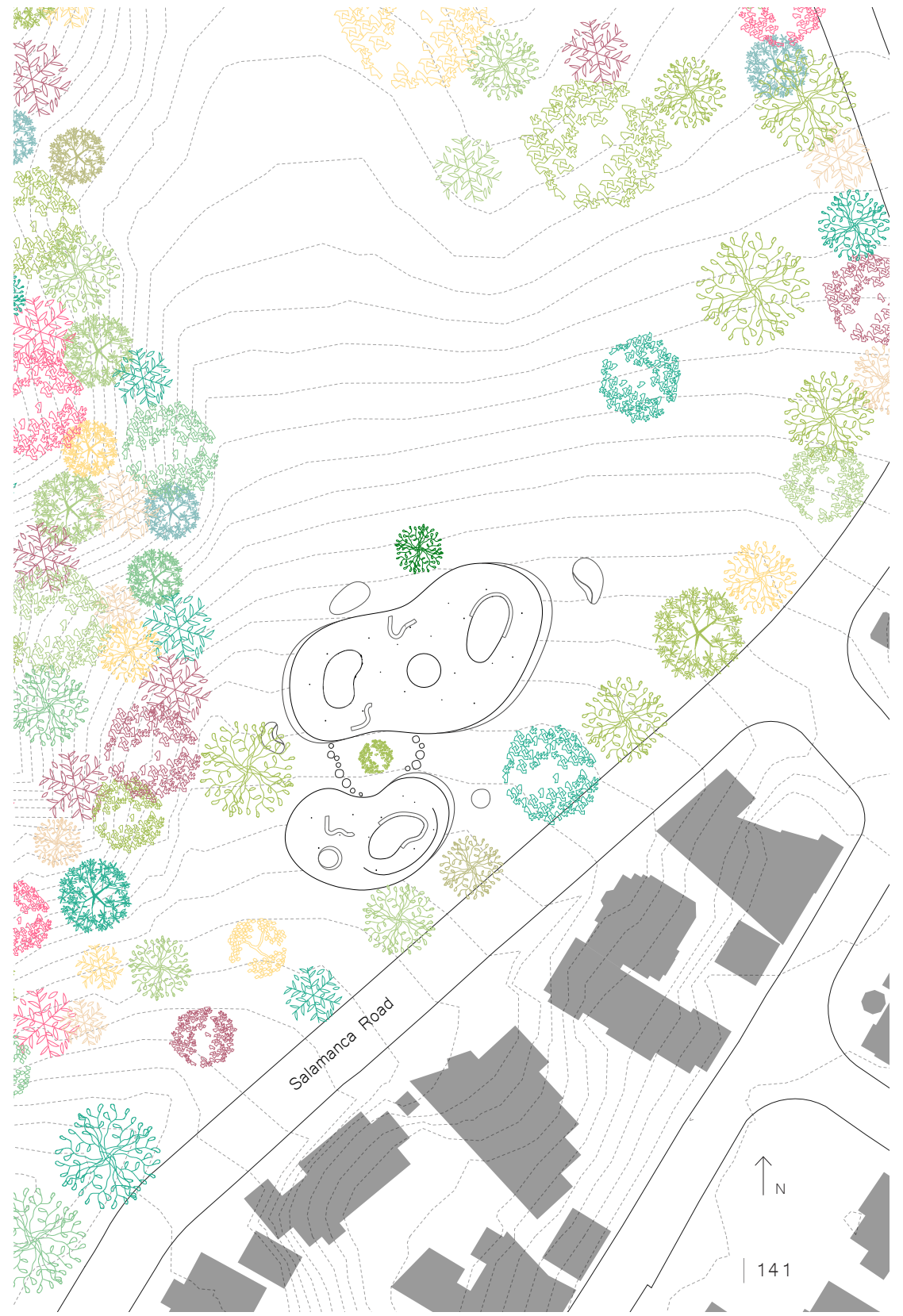




\section{Colour + Whiteness}

The final design considered how to generate colour from a hidden source, however it lacks execution within the representation. The hanging fins have a negative detail on the top face. Lighting strips and colour film is inset to illuminate the roof with a rainbow spectrum against the white setting, while ensuring the source of the colour remains hidden and intangible. The use of colour was approached similar to Steven Holl where, "colour floats freely in space, in an intangible area", generating an ethereal effect as light paints the ceiling surface (cited in Safont-Tria, Kwinter, \& Holl, 2012, p. 35).

The integration of colour contrasting against whiteness follows from the success of the installation. Holl argues, introducing colour into architecture "activates and involves the spectator in the space" (cited in Safont-Tria, Kwinter, \& Holl, 2012, p. 20). There is a greater intimacy when the viewer becomes the participant, simulating curiosity and imagination, whilst engaging with the space. However, despite this effort it was not as successful as other elements of the design. The consideration of whiteness and materiality within the design created very light and transparent spaces, highlighting the notion of lightness and delicacy. 
1 drinks and food kiosk

2 level surfaces

3 glass screen

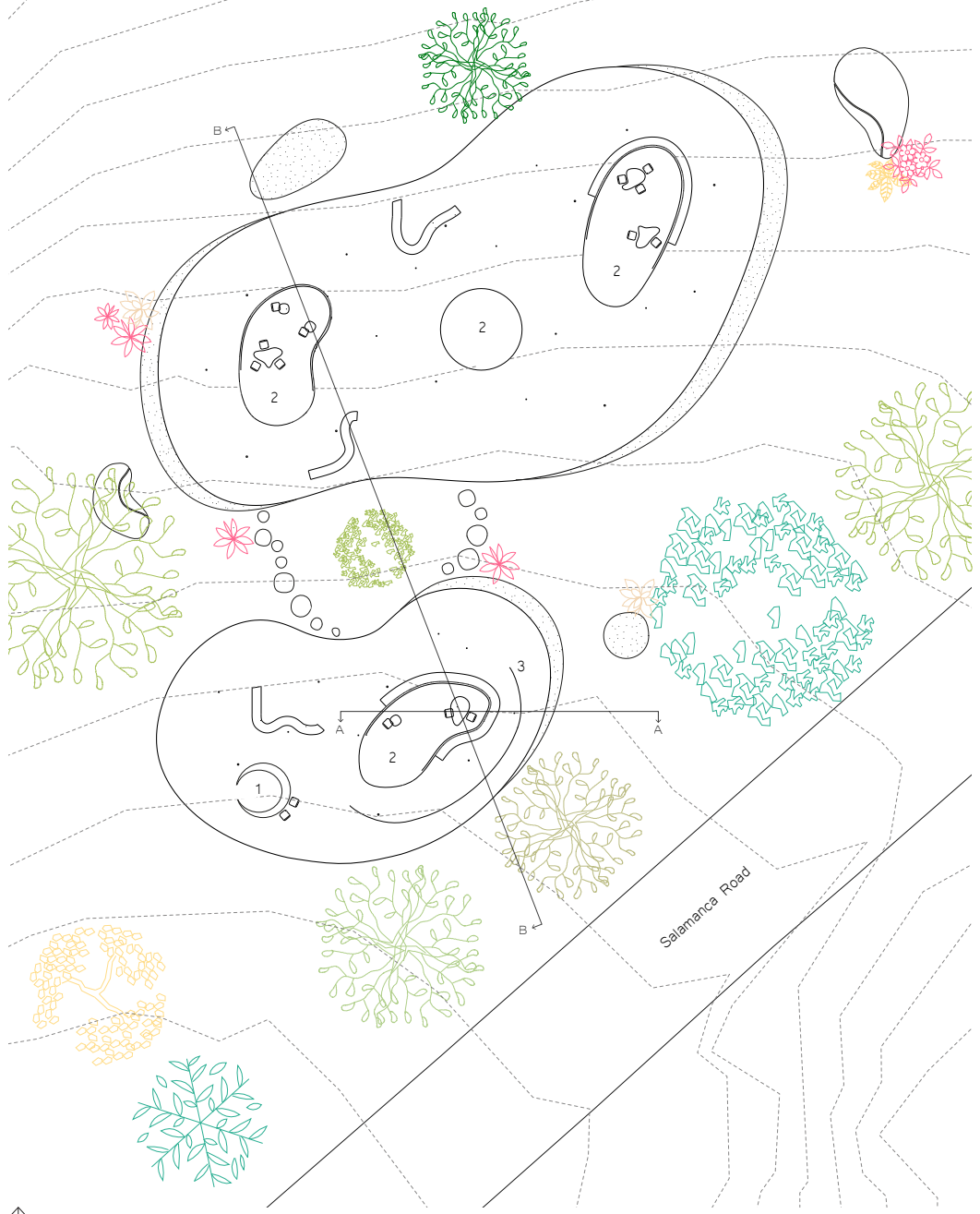

$\uparrow_{N}$ 


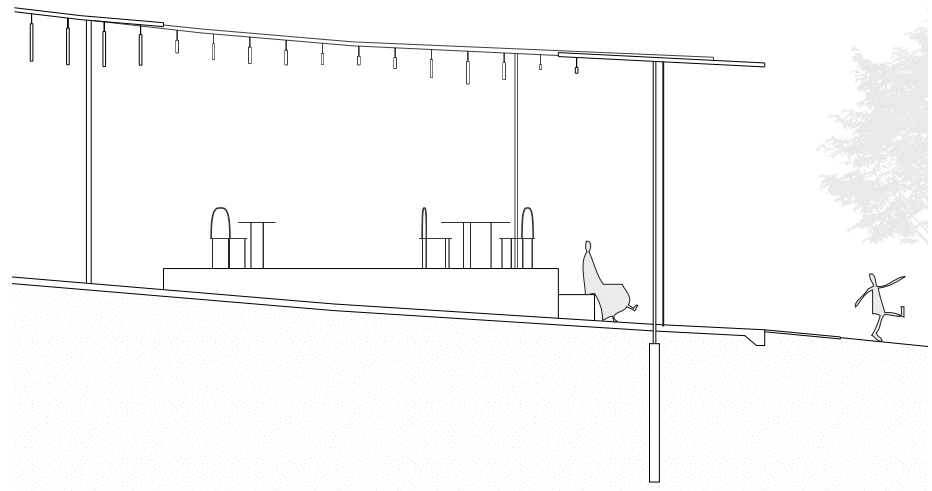

$\wedge$ 103. Section A-A

$1: 150$ 


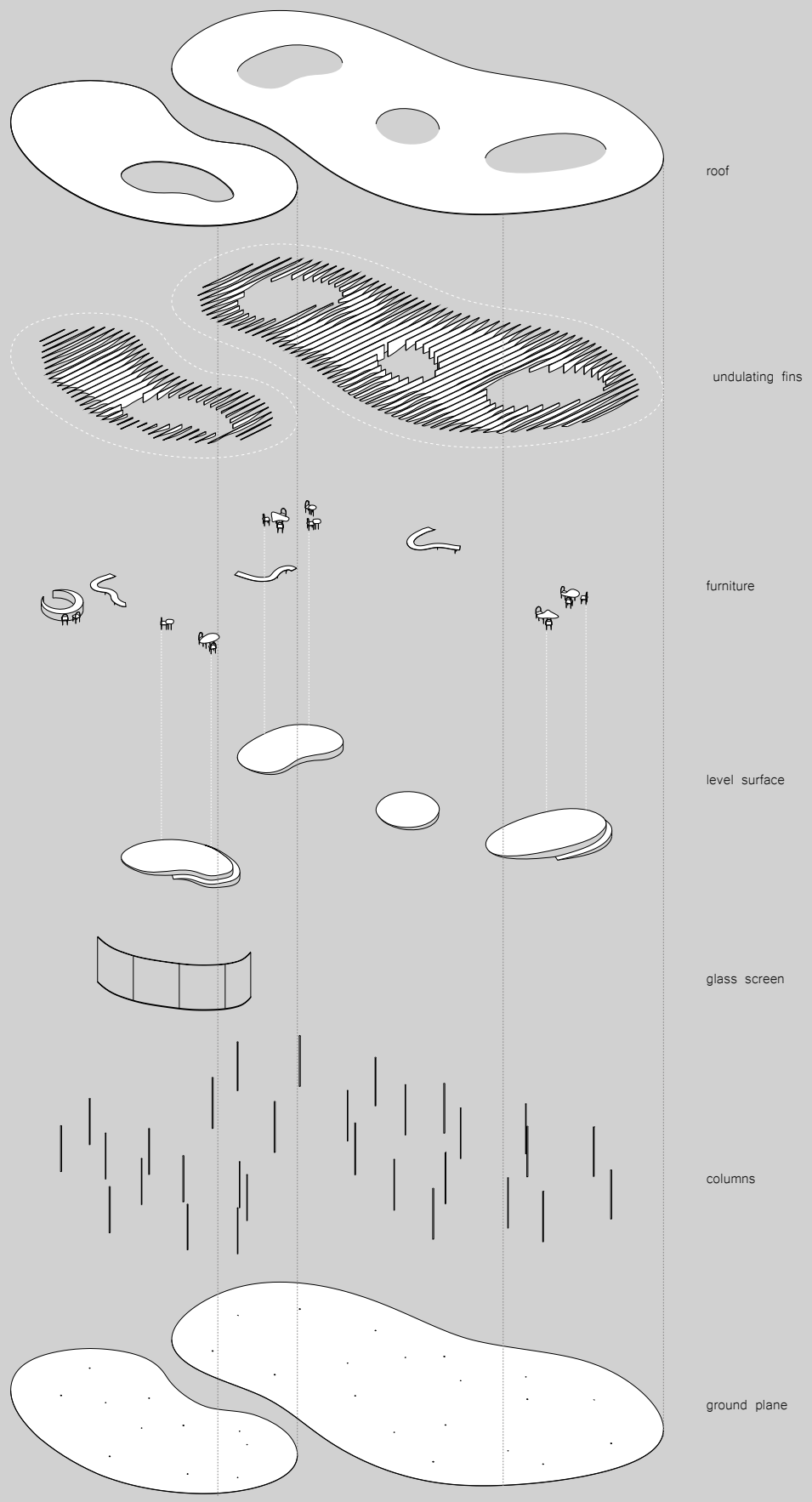




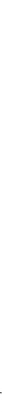

$146 \wedge$ 105. Section B-B 


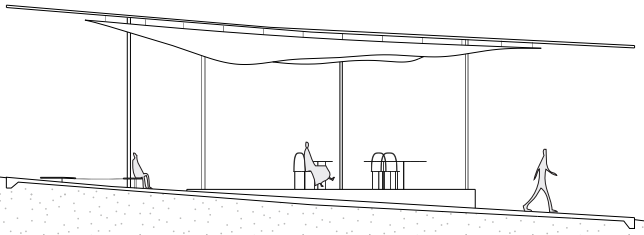




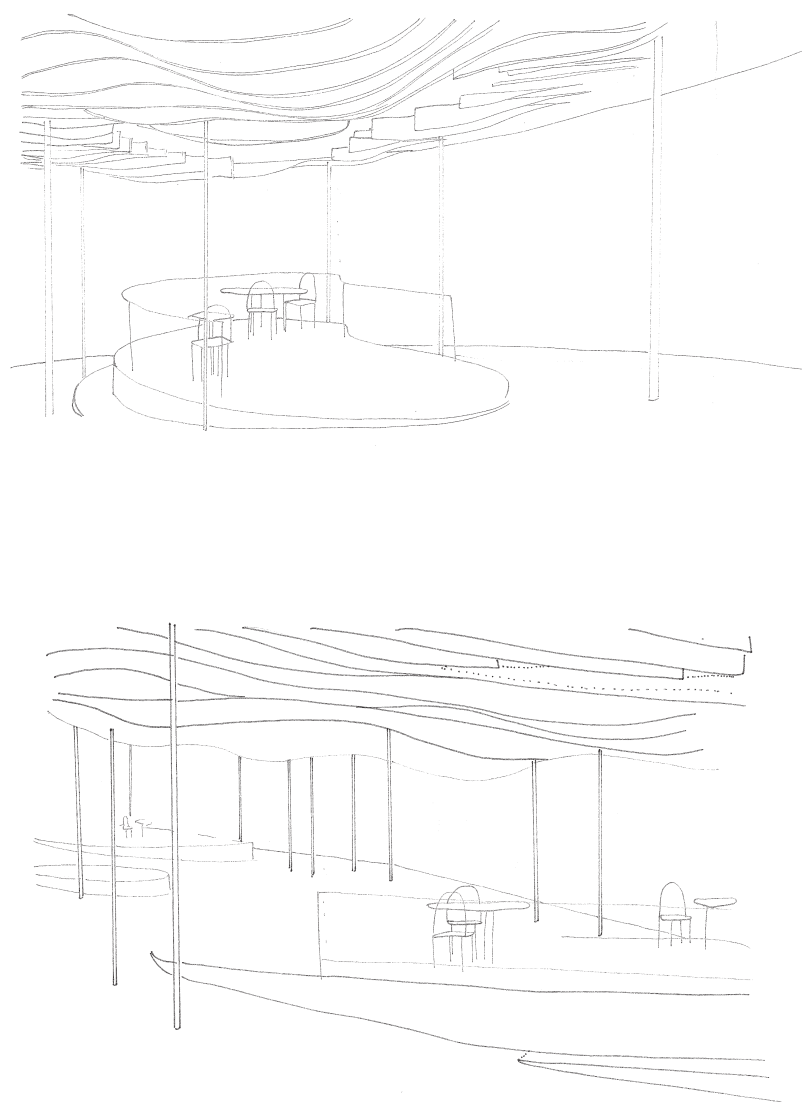

^ 107. Interior sketches 


\section{Details}

SANAA's details were observed and analysed in relation to materials, connections and dimensions. All of these elements combined create a delicate building without visible joints. SANAA's work as argued by Wigley, "is a polemical exploration of thinness" (2015, p. 29), which is clearly evident in the details. After evaluating SANAA's structural knowledge, the café pavilion attempts to suggest materiality, connections and dimensions through the following two diagrams that explore potential detail suggestions. They are not to be read as final details but as thinking through drawing about how the building might come together physically whilst best expressing its aim. 


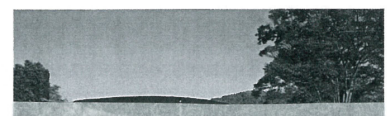

CAFE $J$ TERRACE $2010-2014$

SANAA
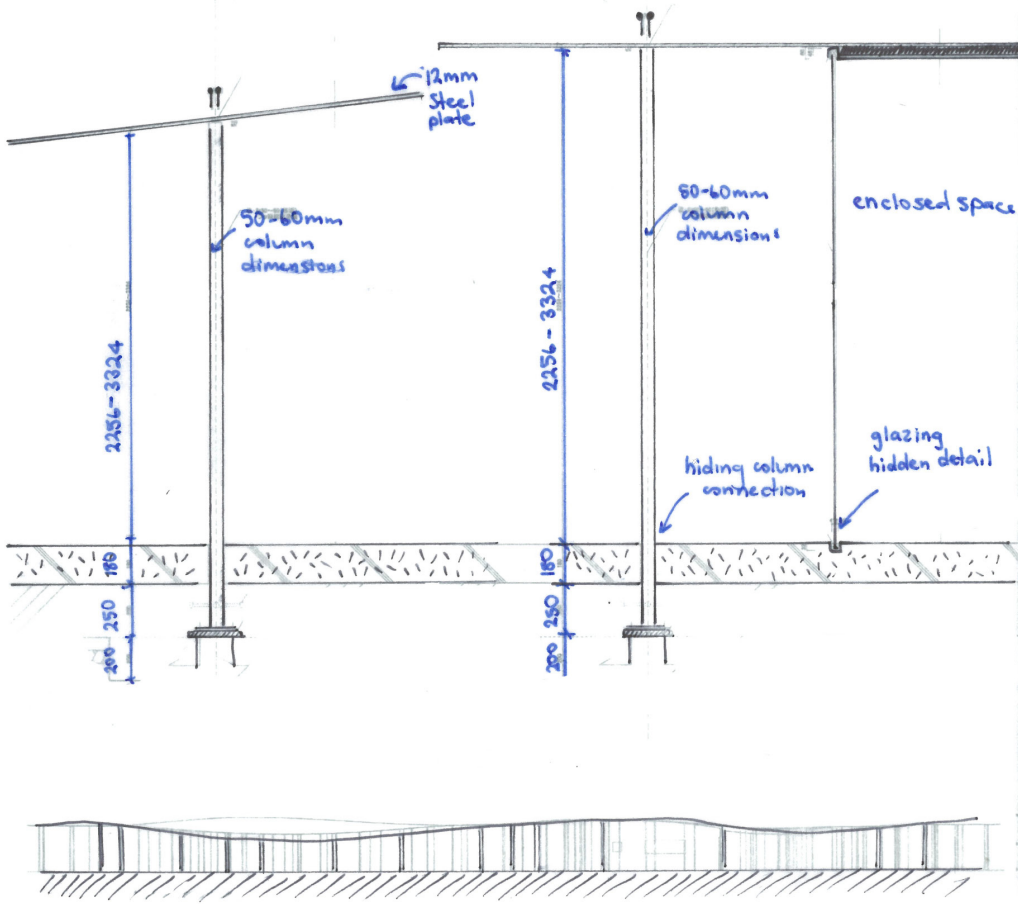


\section{theses}

SONEI-JI CEMETERY PAVILION 2014 KAZUYO SEJIMA

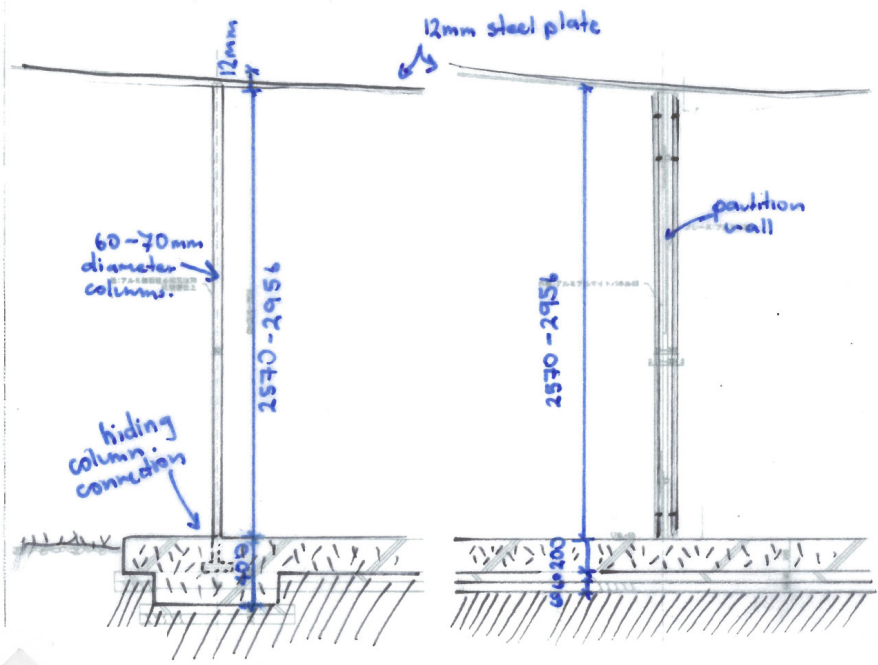

$152 \wedge$ 109. Kazuyo Sejima, Sonei-Ji Cemetery Pavilion details 


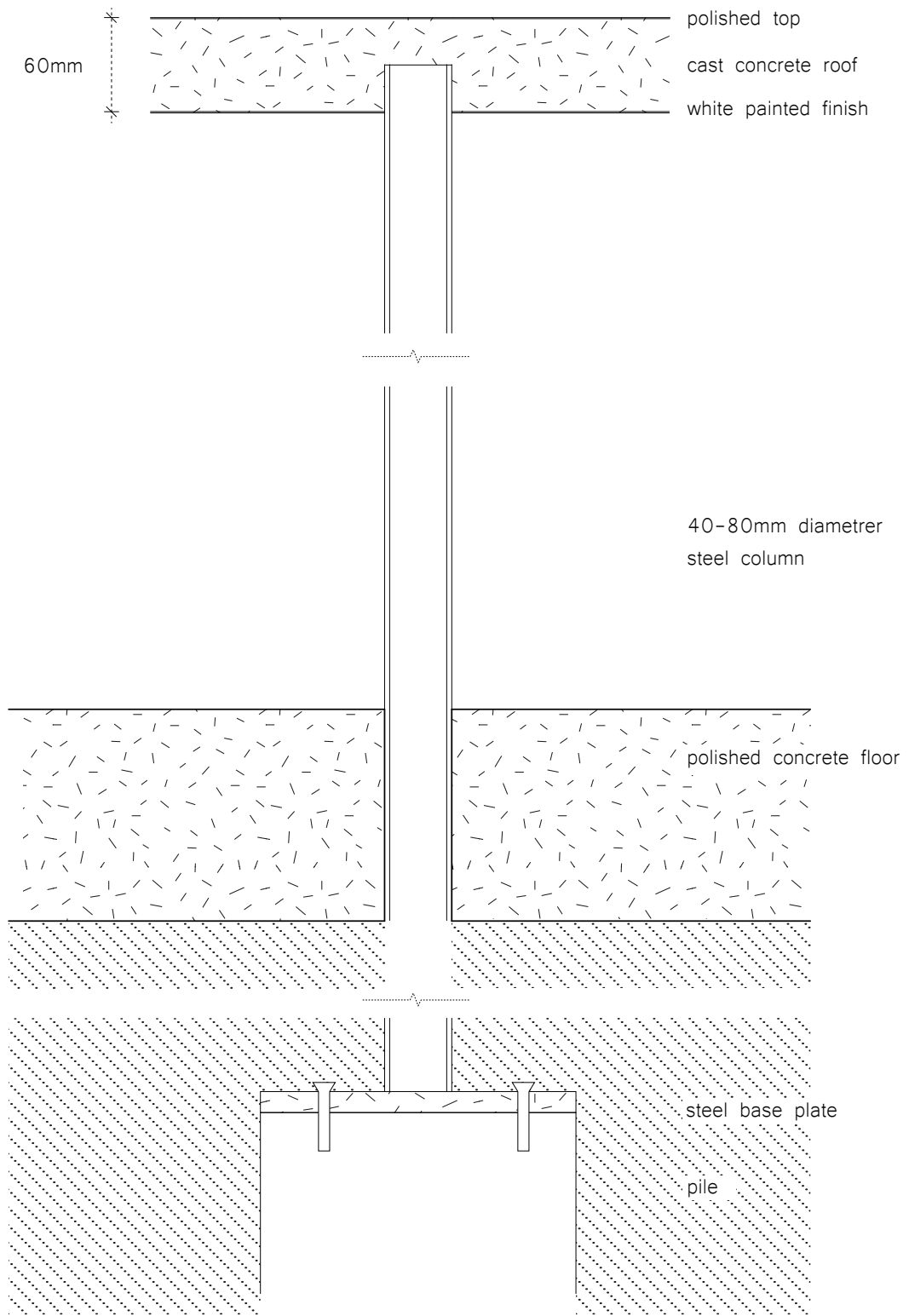

$\wedge$ 110. Diagram of potential column detail 
SERPENTINE PAUILION

2009

SANAA

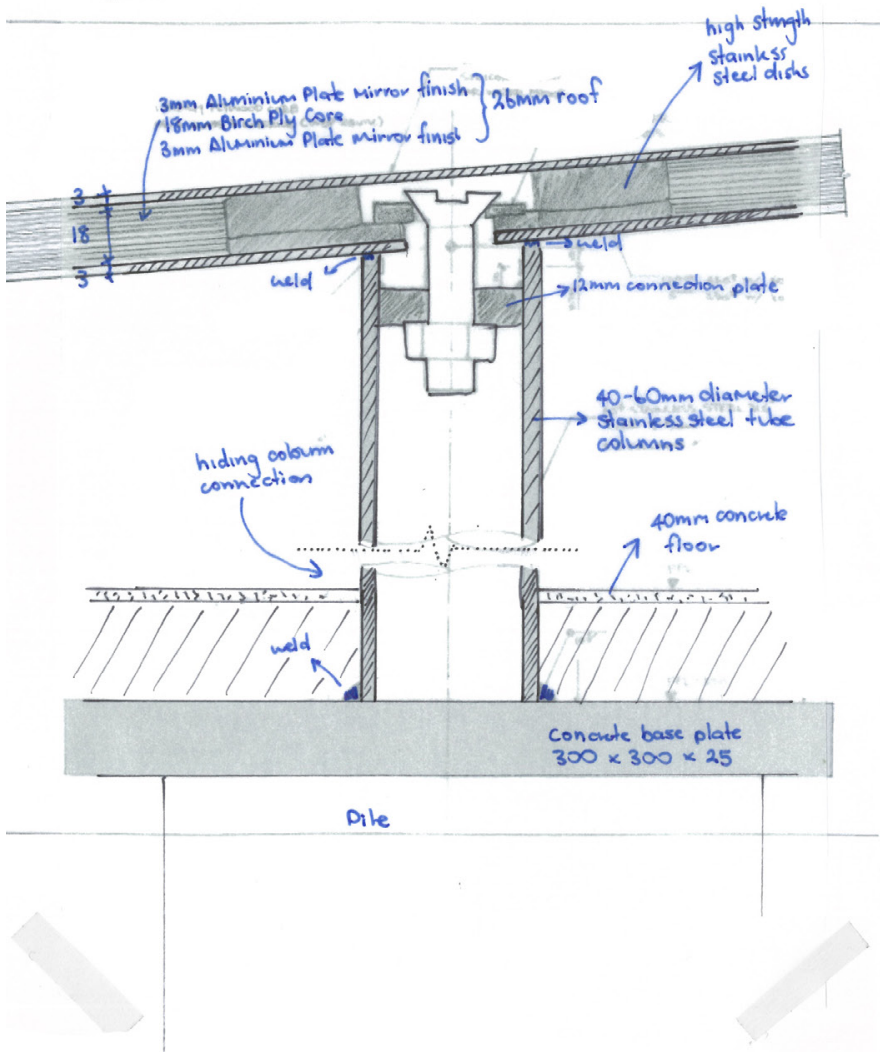

$154 \wedge$ 111. SANAA, Serpentine Pavilion detail 
top $=$

\section{$50 \mathrm{~mm}$ plywood core}

Waterproof memebrane bottom

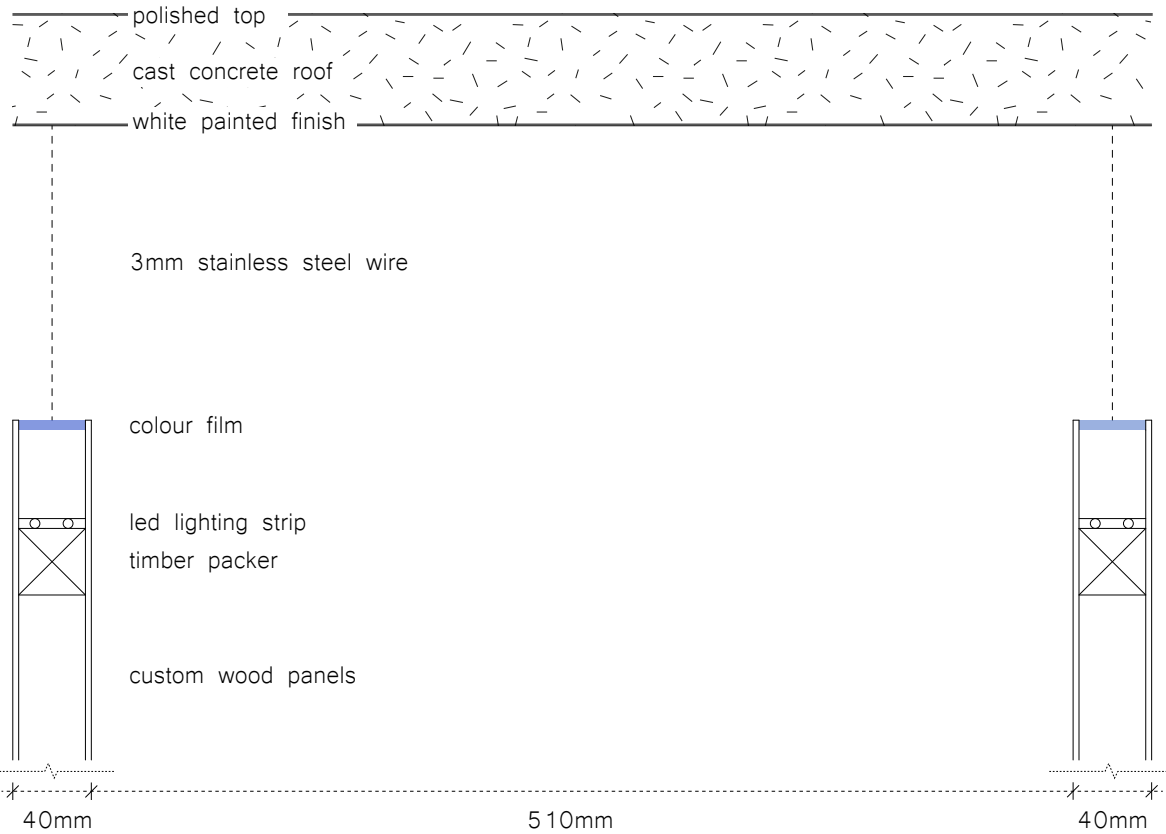




\section{$\frac{1}{6}$}


Furniture

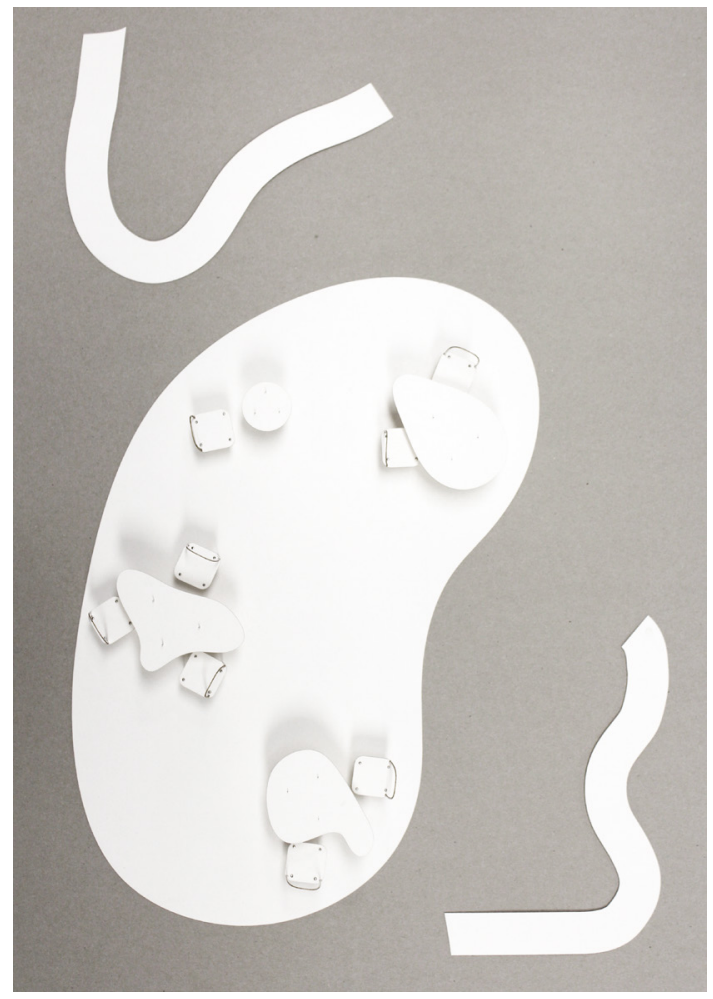

$\wedge$ 114. Furniture top view 


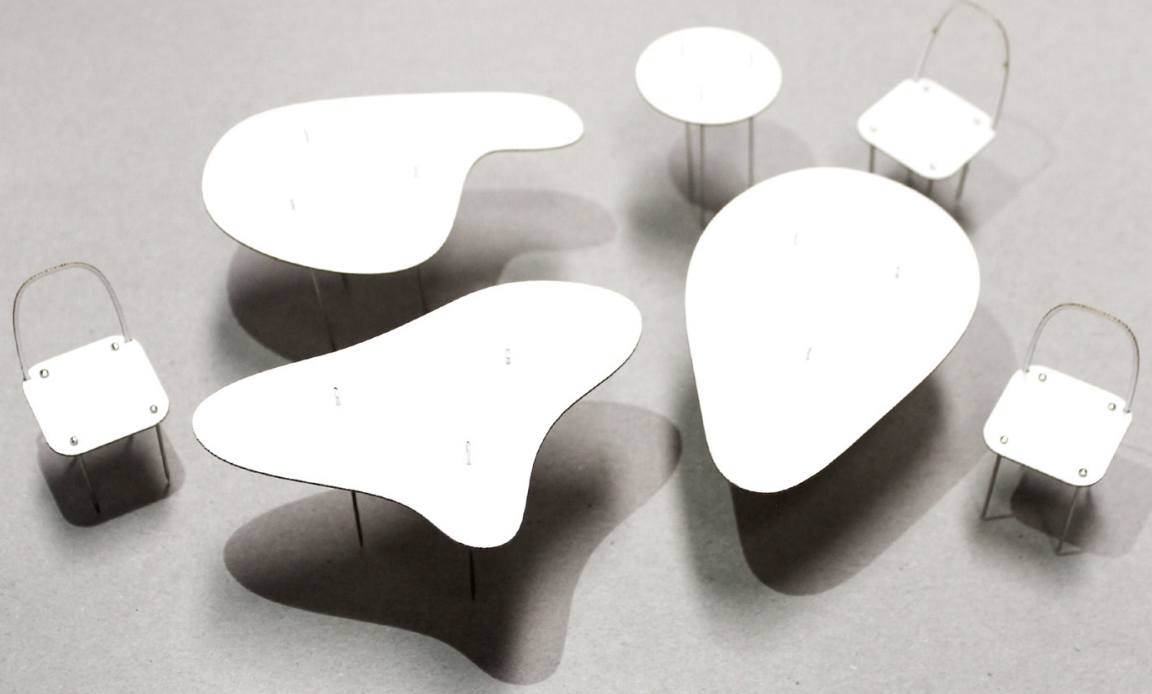

The furniture was physically modelled as a collection example specific to the design. The design follows the same organic curves as the building's form, translating the language to another scale, from landscape to building to furniture. To create a continuity between large and small, the furniture expresses the thinness desired for the tables to mimic the floating plane of the roof above, communicating shape and delicacy. 

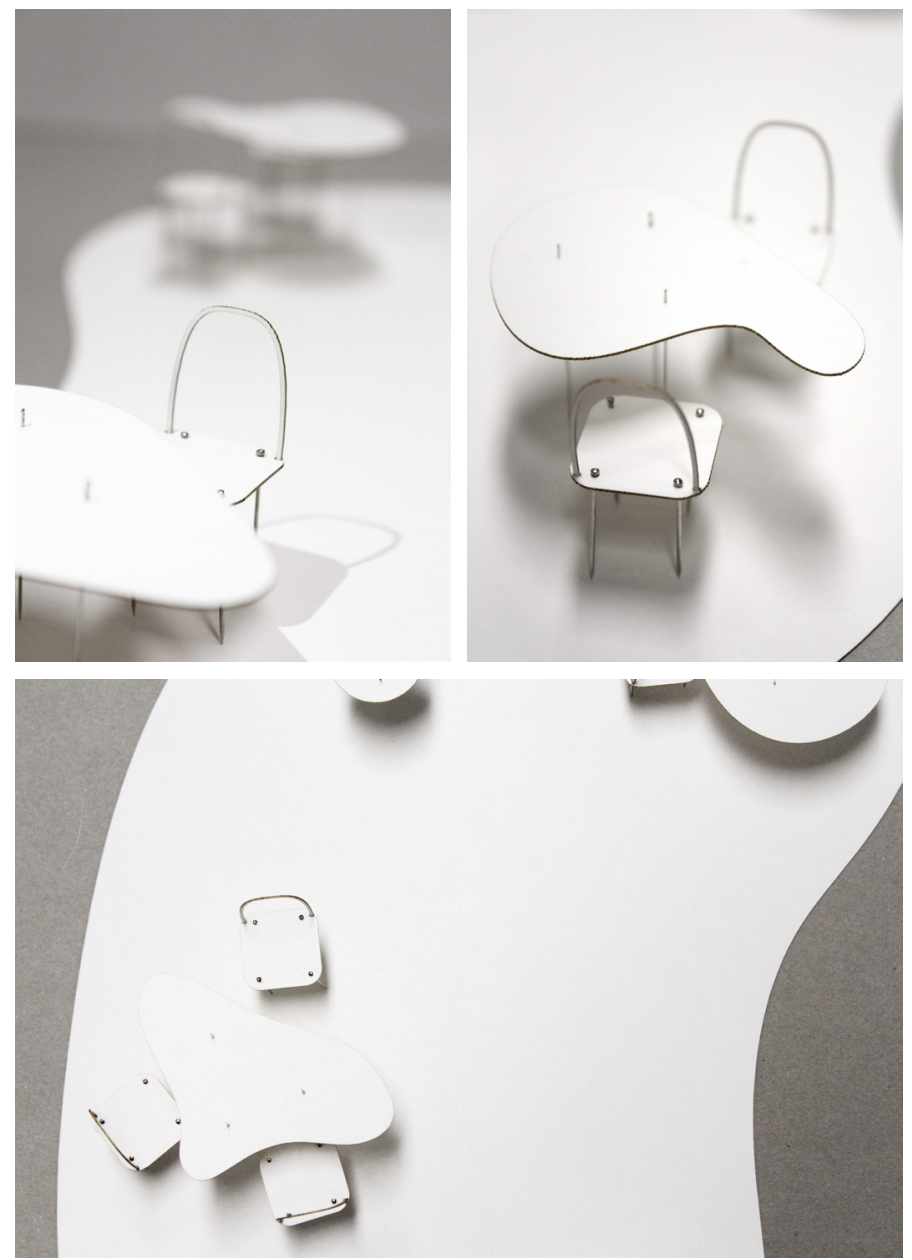

$\wedge$ 116. Furniture communicating shape and delicacy 


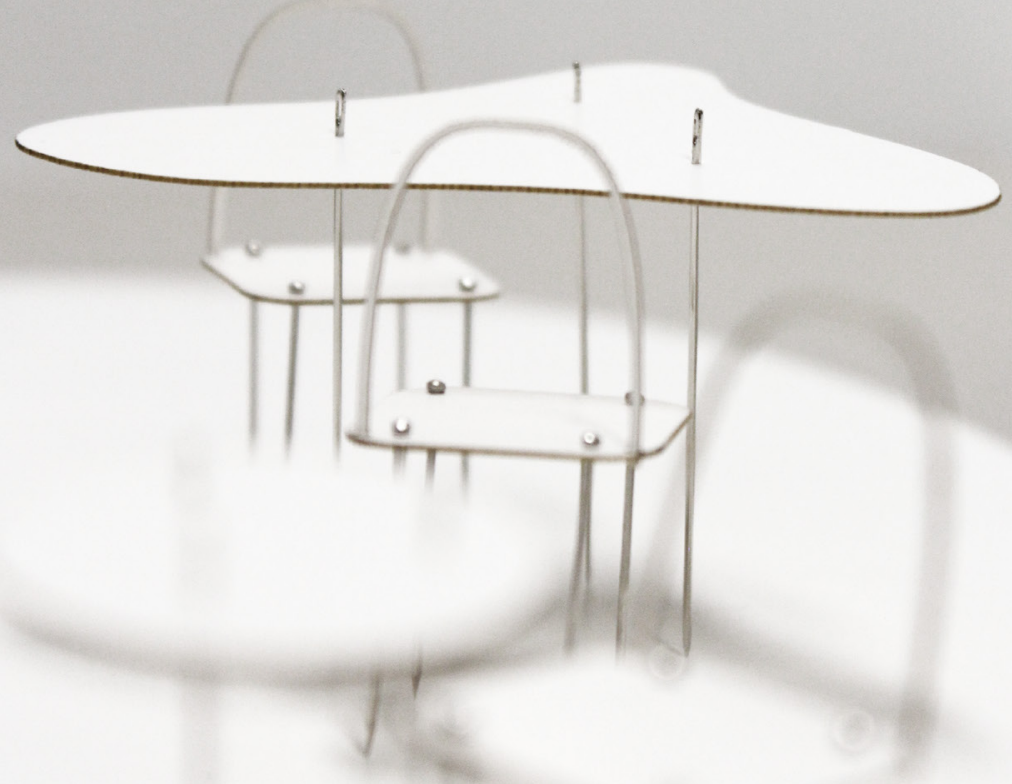




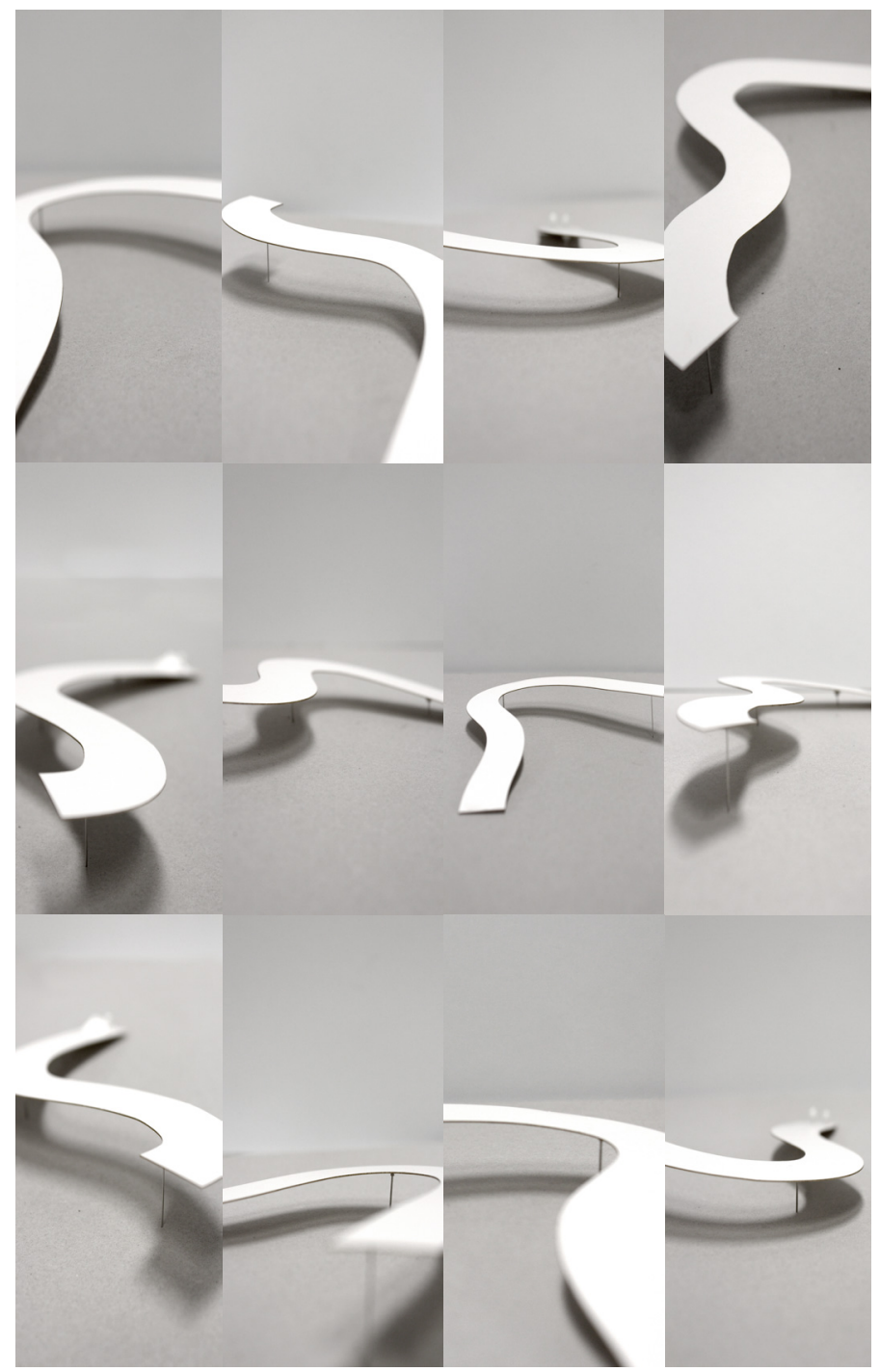

$\wedge$ 118. Seating matrix, soft curves and floating surfaces

$162>119$. Meandering floating bench 
The benches, like the rest of the furniture, attempt to express a vast surface that floats above a delicate structure. The structure aimed to have an intimate engagement with ground, appearing as though it was just touching the surfaces. The benches meanders in both the horizontal and vertical direction, engaging with the slope of the ground floor. 


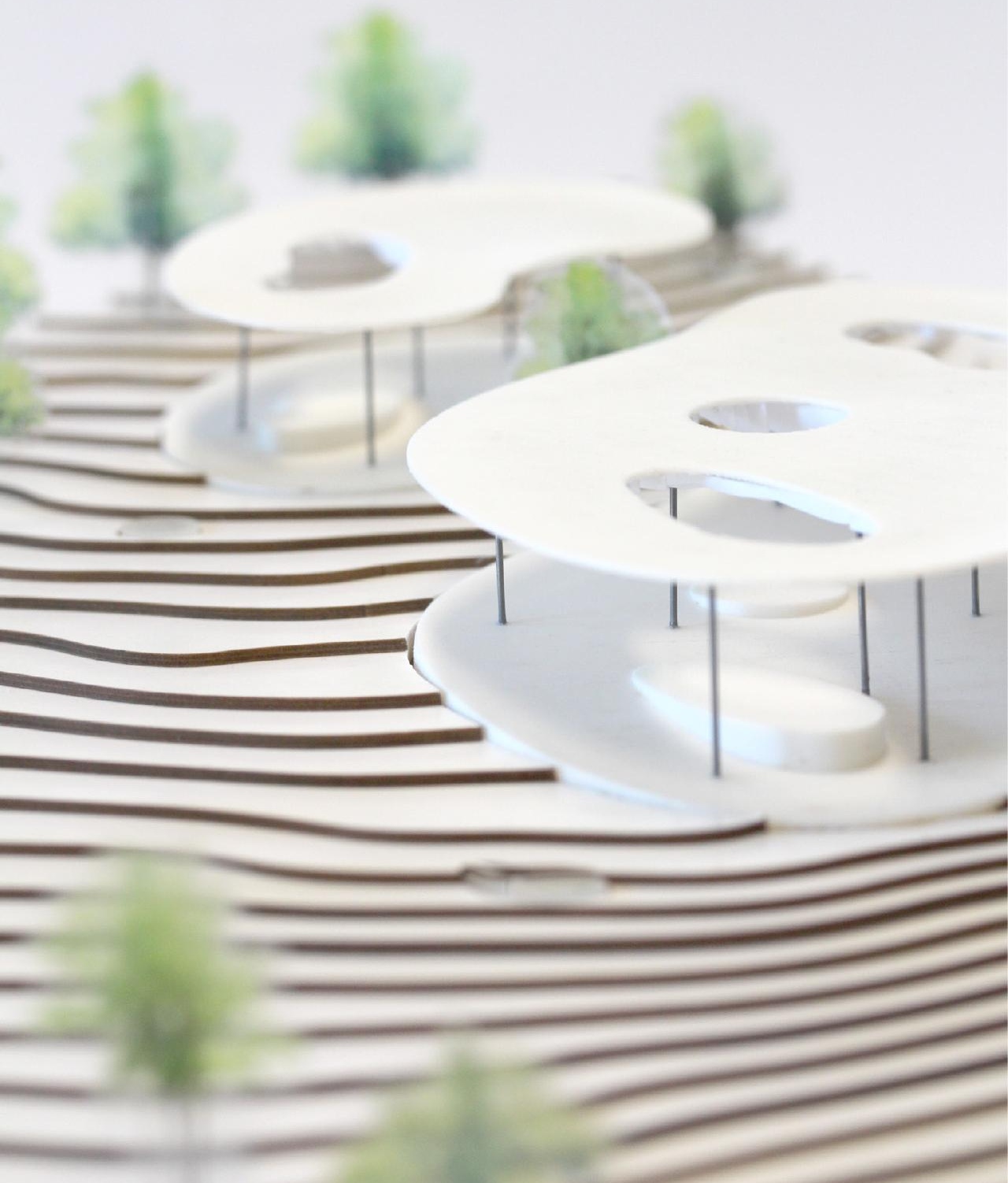




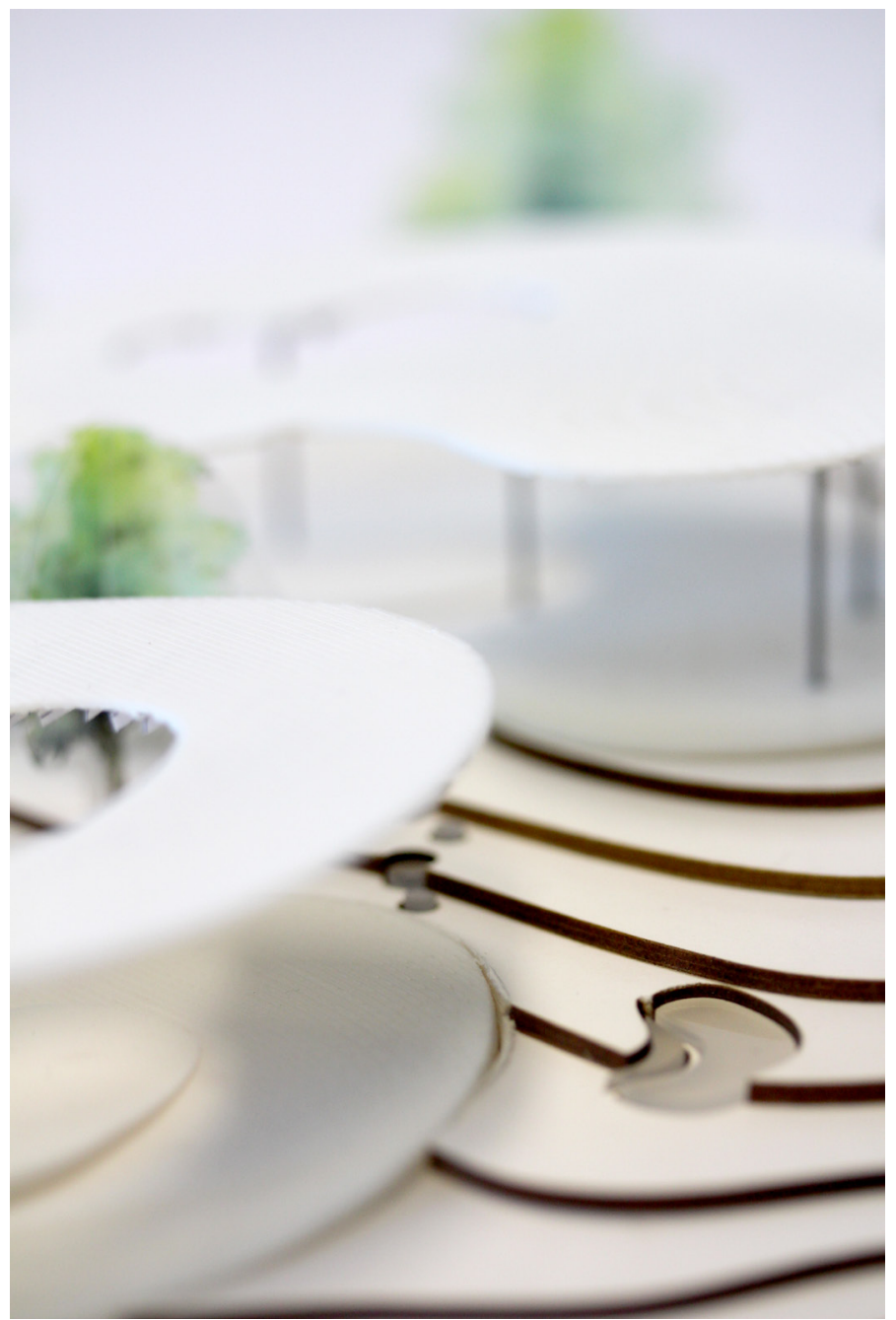

^ 121. Physical model details 


\section{REFLECTION}

The design of the café pavilion attempts to capture the vast and the intimate through heightening an awareness of scale in the spaces created and overall form.

However, on reflection the engagement of the vast and the intimate scale is not as evident as the notion of delicacy. The investigation regarding the vast and the intimate is huge and difficult to narrow down. Each concept is enough to pursue on its own. The design however, successfully explores delicacy and lightness with many interesting oscillations between solid and void, large and small, structure and skin and whiteness and colour. Slender and smooth materials, thinness, lightness and seamless connections all contribute towards a sense of delicacy. Through the process of design, critical reflection and critique at the May 2017 review they all informed a shift in direction. It is through design-led research that I have begun to narrow down my research to focus on delicacy. This method of research is a continuous exploration and testing ground to find new insights and stimulate curiosity in aspects of architecture. Rendell states, design as research "challenges a linear conception" (2013, p. 125) which is evident as my focus has shifted in "a rather lateral or unexpected way" (Fraser, 2013, p. 3).

Rather than the vast and intimate scale becoming the result of the design, the opposing scales are most effective as a tool in evoking delicacy. The thinness of the roof, tapering of the fins outwards, and size of columns all come together to heighten the delicacy of the roof and its floating appearance across the landscape. Playing with scale, light and whiteness accentuates a brightly transparent and delicate space. 


\section{Colour}

A weakness in the design was the execution of colour as other aspects were placed with more excitement and importance. Colour is an interesting aspect that I still think is worth pursuing as it is another driver to activate space. This reflection lead to a shift in direction in the next design chapter when colour is re-considered.

\section{Site}

The café pavilion's engagement with the site and ground plane was harmonious and was successful in developing a design that is influenced by site. However, this development could be also be reviewed as too polite. Site conditions including slope and vegetation impose on the design, informing its shape. The success of this submissive type of architecture is developed in the following design chapter into a malleable typology.

\section{Programme}

The roof successfully modulates the space and applies virtual masses through the undulations and negative space providing clues of programme. However, the design is missing the influence of programme and how programme can inform and shape the design. Despite the deliberate selection of a programme with minimal demands the execution was a programme that was easily inserted into the design rather than influencing the design. If I had not moved onto the public-scale till later, the café pavilion would have benefitted from more development with iterative studies looking at programme as another tool to shape the design. However, the time frame was dictated by the supervisors of the stream. 


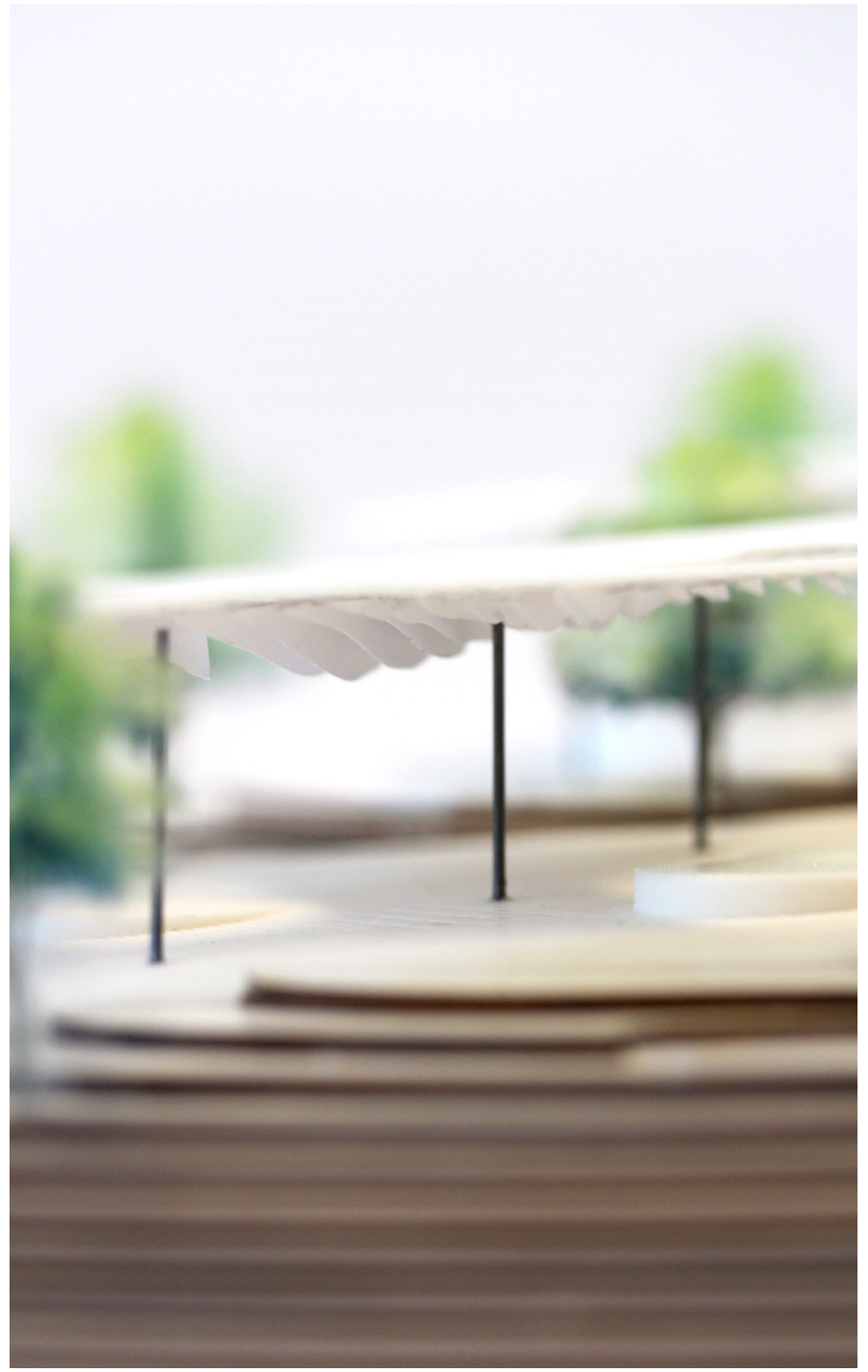

$168 \wedge$ 122. Physical model fins and slope 


\section{PIVOTAL SHIFT}

The direction of this research has now shifted from engaging the vast and the intimate scale simultaneously to exploring the aesthetic concept of delicacy in architecture using scale, colour and whiteness, and materiality as the framework. The ideas behind the vast and the intimate are still relevant but are better suited as part of the scale framework rather than the leading focus. The notion of delicacy is pursued in the next chapter, with another jump in scale testing these ideas at the public-scale. 


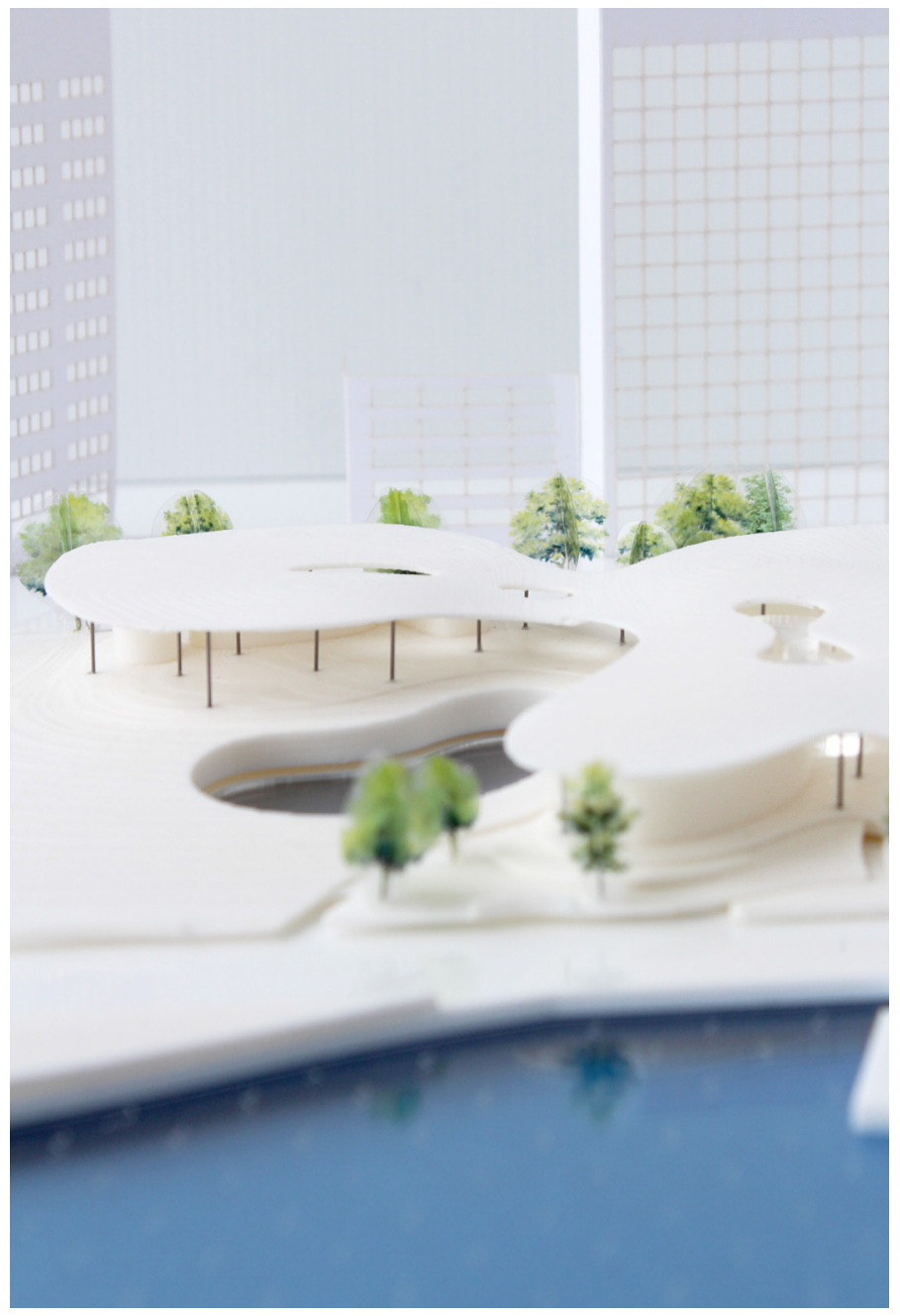


06

PUBLIC-SCALE 


\section{Introduction}

The final design experiment investigated the proposition at a public-scale and continued to shift between large and small. Yaneva argues, "scaling up is immediately and reversibly followed by scaling down” (2005, p. 883) which creates a rhythm that encourages new discoveries and addresses the design through a multitude of levels. This chapter outlines the aim and design methodology before introducing site as a testing ground. Wellington waterfront and the selected site, Frank Kitts Park, were analysed before the design process started. After the initial design explorations, programme was introduced to shape and influence form. Further tests investigated delicacy before a design was developed and critiqued at the August review. The design presented was reflected upon and then developed further for the November final visual presentation. This chapter concludes with a reflection on the final design. 


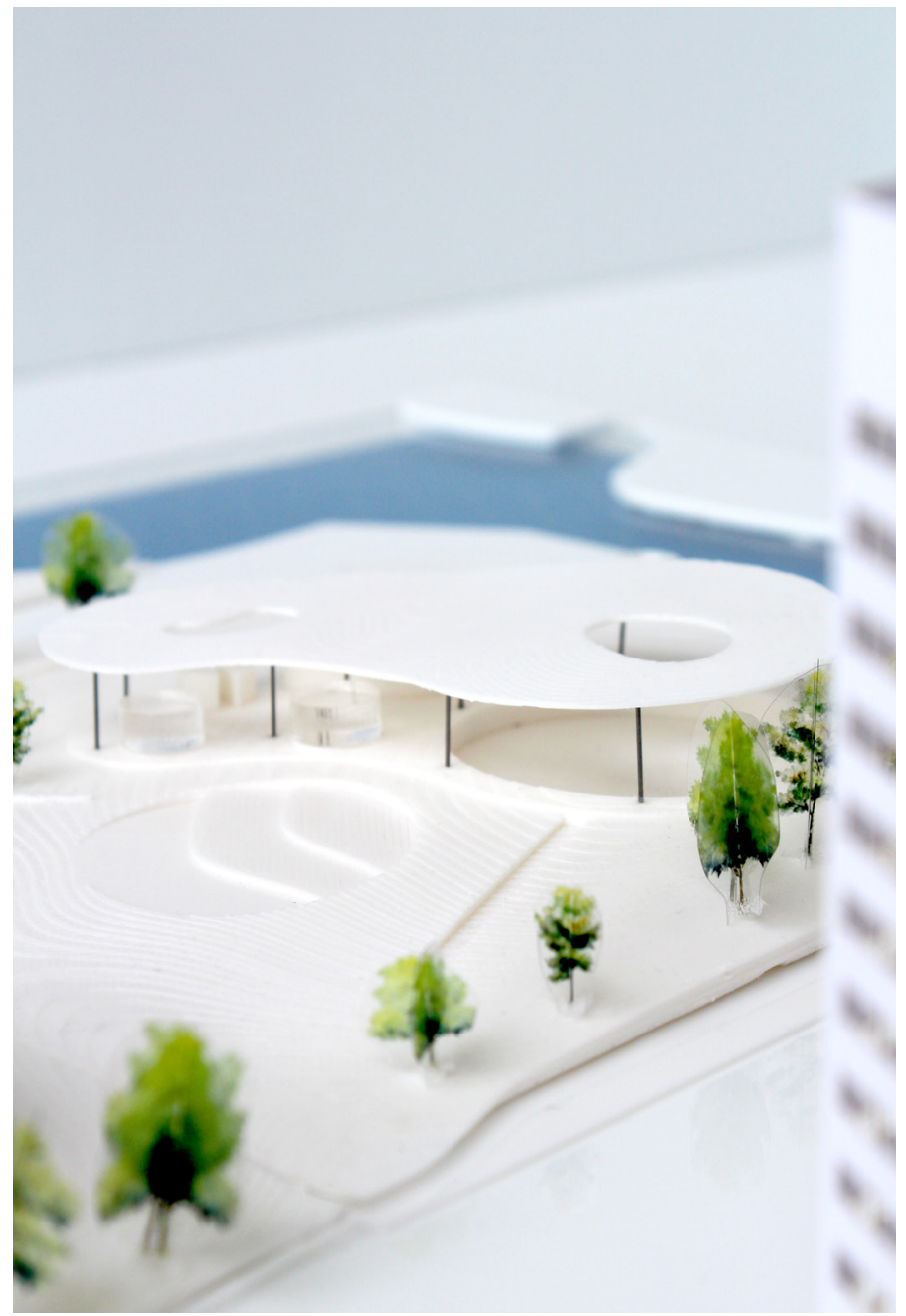


Aim

This experiment aims to investigate and test the notion of delicacy within architecture through the design of a community centre and gallery.

\section{Method}

The same iterative and reflective design process is used to test the aim due to the strengths and successes of the previous design chapters. Physical and digital modelling, drawing, photography were all methods that allowed me to test my research in an explorative manner. The publicscale design is the final 'jump' in scale, however I continue to shift between the large master-planning scale and the human scale to address and refine the design at multiple levels. This was important in resolving the design proposition. The same evaluative framework is implemented throughout the design process and in the final design: scale, materiality, and colour and whiteness. 


\title{
Design Process Overview
}

\author{
non-linear
}
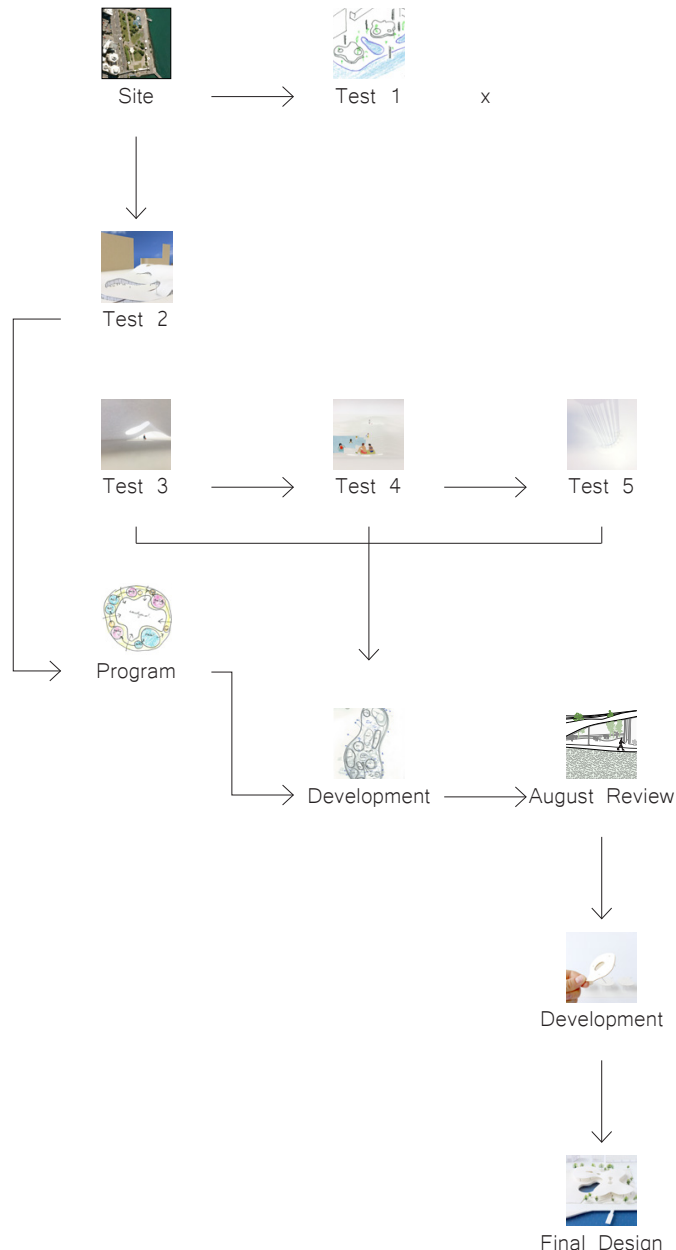

Final Design 


\section{SITE}

The site was located on the Wellington waterfront. It was a testing ground for the research within an urban context. Redevelopments have been proposed for Frank Kitts Park which sparked my interest in the site.

\section{Wellington Waterfront}

One of Wellington's most distinctive and charming areas is the waterfront. The waterfront is home to many acknowledged buildings and attractions, "separating central city from sea, the waterfront is home to a vibrant, everchanging atmosphere with unique features and attractions" (Wellington Regional Economic Development Agency, n.d.). Between 1852 and 1970 a series of reclamation projects took place extending the waterfront out from Lambton Quay. Both public and private projects went under serious development as the waterfront extended out to where it sits today (O’Byrne, 2016, p. 74). These developments stimulate and facilitate pedestrian activity, encourage interactions with the water, maintain view shafts from the city, and push towards creative and innovative design solutions across the waterfront precinct. 


\section{Wellington Waterfront}

Buildings of interest and attractions

a TSB Bank Arena

b The Boatshed

c Wharewaka Function Centre

d Circa Theatre

e Te Papa

$f$ Oriental Boat Sheds

Points of interest and attractions

1 Kumutoto

2 Fergs Kayaks

3 Frank Kitts Park

4 Len Lye: Water Whirler

5 Wahine Memorial

6 Underground Markets

7 Albatross Sculpture

8 Civic Square

9 City to Sea Bridge

10 Jump Platform

11 Taranaki Wharf Jump Platform

12 Solace in the Wind Statue

13 Sunday Markets

14 Waitangi Skate Park

15 Carter Memorial Fountain
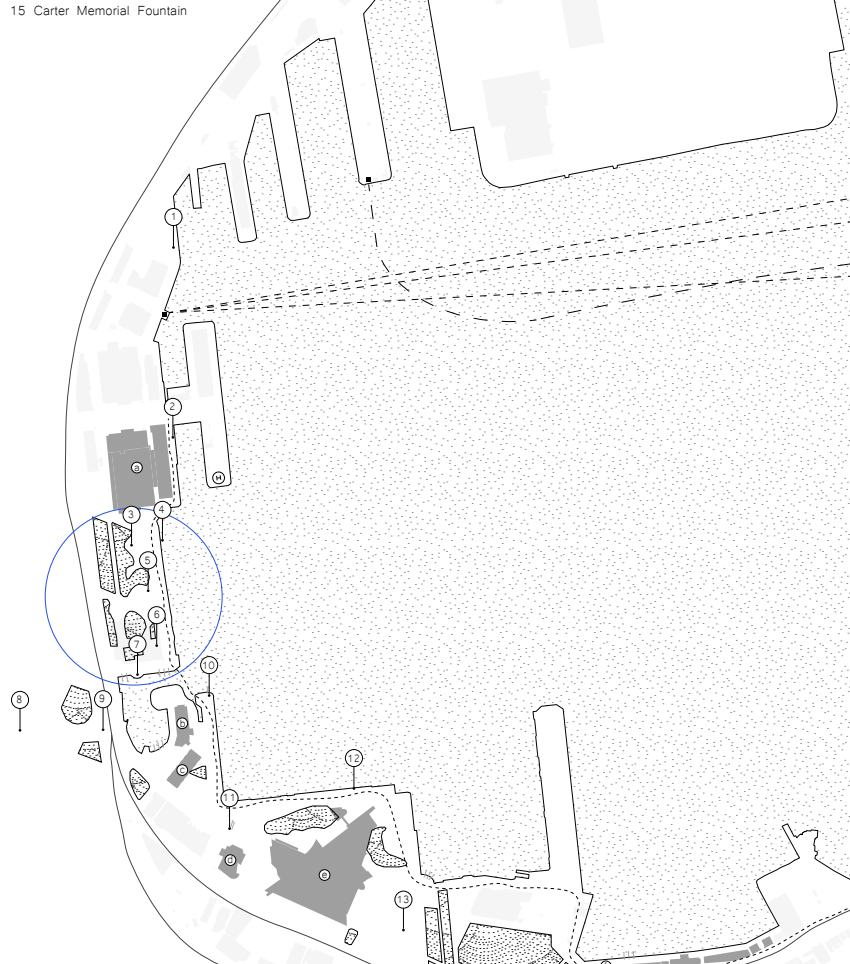

e.

\section{1}

P

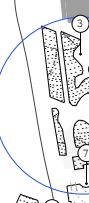




\section{Frank Kitts Park}

Frank Kitts Park, originally named Marine Park, was the first open public space built on reclaimed land in 1974. The park's original design was in response to the annual Nissan race through the city and waterfront. "To accommodate the race, the harbour side of the park was raised one storey to separate spectators from the promenade" (O’Byrne, 2016, p. 228). As a result the park became internally orientated with little to no engagement with the harbour or the city, as Jervois Quay separates the two. Marine Park was renamed Frank Kitts Park in 1979 after the mayor serving at the time (O-Byrne, 2016, p. 79).

Frank Kitts Park has remained a topic of interest throughout the redevelopment of the waterfront as a large public amenity that has been subjected to a lot of positive and negative attention. For example, O'Byrne argues, the "wall, gradient and layout of Frank Kitts Park does not utilise borrowed views, meaning it does not use it context to contribute to the experience of the space" (2016, p. 110). In the following pages the site was analysed in terms of its existing features, conditions and how the park functions today before testing the notion of delicacy. 


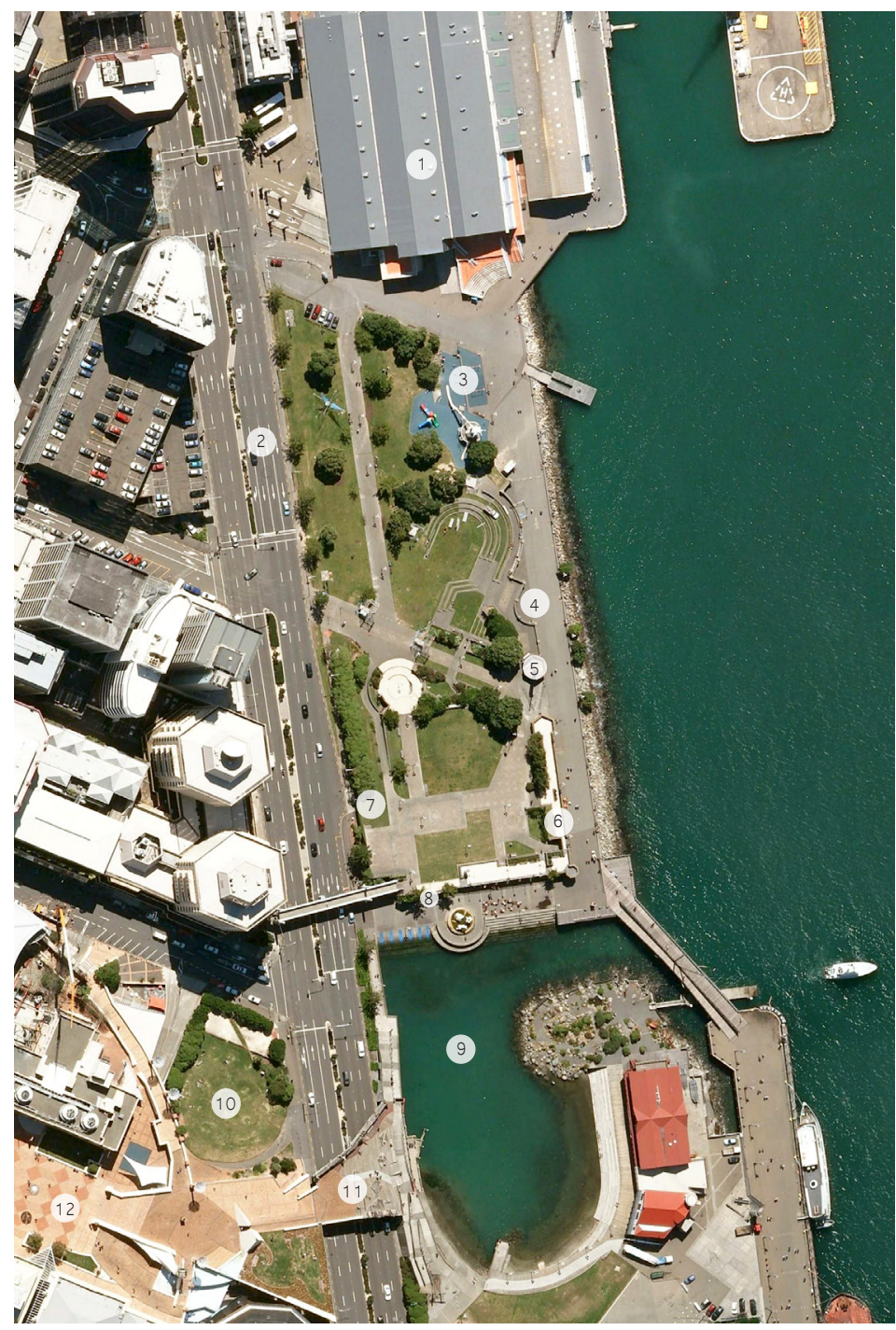
1 TSB Arena
4 Sheltered Seating
2 Jervois Quay
5 Wahine Memorial
3 Children's Playground
6 Retail Businesses
$\begin{array}{ll}7 \text { Underground Parking Access } & 10 \text { Jack Ilott Green } \\ 8 \text { Storage Spaces } & 11 \text { City-to-Sea Bridge } \\ 9 \text { Lagoon } & 12 \text { Civic Square }\end{array}$ 
Site Lines

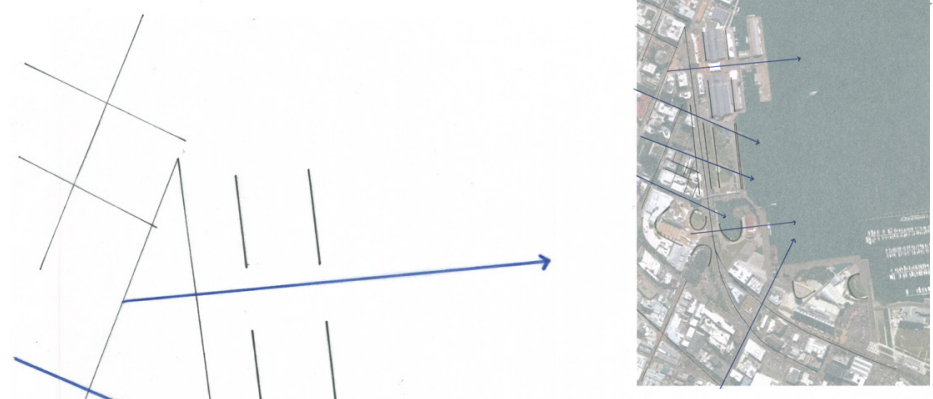

Through physical and visual analysis the site's context was evaluated to be very heavy and linear. There was an opportunity to offer something different to the current urban edge, a contrast of value.

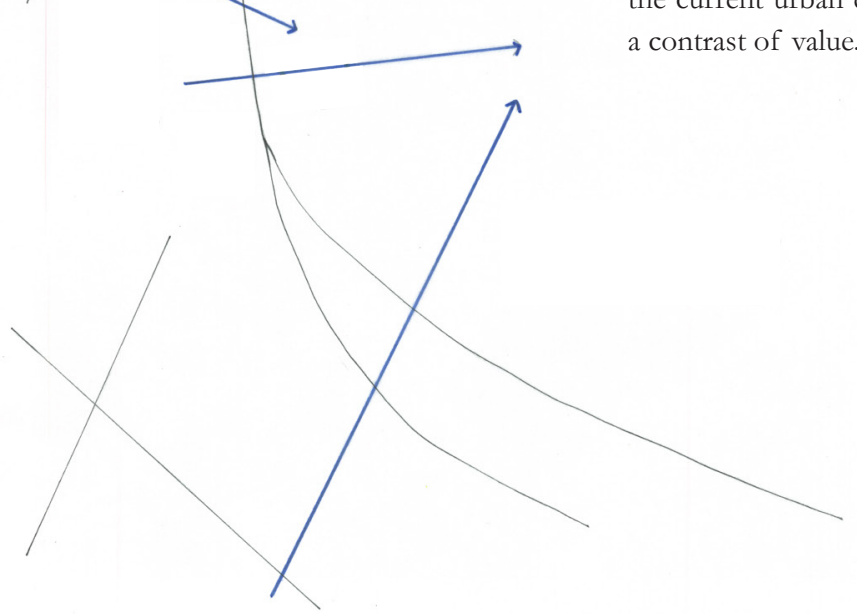




\section{Urban Conditions}

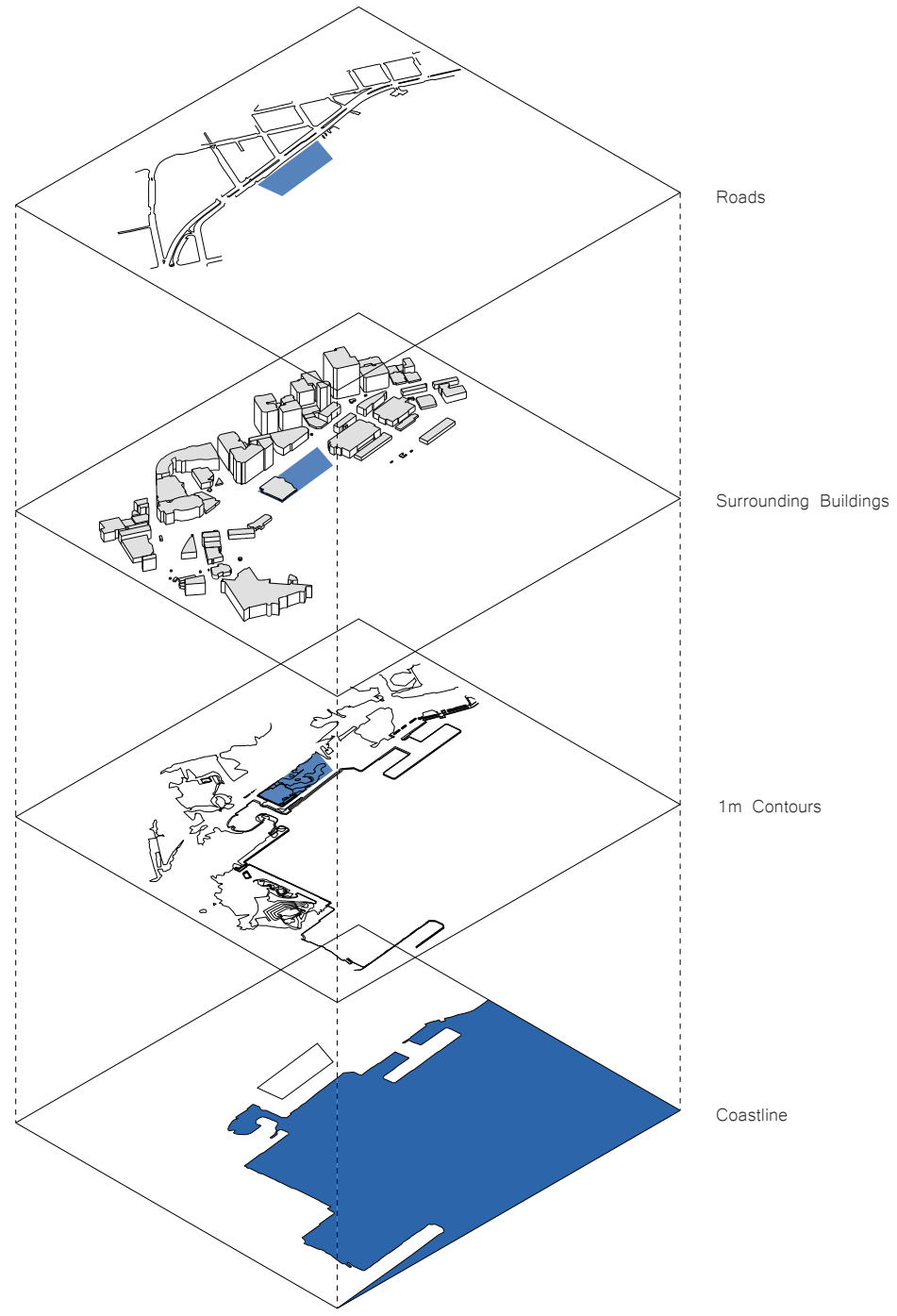


Site Conditions

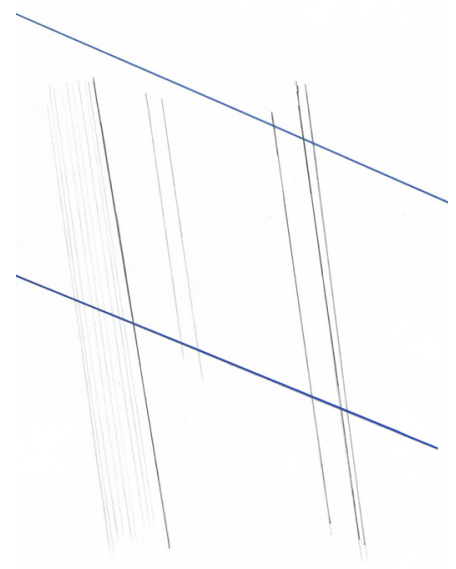

Immediate Site Lines

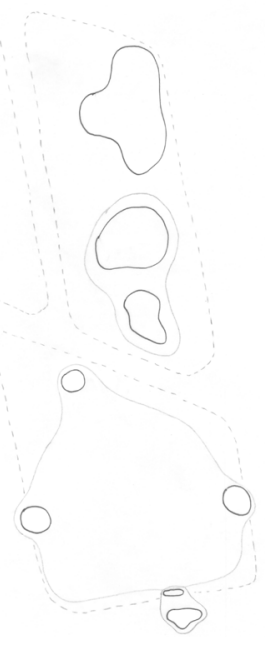

Zones of Activity

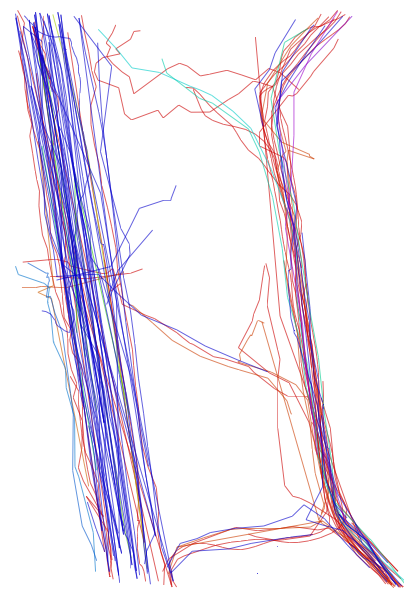

Circulation
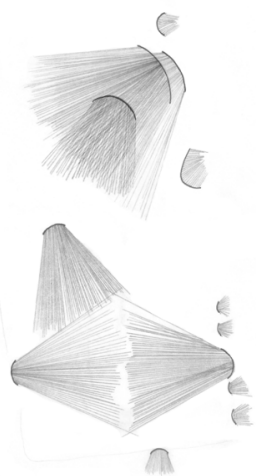

Orientation 
Site Conditions

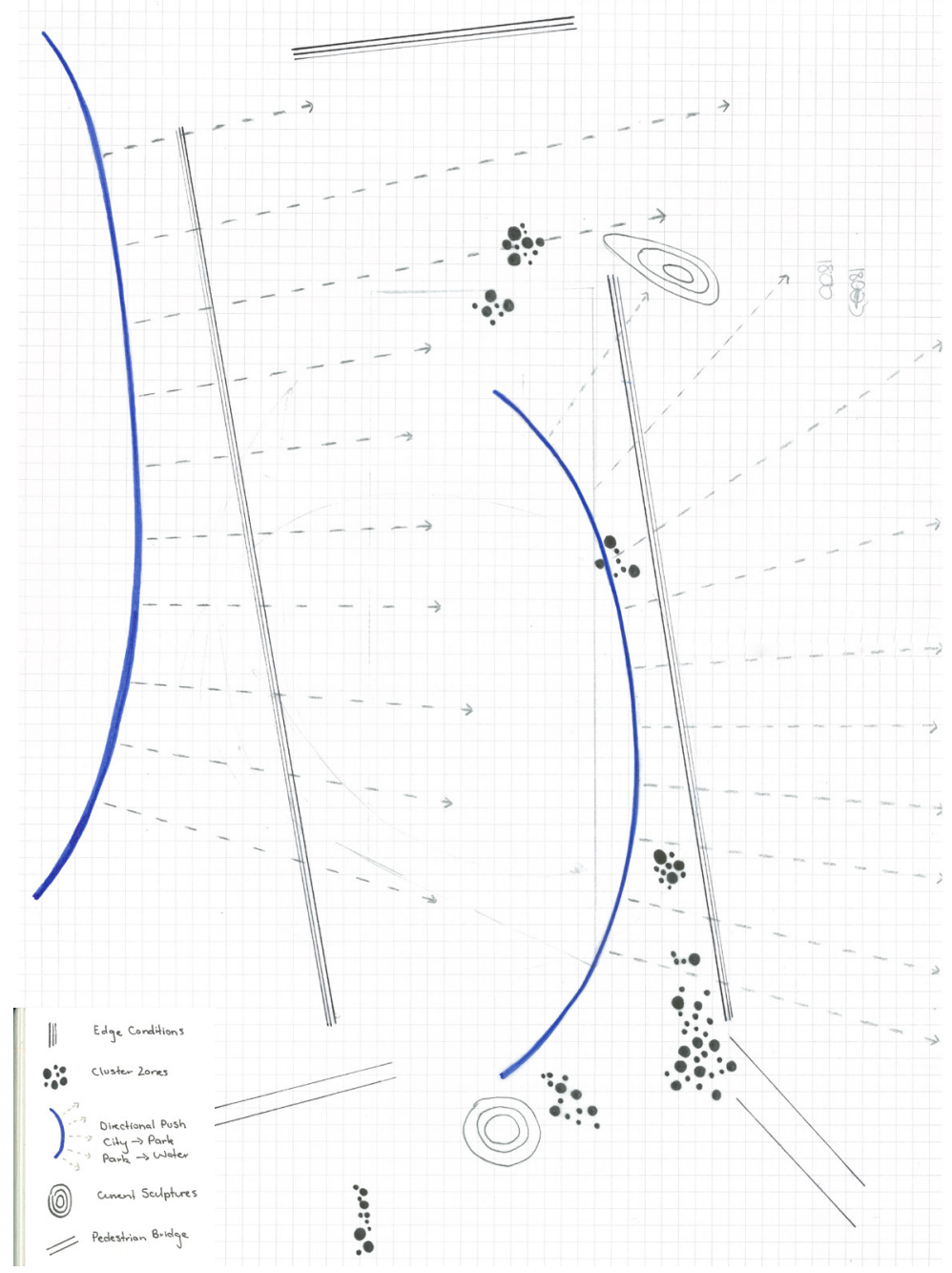




\section{Test One}

\section{Aim}

Explore speculative massing and landscaping on site. This is to investigate potential locations for siting the architecture and activating site.
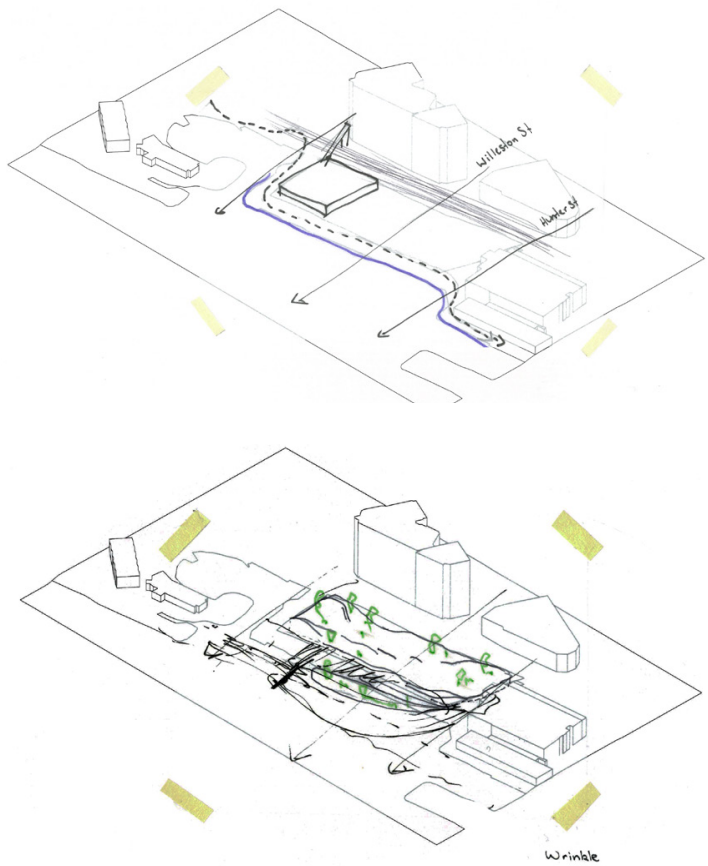

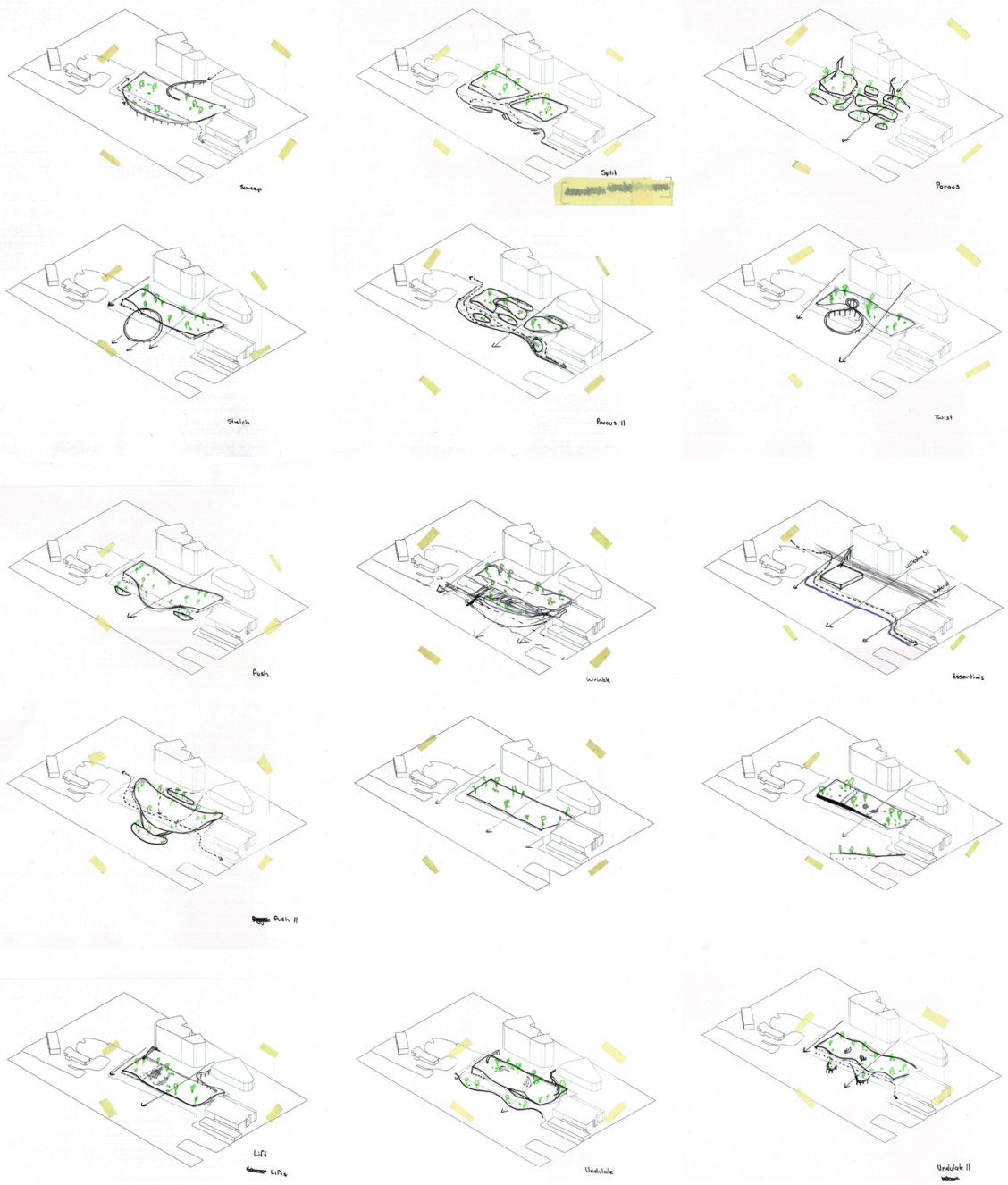

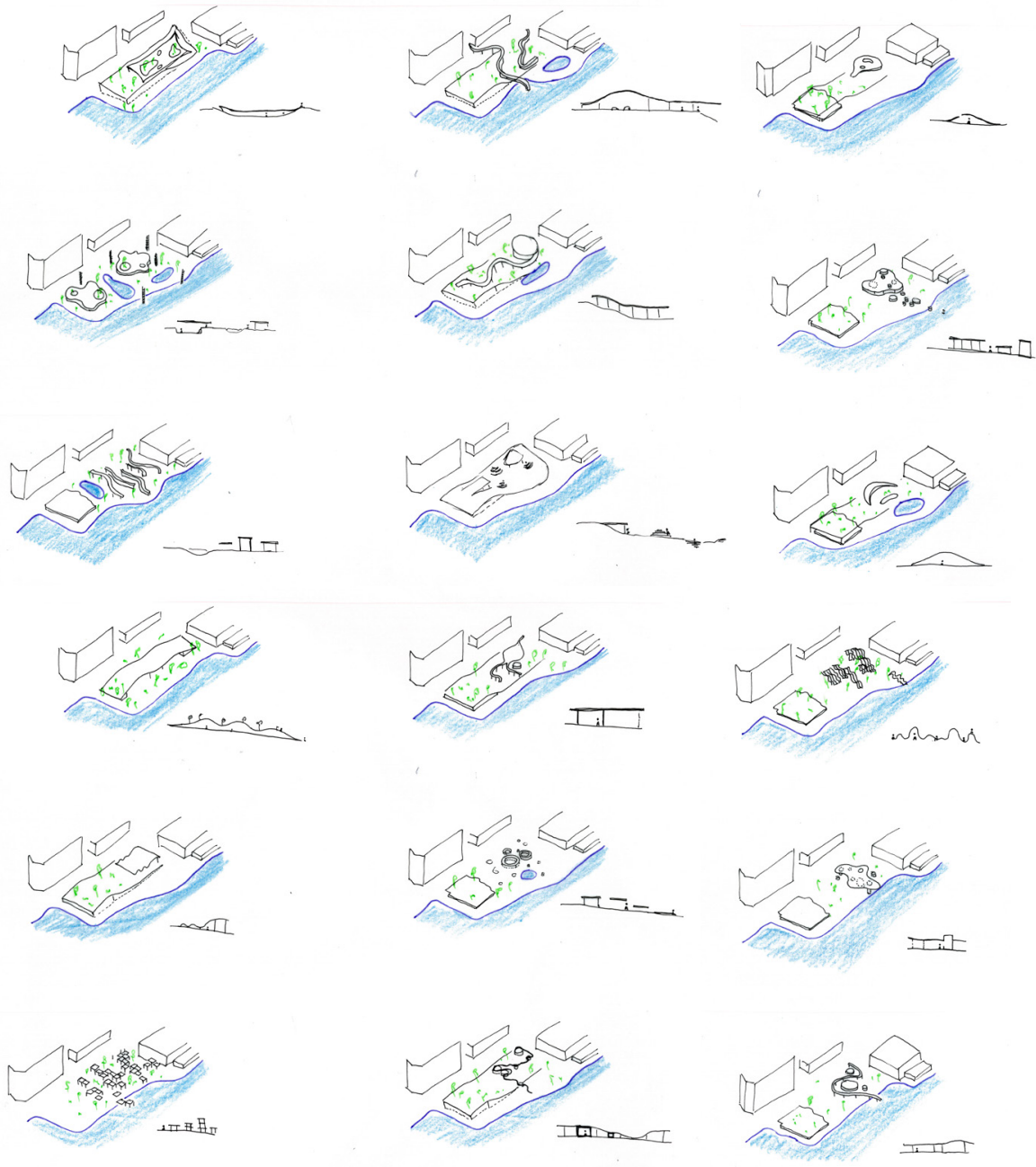

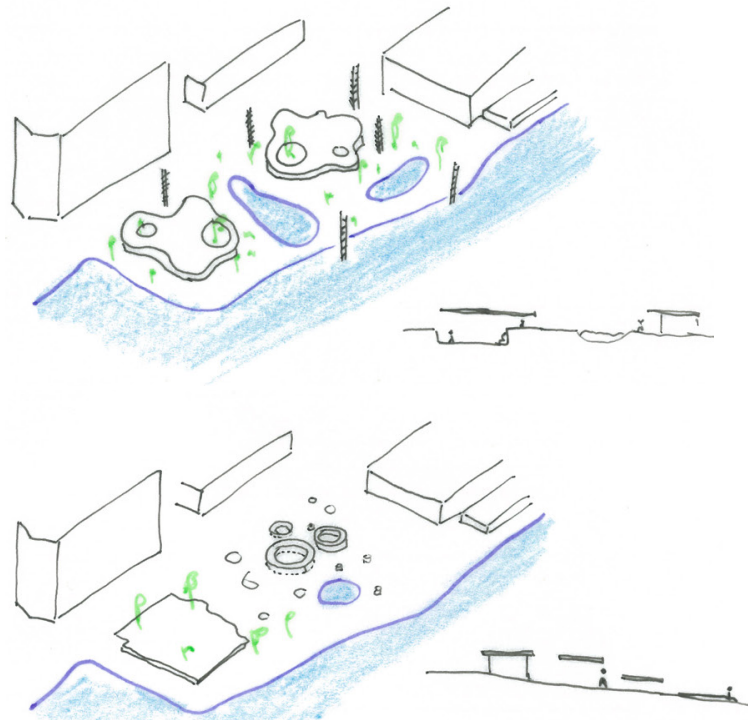

$\wedge$ 135. Speculative site massing

\section{Evaluation}

Without any real constraints the tests were able to be quick and playful getting a feel for massing on site. However, a weakness would be at this scale and pace the drawing are vague architectural forms not solutions. The exploration was successful in initiating the design process through axonometric sketches and section, even if none of these iterations led to further development. This was due to their lack of consideration of programme, delicacy or any constraints. 
Test Two

\section{Aim}

Continuing Yaneva's method of 'scaling up' within the research this exploration aims to scale up the mid-scale design and elements to test potential envelopes on site. Quick sketching is then to be overlaid to consider occupation.

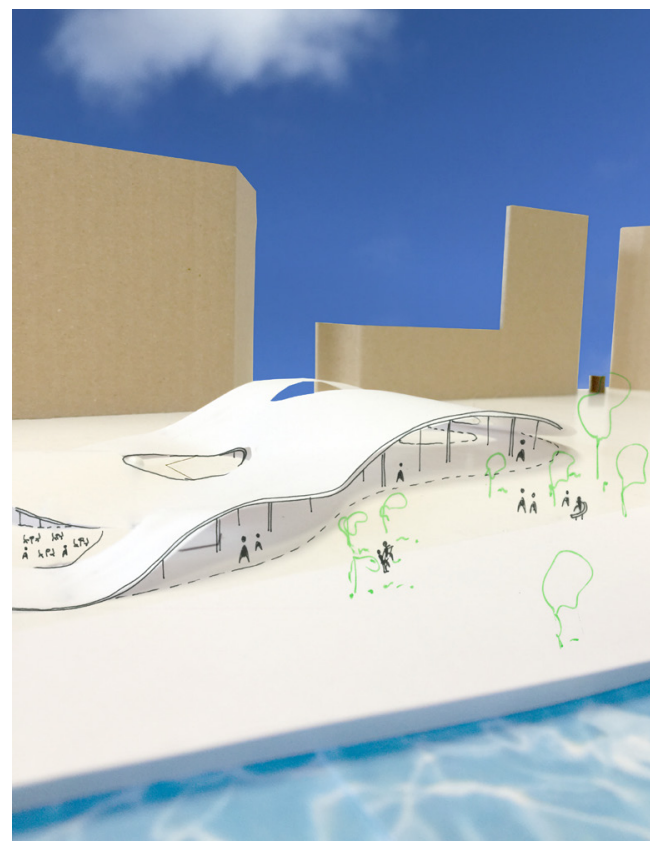

$\wedge$ 136. Exaggerating the 'floating' roof 

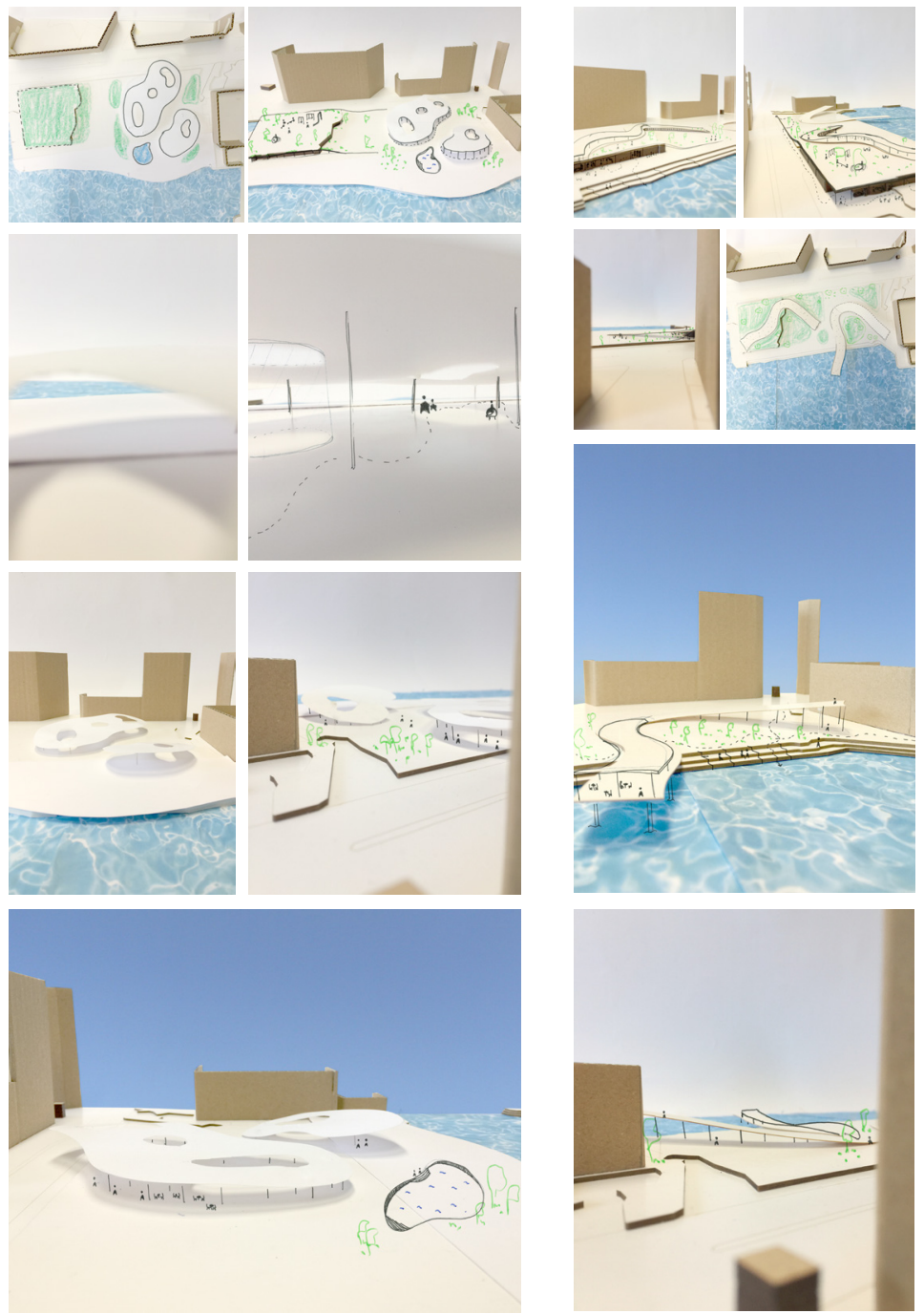

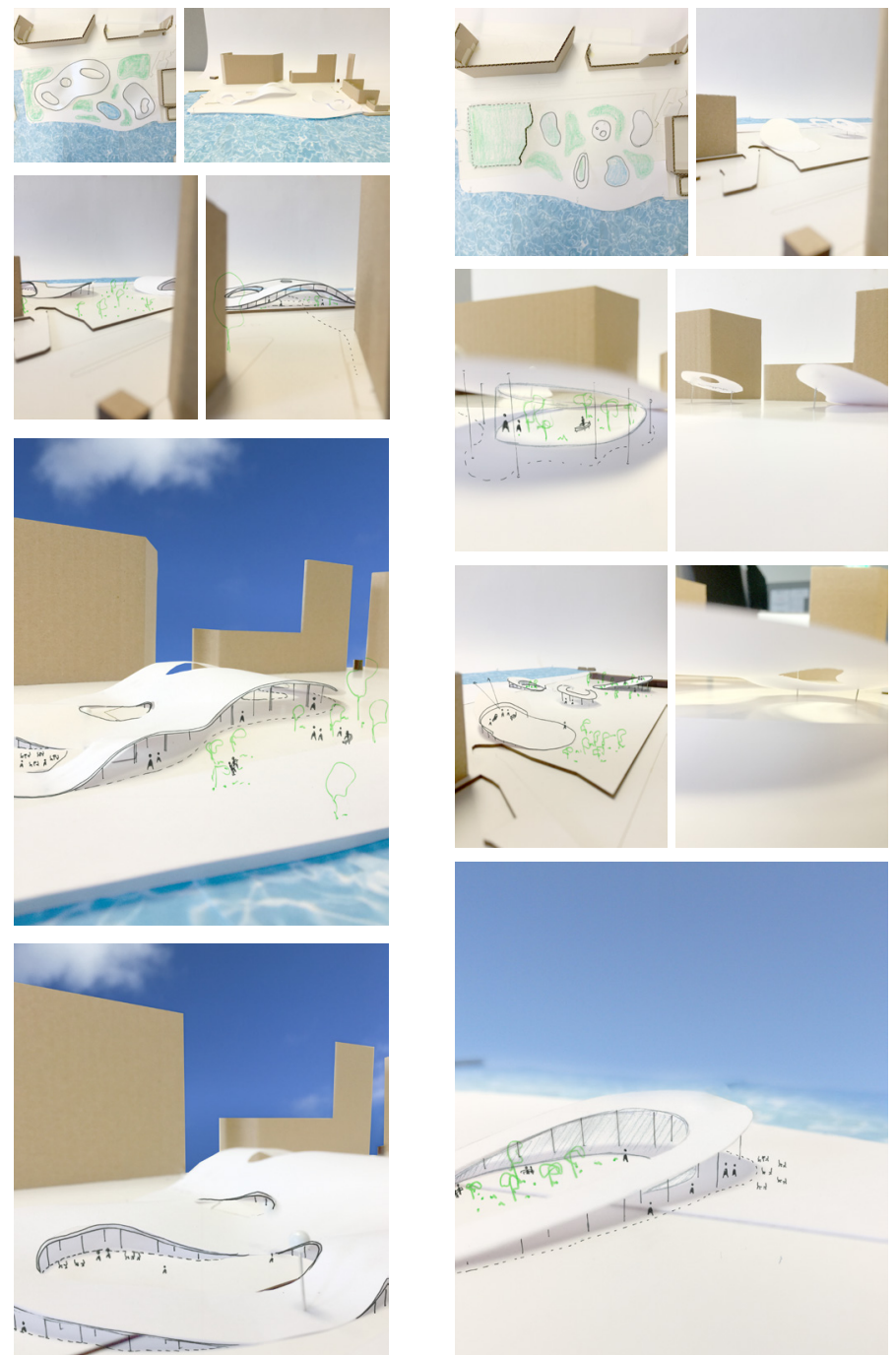

$190 \wedge$ 138. Scaling up mid-scale matrix pt II 


\section{Evaluation}

The harmonious relationship between the roof and landscape was part of the success from the mid-scale design and carried forward here at a much larger scale. The new scale, site and context allows the mid-scale design to easily mould and adjust to site, taking on a new form. An interesting discovery was taking advantage of the flat landscape and allow the architecture to shape the ground plane. Through the paper models the large-scale structures appear thin and light, highlighting their delicacy. A large weakness in this test is the consideration of site. In his analysis of Frank Kitts Park, O’Byrne lists many field conditions that should be taken under consideration. Such conditions include, relationship of spaces, location and types of amenities, fixtures, definition of public and private spaces and structural aspects when regarding site (2016, p. 51). Although the site context was physically modelled it is clear that the investigation is based on form explorations rather than engaging with site conditions. This test was however, successful in understanding an appropriate building scale on site. 

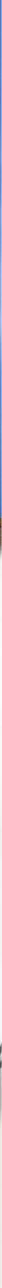
Upon reflection in the mid-scale I highlighted three interesting oscillations in relation to exploring delicacy. Solid and void, large and small, structure and skin. These three oscillating explorations are tested individually in terms of architectural design and occupation. The focus of these experiments is to engage with different spatial qualities that investigate the notion of delicacy. 


\section{Test Three}

\section{Aim}

Investigate the notion of delicacy through solid and void, through drawing and physical models.

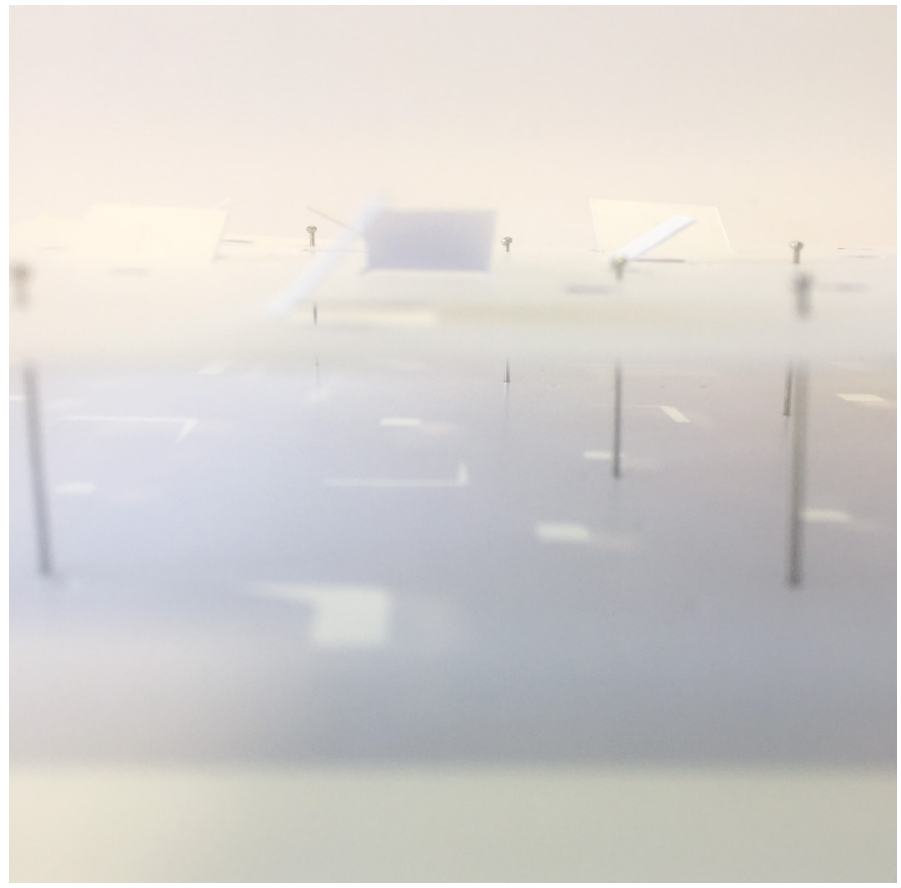


2. Solid + Void

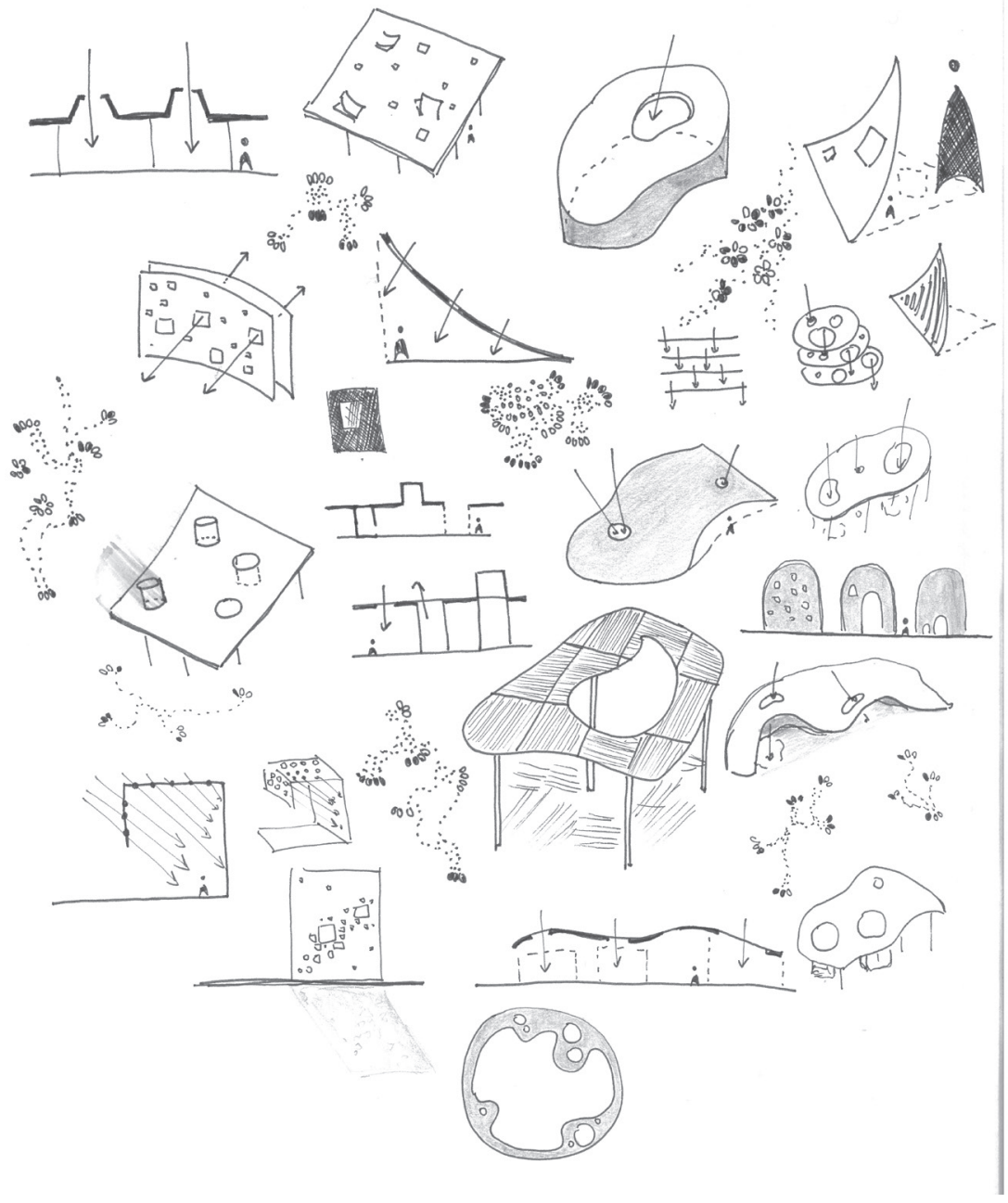

$\wedge$ 141. Solid and void drawing 195 
Solid and Void
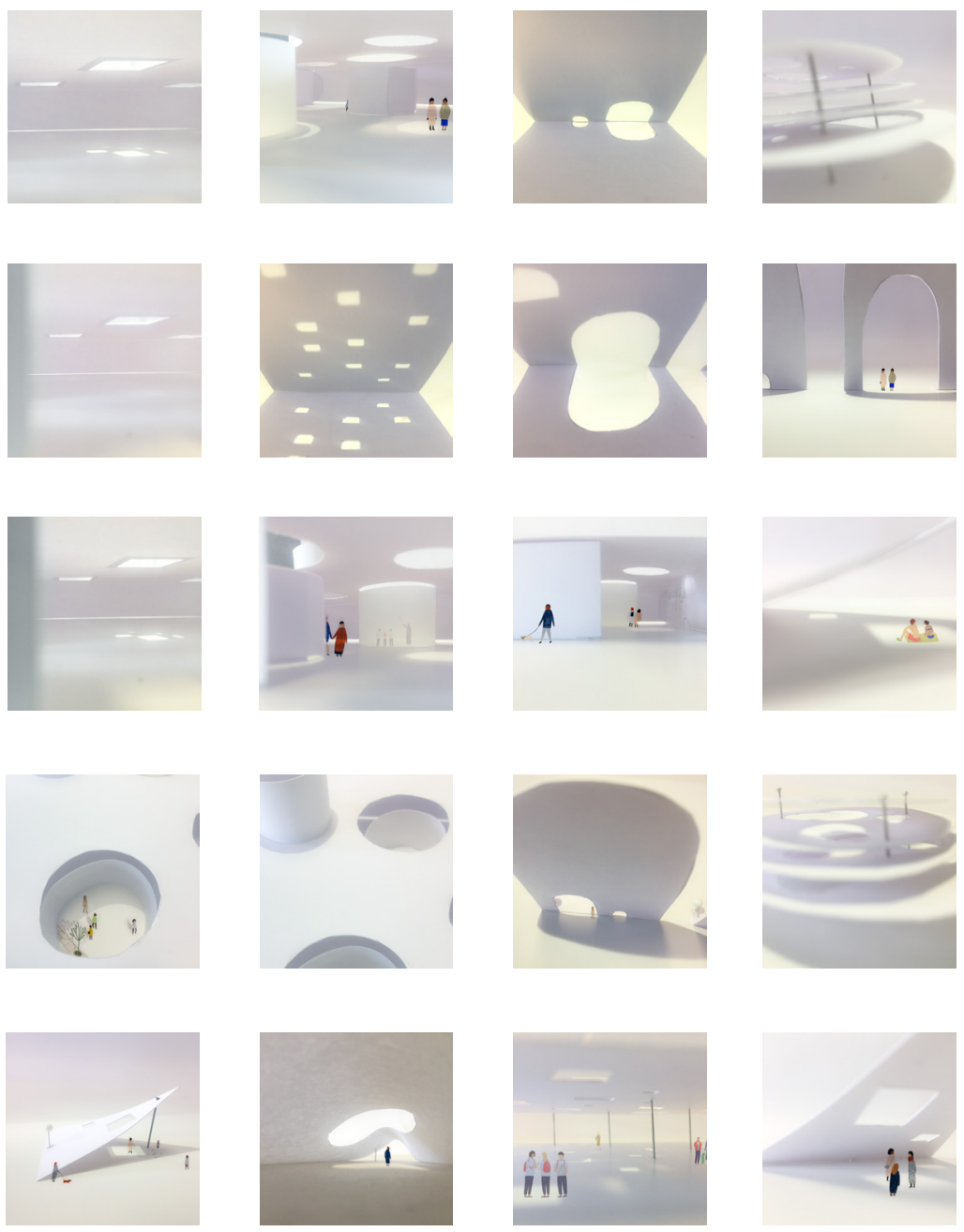
Solid and Void
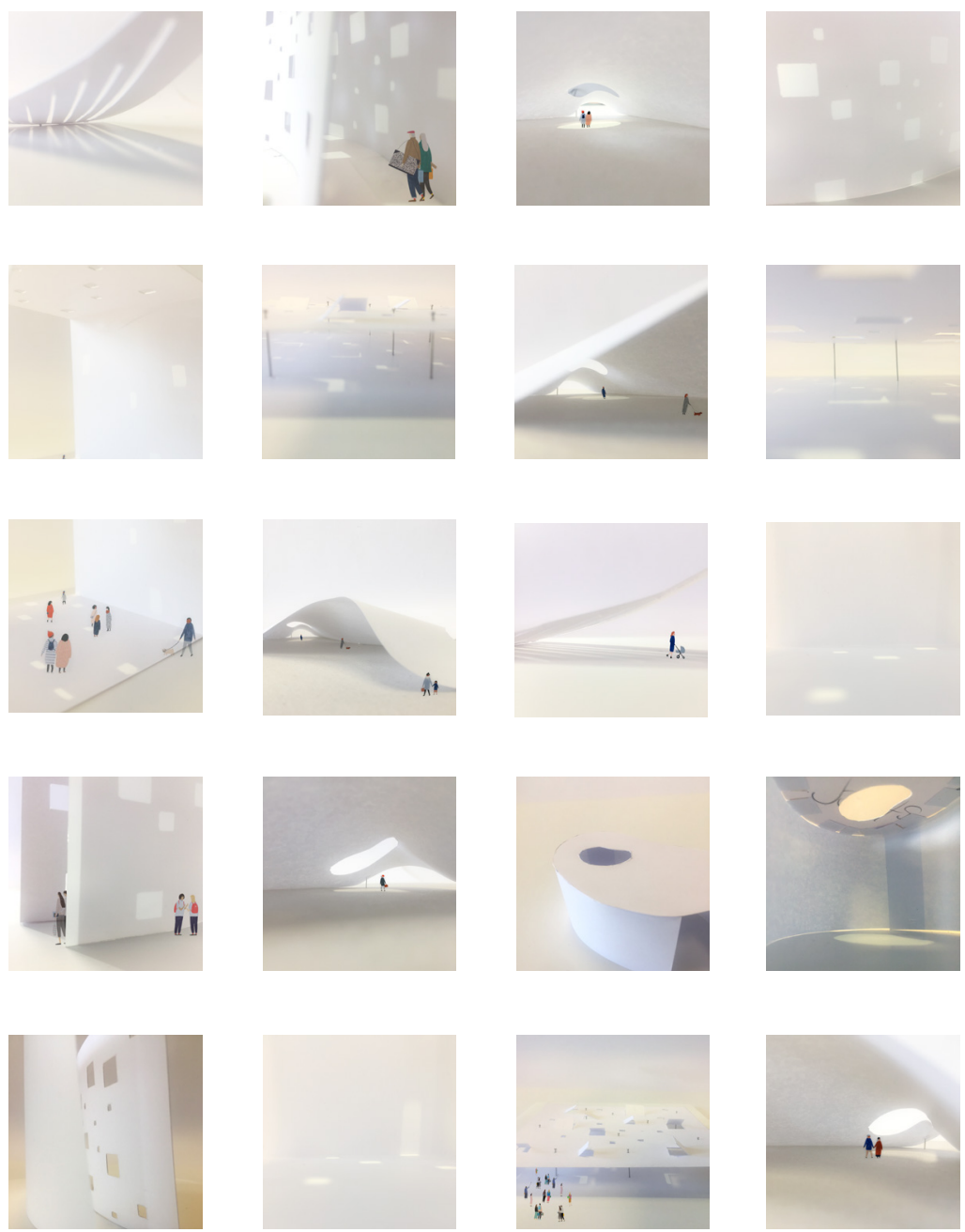

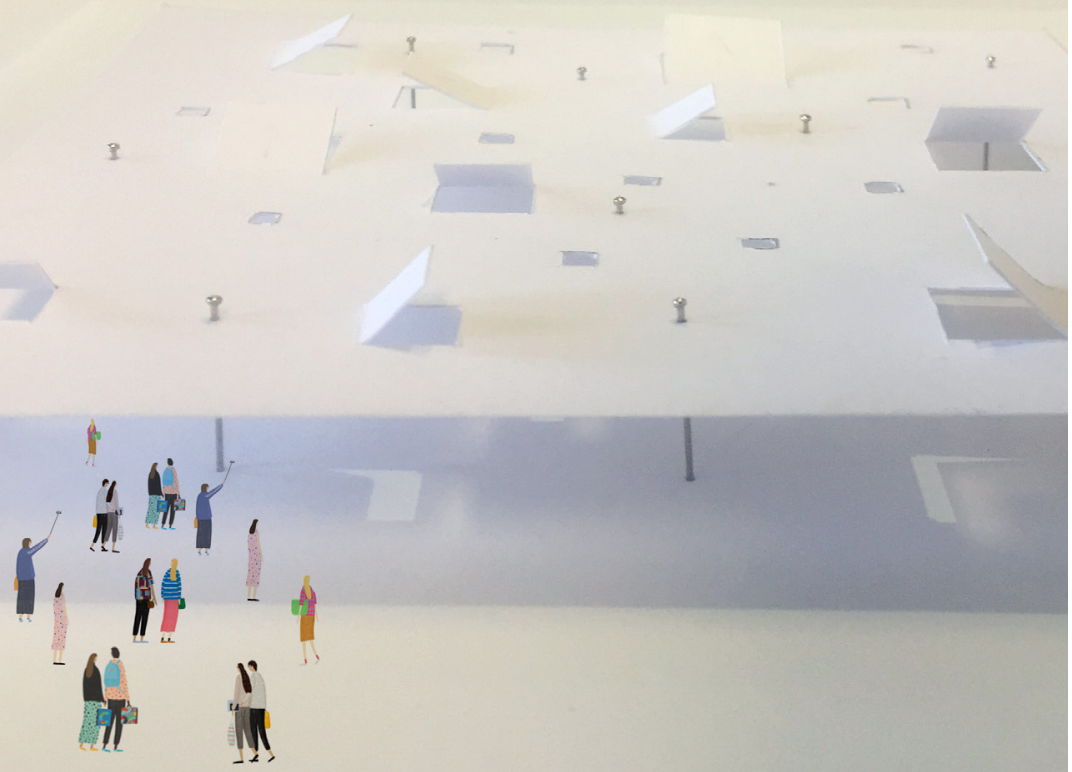

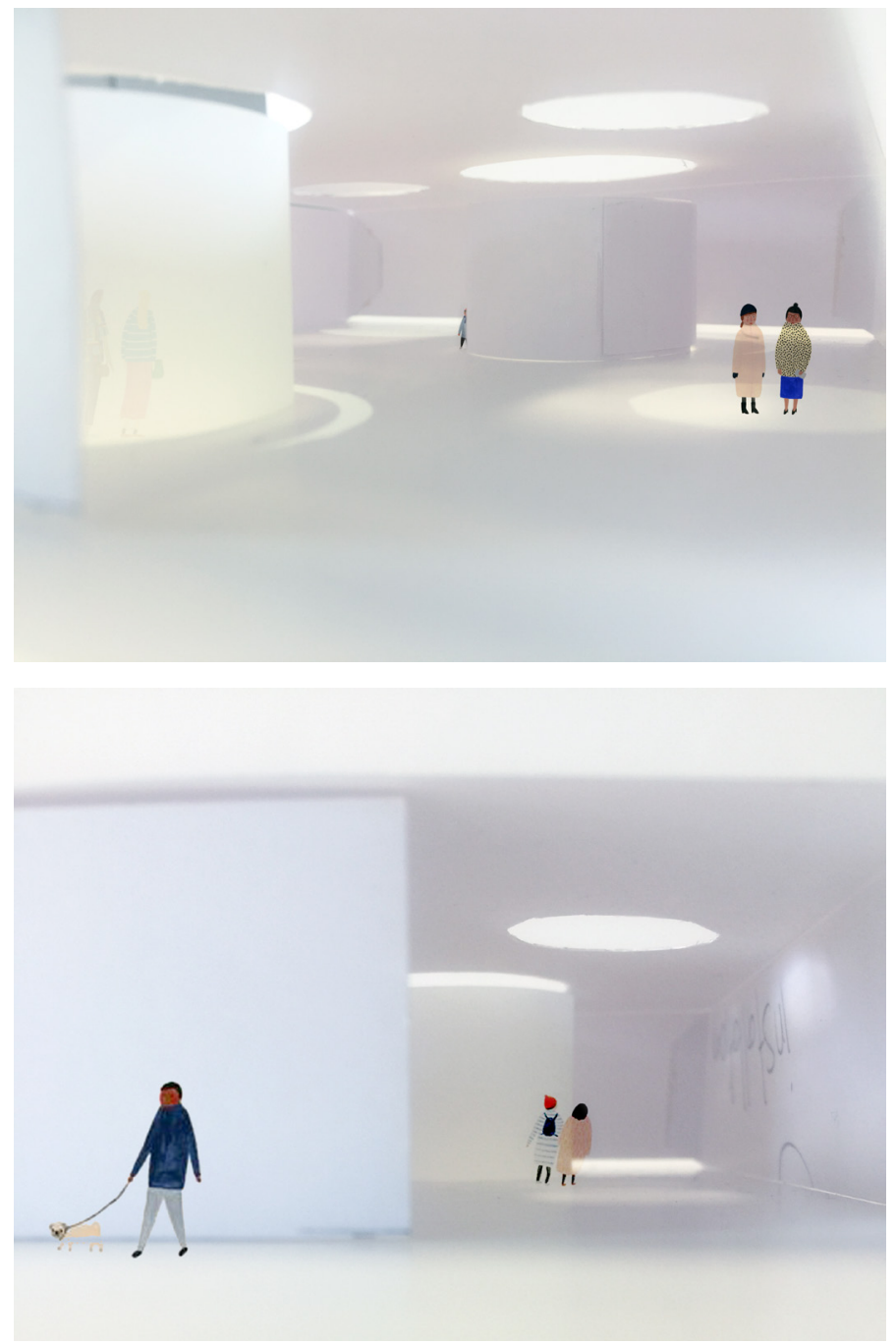

$\wedge$ 144. Interior void experience 




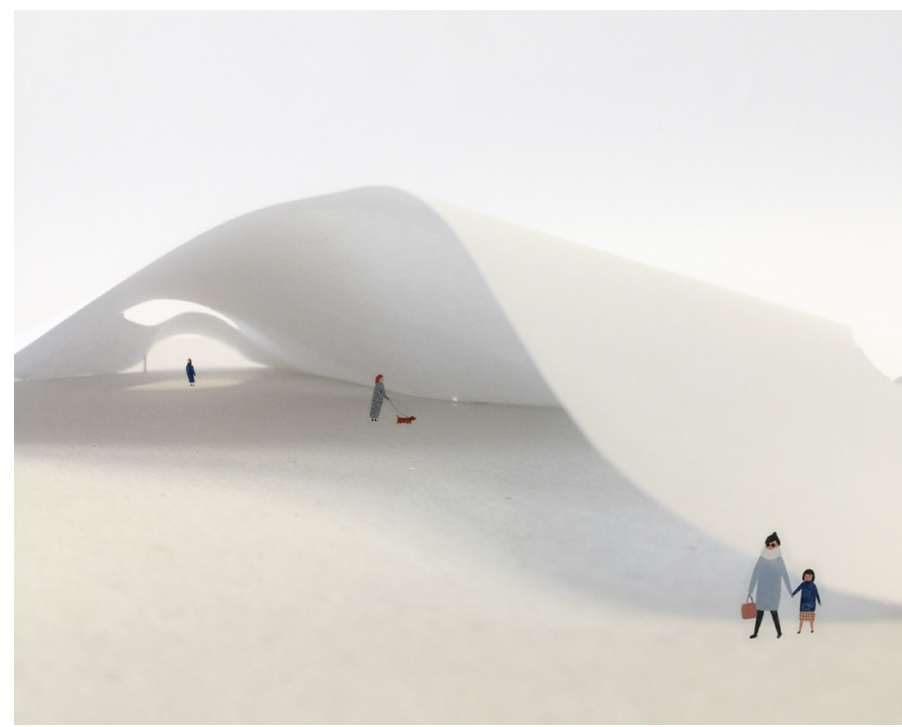

$\wedge$ 147. Solid and void simplified

\section{Evaluation}

A successful exercise to in considering interior conditions and light qualities. Many of the designs in this or the following explorations did not lead to further development, however through their evaluations they led to other discoveries in new directions that were not previously considered. Test three, four and five are all similar in the scale and methods they work at. The method of making small and sketchy paper models follows Yaneva's argument regarding OMA's practice. She argues, "the small model is employed simply as a means to encourage more thinking, it is considered abstract" (2005, p. 885). The success of these small models is their ease to shape quickly with few parameters and encourage inquiry and speculation rather than practical concerns. 


\section{Test Four}

\section{Aim}

Explore the notion of delicacy through large and small. Focus on shifting scales and consider the merge between furniture and architecture. Predominately consider form and occupation through drawing and physical models.

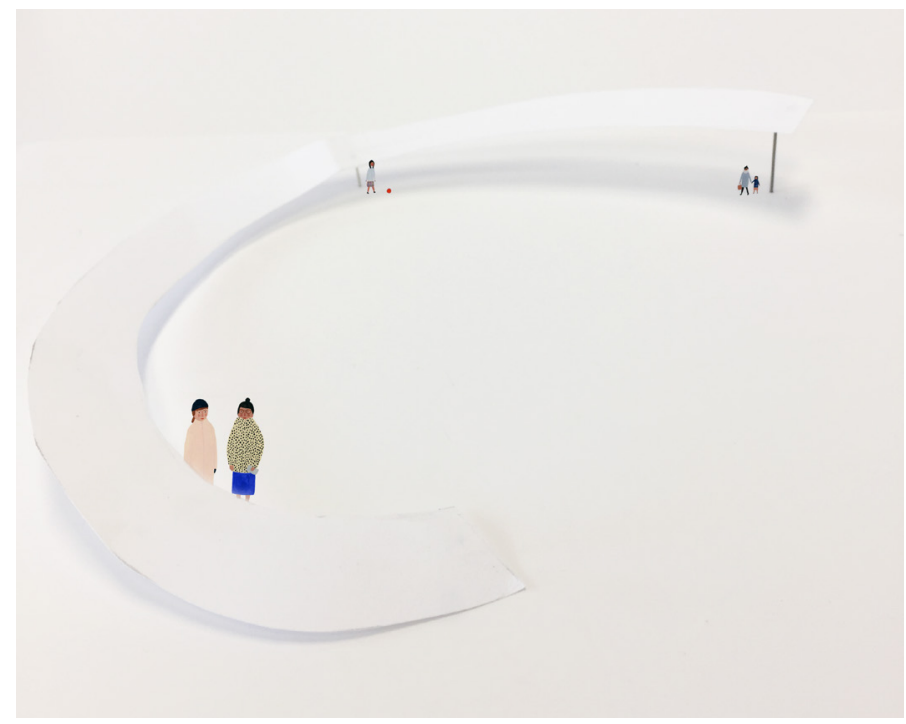

$\wedge$ 148. Bench scaled to structure 
3. Large vs Small
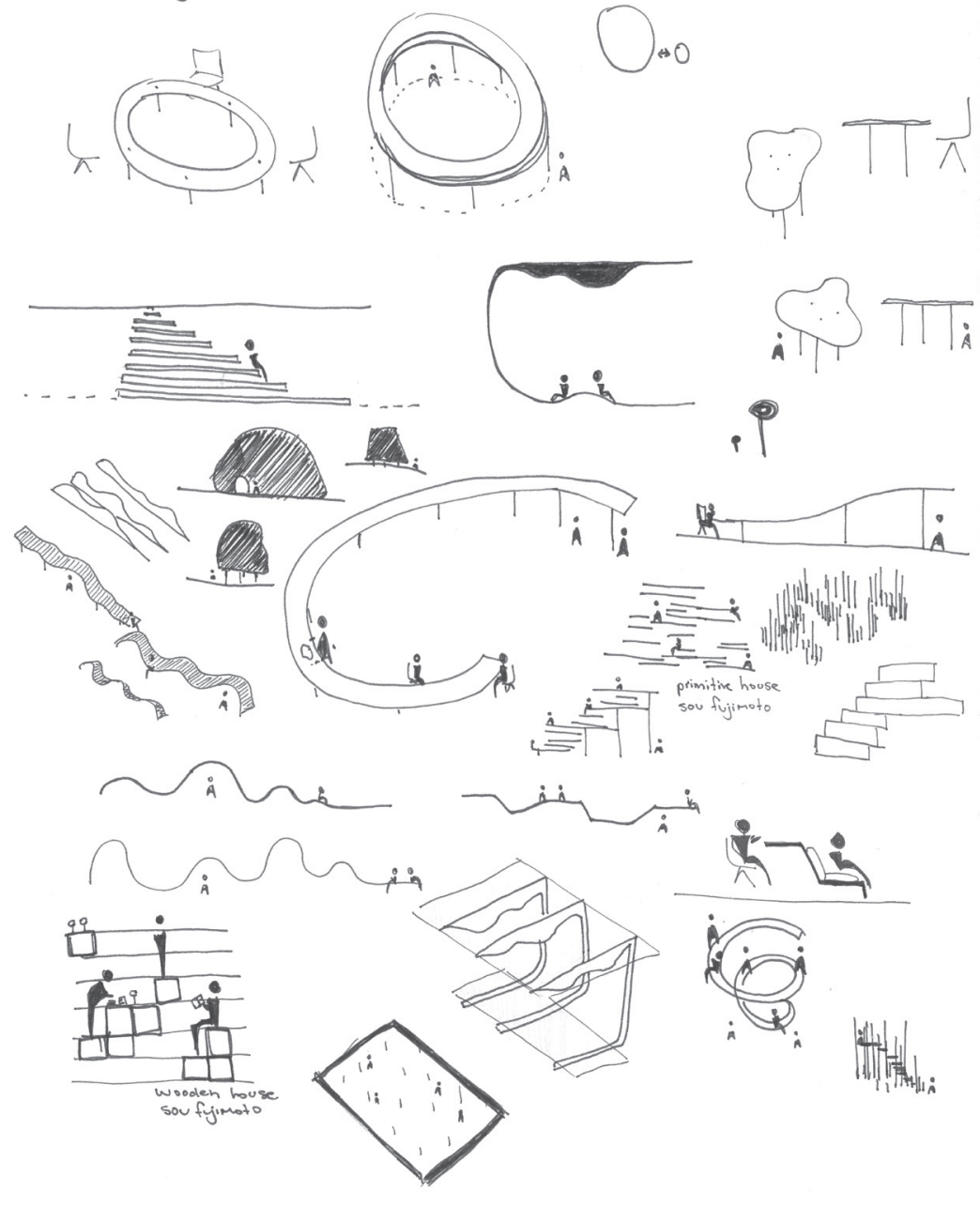

$\wedge$ 149. Large and small drawing 205 
Large and Small
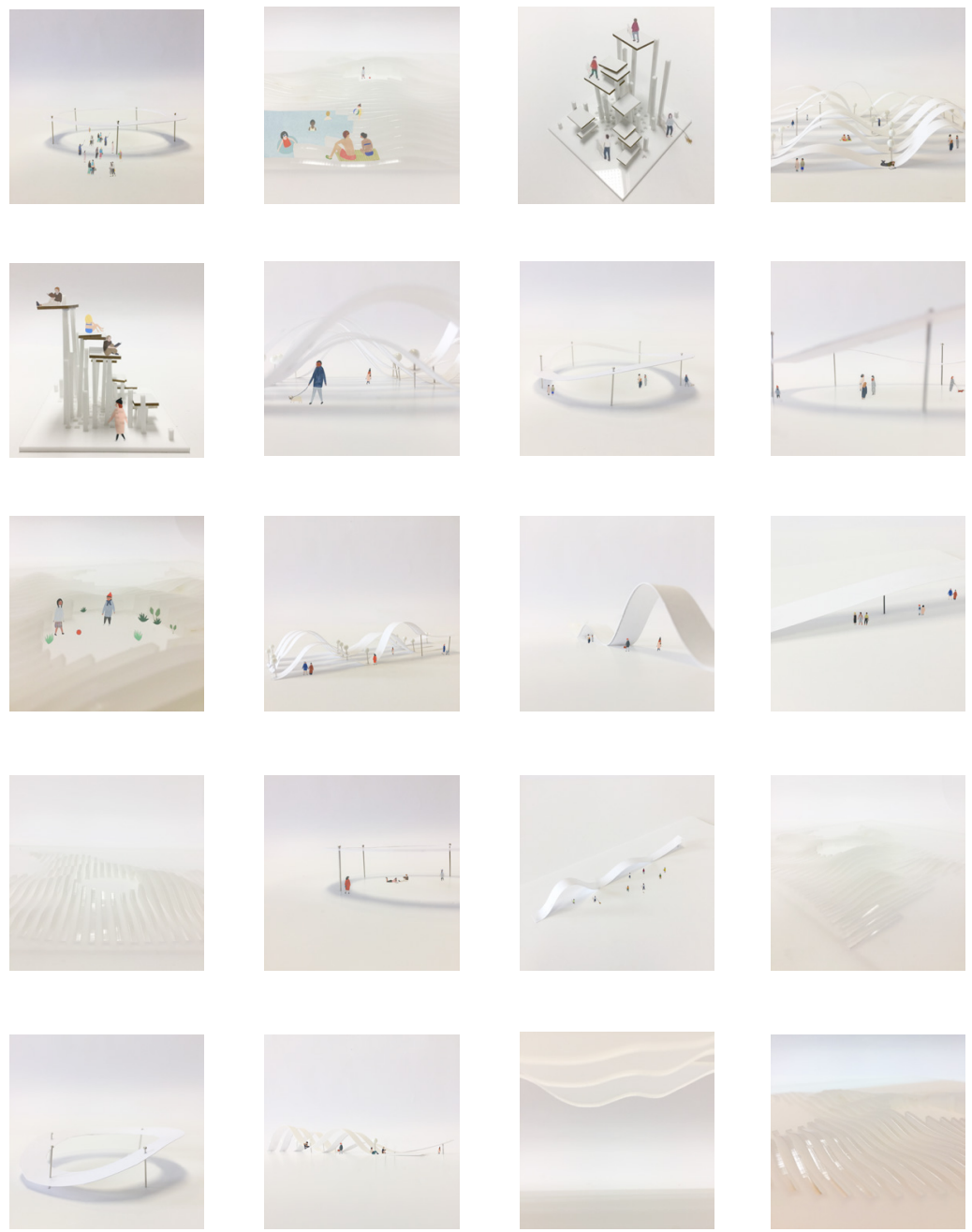
Large and Small
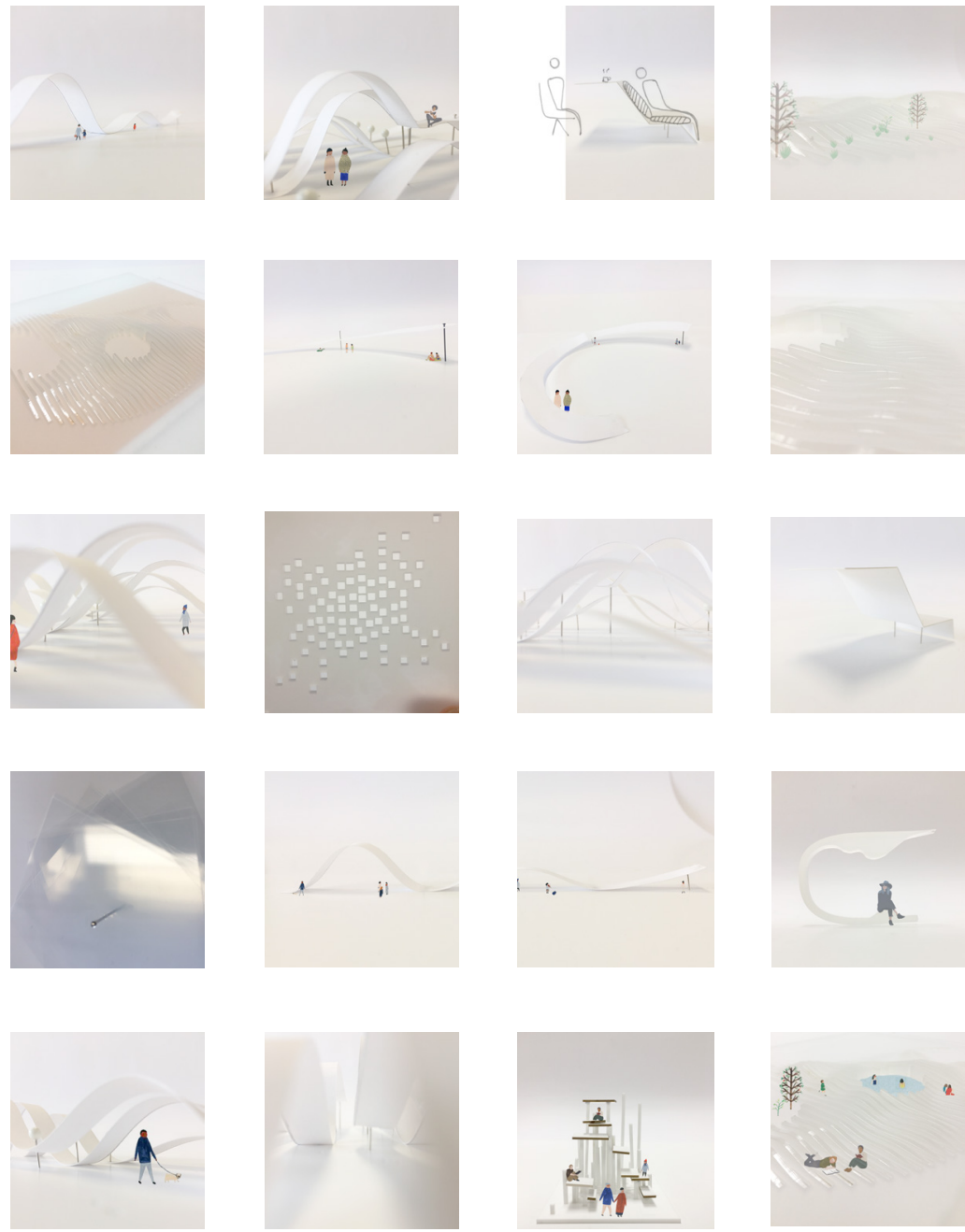


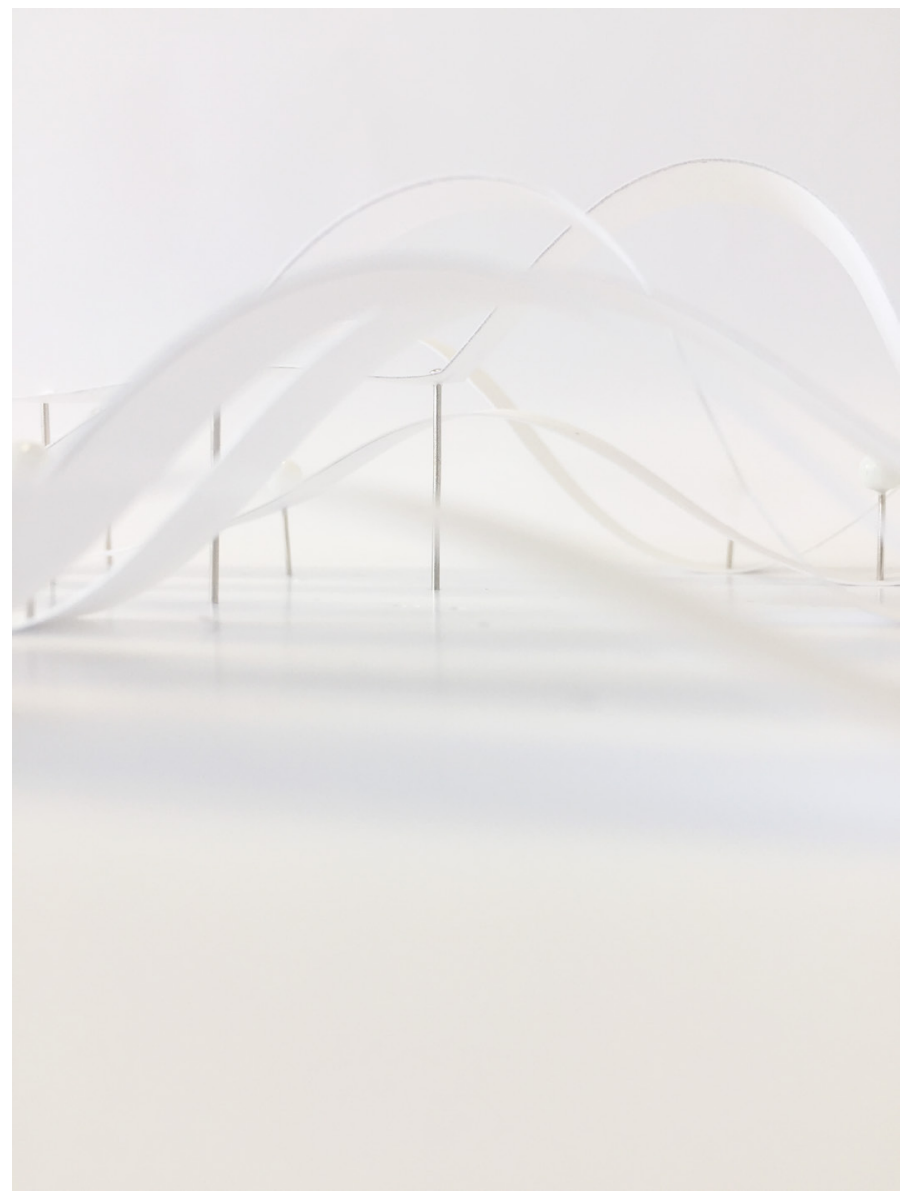

$\wedge$ 151. Undulating surfaces forming roofs, tables, seats and shelter 


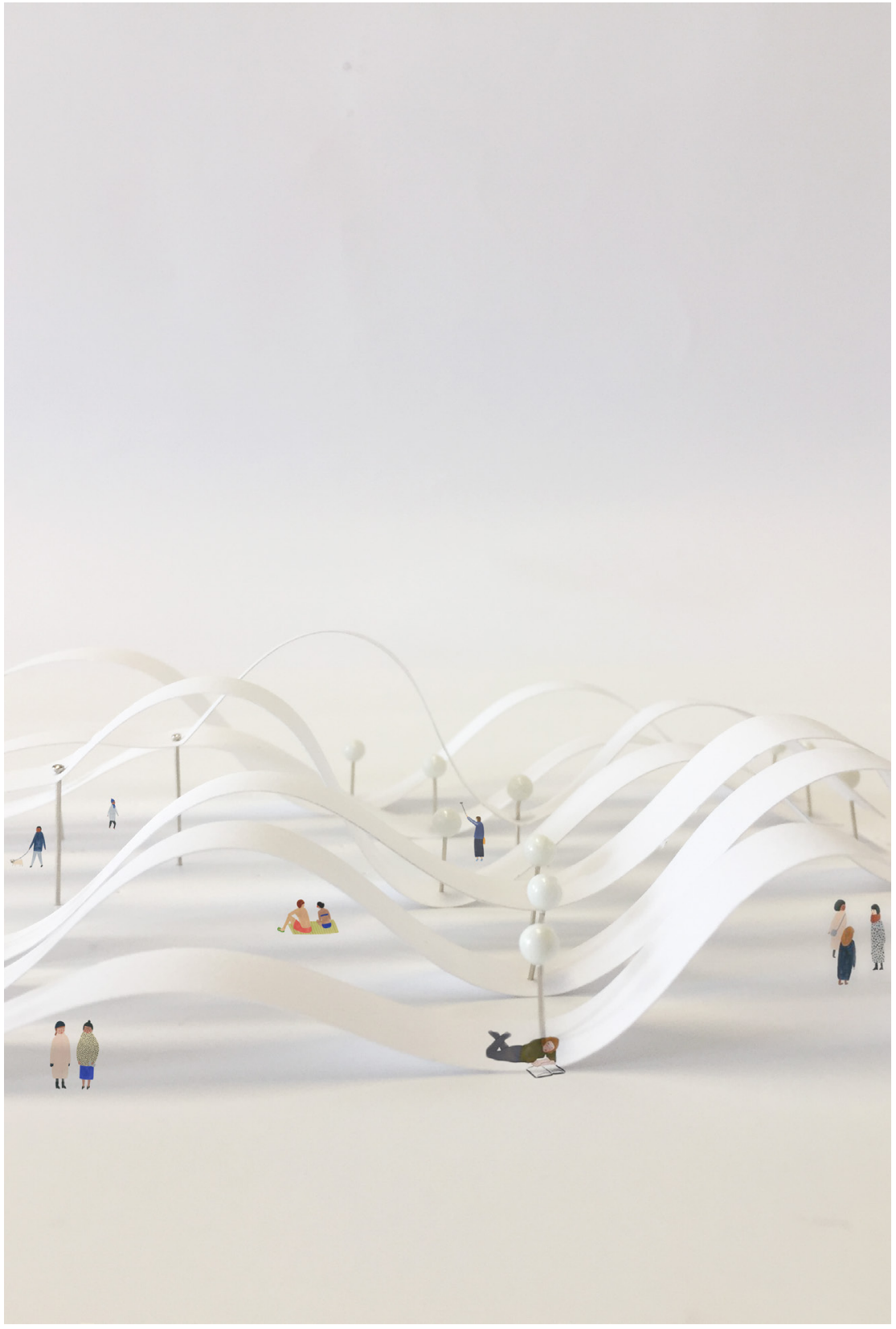


$\wedge$ 153. Undulating fins scaled up 

A

i)

iv
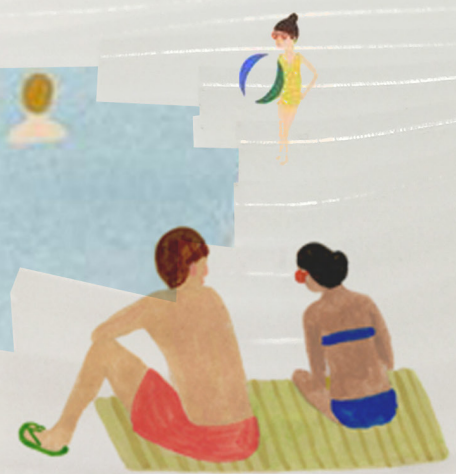


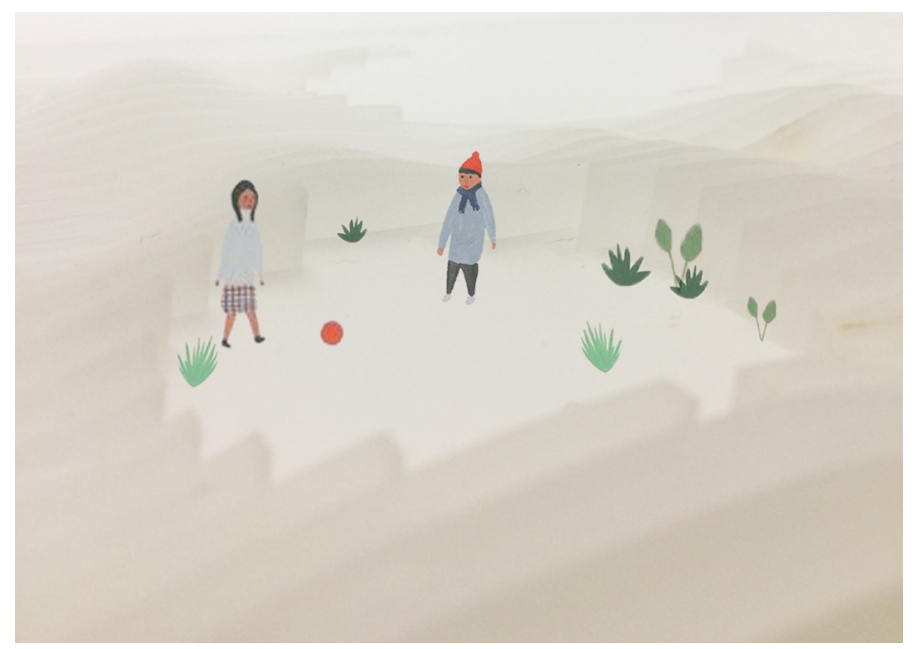

$\wedge$ 156. Occupation and interaction within a void

\section{Evaluation}

The idea behind this developed from the mid-scale furniture to building relationship, however, on reflection, this was not as successful as intended. Despite being a fast paced exercise, the sketches are more successful in quickly exploring this rather than the models. The physical models are simple and elegant but are not clear in expressing the aim. Despite this, there were some interesting discoveries unrelated to the aim, and these elements are later developed upon, such as the undulating landscape, a scaled up and mirrored version of the mid-scale fins. Another discovery was the consideration of the fins as structure and how it transitions to furniture. 


\section{Test Five}

\section{Aim}

Investigate the notion of delicacy through structure and skin. These two terms can be explored separately and together focusing on light, shadow, materiality and layers.

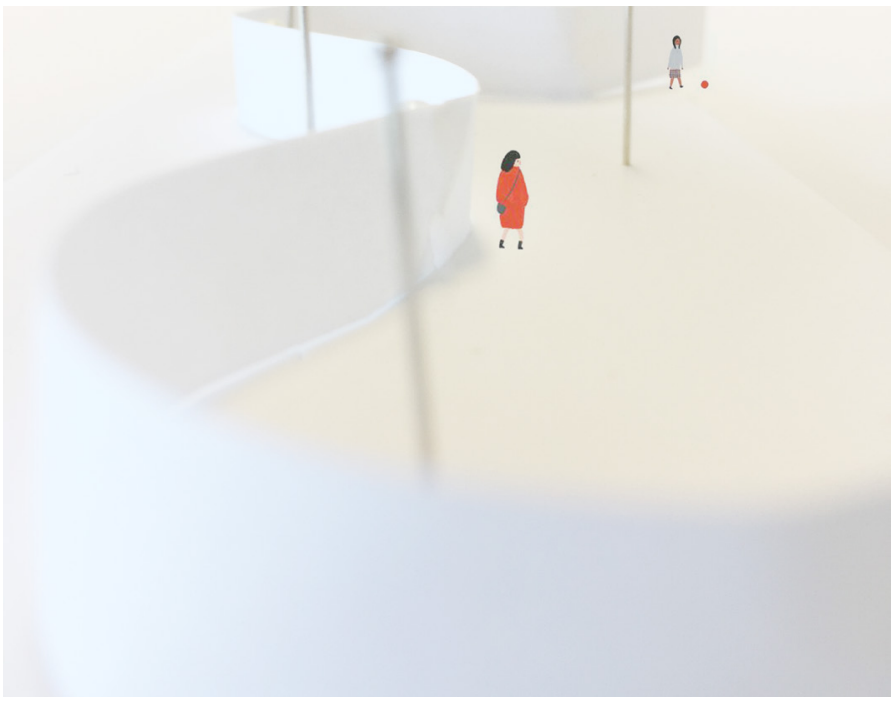

$\wedge$ 157. Wrapping and rigid 


\section{Structure vs Skin}
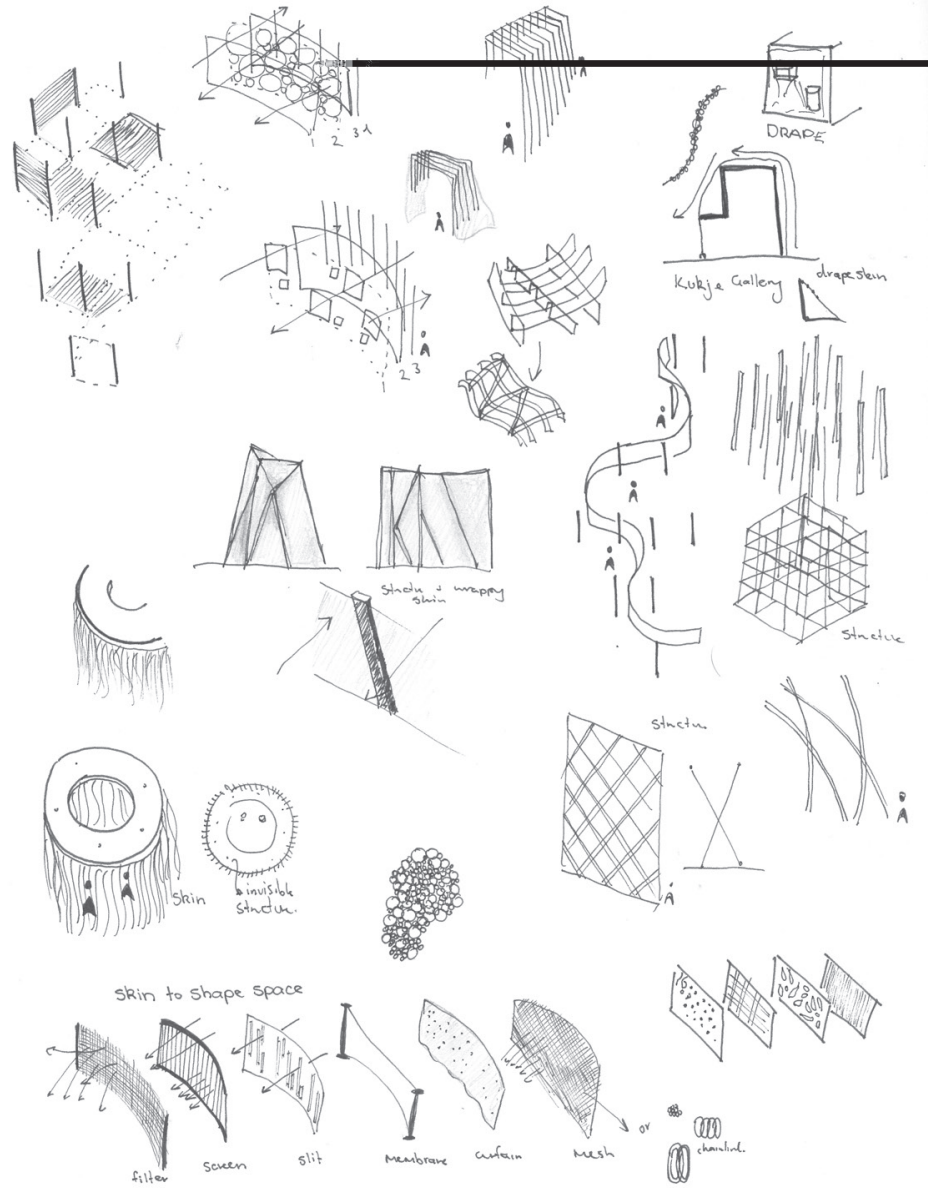


\section{Structure and Skin}
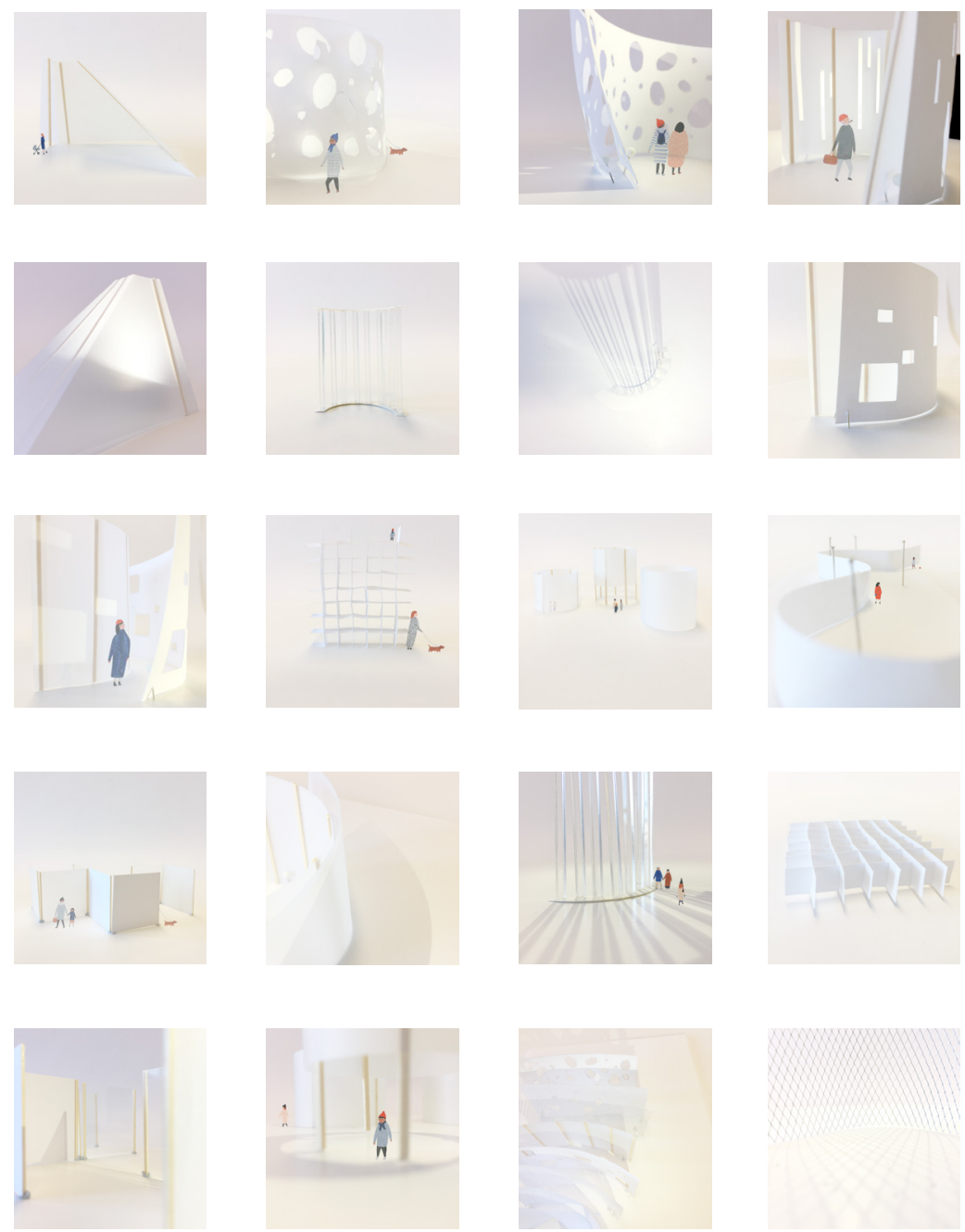
Structure and Skin
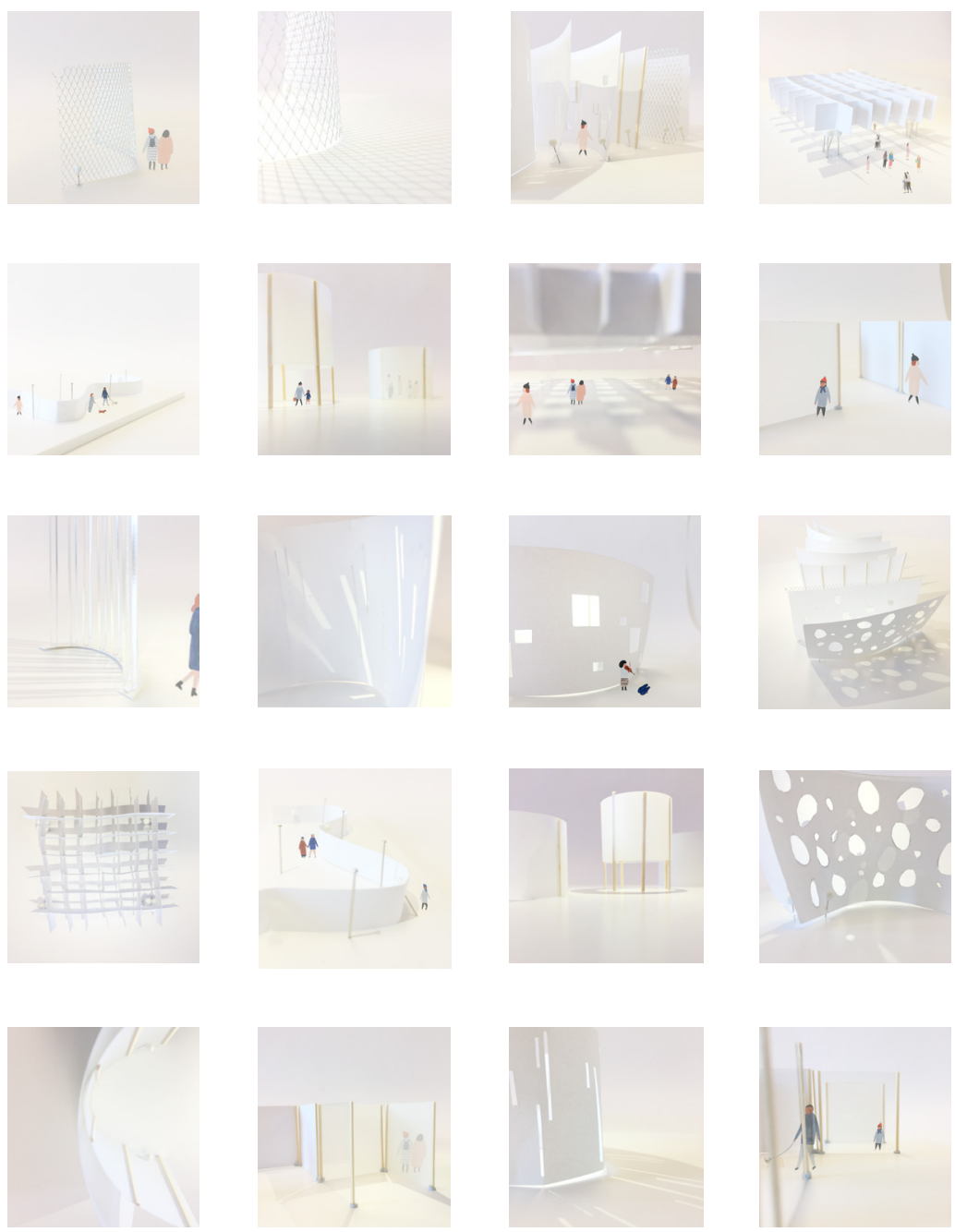


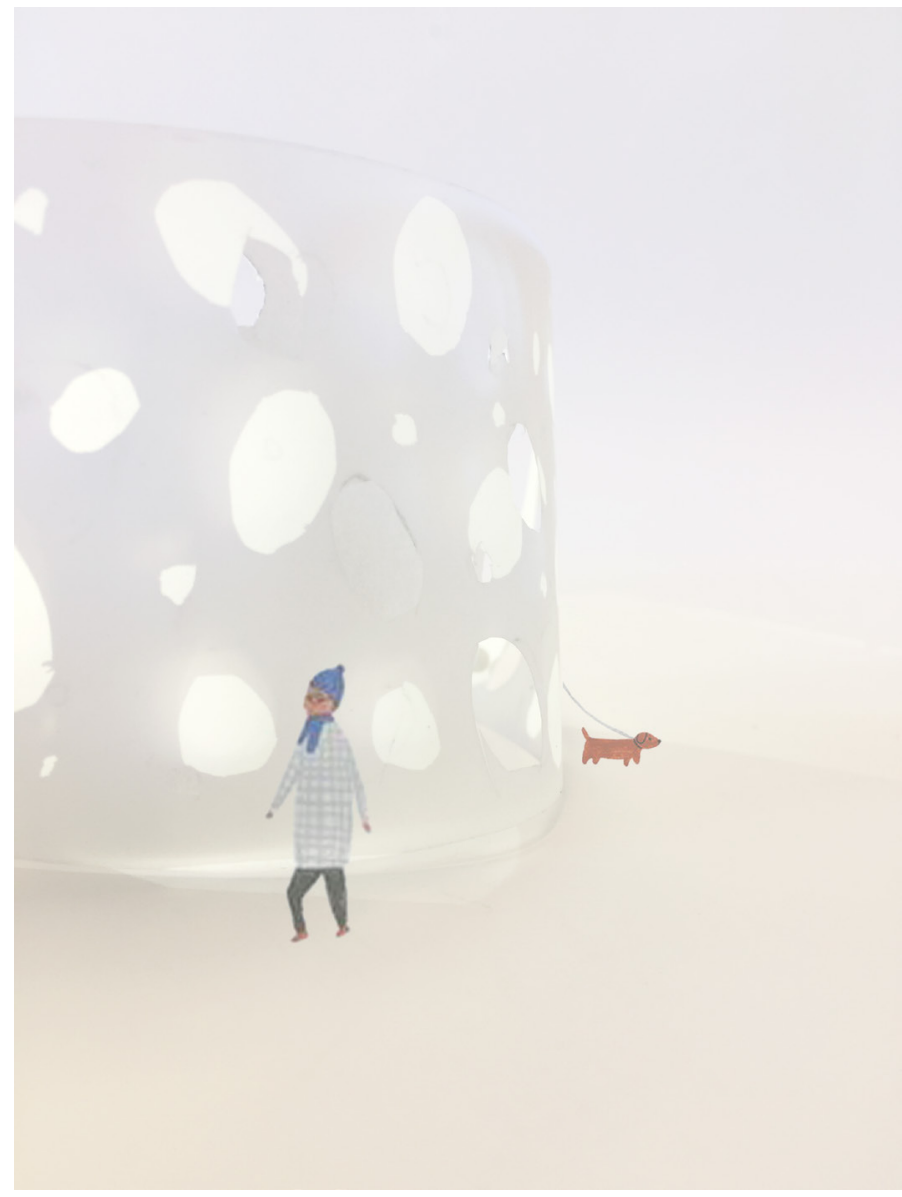

$\wedge$ 160. Lantern effect 


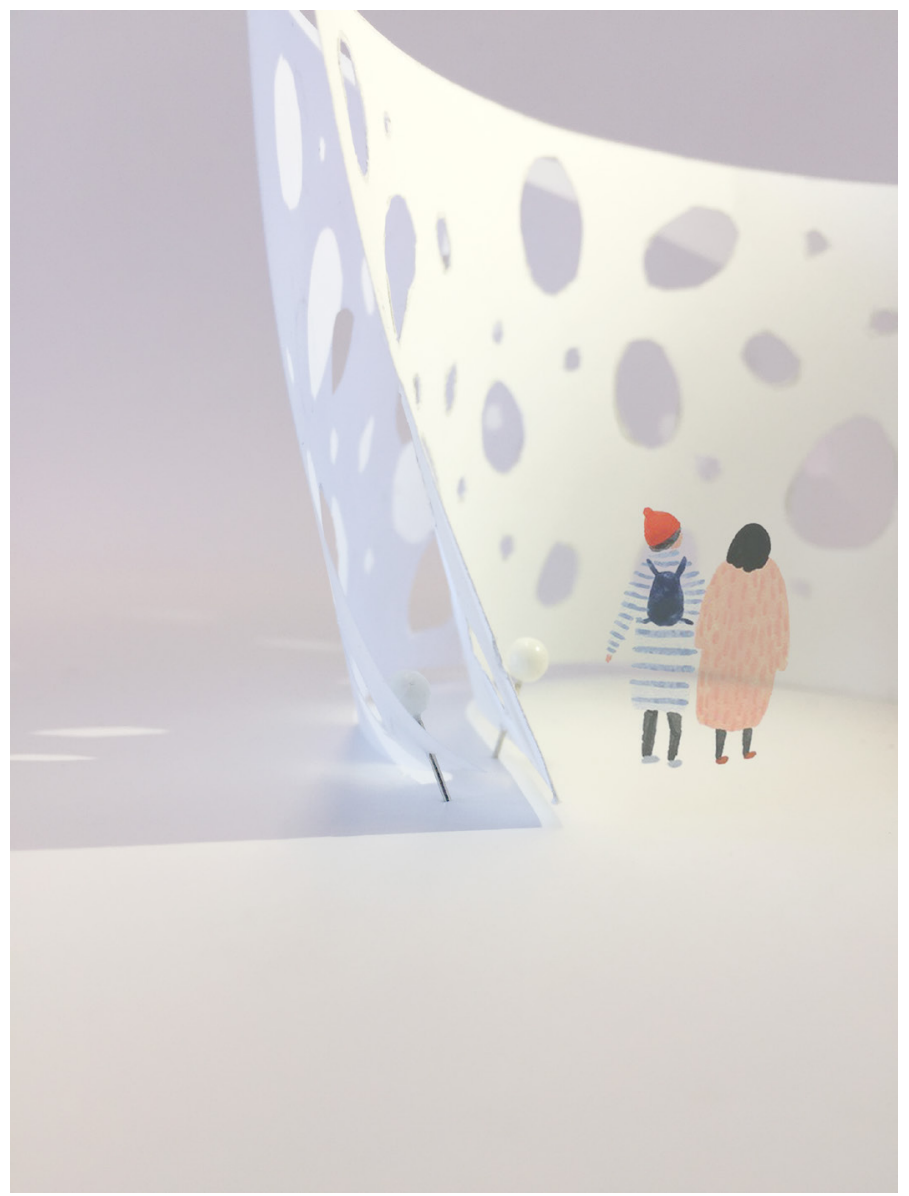

$\wedge$ 161. Layered surfaces and offset perforations 


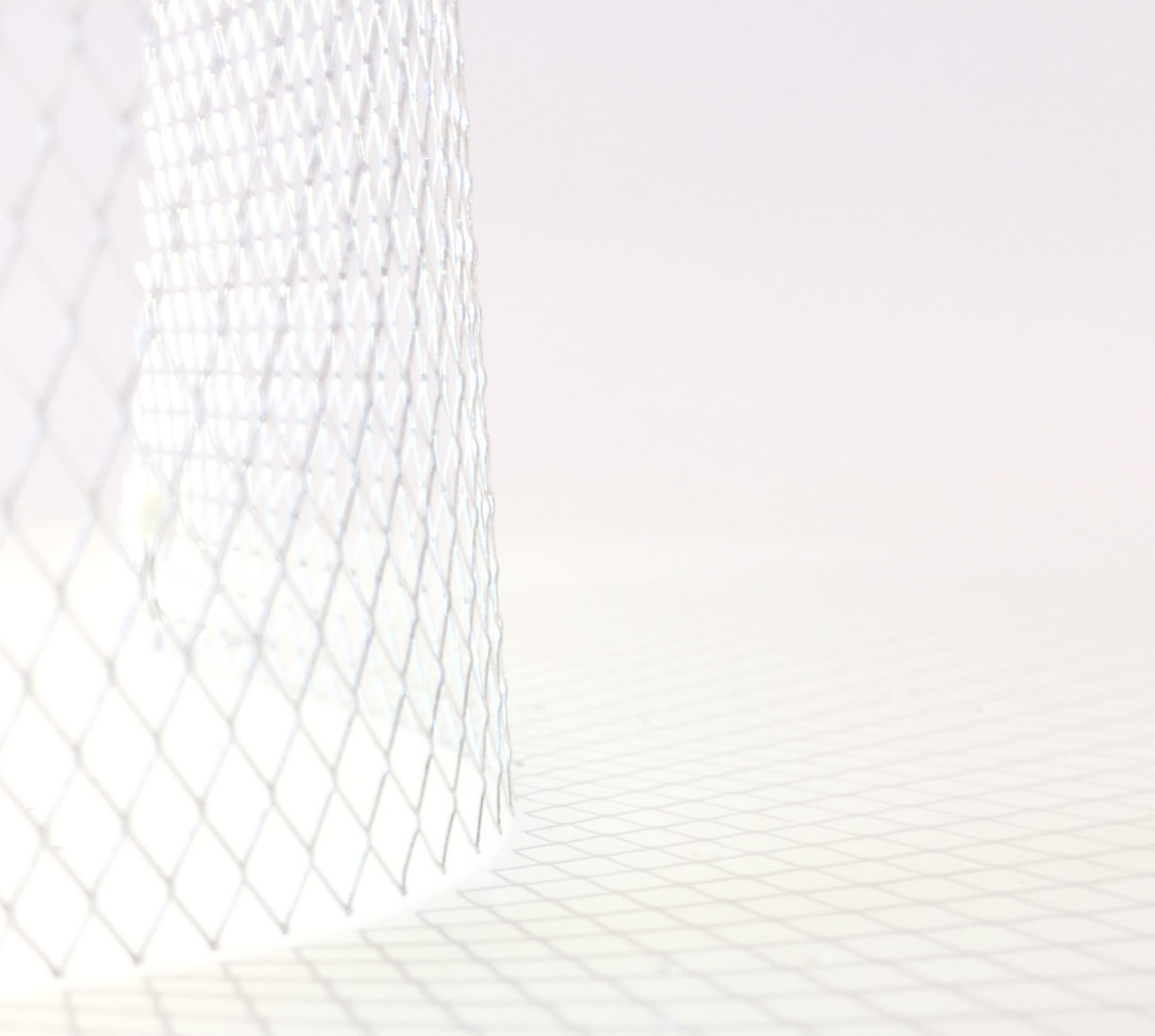




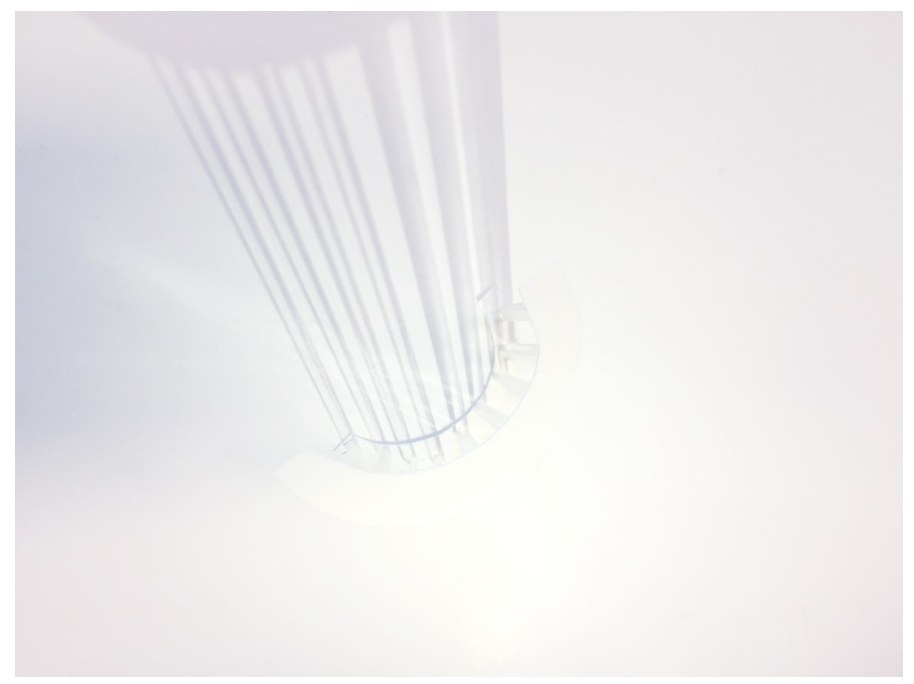

$\wedge$ 163. Clear acrylic screen

\section{Evaluation}

Another successful exploration in terms of quickly testing ideas through drawing and physical modelling. The 'skin' aspect was successfully investigated through exploring screens, filters, membranes, mesh, slits and levels of transparency. The 'structural' aspect however was a weakness. The use of paper limited this area of exploration. The consideration of structural would be more successful later in the development process as it deals with more practical concerns. There is an evident interplay between tests three, four and five. A clear vocabulary was distinguished from these explorations, and the further developments made translated these ideas into an architectural design. 


\section{PROGRAMME}

The following design inquiry was informed from the reflections in chapter four regarding programme and is potential to influence design. Thus for the gallery, I analysed relevant galleries and a few other public buildings, investigating scale, circulation and function. These examples helped determine my own spatial sizing in relation to the scale of my site and requirements. The following pages explore programme influencing and driving form.

$$
\begin{aligned}
& \text { Program Considerations NoTES } \\
& \text { Community centre } \\
& \text { - San vicente fener commumly centre } \\
& \text { - towada community plaza } \rightarrow \text { Kengo Kuma } \\
& \text { ivi-i autrieal landscape inside } \\
& \text { - Grace Fams msanaa } 20 \\
& \text { galley } \\
& \text { - Austualian centr for conterporary aut (ACCA) } \\
& \text { - Kukje Galley } \rightarrow \text { SO-lL } \\
& \text { - Toledo Muserm - Glass Pacillion a SANAA } \\
& \text { - Loune-lens } \rightarrow \text { SANaA } \\
& \text { - } 21 \text { st centur museur of art Kanazawa } \rightarrow S \Delta N \Delta A \\
& \text { Pavilion } \\
& \text { - Korogan Pavilion } \rightarrow \text { Assistant } \\
& \text { - Floating Pacilion } \rightarrow \text { Shen Ting Tseng } \\
& \text { - Viethankese Food Pacilion } \rightarrow \text { MIA Design Studio } \\
& \text { - Serpentive Pacilion } \rightarrow \text { SANAA } \\
& \text { public space } \\
& \text { - Nautilus o TEN+NaOCAty ereative } \\
& \text { - Undergrond Parhing Katwijk aan zee } \\
& \text { - Rolex leaming centre } \rightarrow \text { SANAA } \\
& \text { - KAIT kangawa institute of technology sJunya ishigami }
\end{aligned}
$$




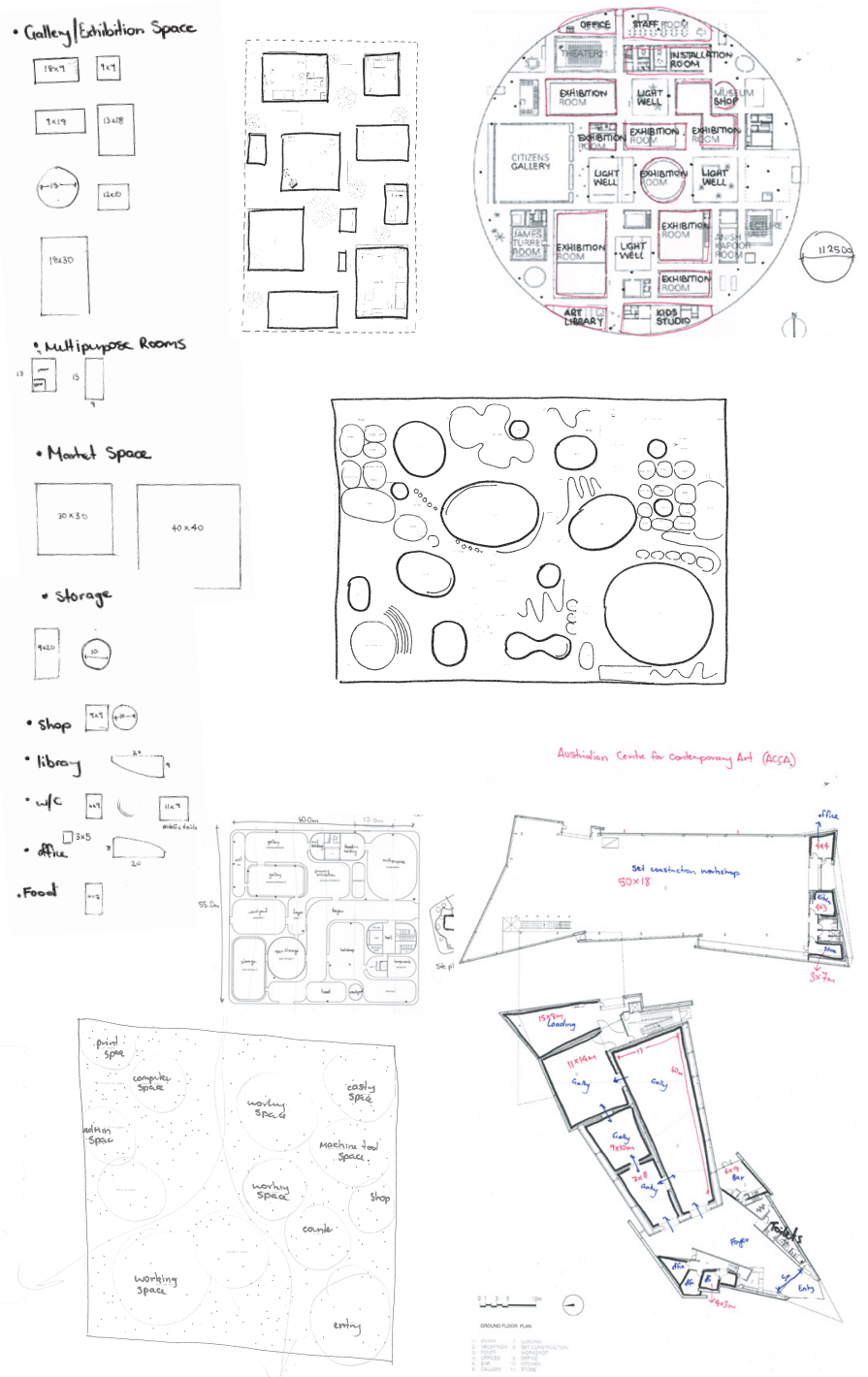


Programme is used as a generator in this research. It was an exploratory tool to help generate spatial solutions that investigated delicacy alongside considering practical concerns. This stage in the design process reintroduces site signalling a shift towards investigating pragmatics. The programme primarily consists of a gallery and community centre. There is also additional park and landscaping considerations. The programme helps activate the site and add to the waterfront with public events and activities such as markets, youth group gatherings, small performances, retail and exhibitions.

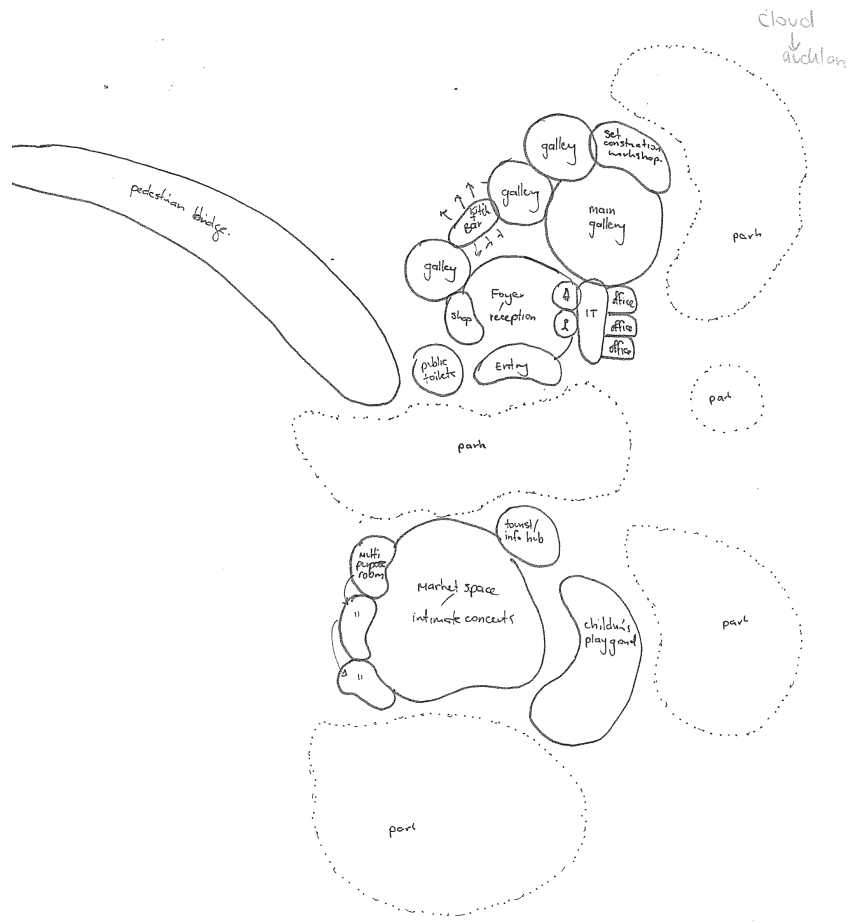



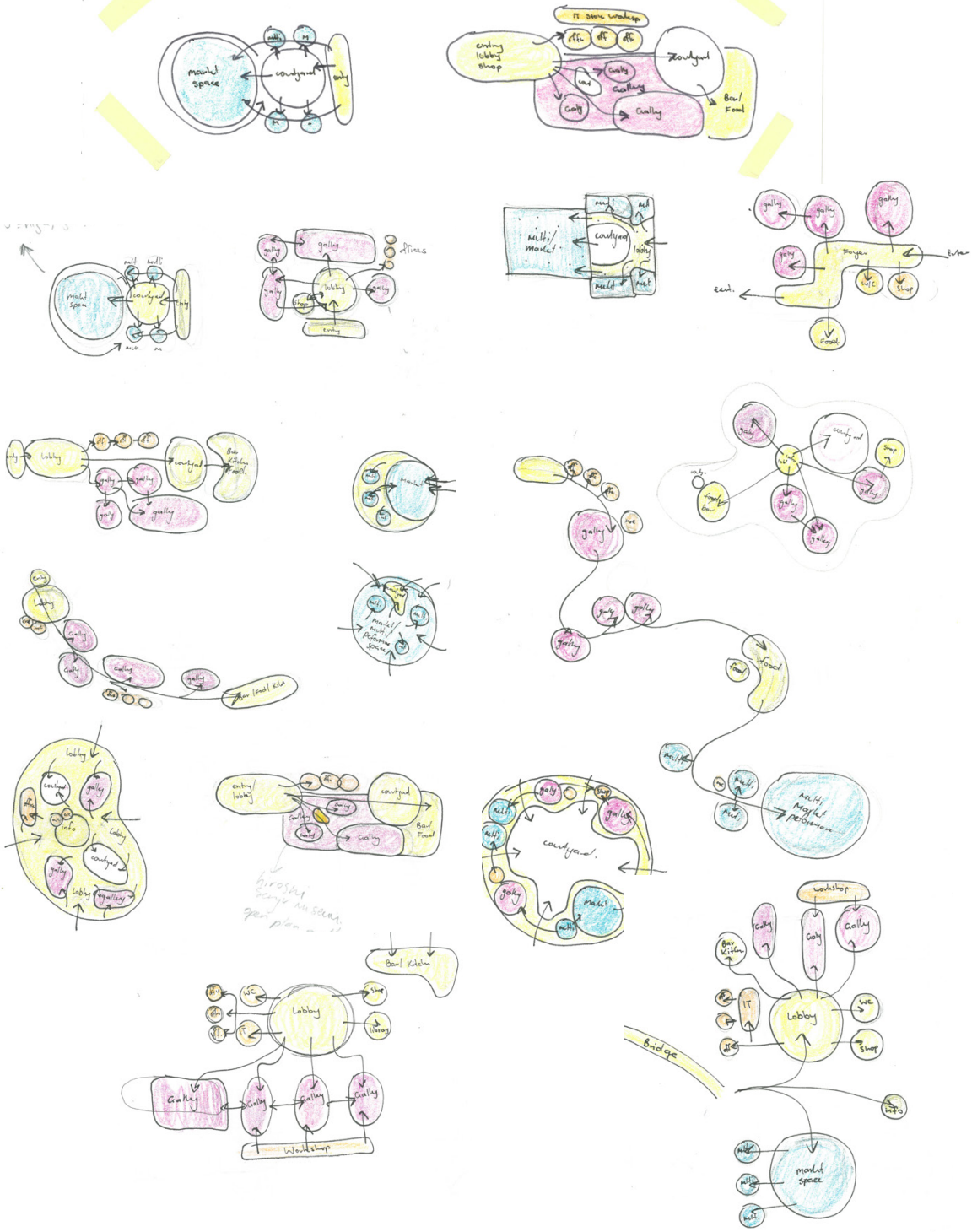

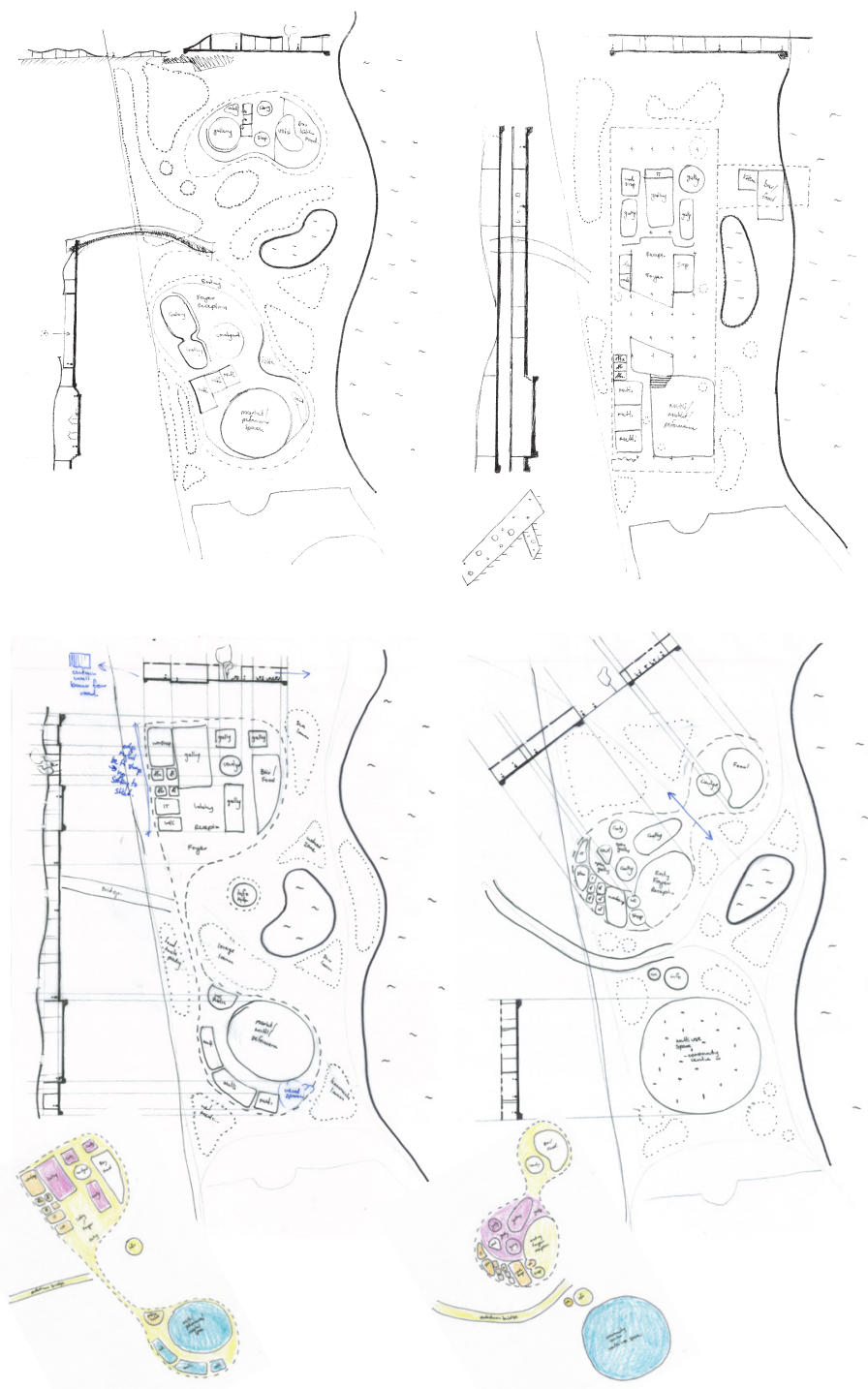

$226 \wedge$ 168. Program diagrams integrated on site 
The programmatic diagrams led to the investigation of spaces within spaces, encouraging free informal movement. These were then scaled and moulded with site, shaping the design together. Through this process there was a period of being 'stuck' and finding the explorations lacking engagement or potential. To shift direction, test two was re-introduced with the added pragmatics of site and programme, which lead to the subsequent design developments.

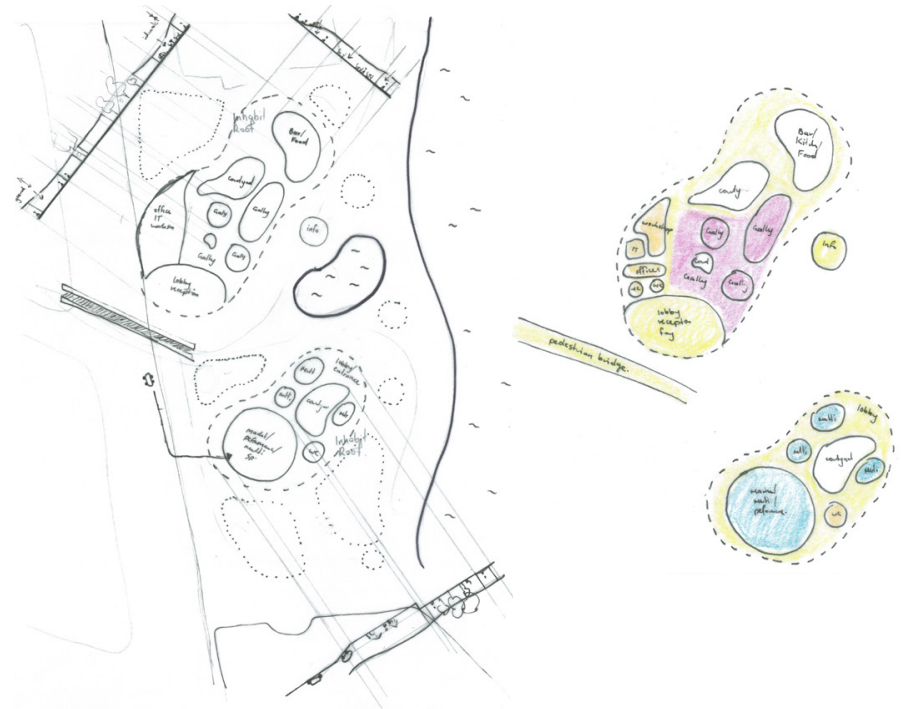

$\wedge$ 169. Scaling up mid-scale with pragmatics 


\section{DEVELOPMENT}

The public-scale developed upon what was discovered and experimented in the installation and mid-scale stage. Further ideas were tested and explored regarding how to approach delicacy, site and programme.

The selected envelope offered as a base which was then developed upon into a building that responded to the proposition for the August Review.

The site's hard urban edge and linear lines provide a valuable contrast for the curvilinear language I proposed. Delicacy in architecture is able to read more clearly in relation to something more brutalist in comparison, which is what the site's context provides. As discussed in chapter two, scale is able to provide a similar contrast accentuating delicacy. Kirk argues, the "fine becomes finer" adjacent to the "coarse and plain" (2007, p. 26). Another example of delicacy highlighted through contrast is through the consideration of materials. Kubota Architect Atelier "combines delicately tapered surfaces with sturdy concrete walls" in their design of FU House (Griffiths, 2017, np). The architects contrast wafer thin edges next to large panes of concrete which in turn makes the delicate appear more delicate. 
Initial master-planning

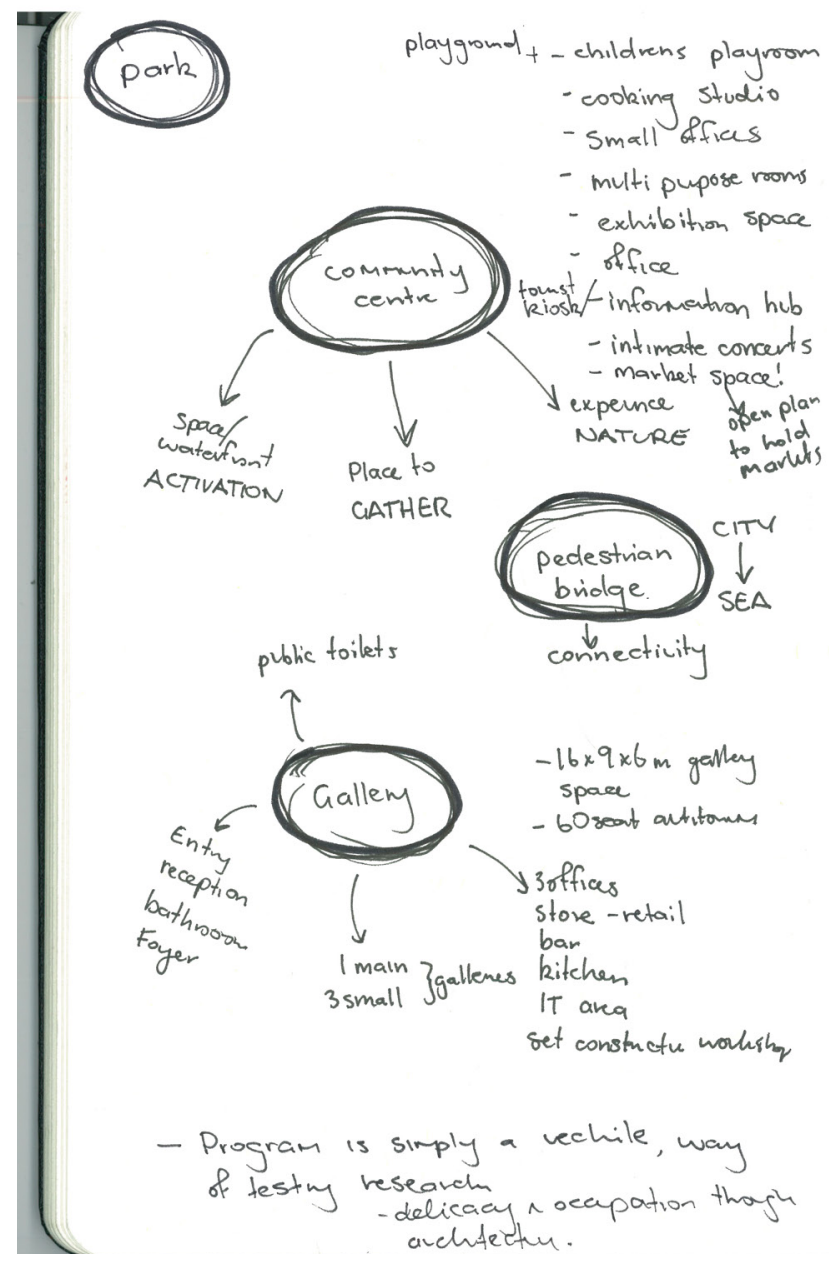


The Building

The design is developed through drawing, predominantly in plan and section. Light, colour, structure, slope, connection details, materials, circulation and roof access are all considered and developed upon.

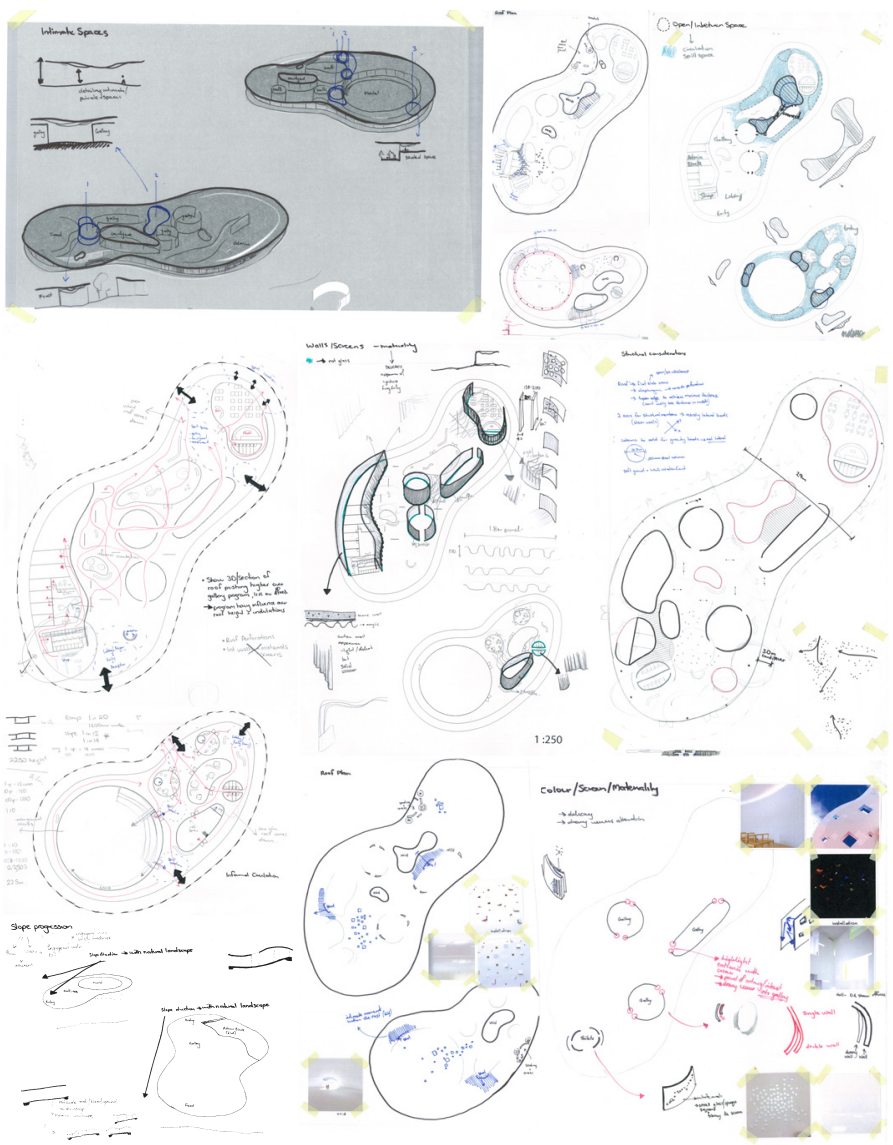

$\wedge$ 172. Developing the design in plan 


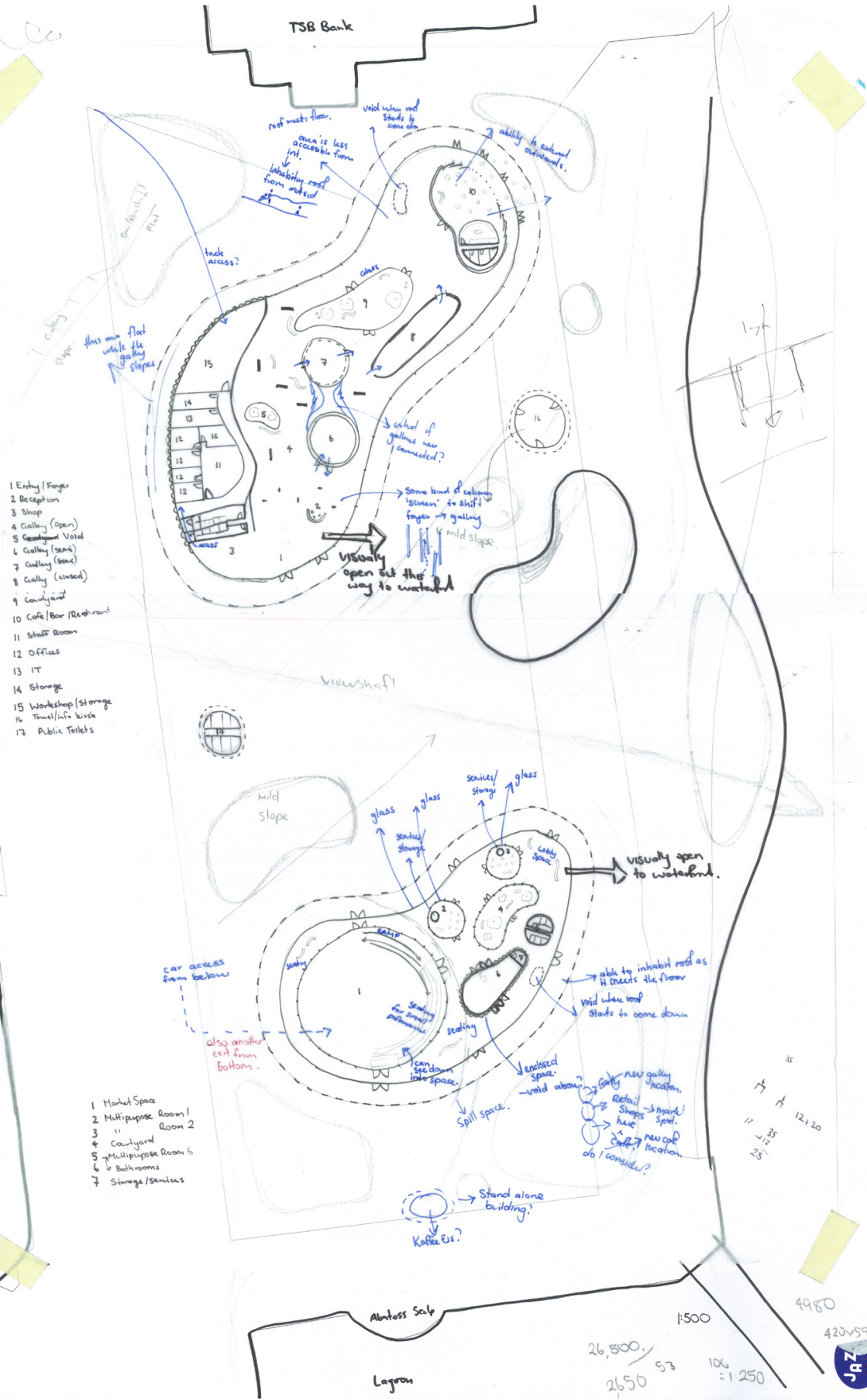


Working in plan

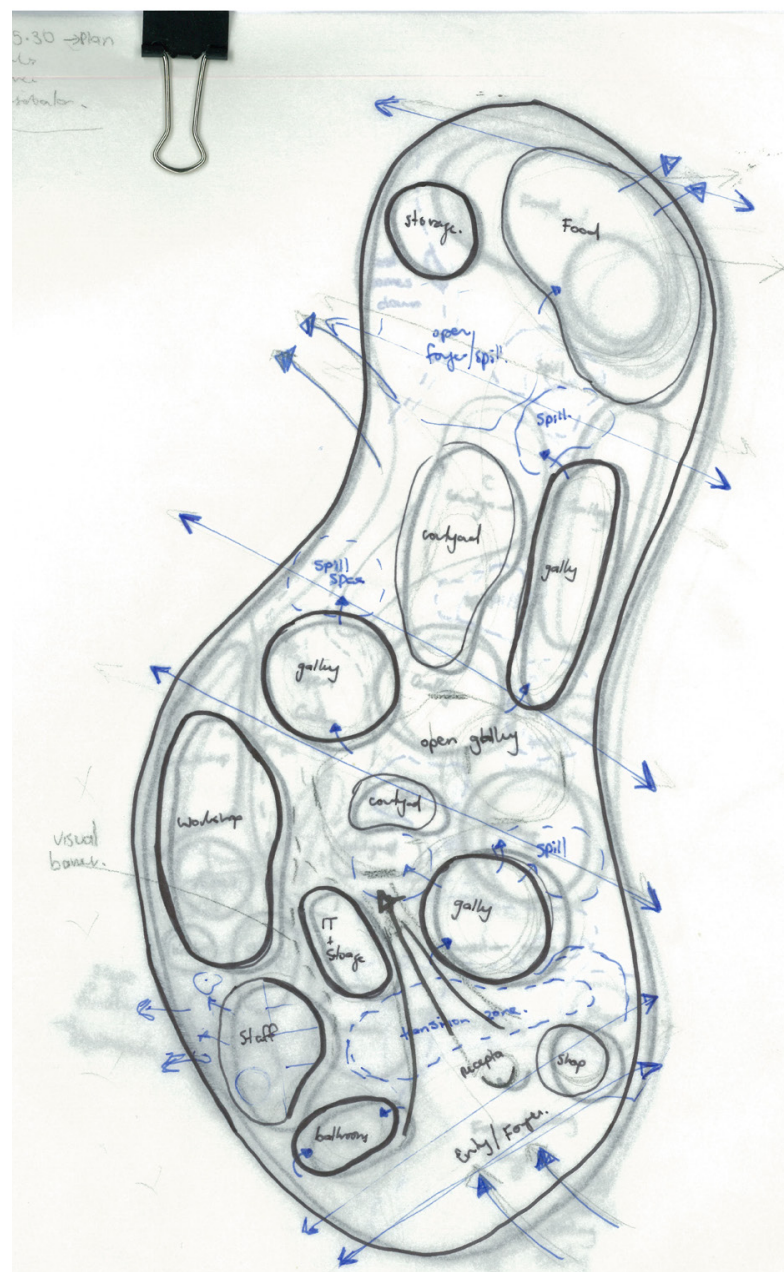


Working in plan
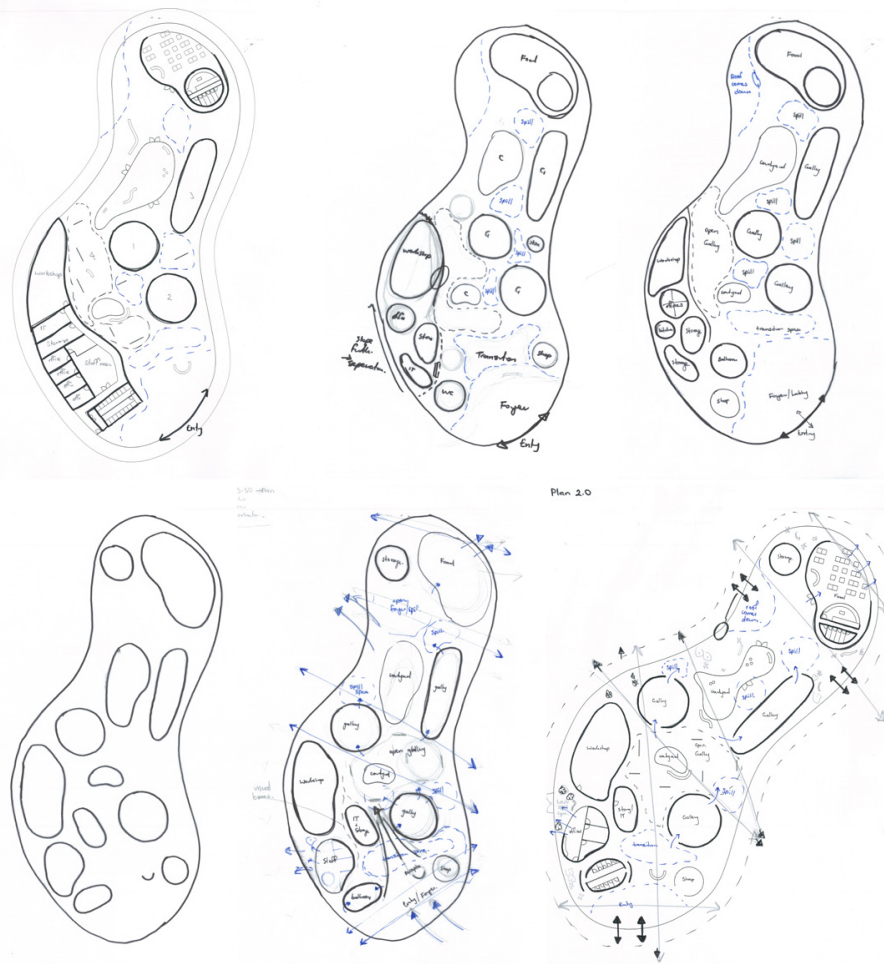


\section{Community Centre in Section}

The section was important for exploring level changes and the relationship between the landscape, floor plane and roof. The following pages communicate the explorations in section and detail for both the gallery and community centre.
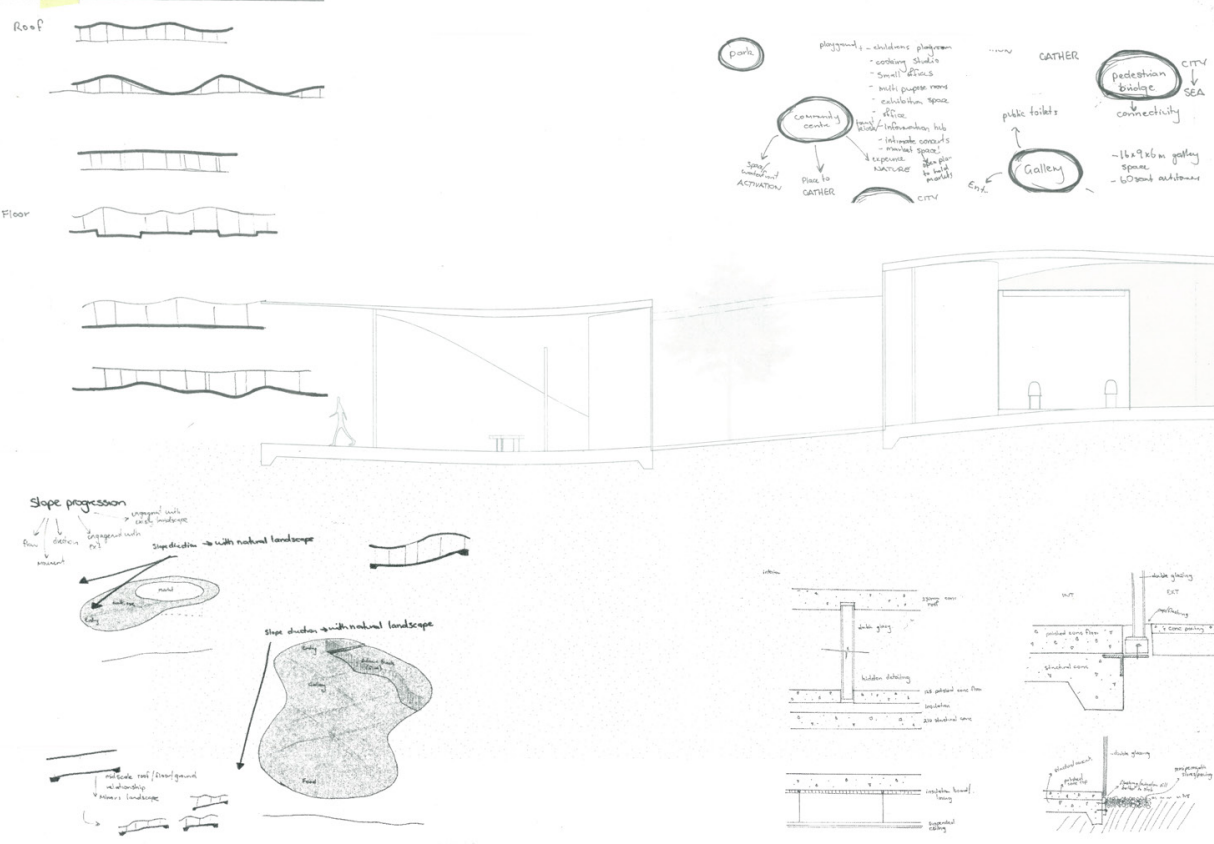
The following was considered in section:

- How does the program influence the relationship between the floor and the roof and the size of the spaces?

- How do the buildings engage with or oppose the landscape?

- How can the detail connections of the glazing appear seamless?
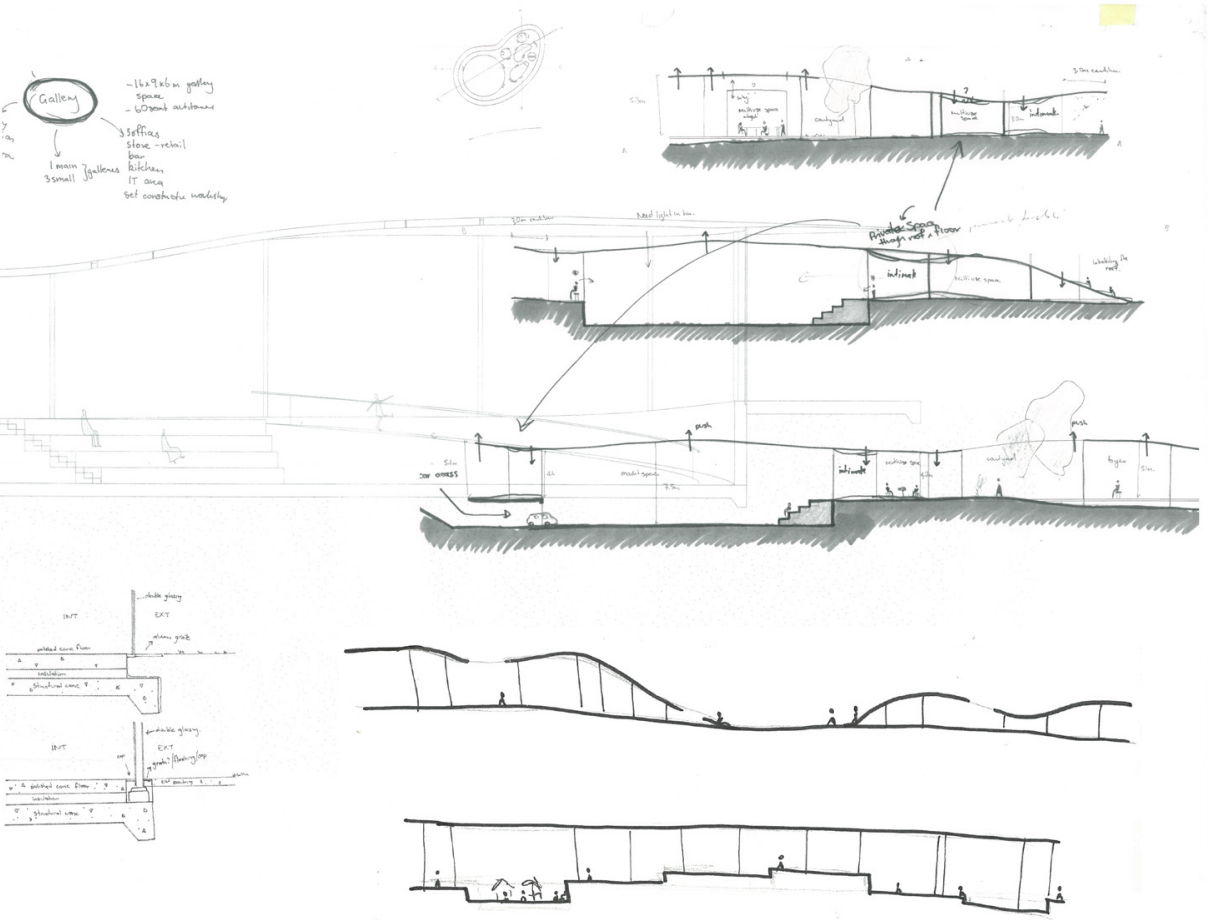
Gallery in Section

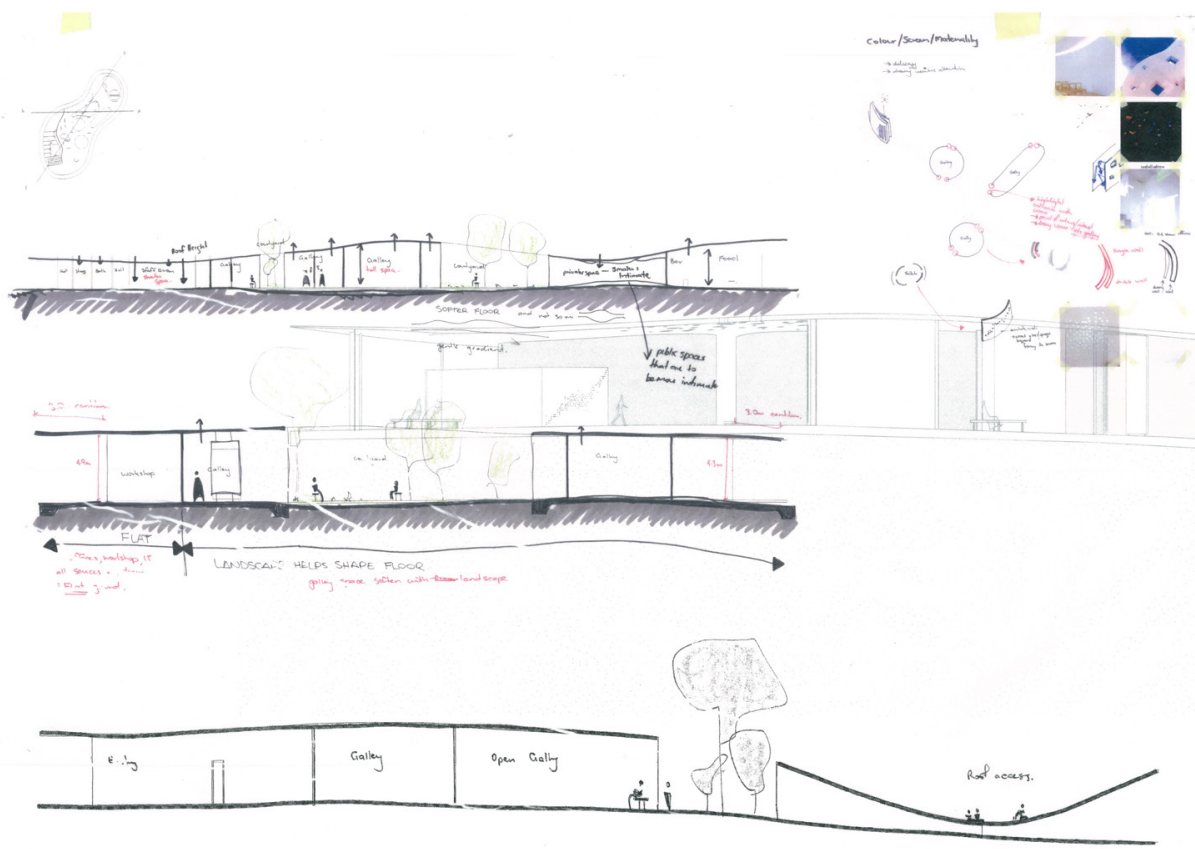




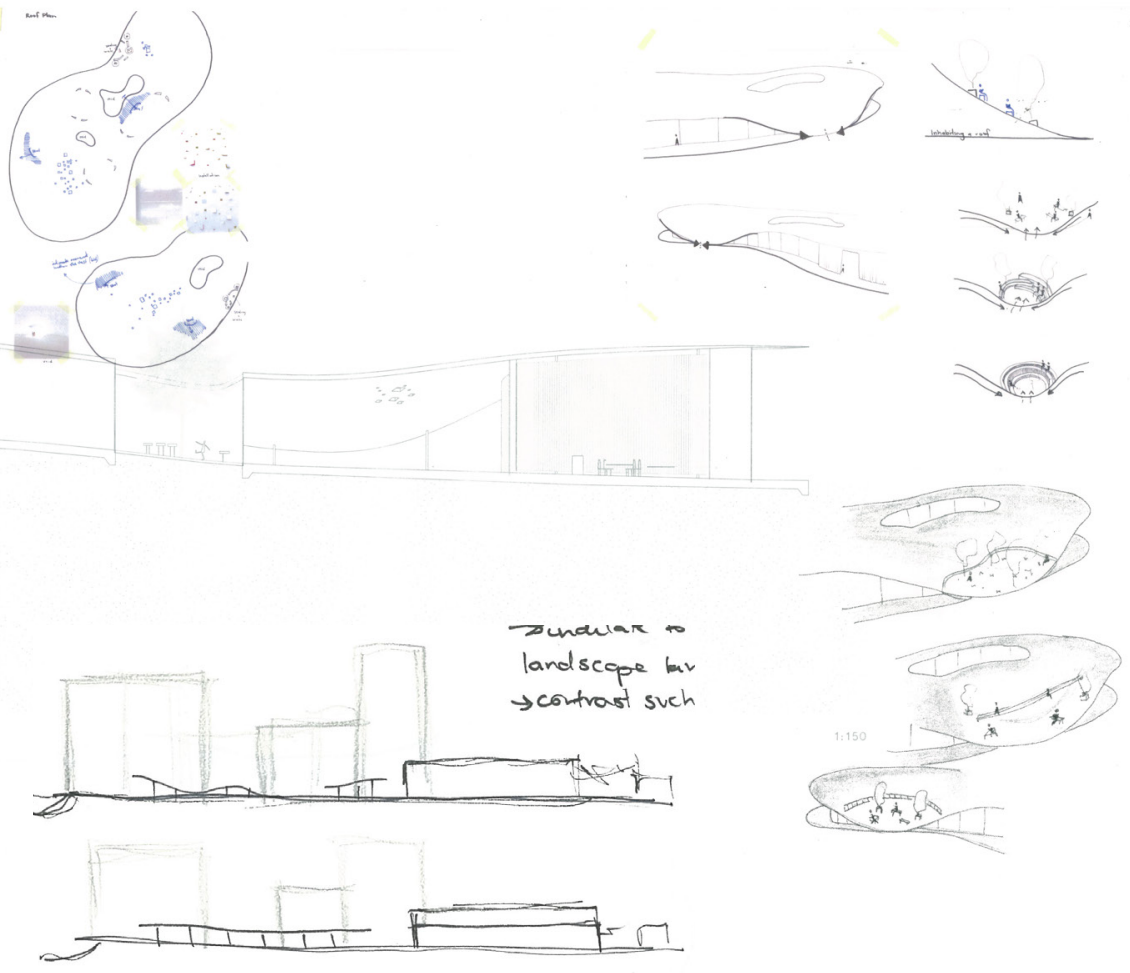




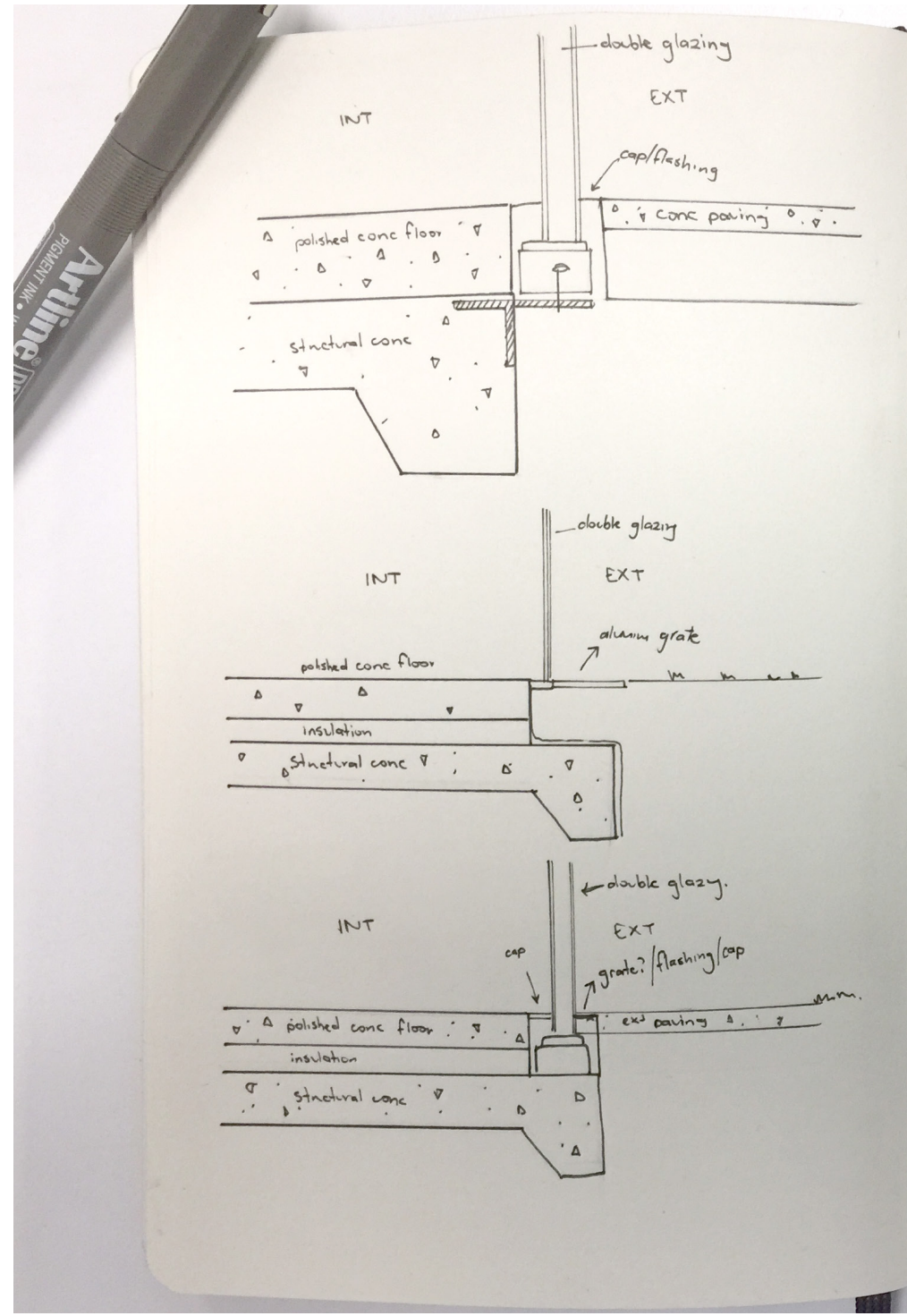


intevion
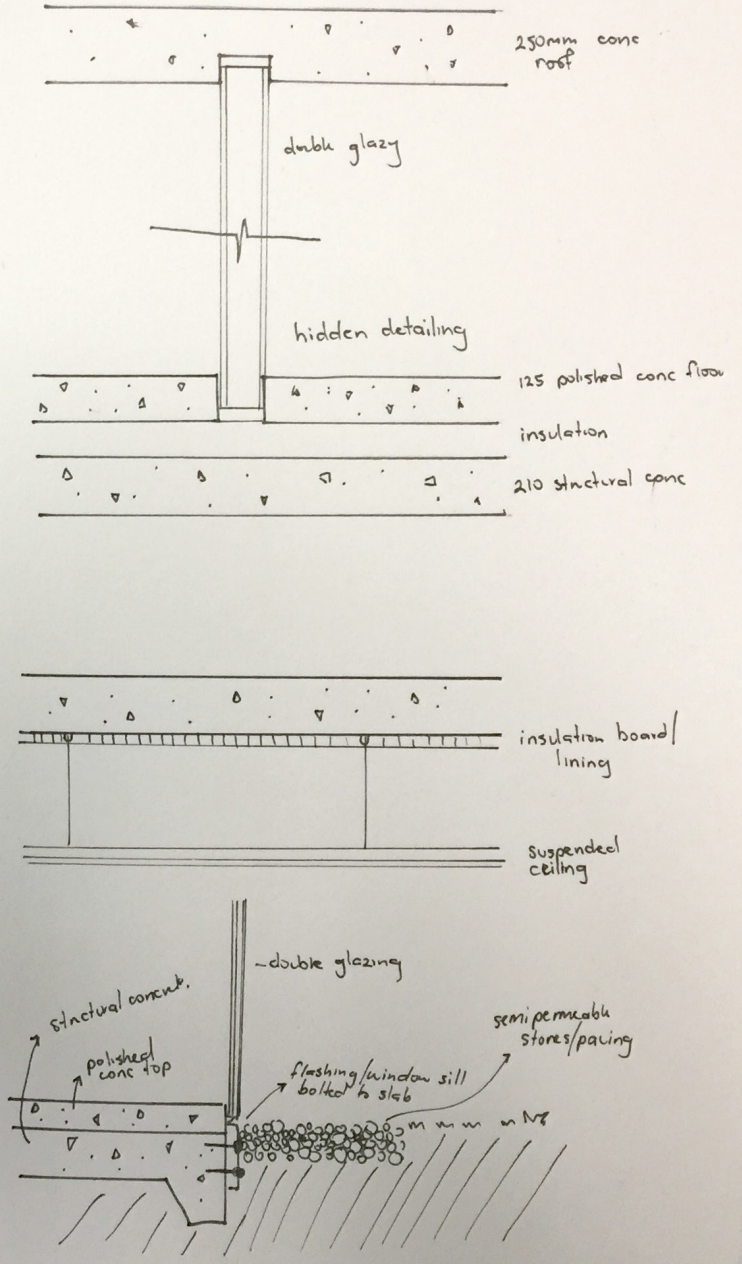



\section{AUGUST REVIEW}

The design was presented at the August review to a panel of reviewers. The following pages communicate the developing design in plan, section and perspective as the most up-to-date version that was presented. The proceeding development work was also shown. 


\section{Gallery}

1 Entry

Reception

3 Foyer

4 Shop

5 Bathrooms

6 Gallery

7 Courtyard

8 Office

9 Staff Kitchen

10 Workshop and IT

11 Storage

12 Cafe

$13 \mathrm{Bar}$

14 Kitchen

15 Rooftop seating
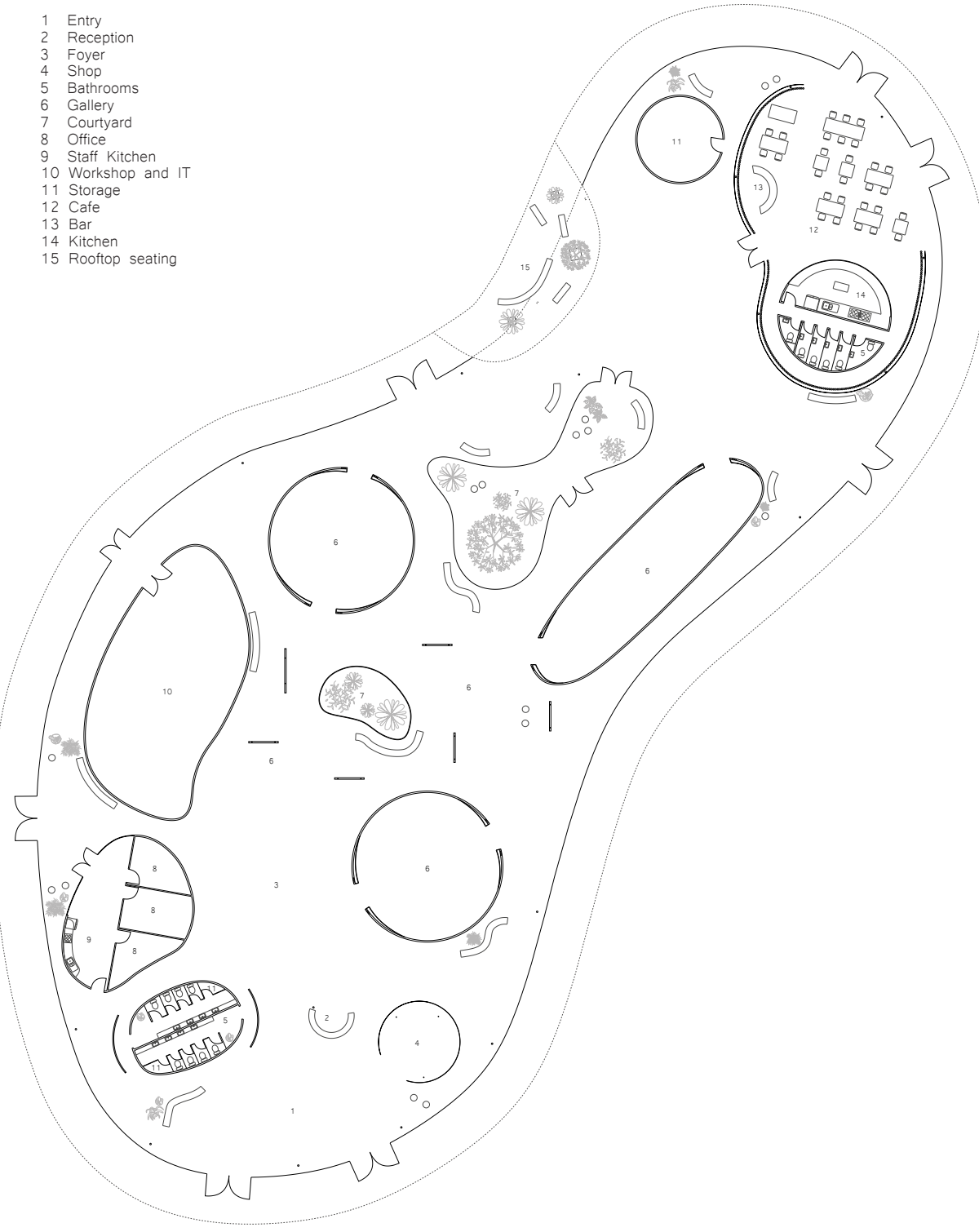


\section{Community Centre}

1 Multi-use space

Storage

3 Courtyard

4 Bathrooms

5 Large multi-use space

6 Rooftop seating

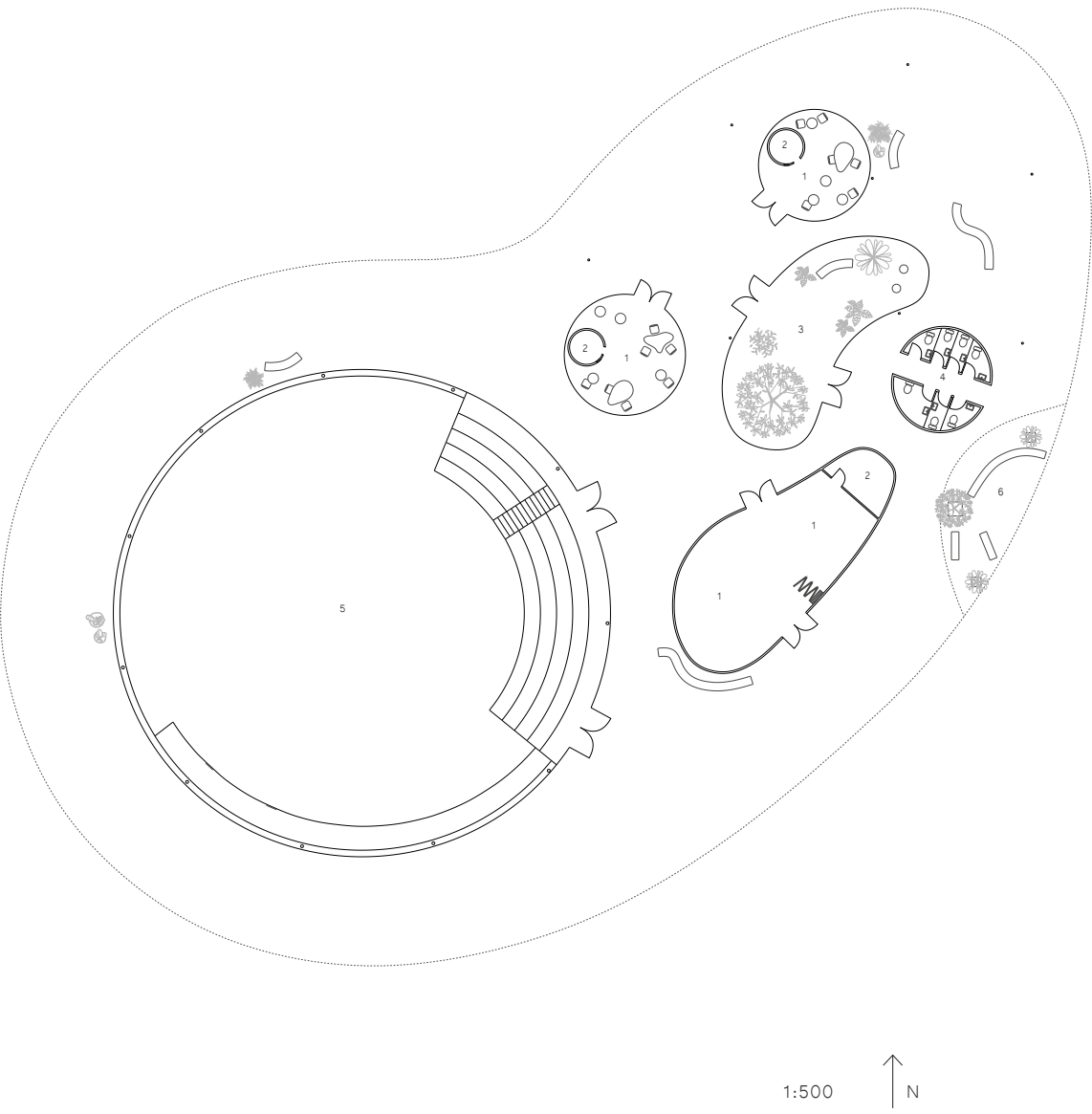




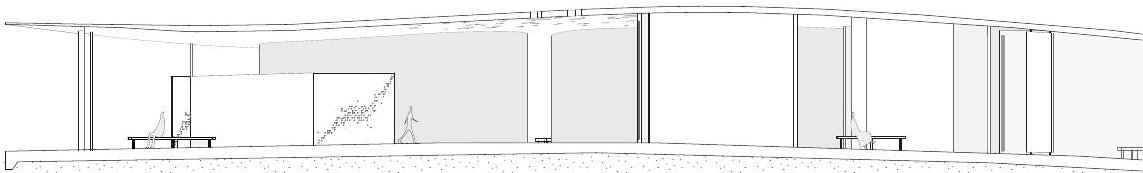

$\wedge$ 182. Gallery section

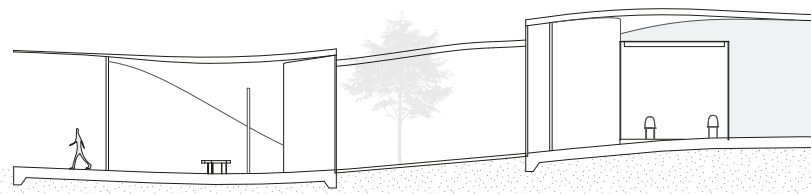

$\wedge$ 183. Community Centre section 


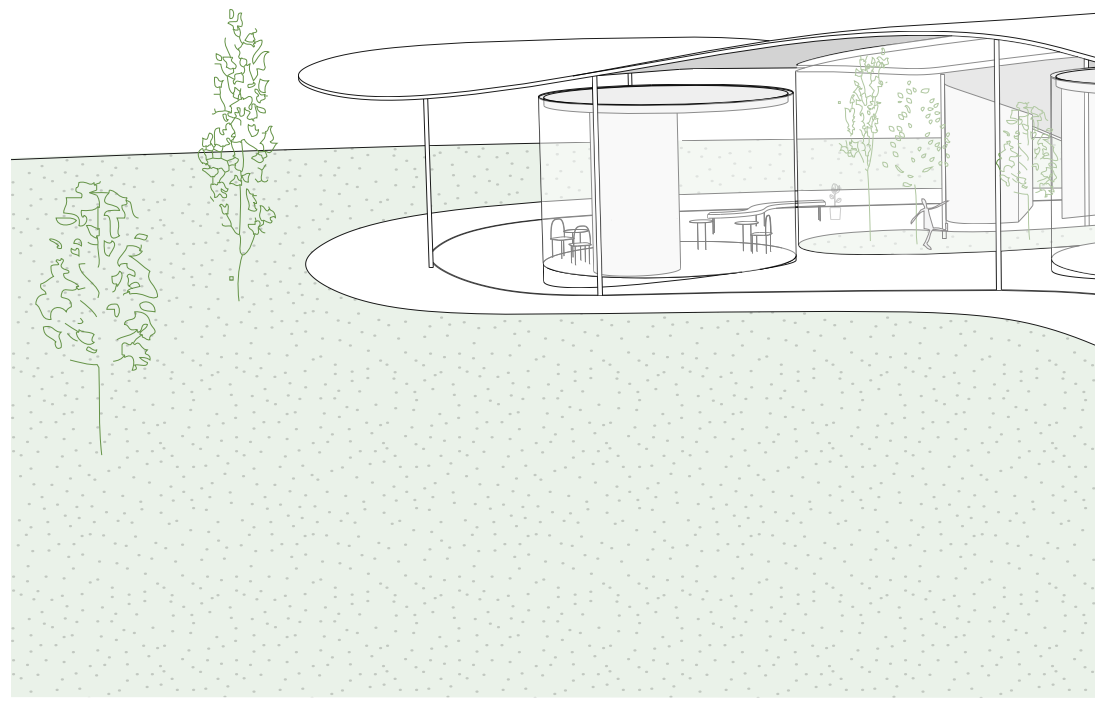

$\wedge$ 184. Community Centre perspective 


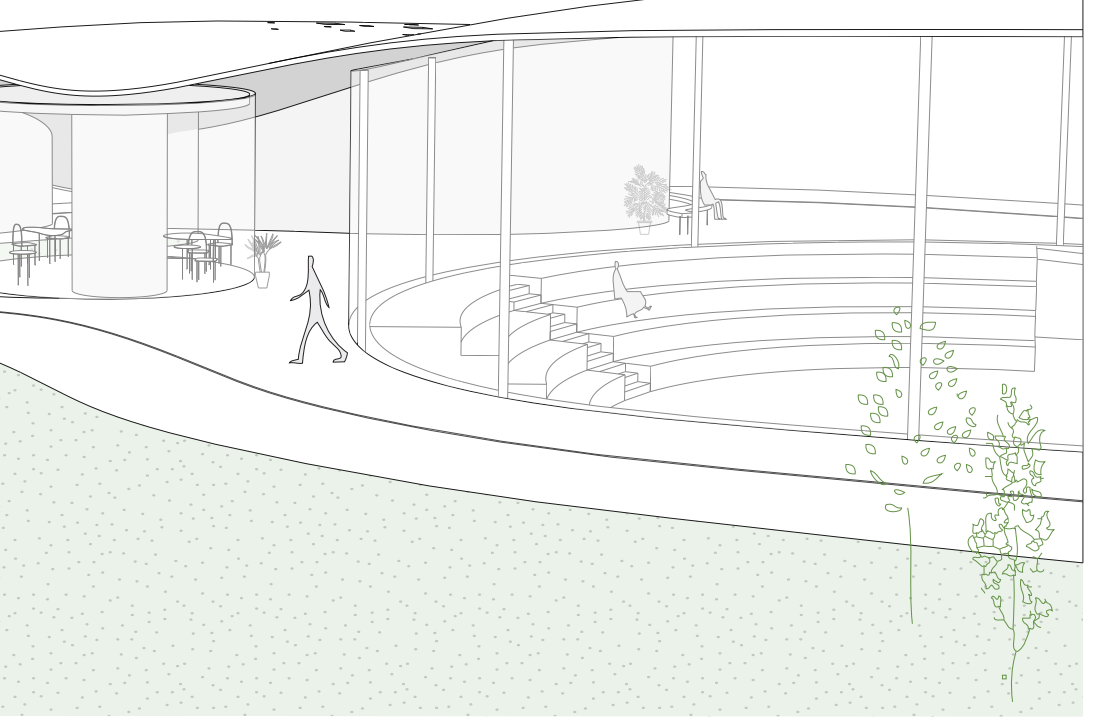




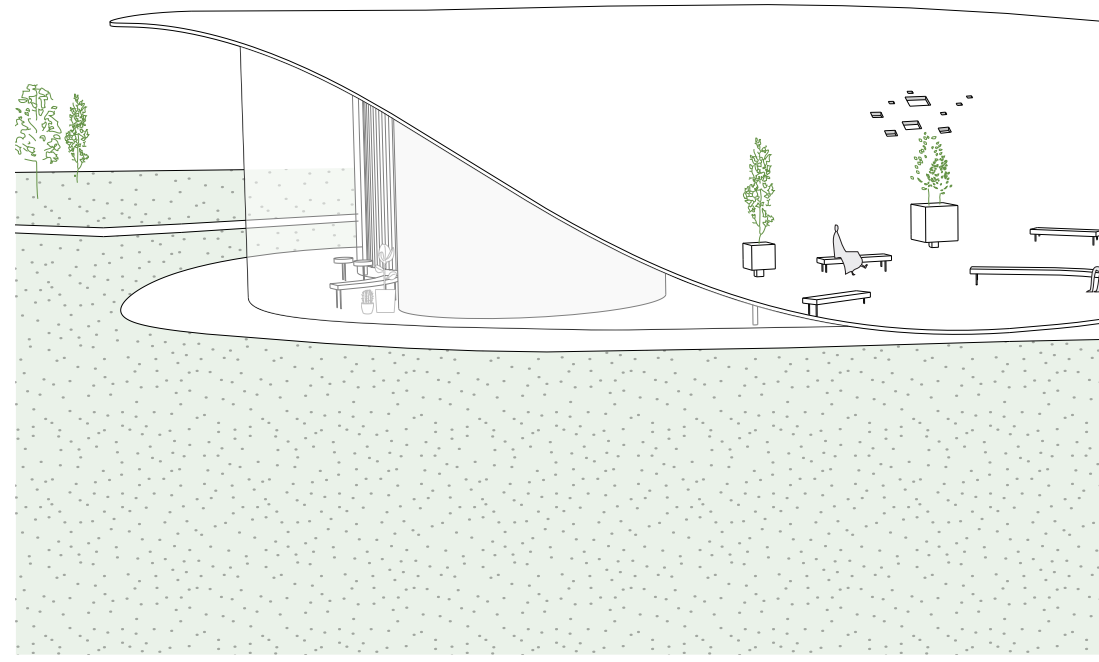

$\wedge$ 185. Gallery perspective 


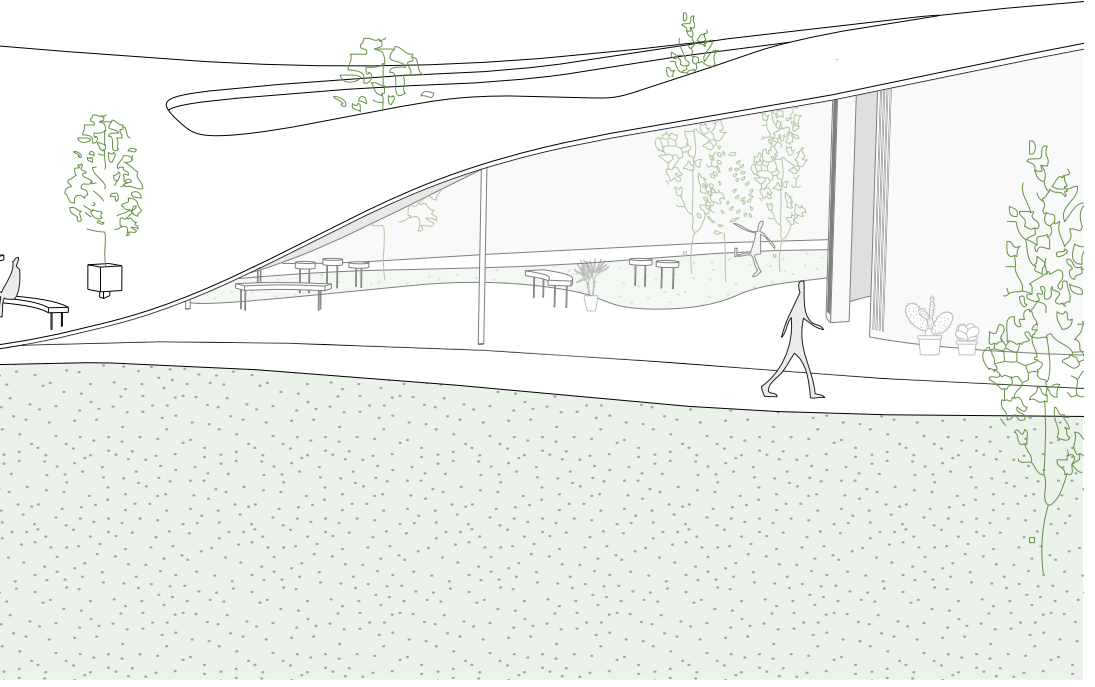


August Review

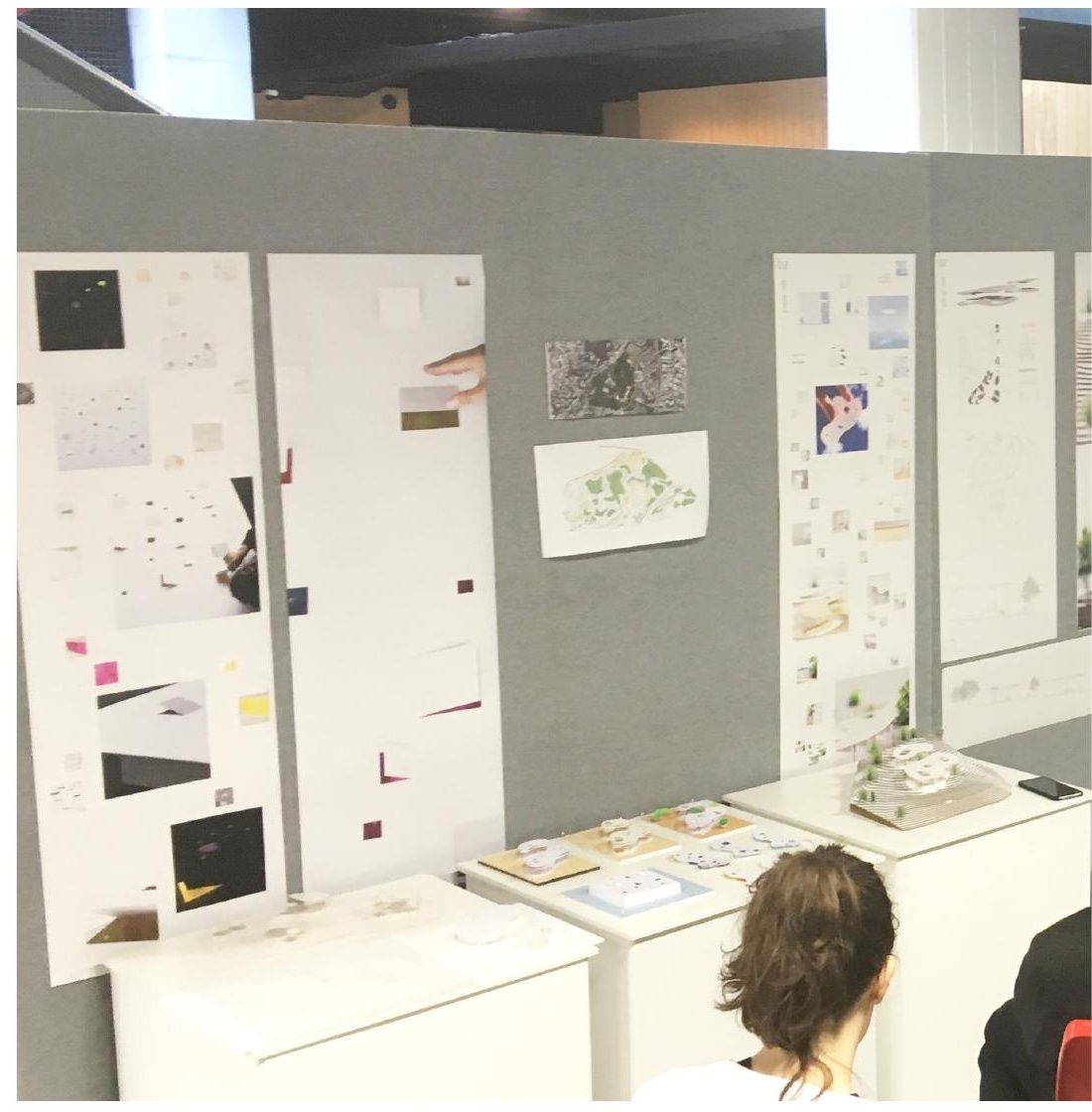

$\wedge$ 186. Presenting at the August Review 
August Review

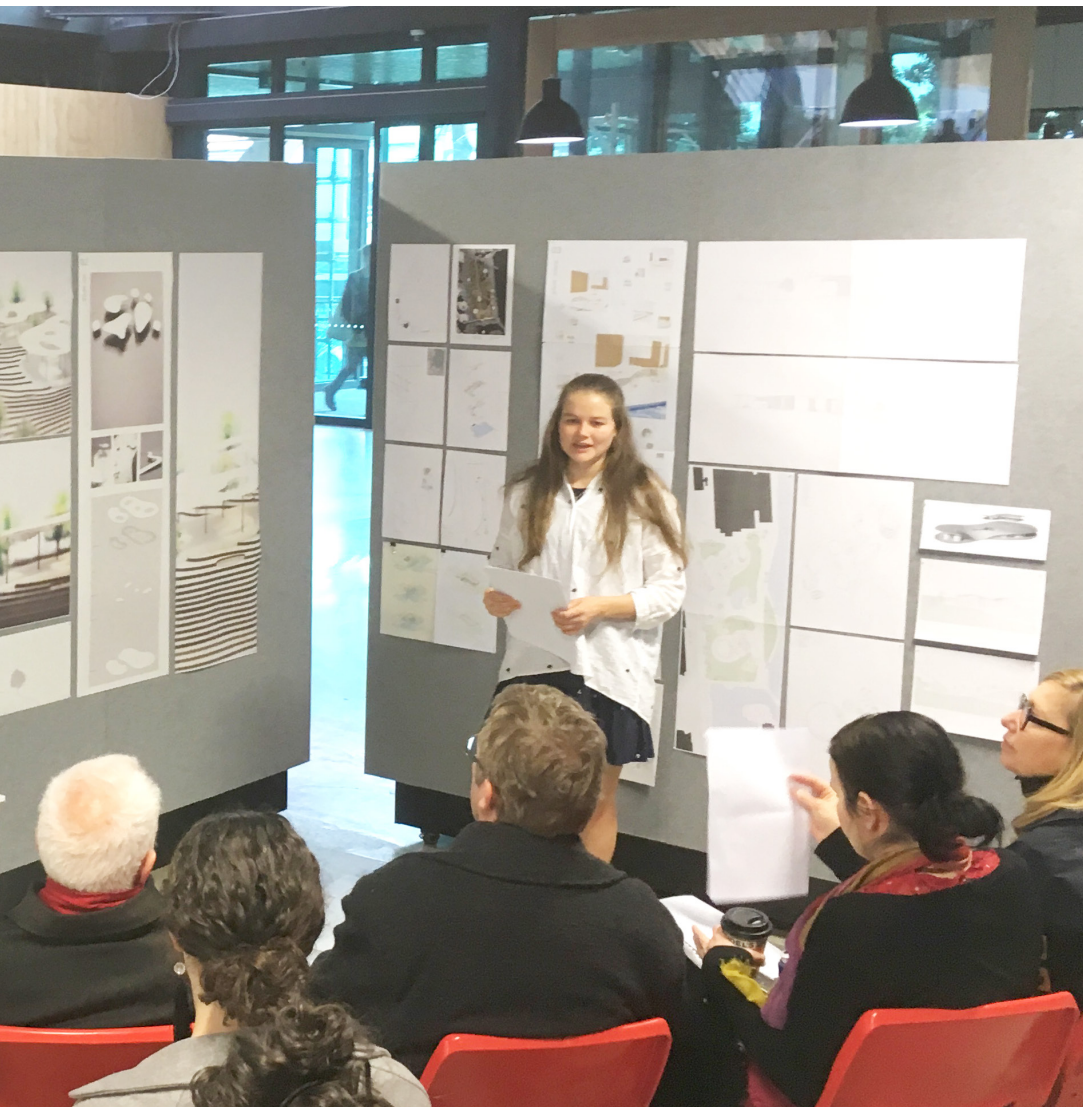




\section{August Review Reflection}

The August Review provided insightful comments and feedback in helping the design progress along, specifically focusing on continuing the visible relation between the proposal and response, as some elements could be clearer. Reflecting upon the comments and moving forward, there are multiple aspects that I continued to develop upon towards the final design.

1. Explore the envelope and plan further to see if there is any potential in developing it further from the mid-scale shape. Programme, site and circulation can all be drivers, influencing and developing the outcome.

2. Explore the roof further in terms of its structure and appearance in furthering its argument about delicacy. Considering the ribs/fins from the mid-scale as structure rather than ornamentation. Also re-consider where the roof currently connects to the ground as it makes the building appear heavy.

3. Consider the interior spaces more. Draw from some of the later explorations that delve into materiality and size. Connection and disconnection to the roof will also be important.

4. Consider the design from the exterior right down to the detail as it is currently not considered enough at the intimate scale. Objects have been standardised through the digital drawing process and are not evoking delicacy at the intimate scale. 


\section{Developing the Envelope}

\section{Aim}

Develop the building envelope and plan presented at the August Review further through drawing and physical models. This is to investigate if there is any potential in developing the design further from the mid-scale but continuing the same language. Site, programme, circulation and aesthetics are all driving elements in this exploration.

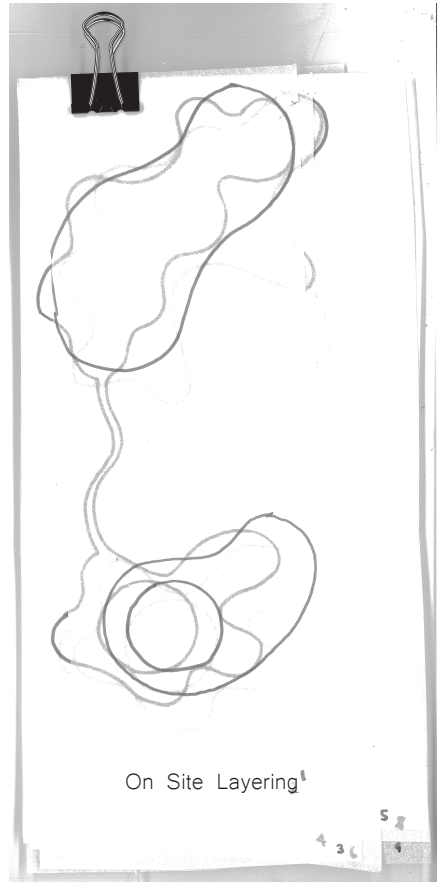




\section{Process}

On Site Layering

Current floor plan as a base. Extending the envelope further, engaging with more curves. Informal.

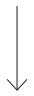

On Site Sketches

4 envelope iterations integrated form, site and program.

Form Models

Physically modelled a series of iterations which were a developed upon the previous stage with aesthetic adjustments.

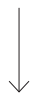

Developed Drawings

Selected form was further developed upon in regards to site, program and circulation through sketches.
Final Envelope Physical Model

Constructed physical model exploring transparent and solid spaces according

to program. Overall composition.

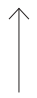

Developed Drawings

Developed the plan through drawing and considering the roof and its relationship to program.

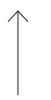

\section{Quick Sketches}

Developed upon design to be more responsive and less forced through quick sketches. Considered the relationship between the two buildings.

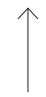

\section{Physical Model}

Constructed an original and developed model exploring transparent and solid spaces according to program. Overall composition. 


\section{On Site Sketches}

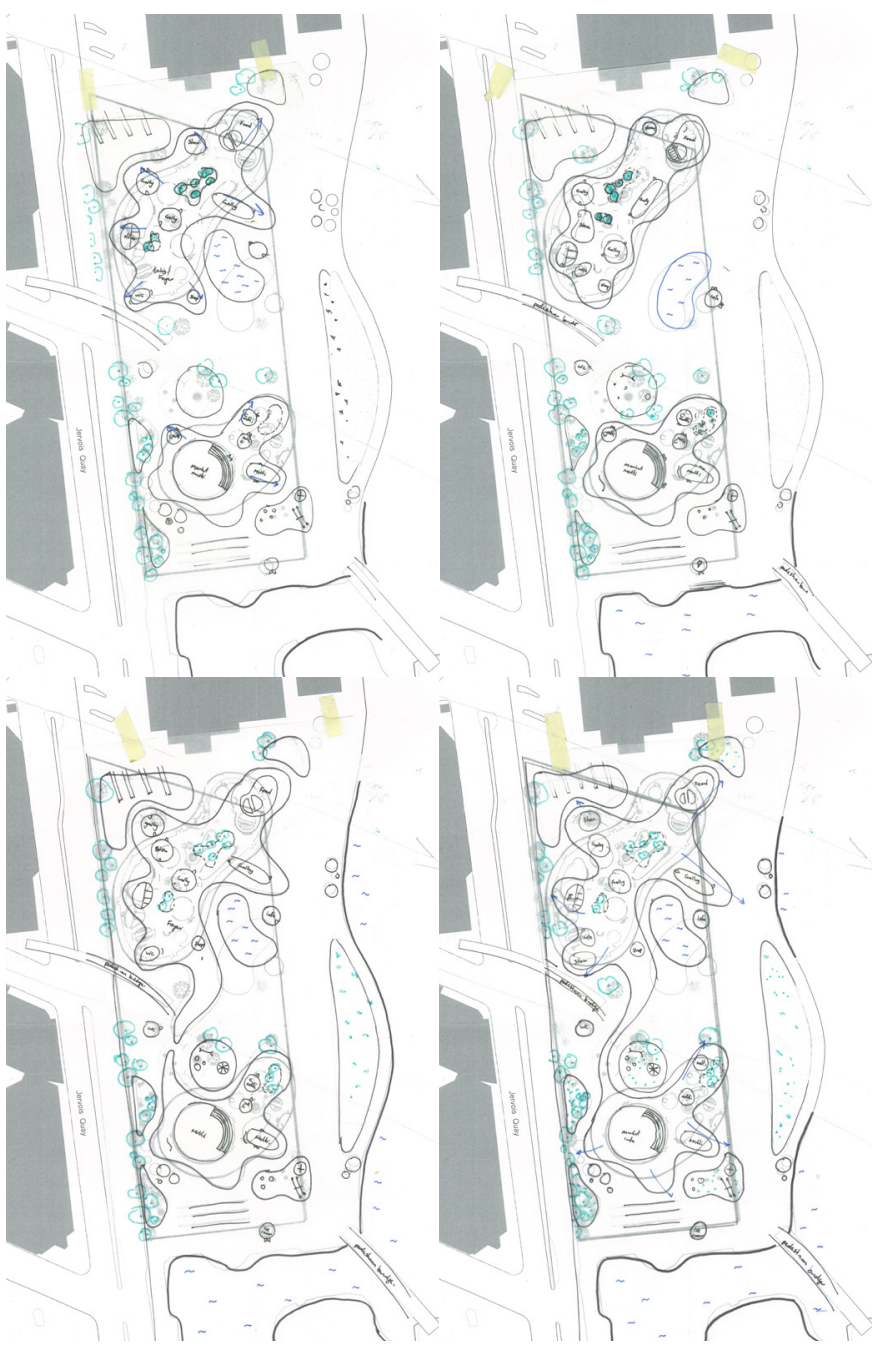



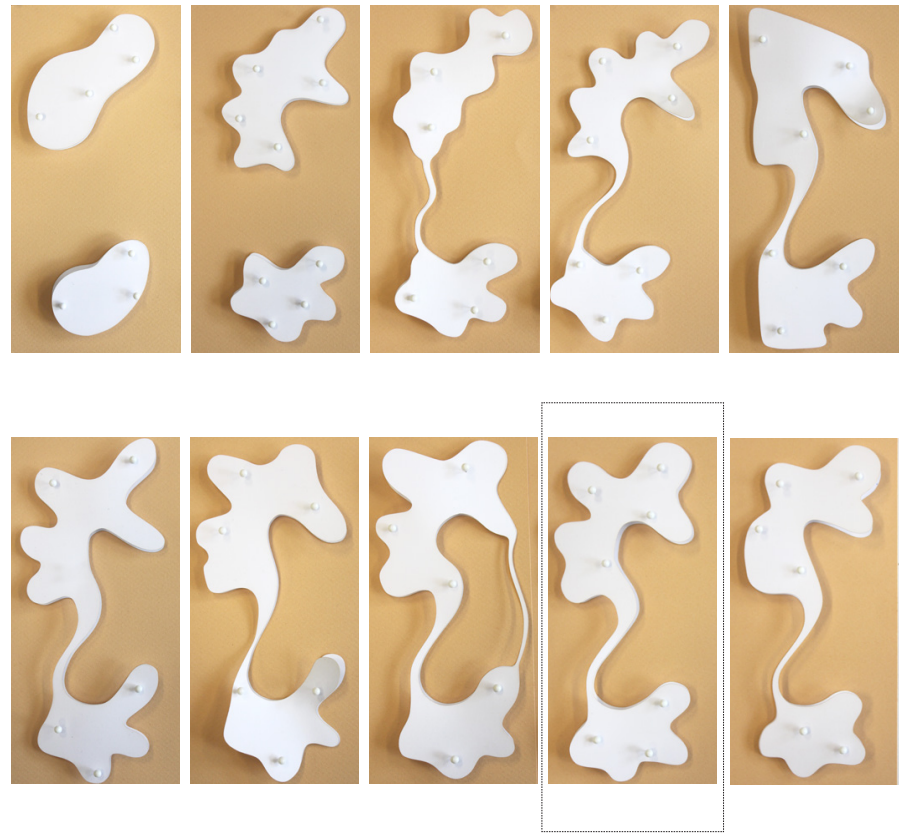

Selection 
Developing the Iteration

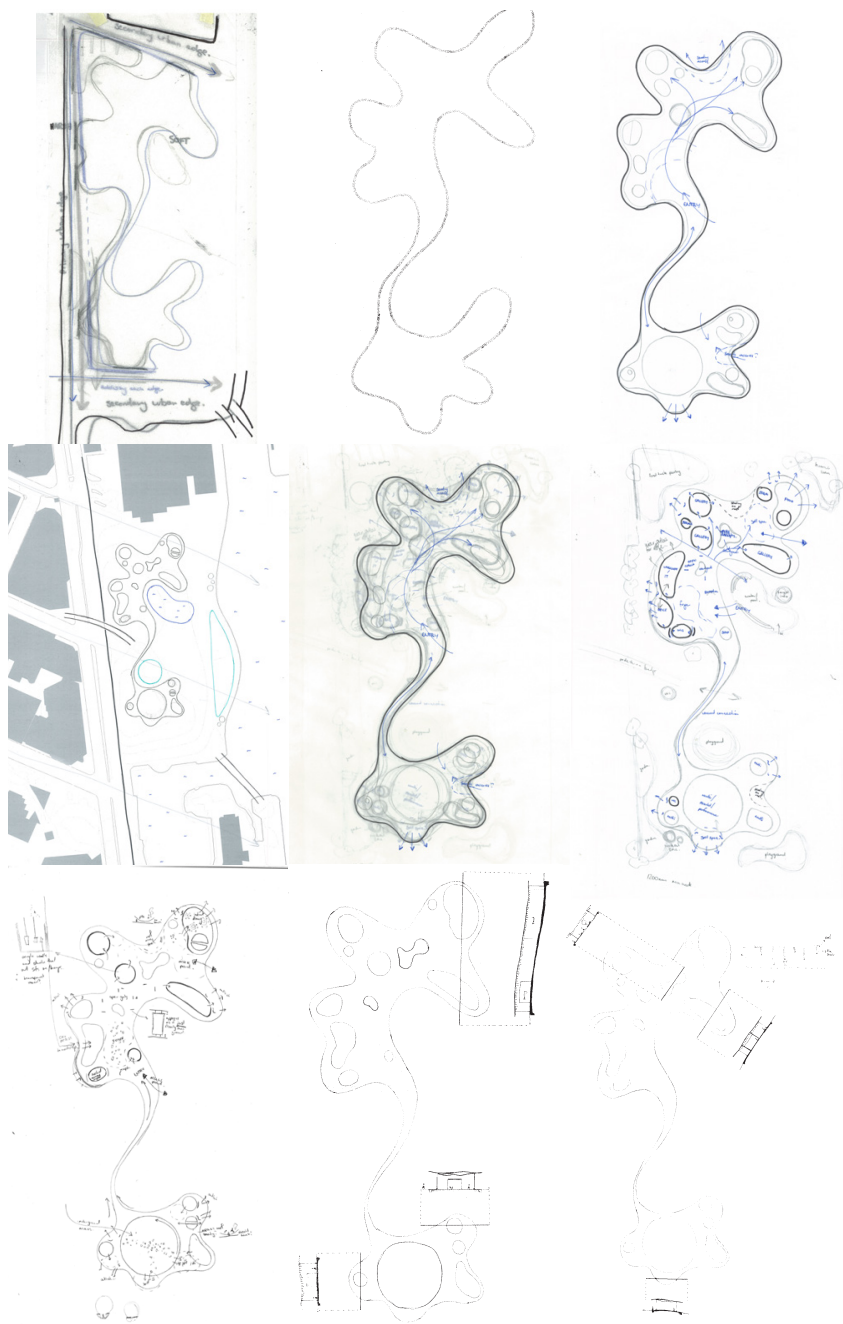



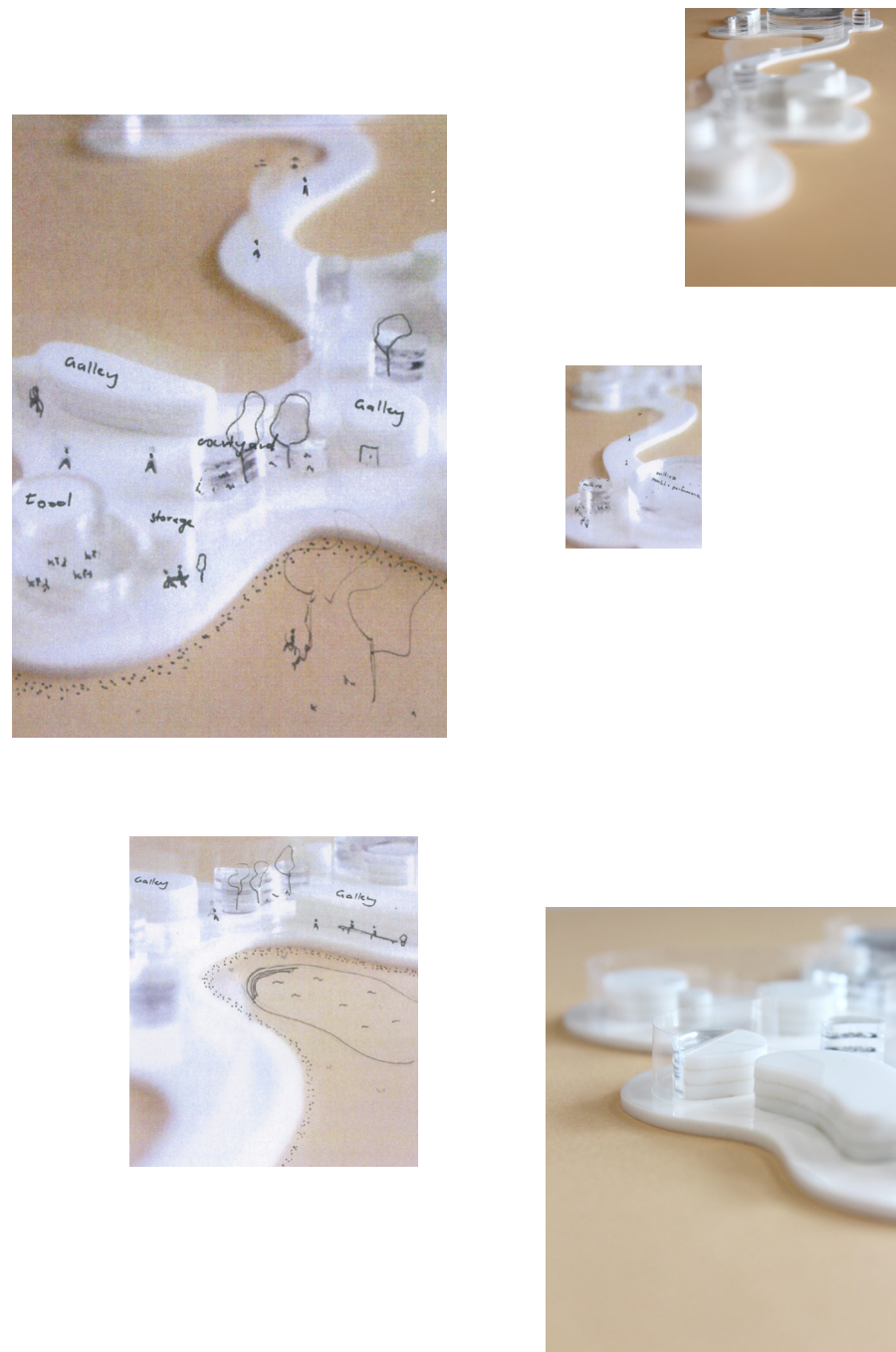


\title{
Physical Model
}

\author{
Original Design
}

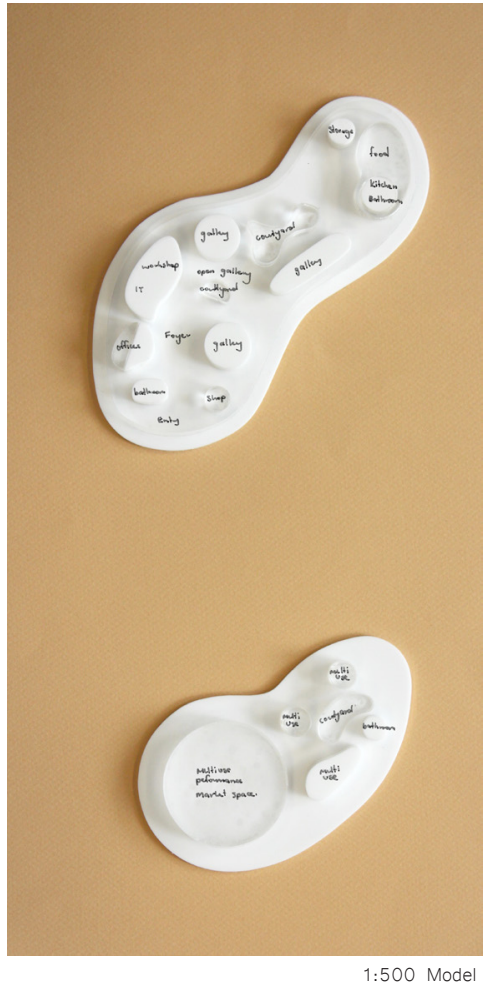


Physical Model

Developed Design

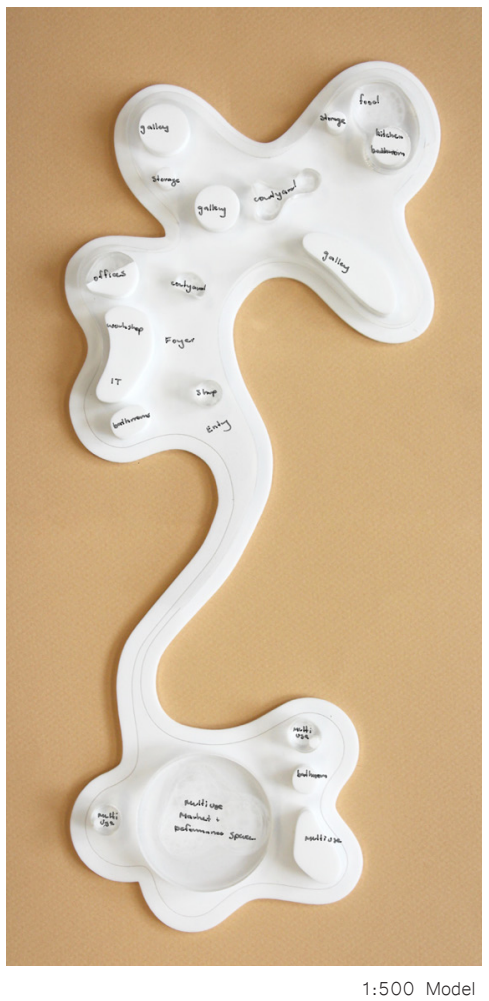




\section{Quick Sketches}

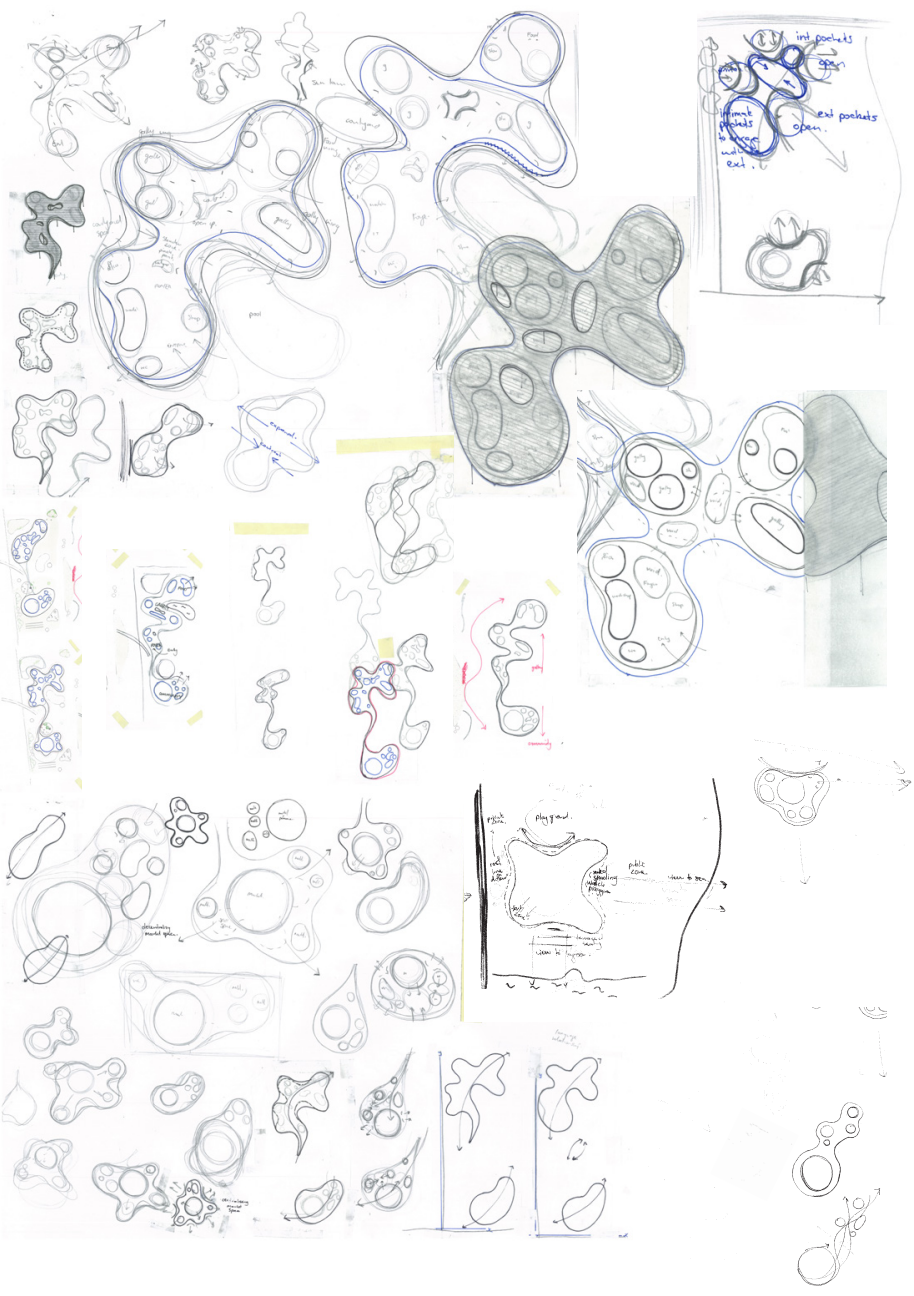



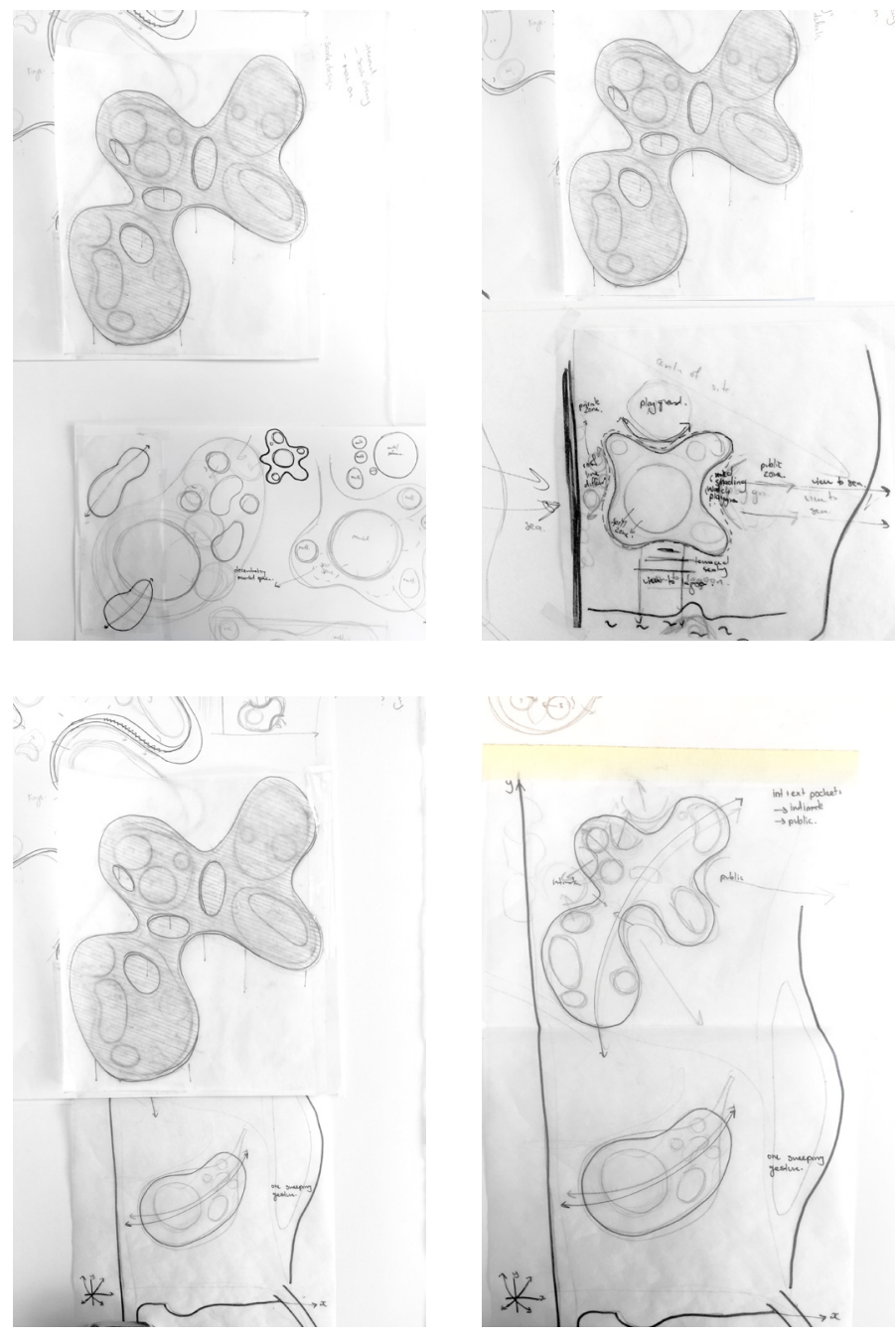
Developing the Plan
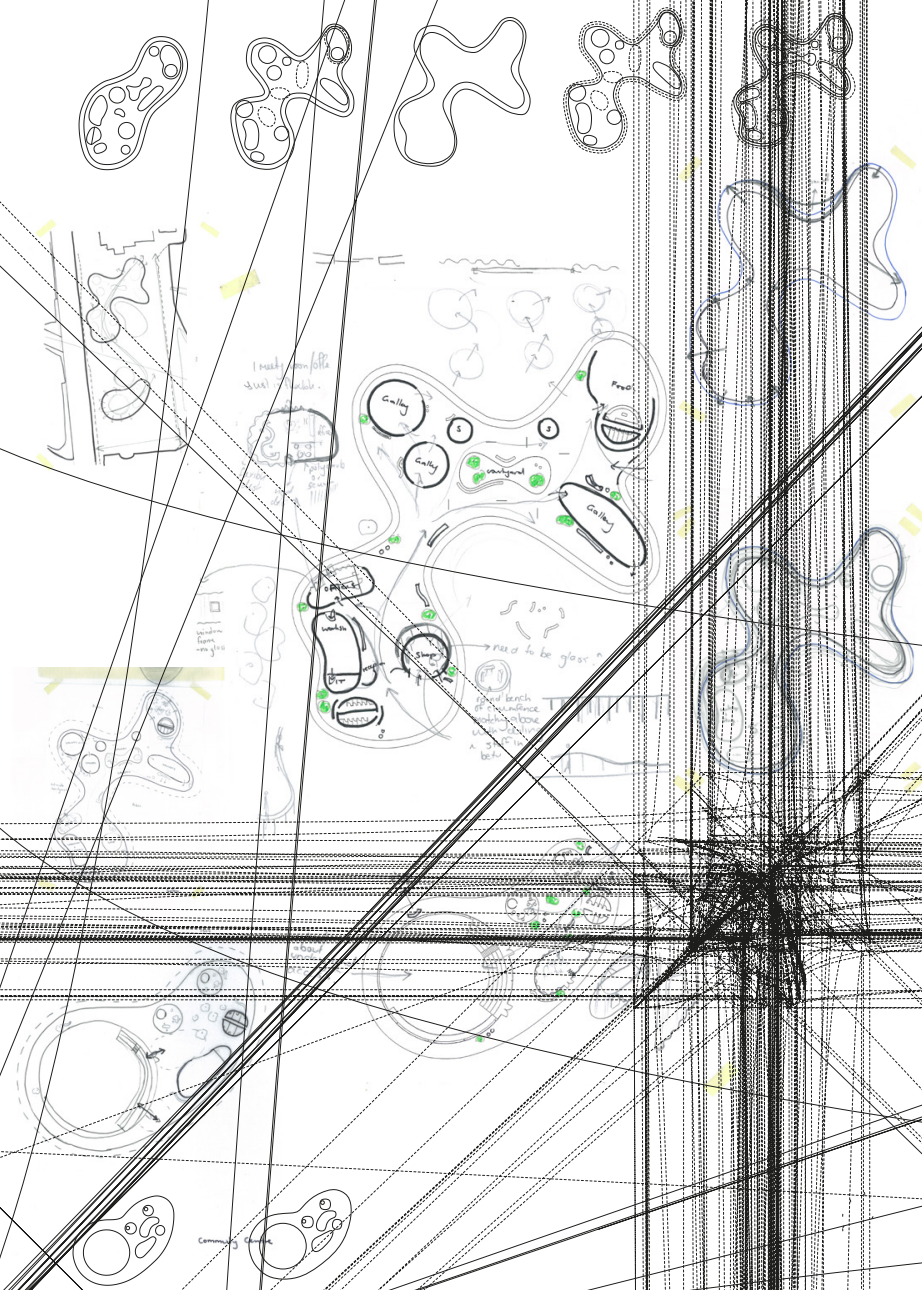
Through this development, I also reconsidered the roof and its relationship to the floor plan. Rather than mirroring the exact footprint below, which has been evident in my previous designs, I used programme as the driver to push out the roof's extents. The roof extends further out and pulls back in relation to spaces that require more or less light and how public and open the space needs to be. This design development enables the roof to cantilever further out than originally expected in areas, highlighting its thinness and delicacy.
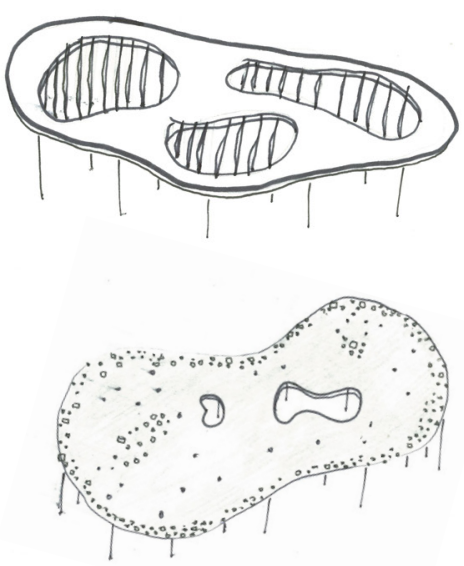

$\wedge$ 198. Initial roof perforation sketches 


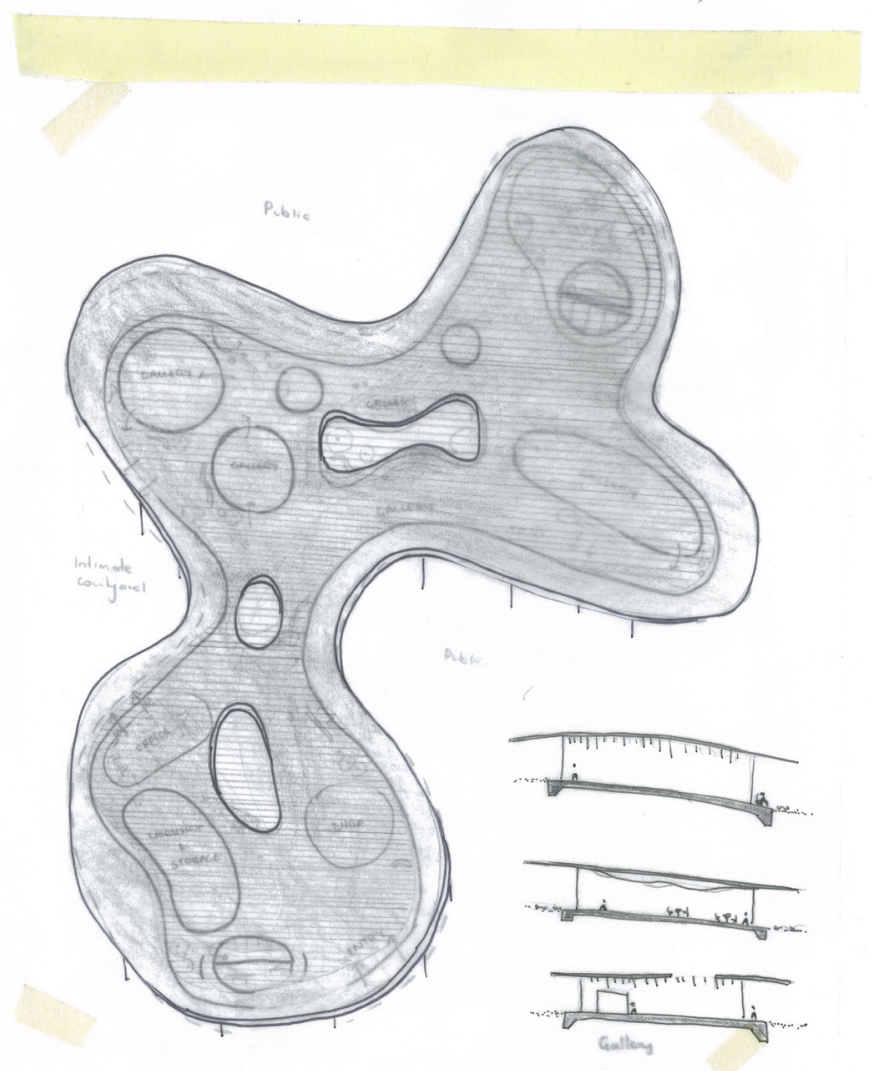

$1: 500$

$\wedge$ 199. Gallery roof and spaces below 


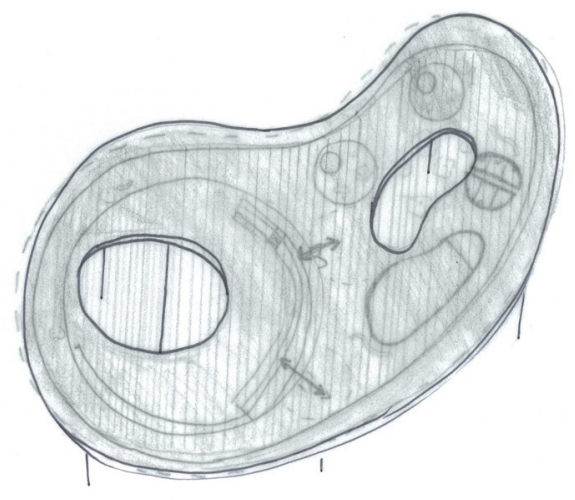

Commotily centre 
Physical Model

Final Envelope

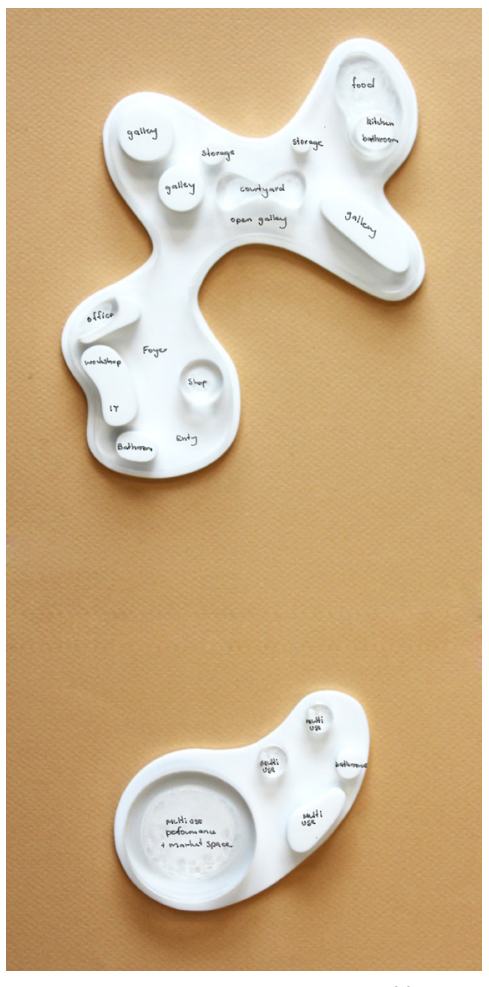

1:500 Model 

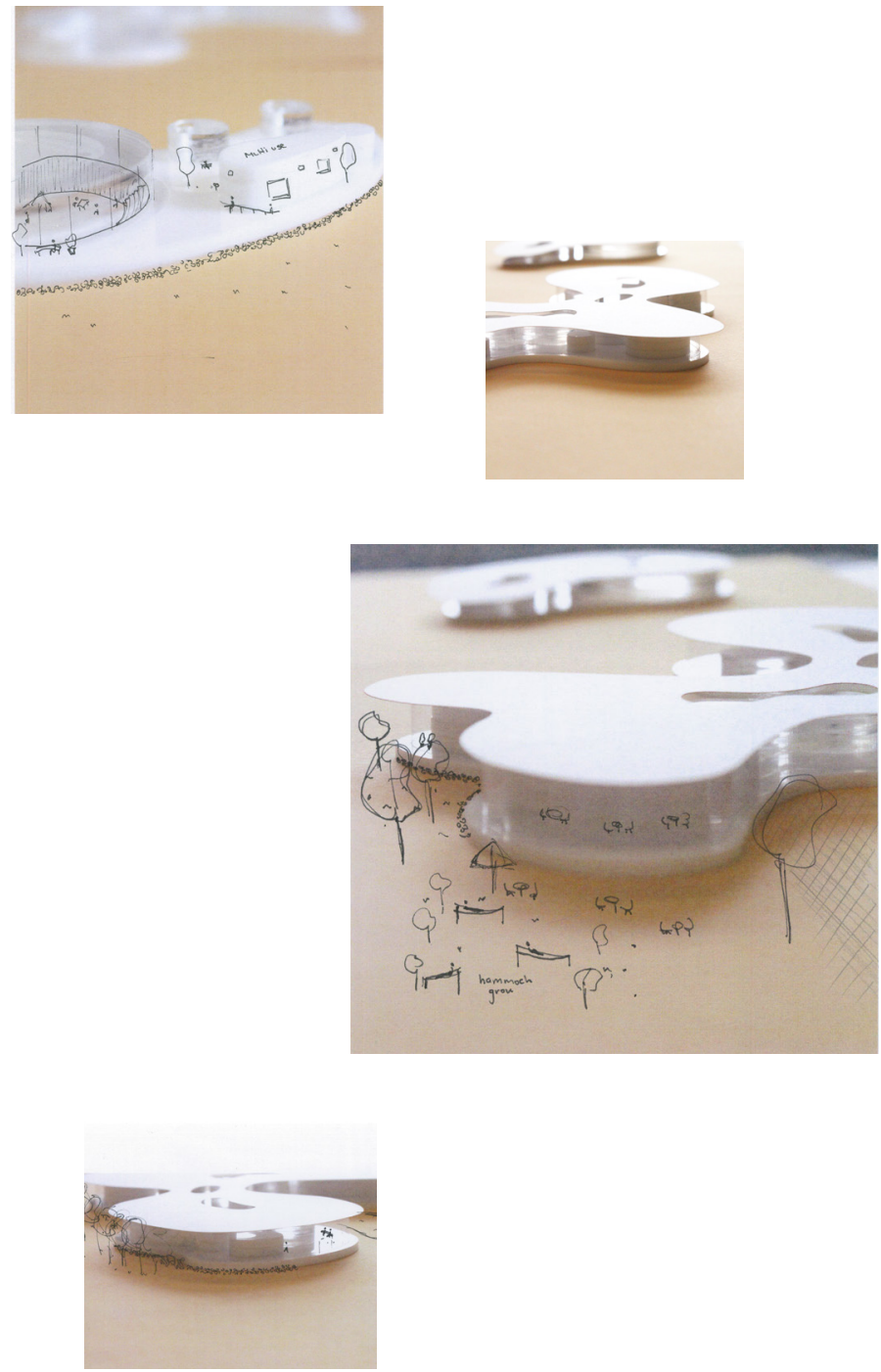


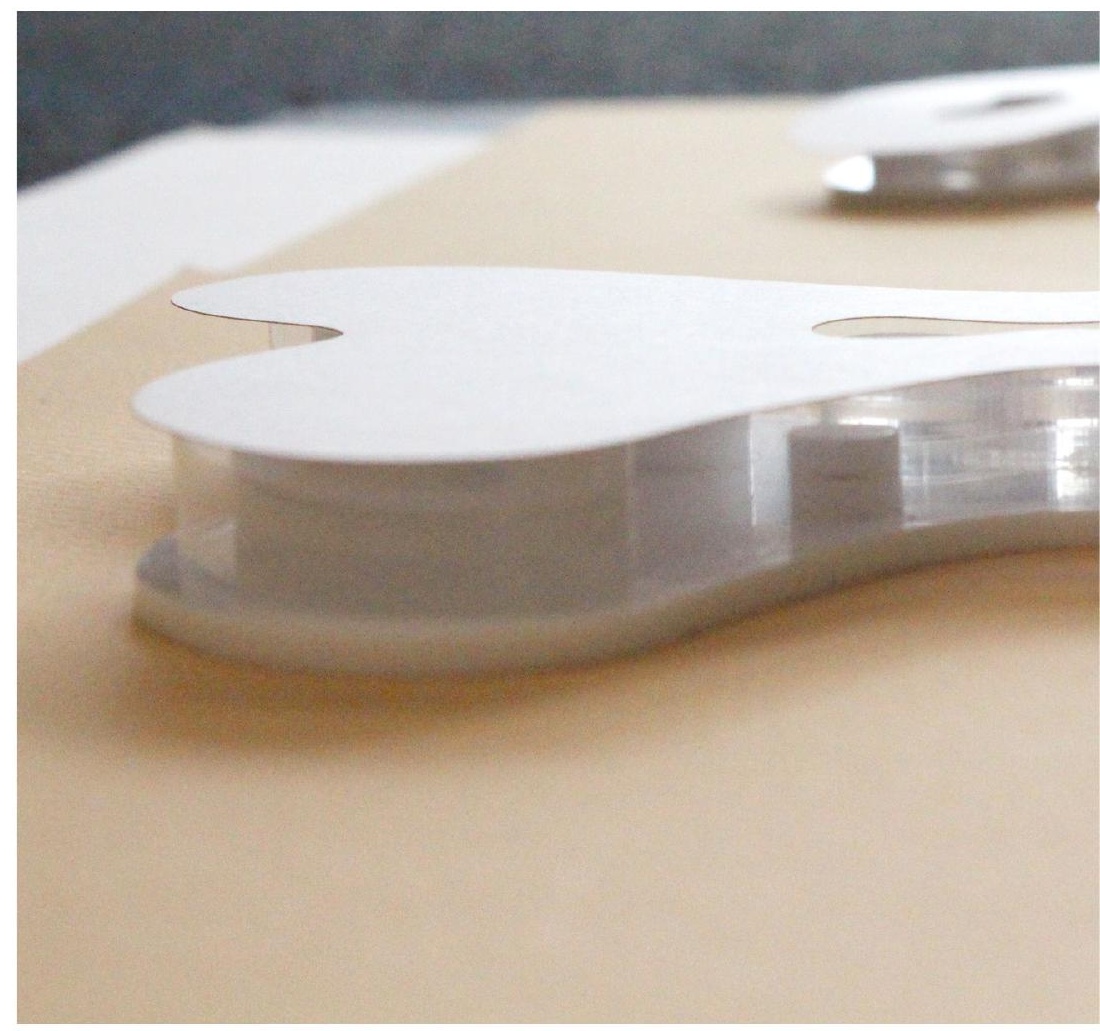




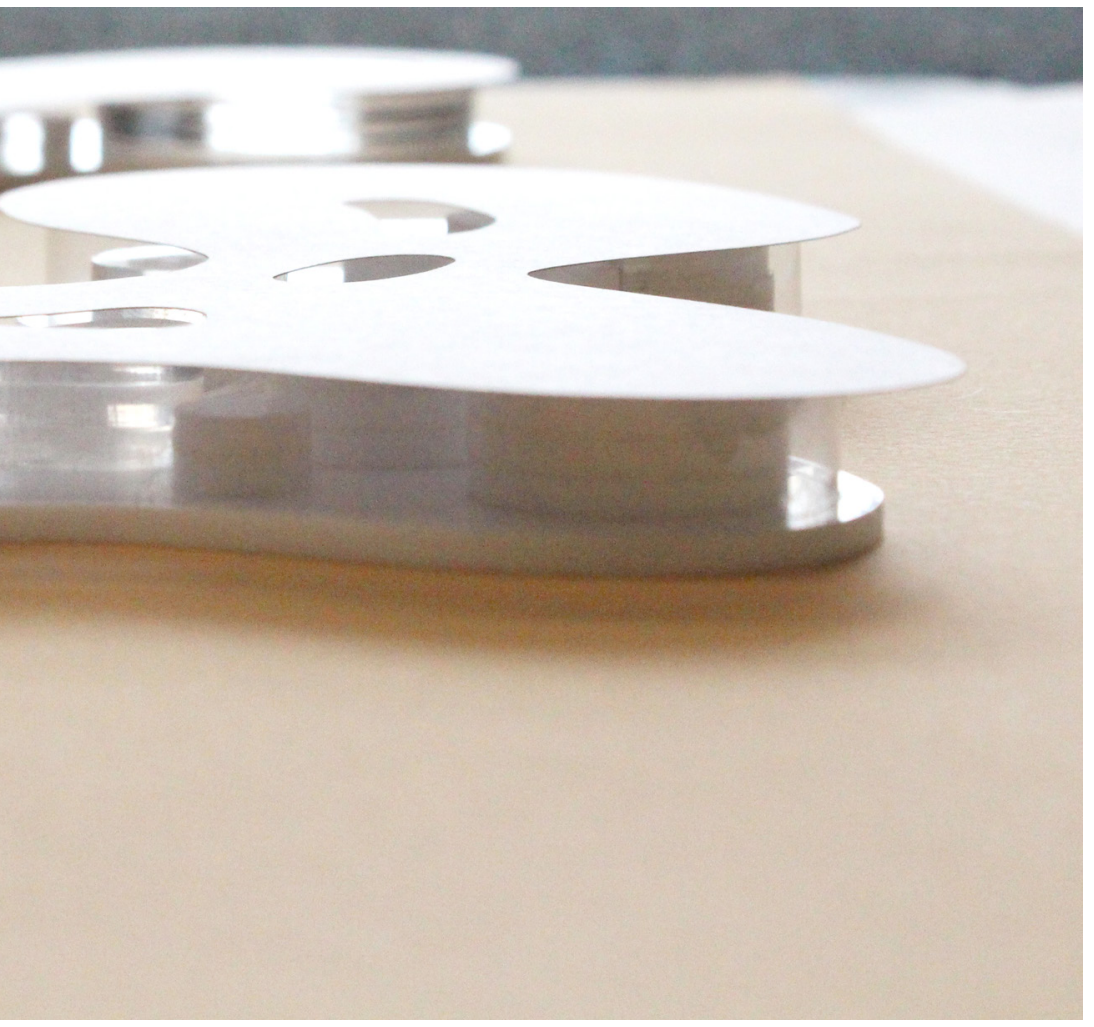




\section{Evaluation}

This exploration was necessary to justify design decisions and ease my own concerns about the building's form in relation to the mid-scale design. Explorations were trialled, tested and compared against the current design. Upon reflection, it became clear that although I was pushing programme outwards to inform a more organic shape, it felt forced. Once I developed a new plan and visually compared it against the old plan I realised there was still potential in this investigation, it just needed to be both pushed further and pulled back.

Quick sketches exploring different forms enabled me to think about programmatic zoning (both interior and exterior), natural light requirements for different programmes and how the roof might respond to that, pushing the form with rationale.

Through playful sketches, the gallery design reacted to multiple external factors, allowing site, slope, context, views and orientation alongside programme to all mould and impose on the design. Although all these elements shaped the design, the overarching typology remained the same. Upon reflection, I found success in this curvilinear typology and its malleable strengths. The community centre design was pulled back closer to the original as the sketches did not offer anything more successful. This was evaluated in regard to its relationship with the gallery building, but also site, programme and circulation. 
Developing the Roof

\section{Aim}

Explore the roof in terms of its structure and appearance to increase its perceived delicacy. Consider the ribs/fins from the mid-scale stage as structure rather than ornamentation.
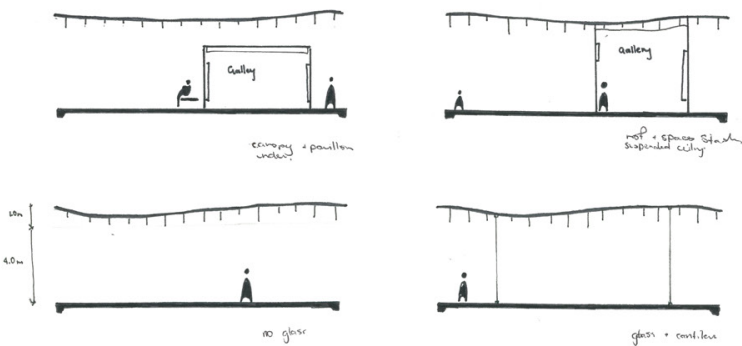

chass, contilere
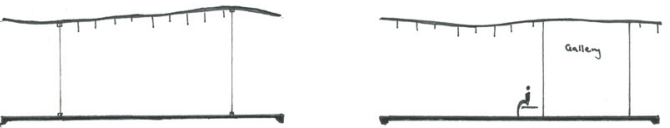

gless t contiliu.
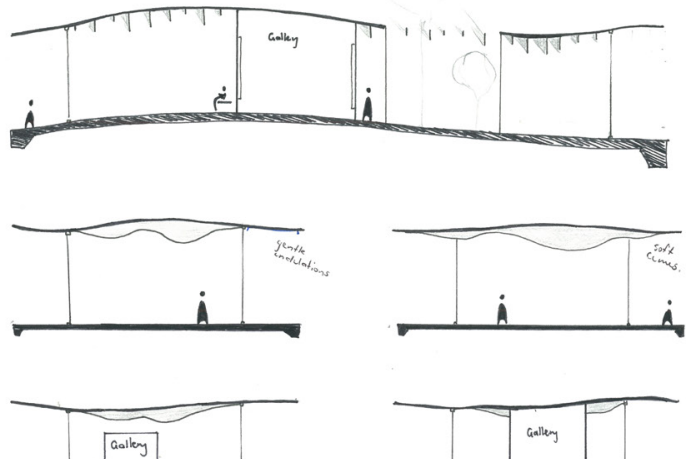


\section{Roof Model Iterations}

The series explores the material composition of a small segment of the roof. Material, structure and light are key drivers in this iterative series.
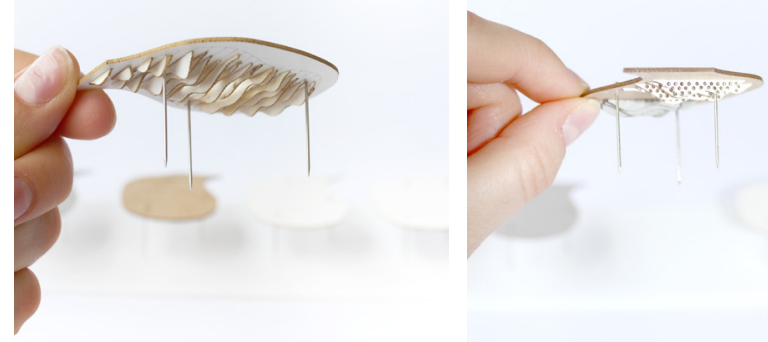

$\wedge$ 205. Standard and perforated fins 


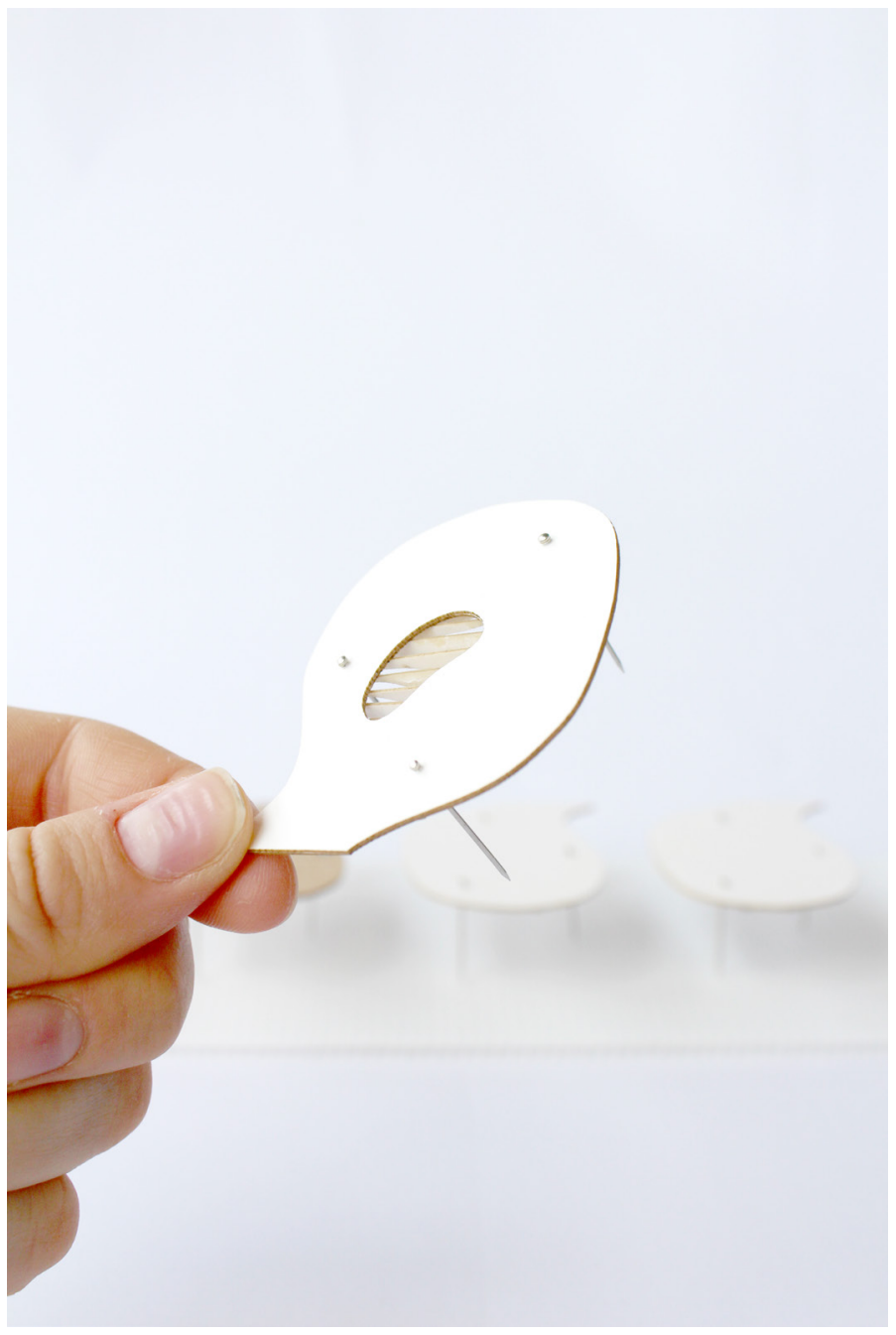

$\bigwedge 206$. Perforation and structure visible

275 

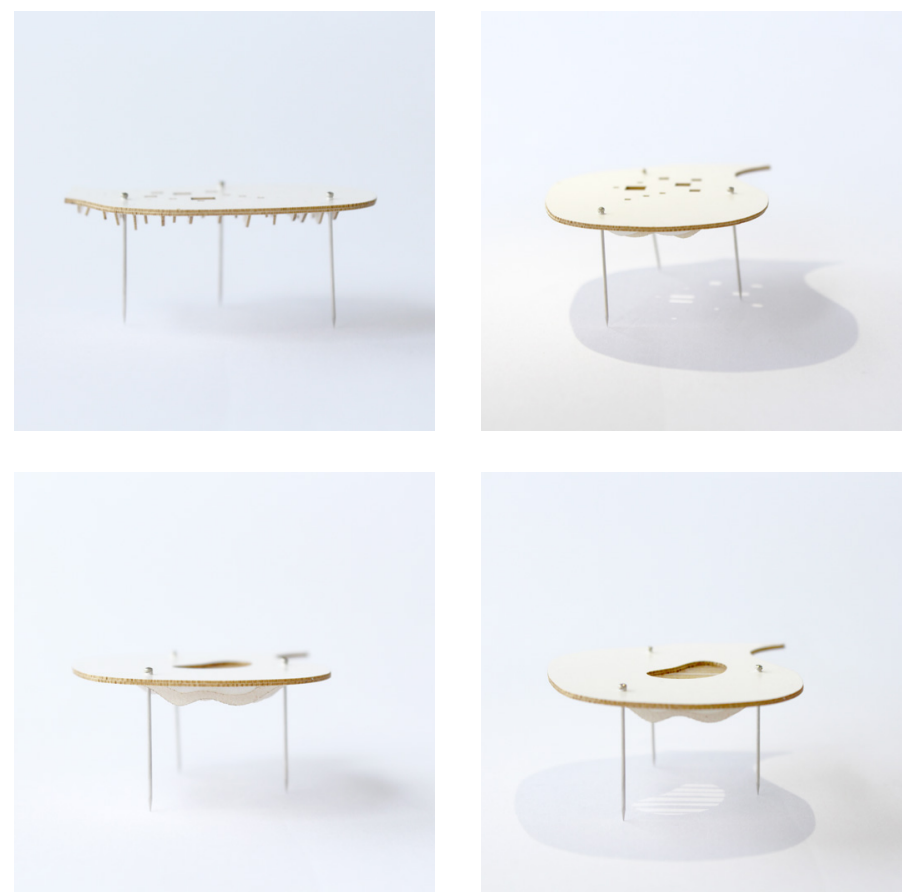

$\wedge$ 207. Structure, scale, perforations and light explorations 


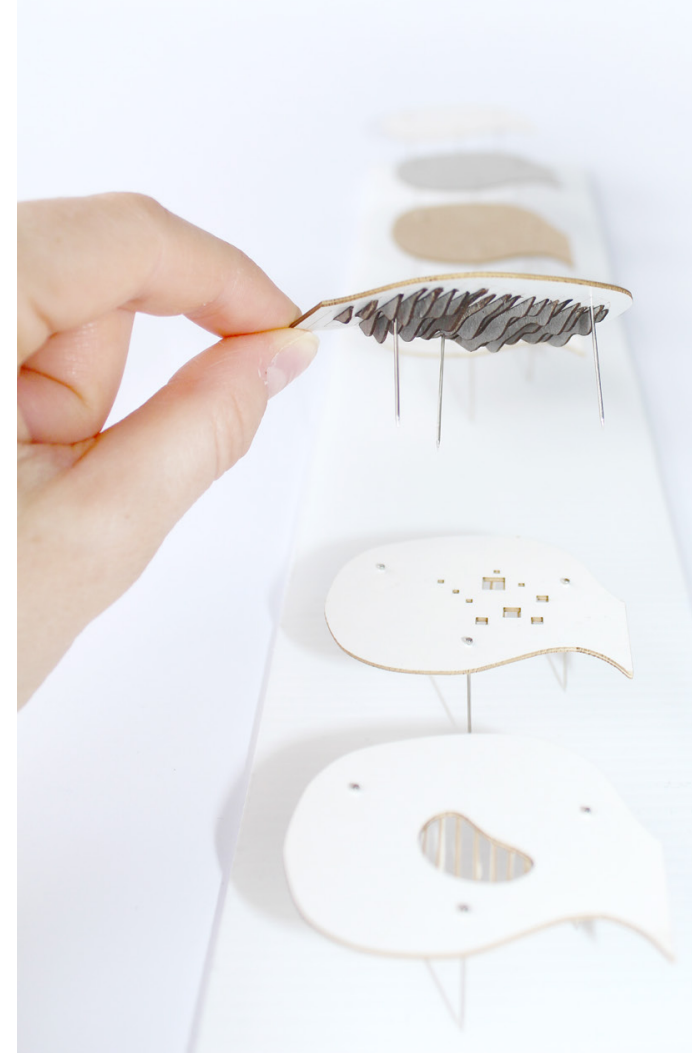

$\wedge$ 208. Roof iteration series 


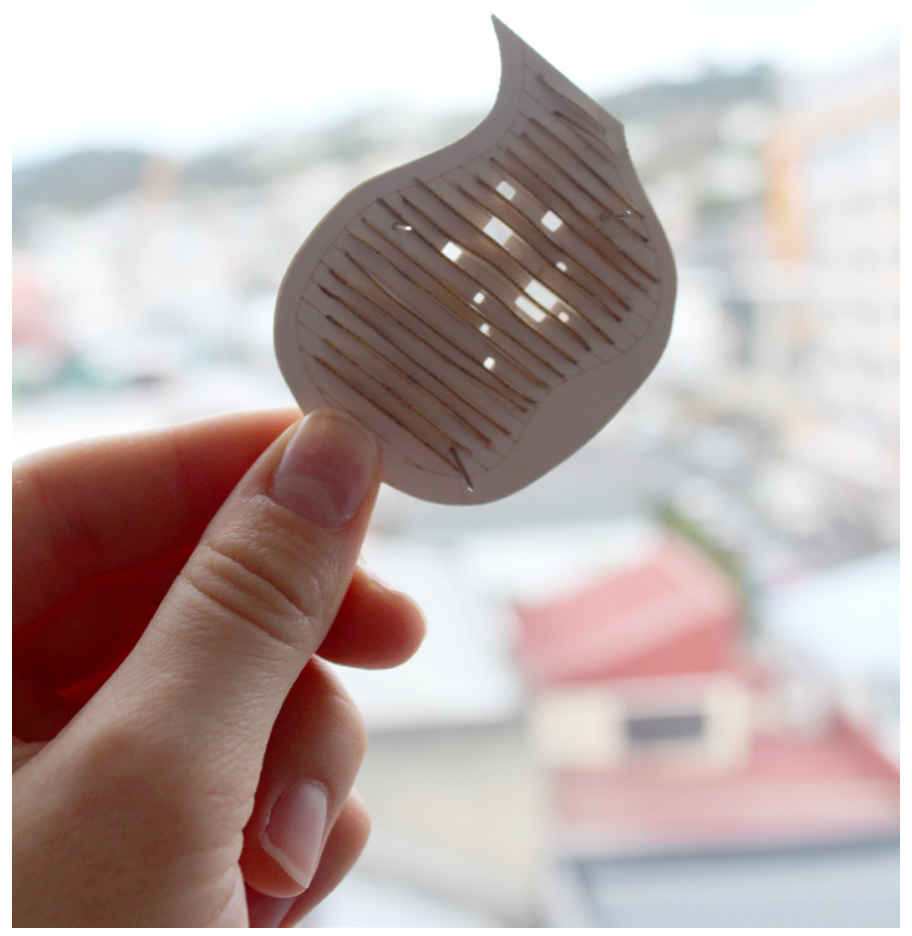

$278 \wedge$ 209. Smaller roof perforation 


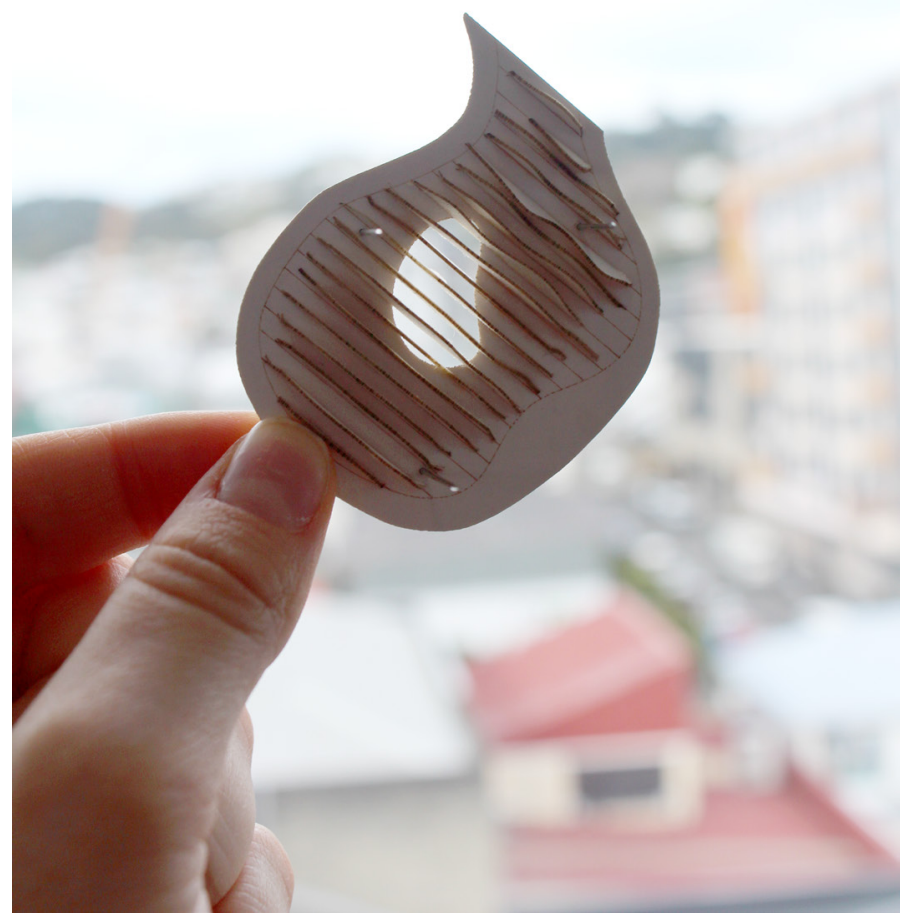

$\wedge$ 210. Larger roof perforation 


\section{Evaluation}

Continuing on from the developments made in the previous test in regards to the roof, this test combined delicacy and structure through the integration of fins. The paper models in the envelope development did limit the vertical exploration as it follows the undulations of the landscape. The roof shape is also exaggerated depending on the programme below. Despite these undulations not being evident in the models the drawings make up for their weakness. The drawings communicate the successful explorations of the tapering fins and undulating roof but also show the weaker developments, where the interior spaces connect with the roof or the fins continue right to the roof's edge, disrupting the sense of delicacy. This test was successful in integrating the design and structure together to achieve a delicate solution that develops on the comments made at the August review. Materiality, tapering, structure, perforations and relationship to the interior spaces were all considered.

Although the smaller perforations in the model iterations do appear delicate, the rigid squares do not follow the same language as the rest of the building. The success of the larger organic perforations is the light and shadow on the floor, highlighting the structure in a delicate way. Rather than the perforations being delicate, it is the light effect on the ground which the occupant can engage with. 
Developing the Interior Spaces

\section{Aim}

Develop the scale, materiality and occupation of the interior spaces to a high level of detail.
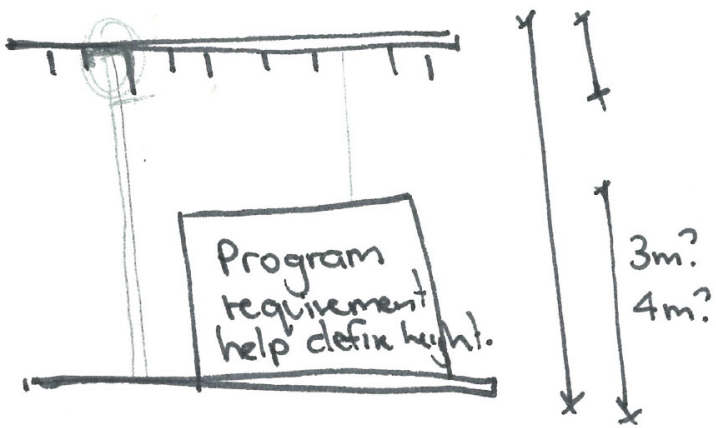

$\wedge$ 211. Initial sketch to address intimate spaces 

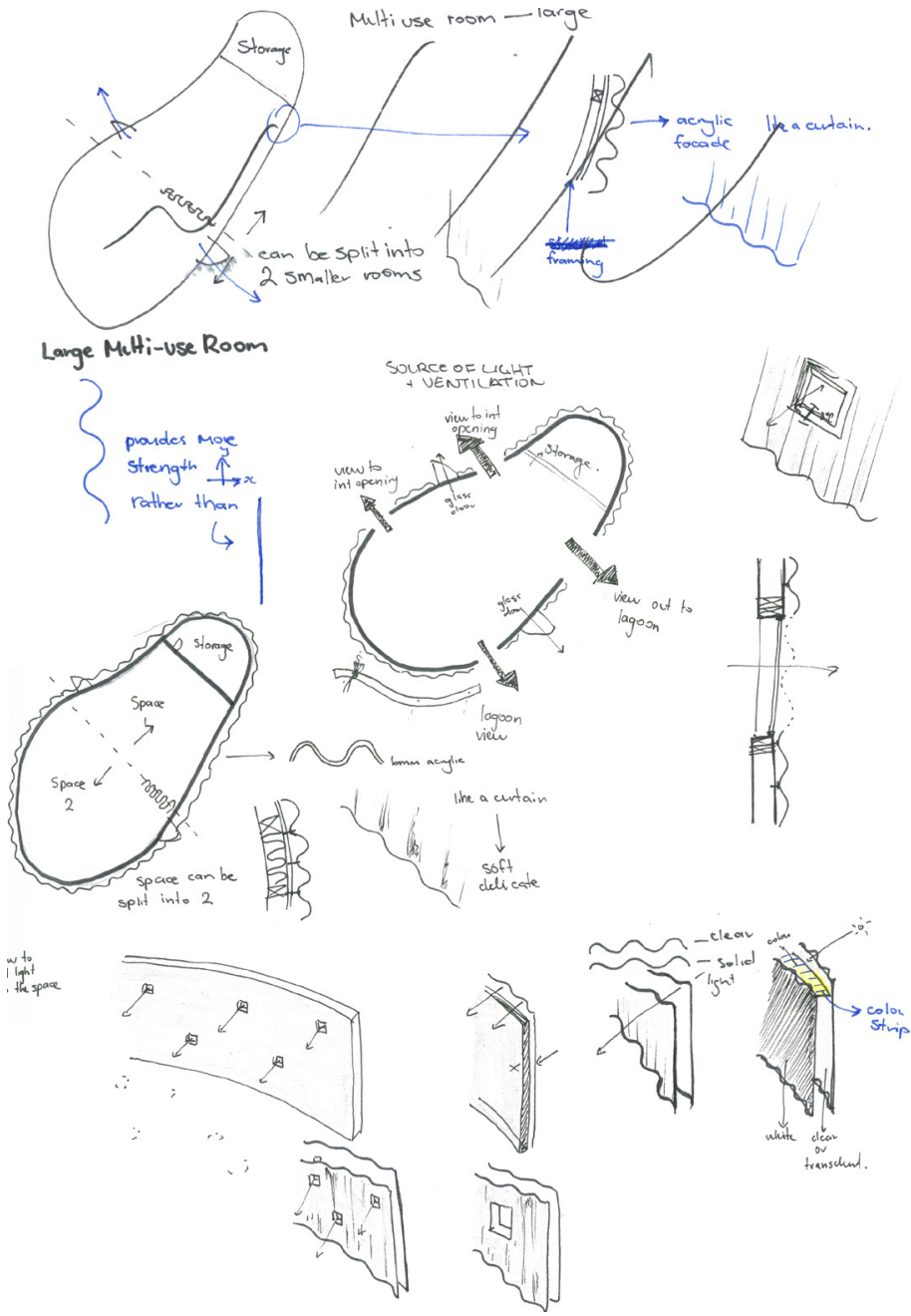


\section{Evaluation}

The development was necessary to solidify the interior pavilion spaces. Location, shape, scale and materiality were all considered in relation to programme. The gallery has three sections; admin/entry, galleries and café. Scale and material were considered in relation to public and private spaces and their required heights. For example, as the galleries increase in size in plan they also increase in height. Minor programmes such as bathrooms and the smaller multi-use spaces are smaller in height and size. This ensures the pavilion type spaces below the canopy vary, offering different engagements. A successful outcome from this exercise was expanding on the smooth material palette of concrete and glass. Curved acrylic shaped like a flowing curtains modulates the vertical surface in selected areas such as the café, office, multi-use spaces and bathroom partitions. This creates intimate moments of intrigue within the building at the human scale. 
Developing the Details

\section{Aim}

Develop the details at an intimate scale. Focus on furniture and connections to emphasise the delicacy throughout.

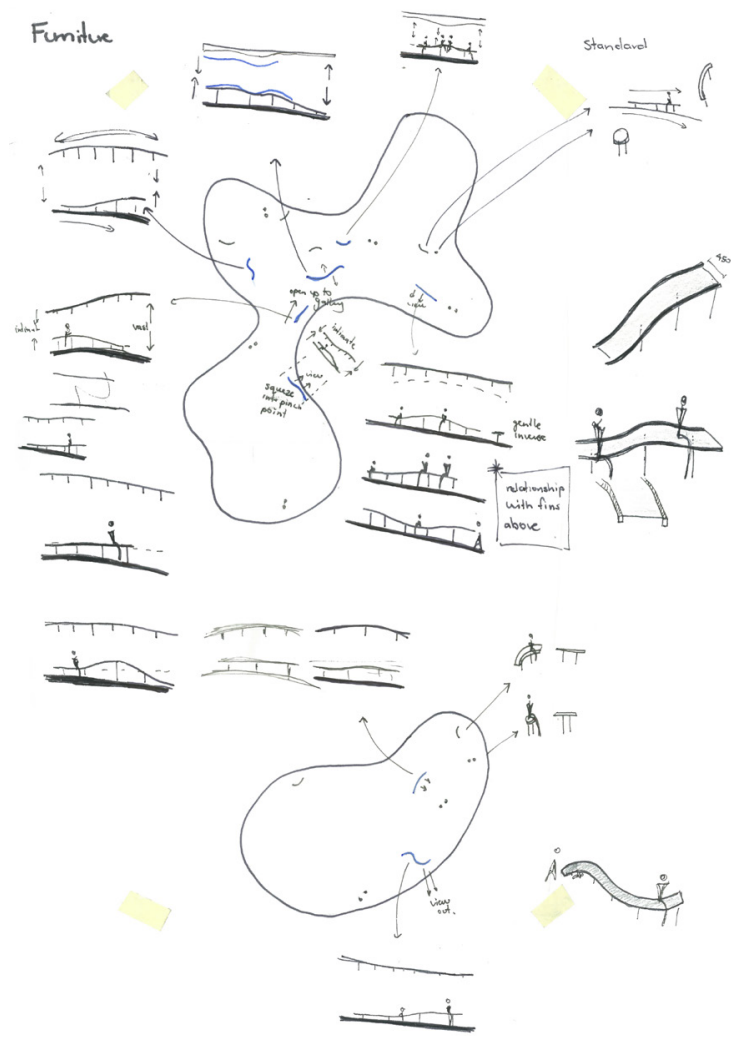


Shop and Cafe Furniture
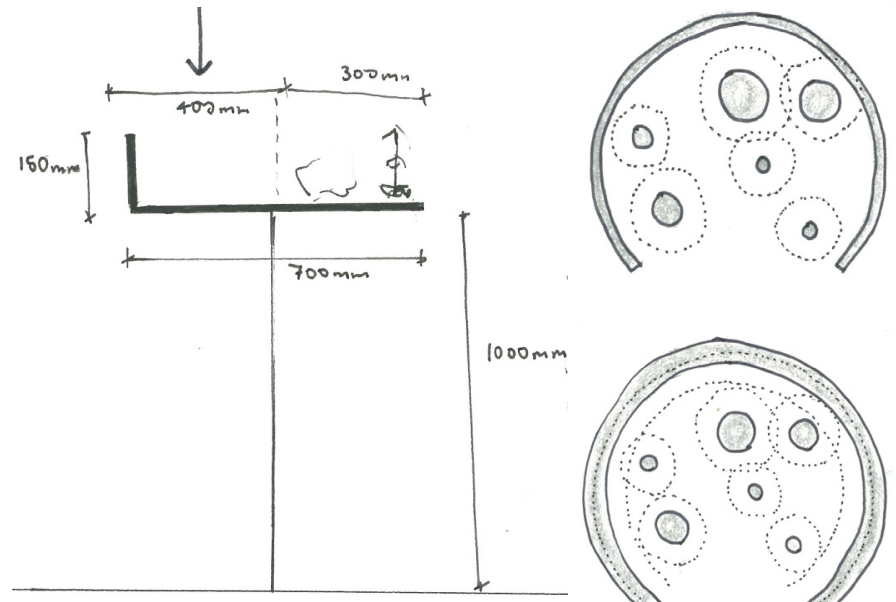

$\wedge$ Shop table pragmatics

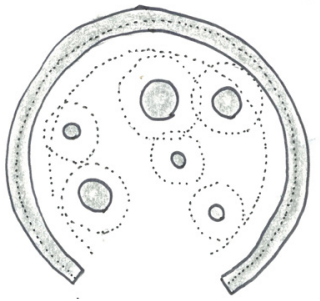

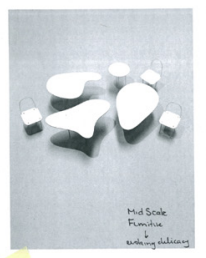
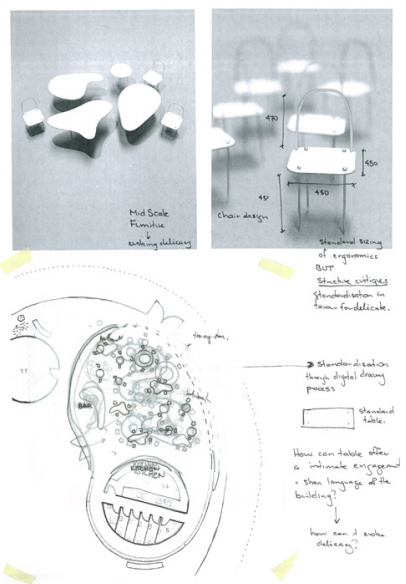
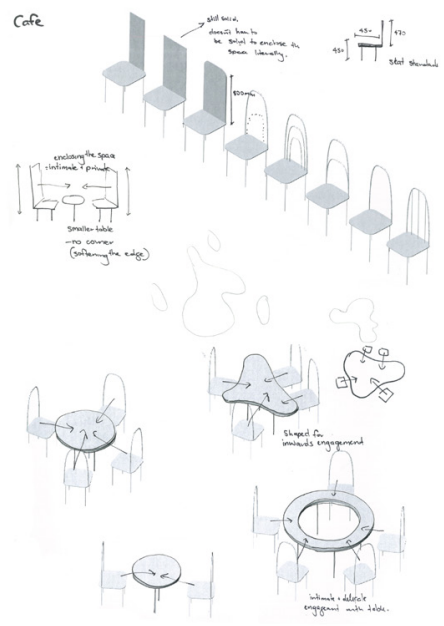

$\wedge$ 214. Cafe seating development 


\section{Furniture Iterations}
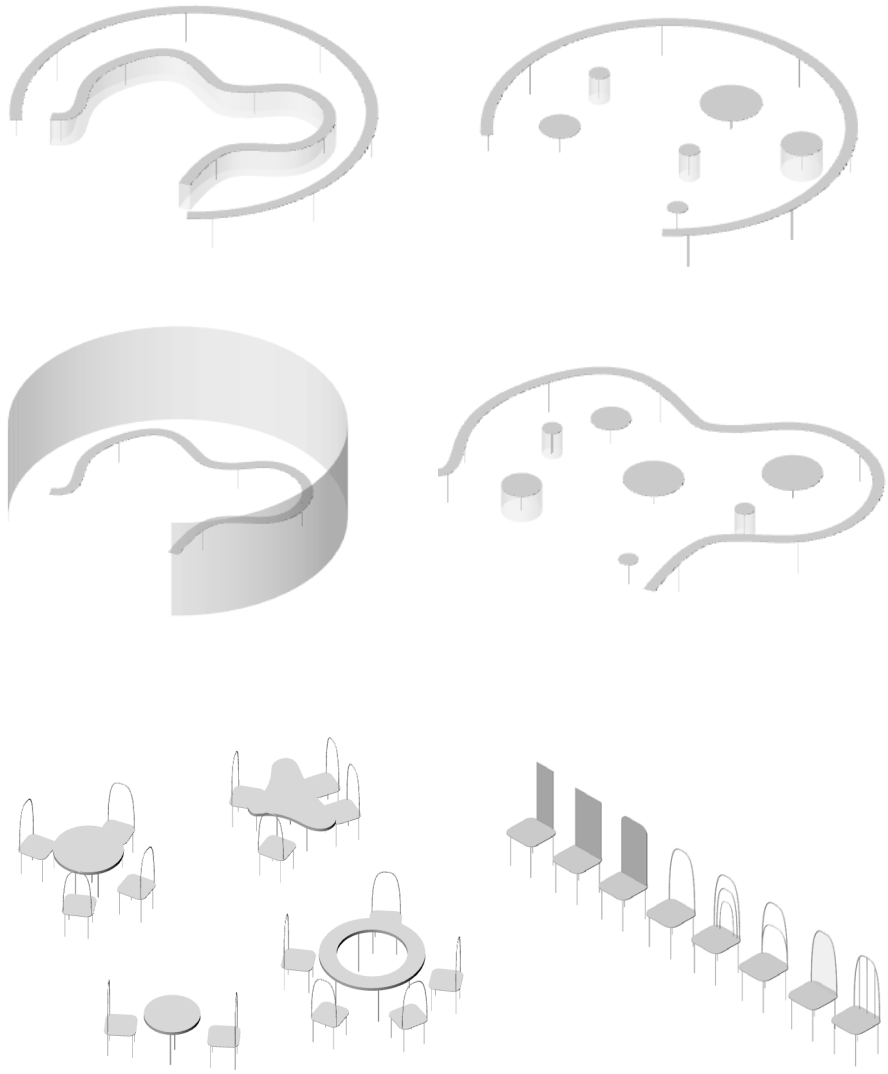
Facade Analysis Example

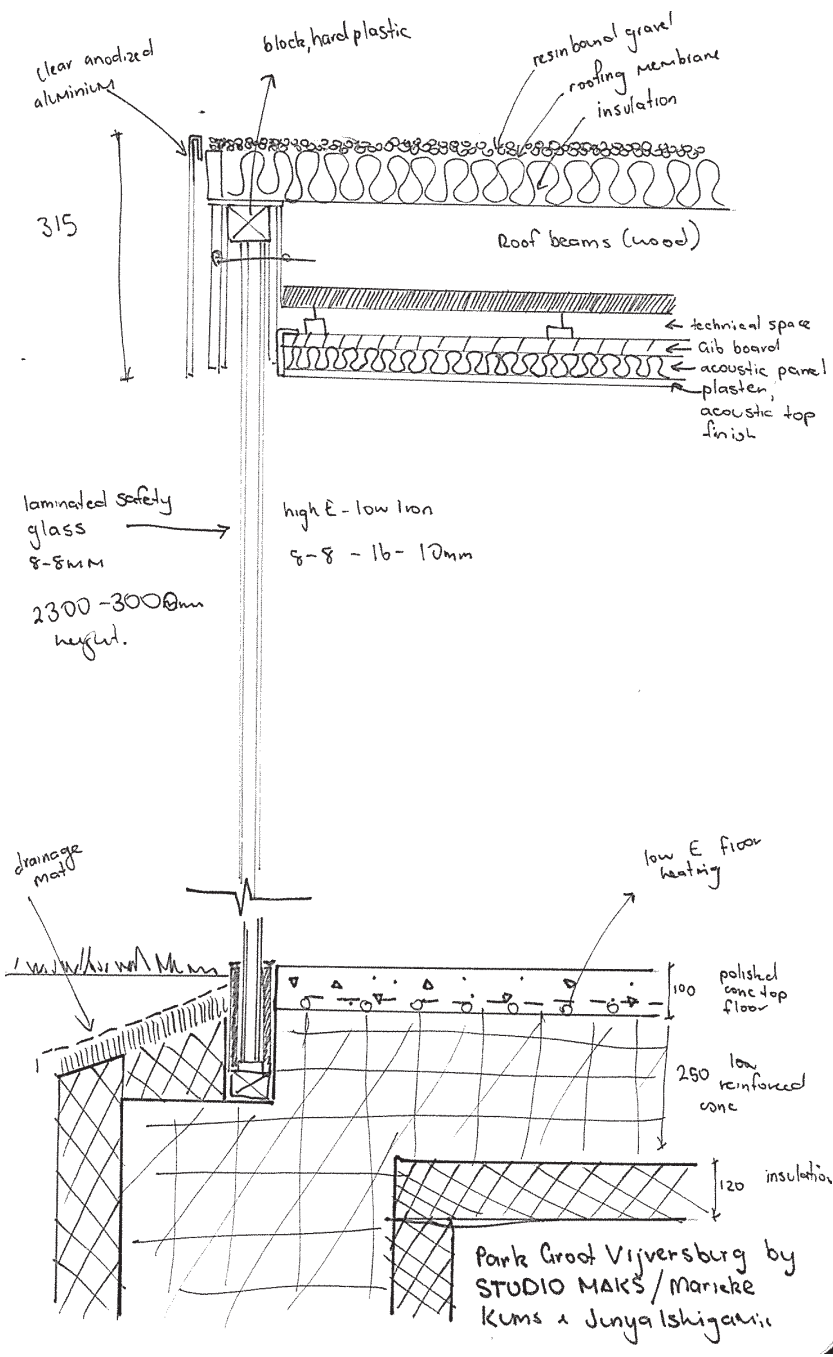

$\wedge$ 216. Analysing facade detail 
Detail Concepts

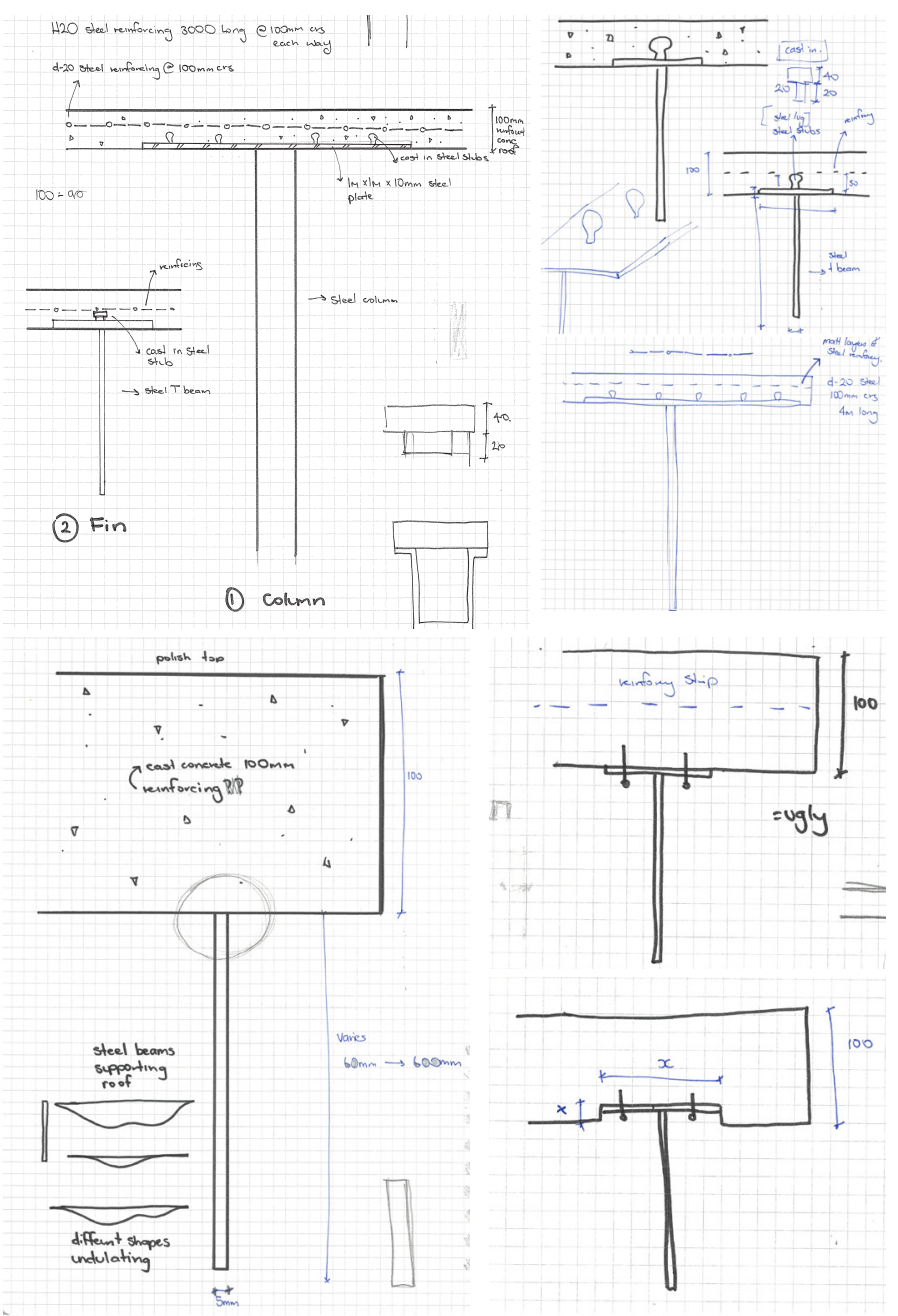




\section{Detail Development}

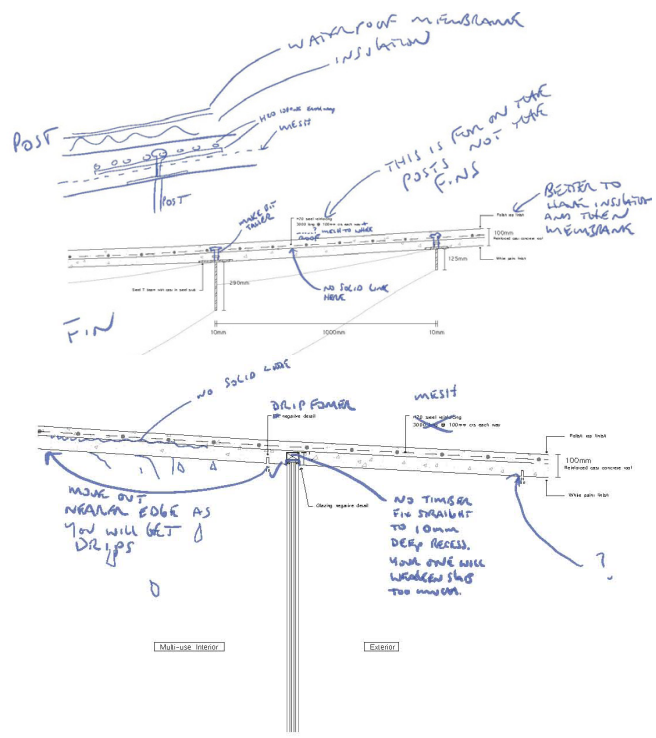

iㅛ. $5.5000 \mathrm{mim}$

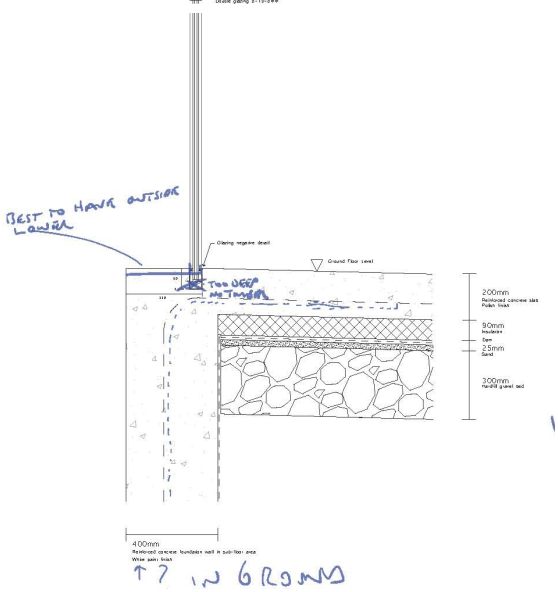

^ 218. Developing fin and glazing detail 

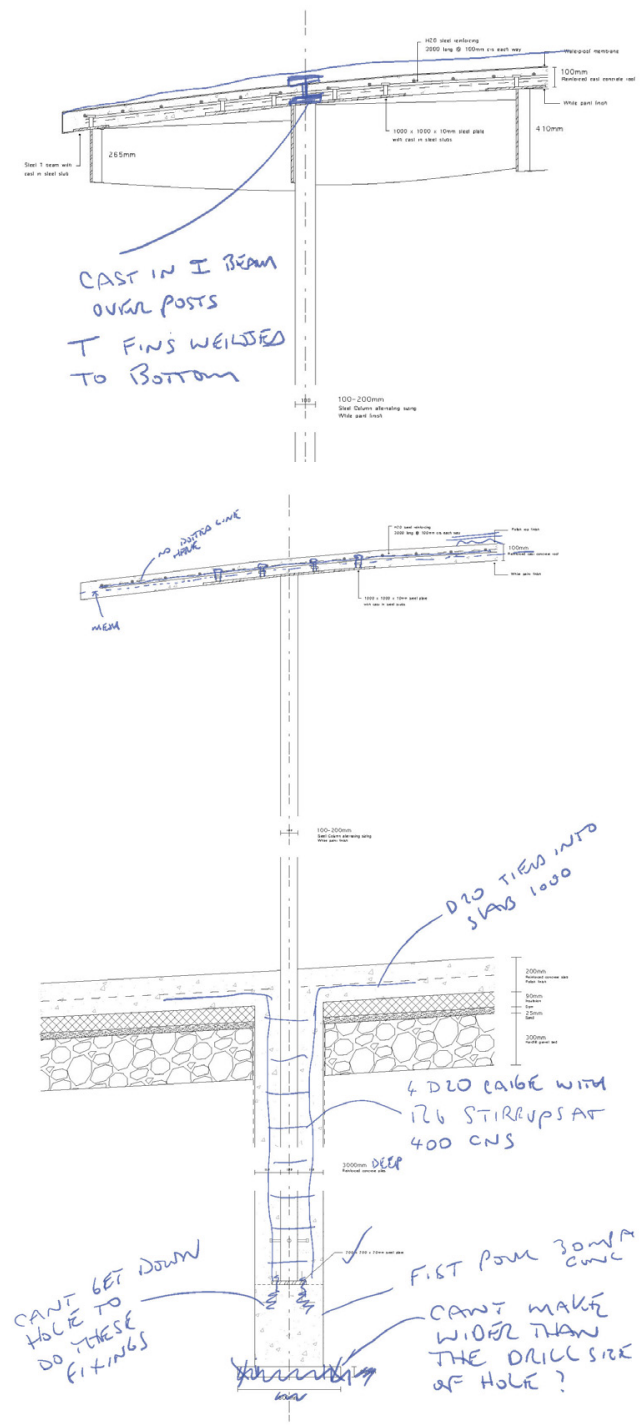


\section{Evaluation}

The consideration of custom-designed furniture for the building was crucial to extend the language to another scale. Similar to the seamless progression from space to space, the sloped floor transitions into benches following the curve of the building. The material selection is applicable to both the building and furniture, considering the best strength to weight ratio material. A success from this exploration was the development of details that reconsidered standard connections. Standard connection can appear heavy, bulky and lack clean edges, all elements that do not explore the proposition. It was essential to make the connections appear effortless and seamless, in favour of the delicate. This amount of detail consideration has proven that the appearance of ease comes with many hidden complexities. 


\section{Landscaping Considerations}

\section{Aim}

Develop the landscape support the building's response to the proposition.
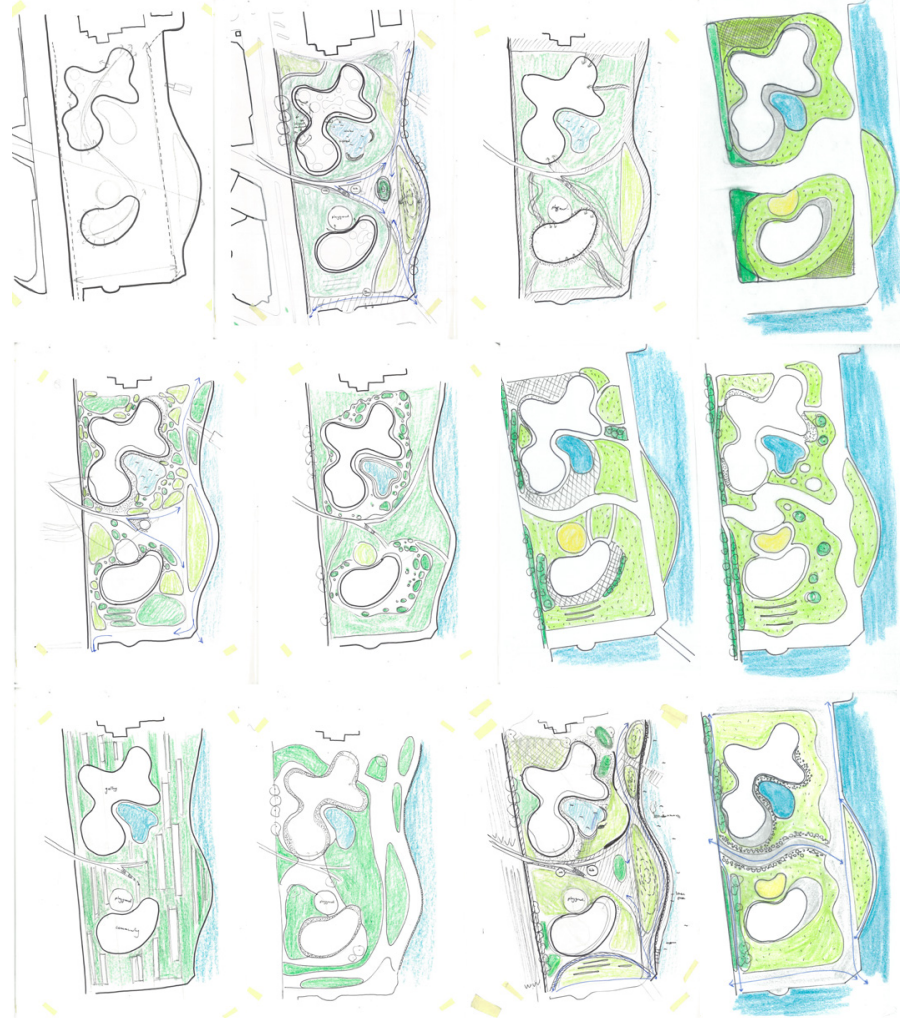

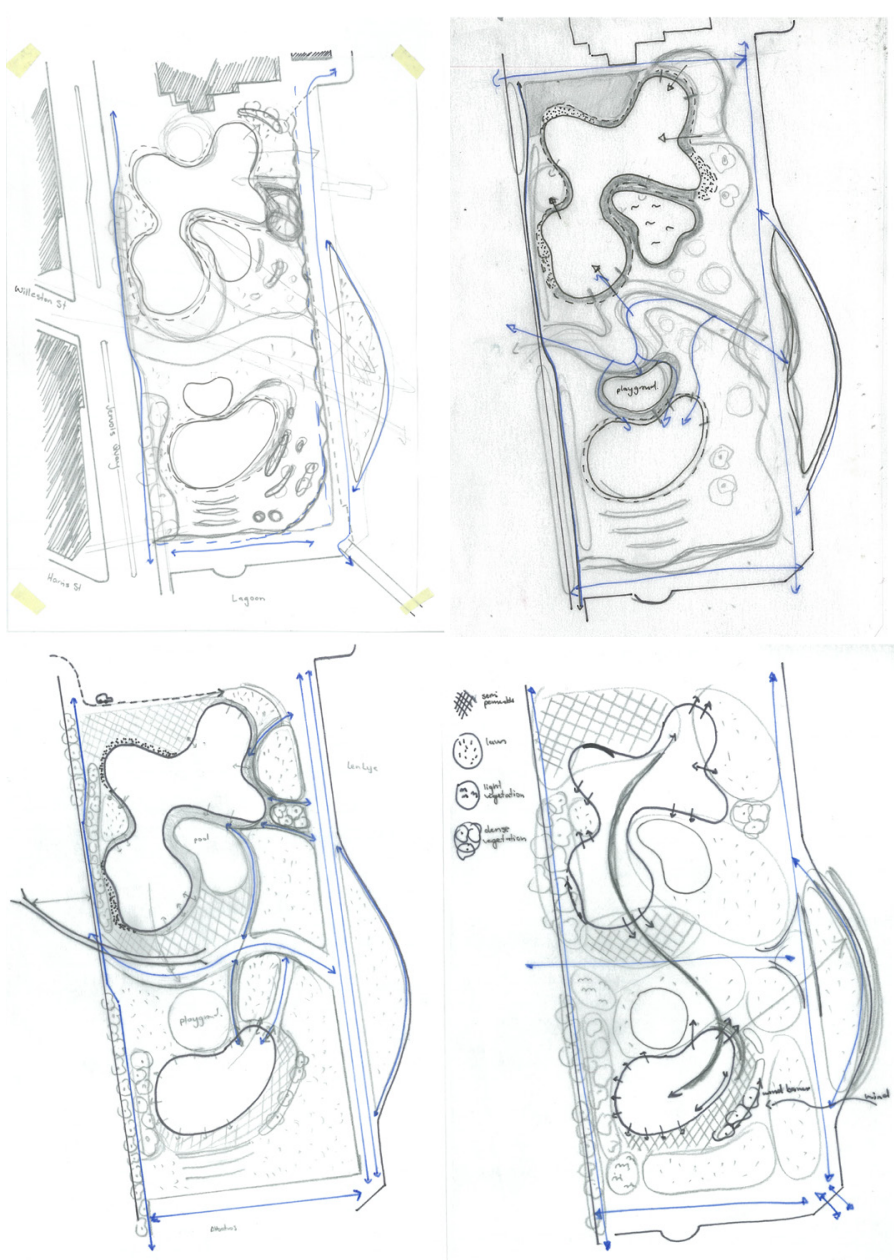
Sketch Development

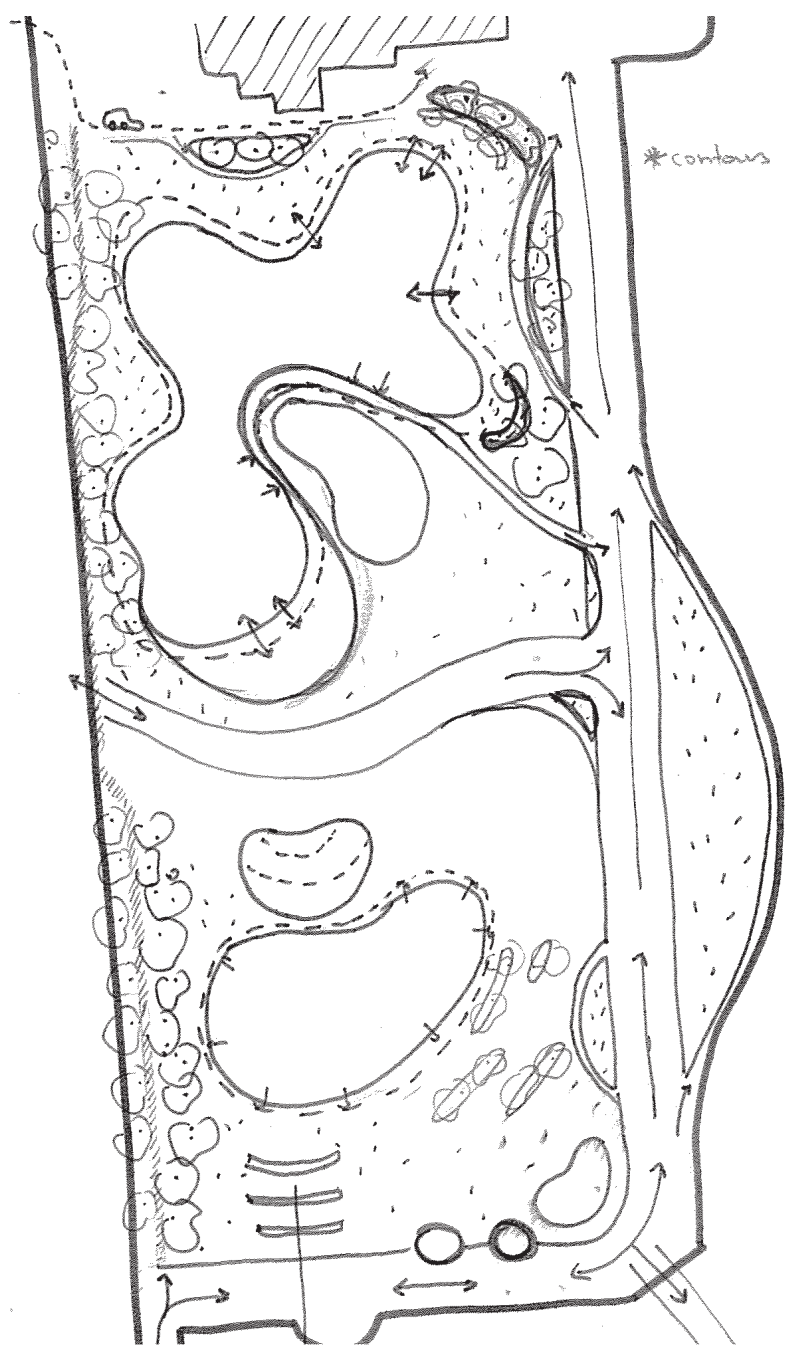


Digital Development

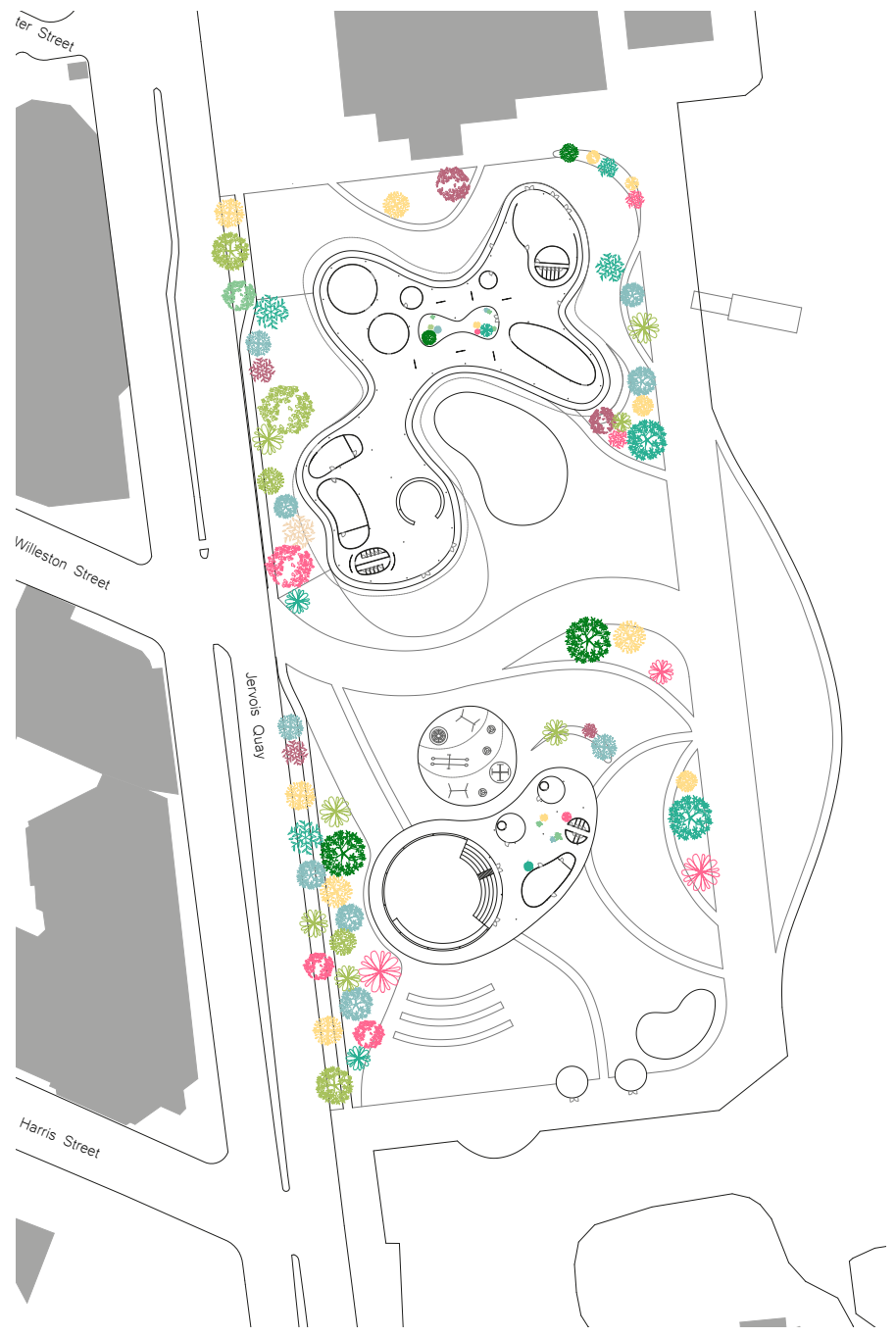




\section{Evaluation}

The surrounding landscape presented an opportunity to extend the language of the building to another scale. The earlier iterations were simple and rather unsuccessful due to their lack of detail engagement with the site. Reflecting on these weaknesses informed subsequent designs that employed the pragmatics of site, requirements and design technique 'borrowed scenery' to engage with the rolling hills across the harbour. The success of designing with borrowed scenery was using near and far landscapes and natural elements to enhance the architecture and create an effortless continuity between interior and exterior (Wybe, 2015, p. 32). It enabled occupants to engage with nature and the landscape intimately. Site requirements that were considered involved circulation, view shafts, public space, buffer protection, orientation and materials. These elements all align with O'Byrne's research on the Wellington Waterfront and more specifically on Frank Kitts Park redevelopment considerations (2016, pp. $51,113,236)$. 


\section{Development}

The following pages communicate the sectional drawings in their final stages of development and screenshot moments from the digital model. The earlier sectional drawings did not communicate enough information and as a result of this weakness they were developed further. These developments communicated elements such as the building's structure, consideration of services and how they could be integrated into the design to magnify the proposition. The screenshots acted as a 'walk through' tool to select the most effective moments from the building to communicate in perspective.
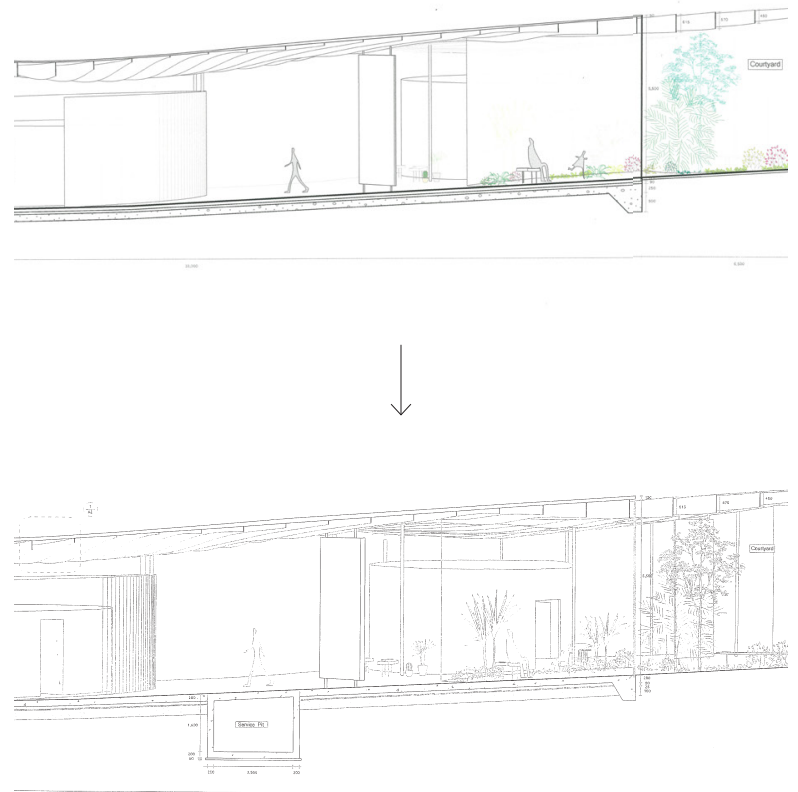


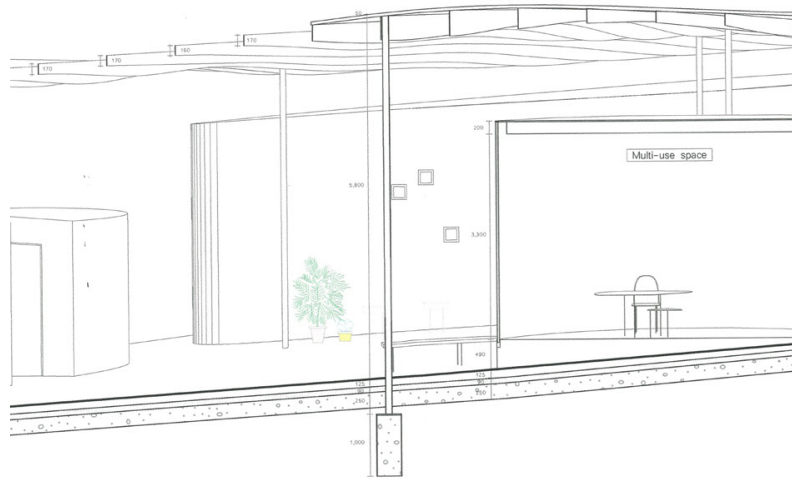

sasoo

$\checkmark$

(돈

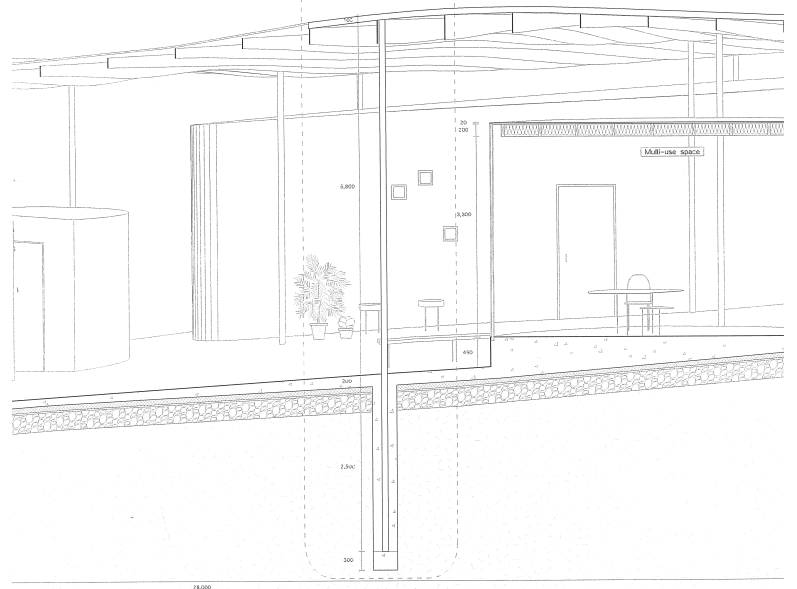

$\wedge$ 226. Gallery section developing 

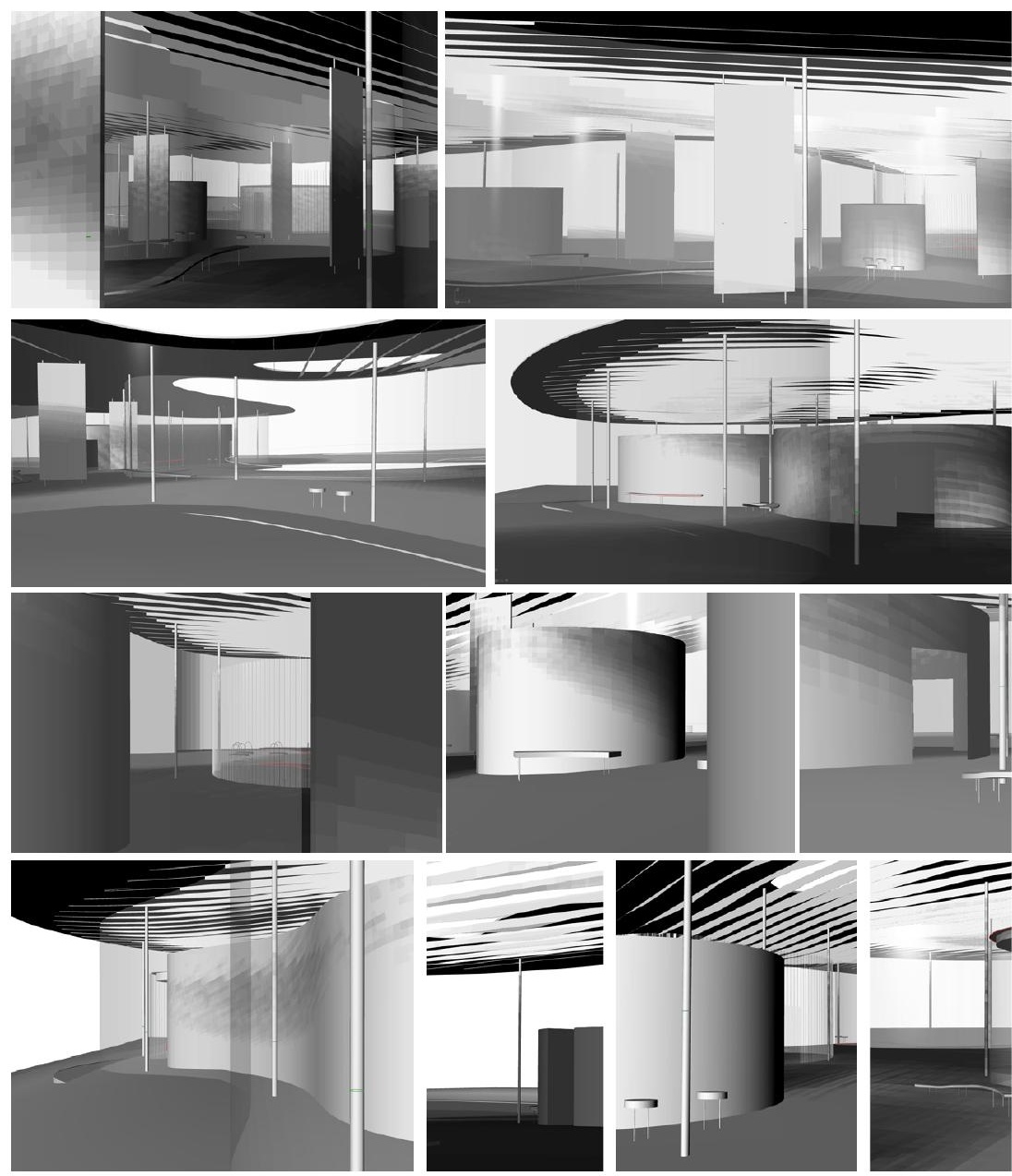


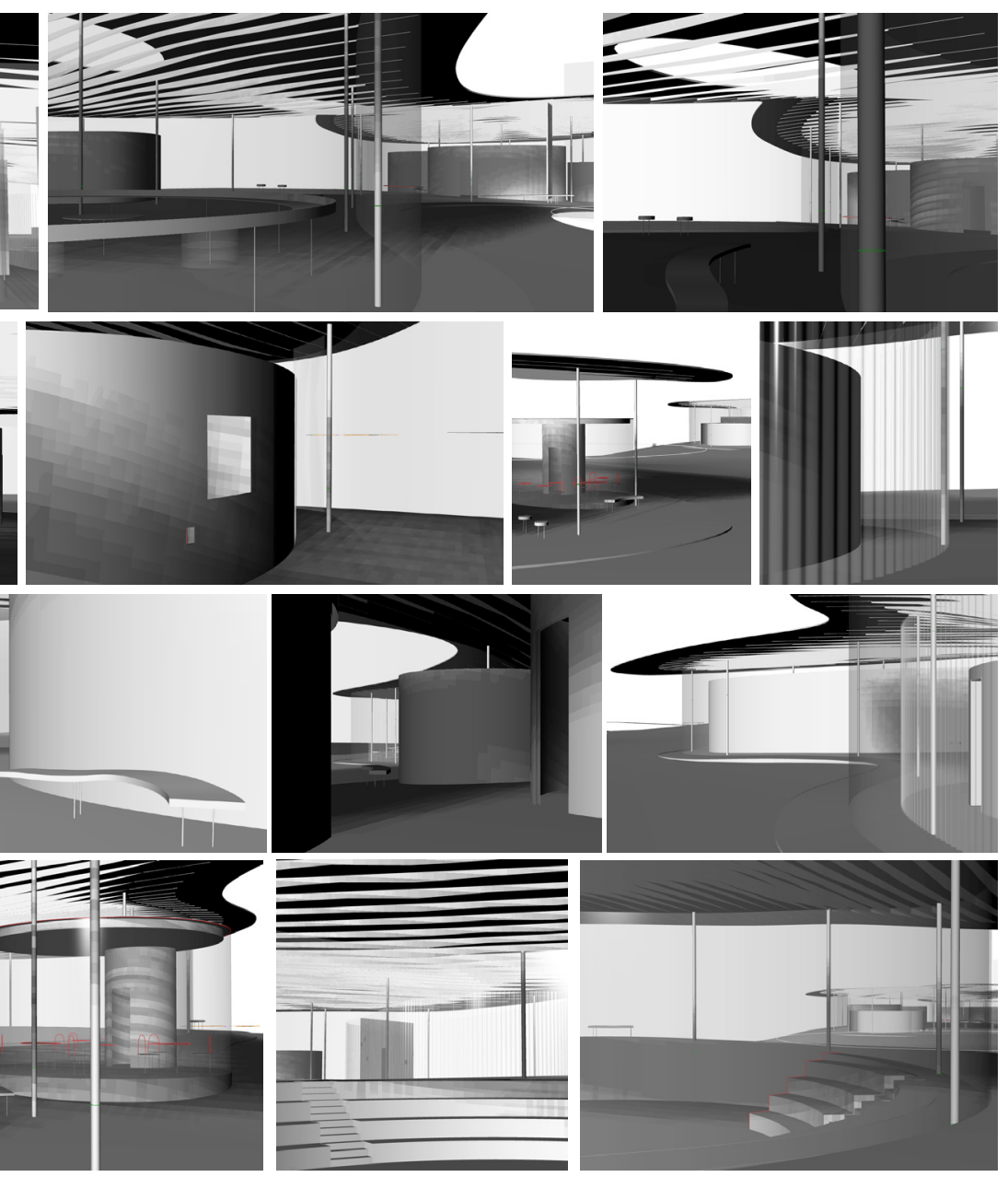




\section{FINAL DESIGN}

The gallery and community centre is located on two gentle slopes within Frank Kitts Park. The final design attempts to capture a seemingly effortless building that evokes the perception of delicacy. 


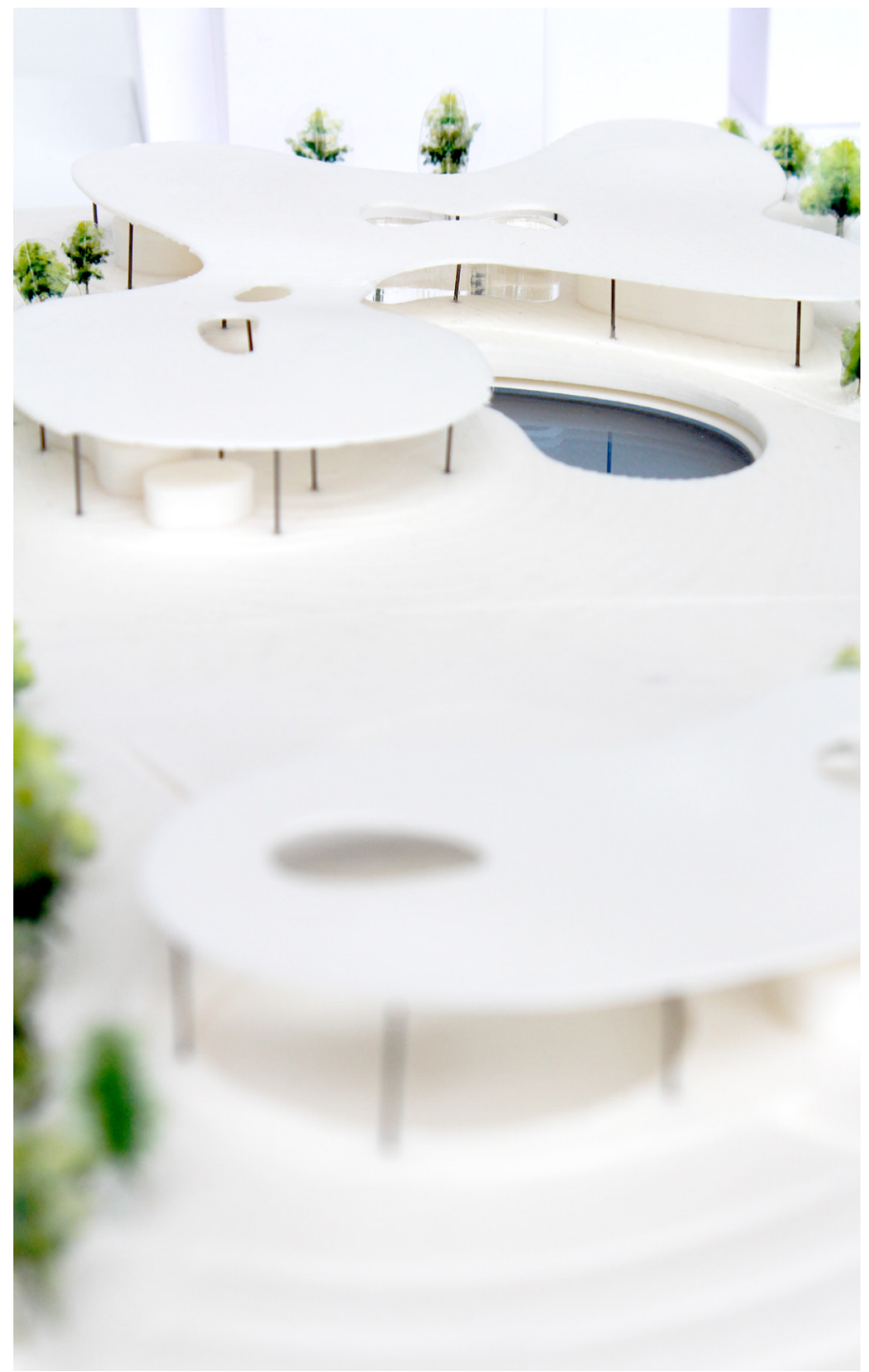

^ 228. Final physical model 303 


\section{Master-plan}

The main circulation along the waterfront promenade and through the centre of the site has been retained with various minor paths moving through the site and the buildings. Due to the nature of the landscape, the circulation is relatively informal, creating open spaces that connect the inside and outside, and provide the occupant with the freedom to determine their own circulation.

Vegetation buffers protect the site from Jervois Quay, and the view shafts from the city to sea are retained. The landscaping technique, borrowed scenery, extends the building's language to the landscape and borrows from the hills across the waterfront. The buildings open out in all directions, creating both public and private pockets within the landscape. The language of the building extends outward into the landscape creating moments of intimacy

\section{The Buildings}

The two buildings share the same language of a soft and organic envelope that allows people to move through the spaces in a fluid and seamless manner. Much like the installation and mid-scale, two seemingly paper-thin canopies attempt to float over the landscape with a series of intimate pavilion type interior space below that change in scale and material according to programme. The final design attempts to pursue the appearance of delicacy.

The following pages provide visual representation to communicate the building. Due to the format of this portfolio document, the drawings do not follow a traditional layout. The zoomed-in areas aid in communicating the design intent, for clarification. For the visual presentation these drawings were presented in a traditional format. 


\section{Master-plan}

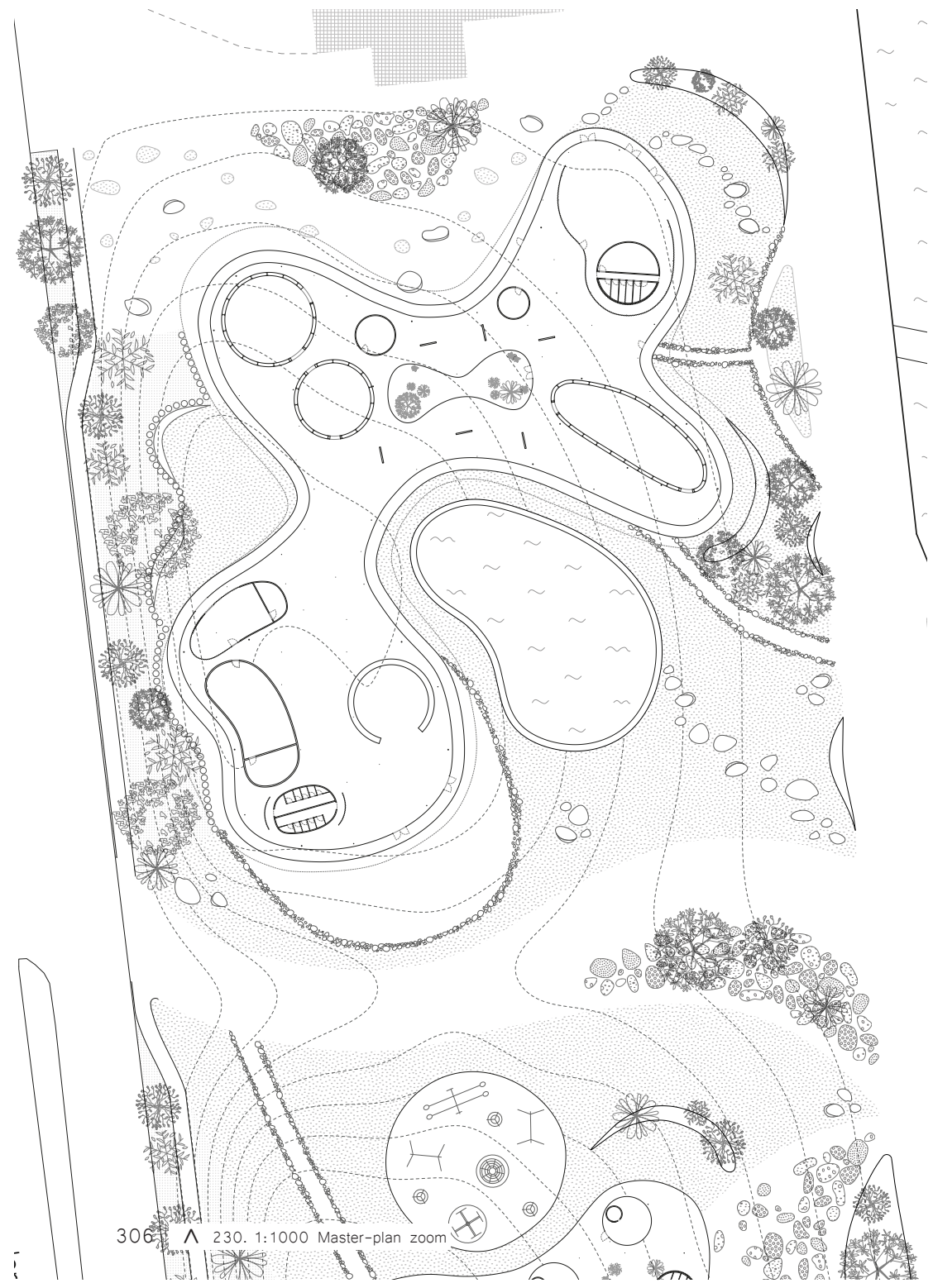


Master-plan

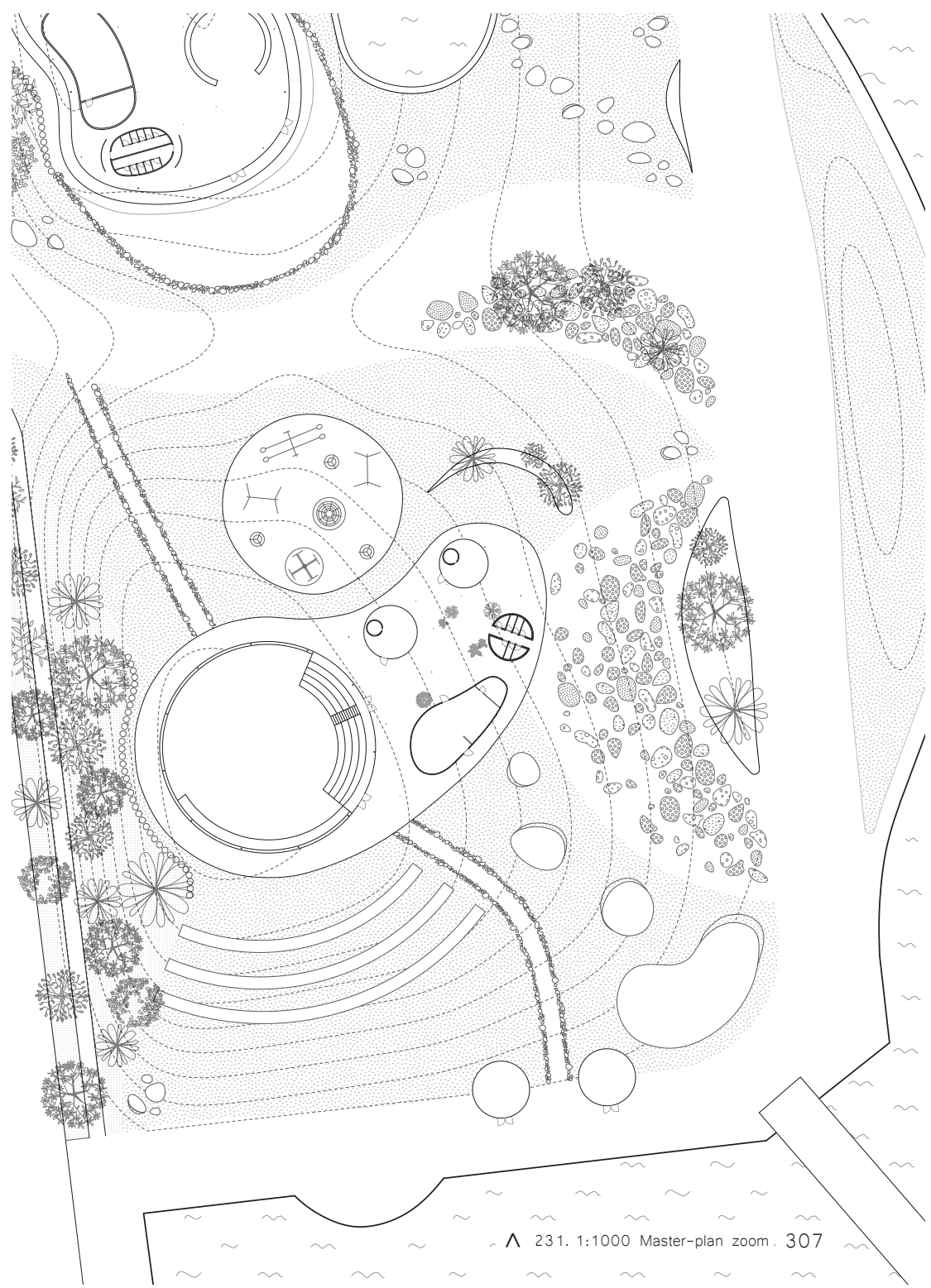


Gallery

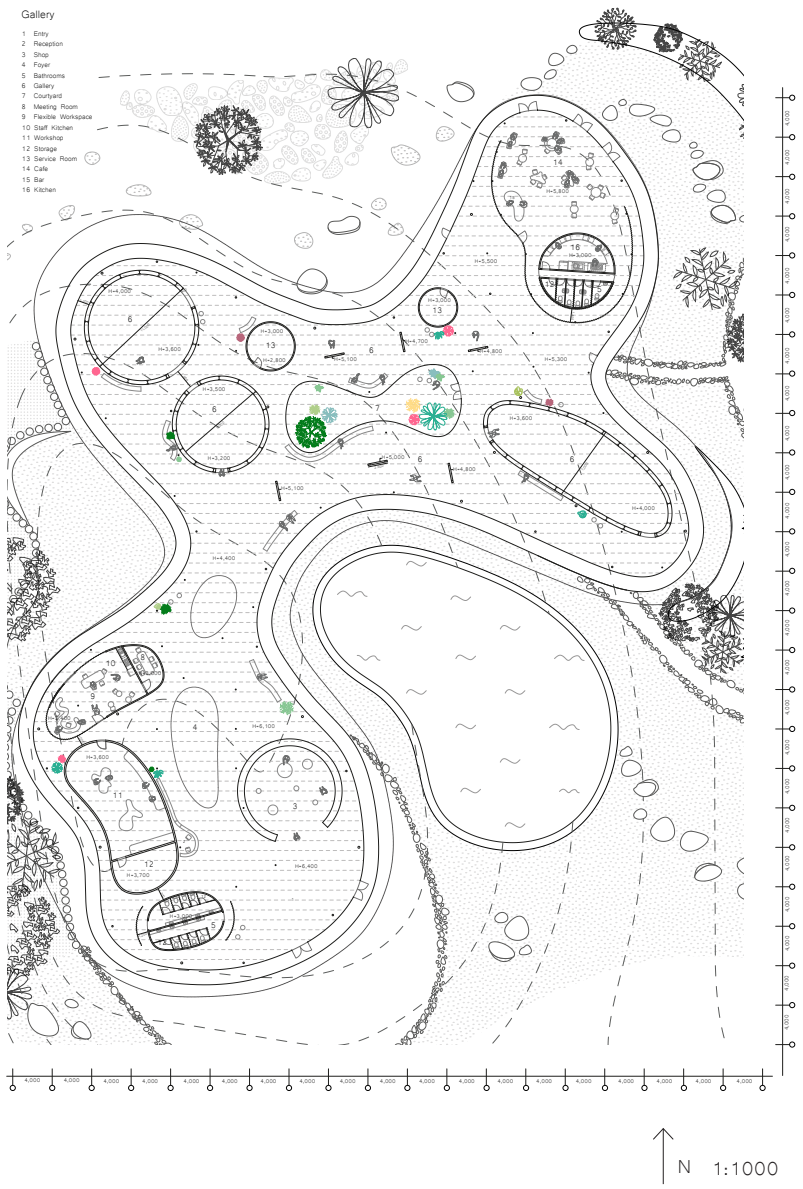




\section{Gallery}

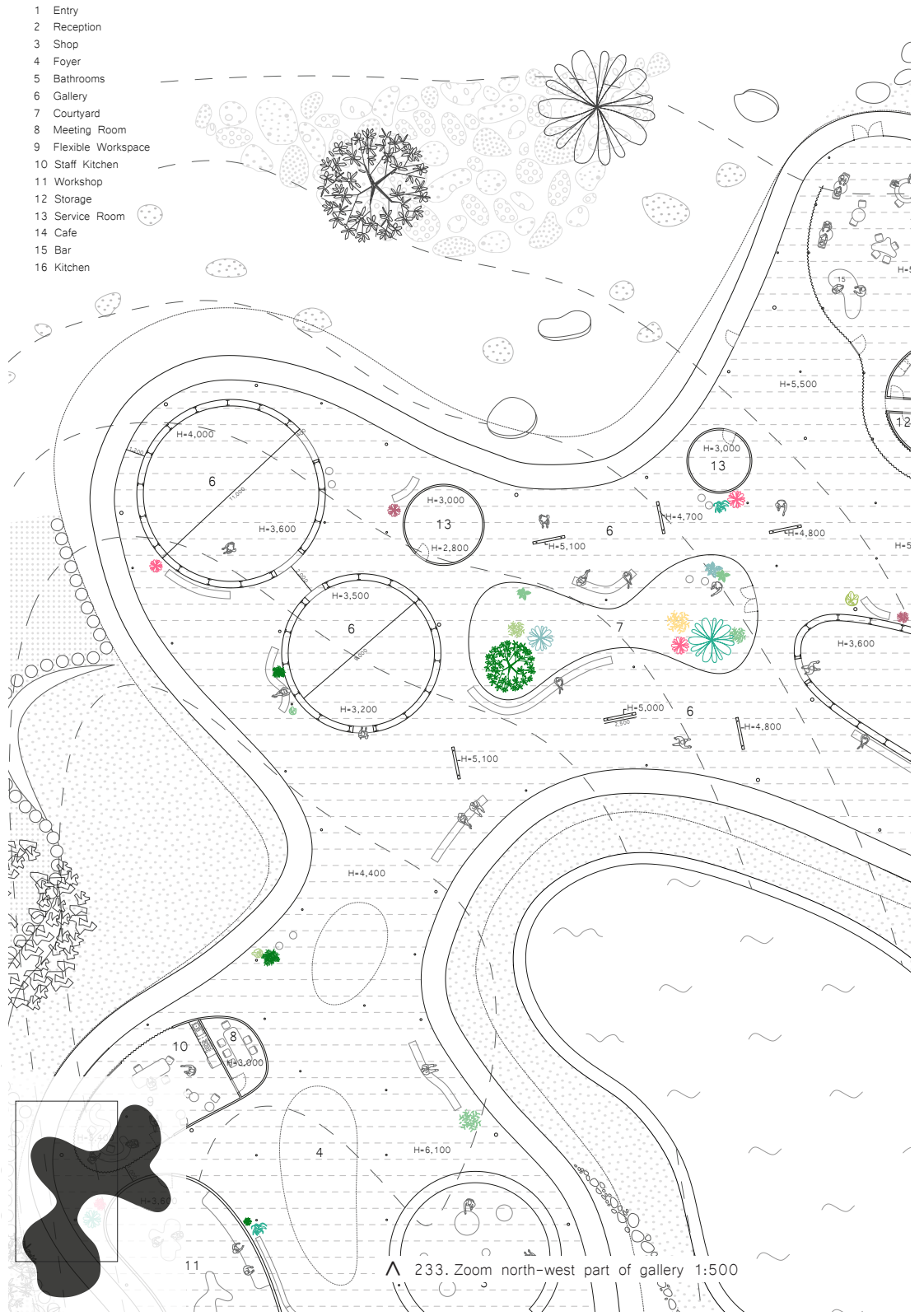




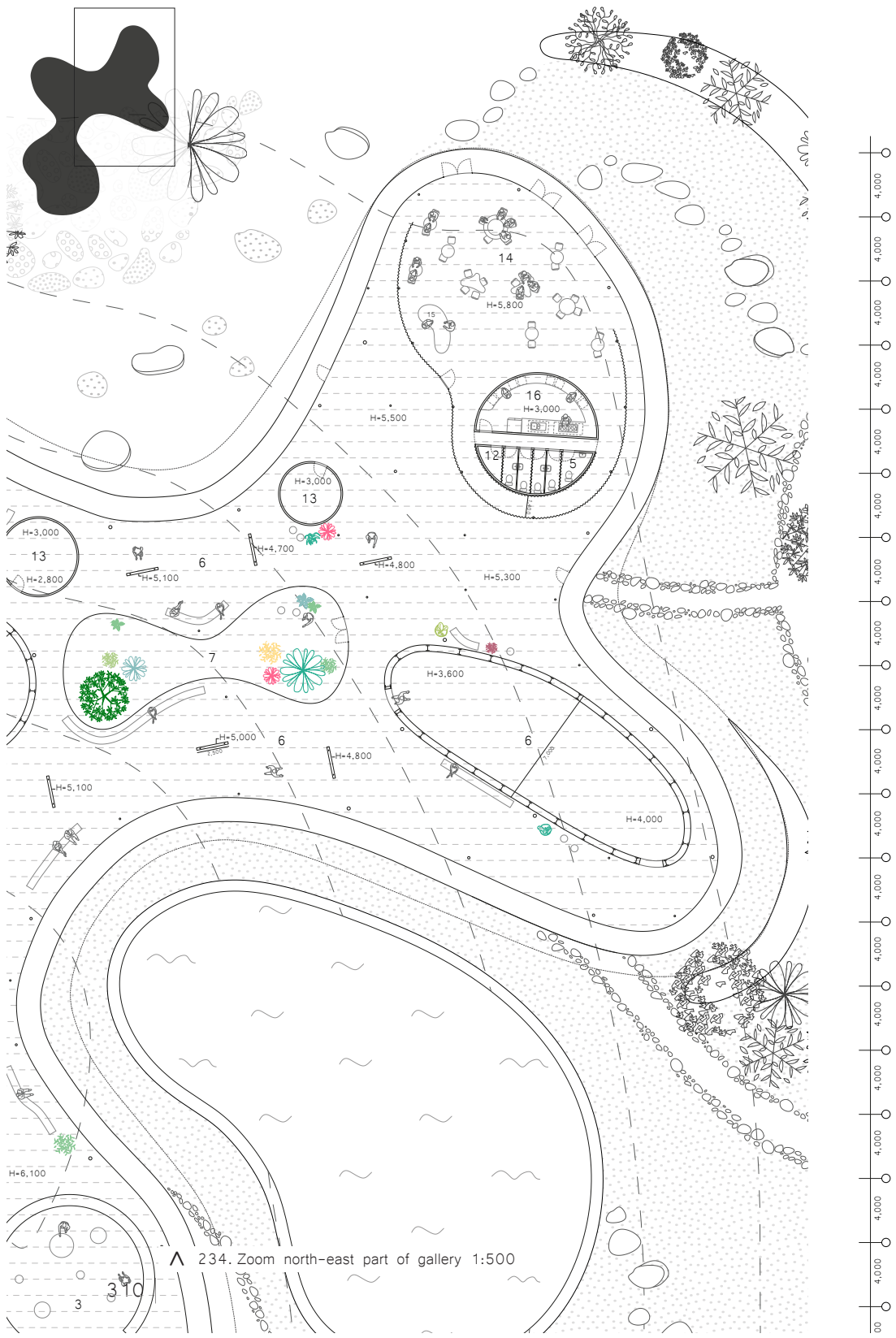




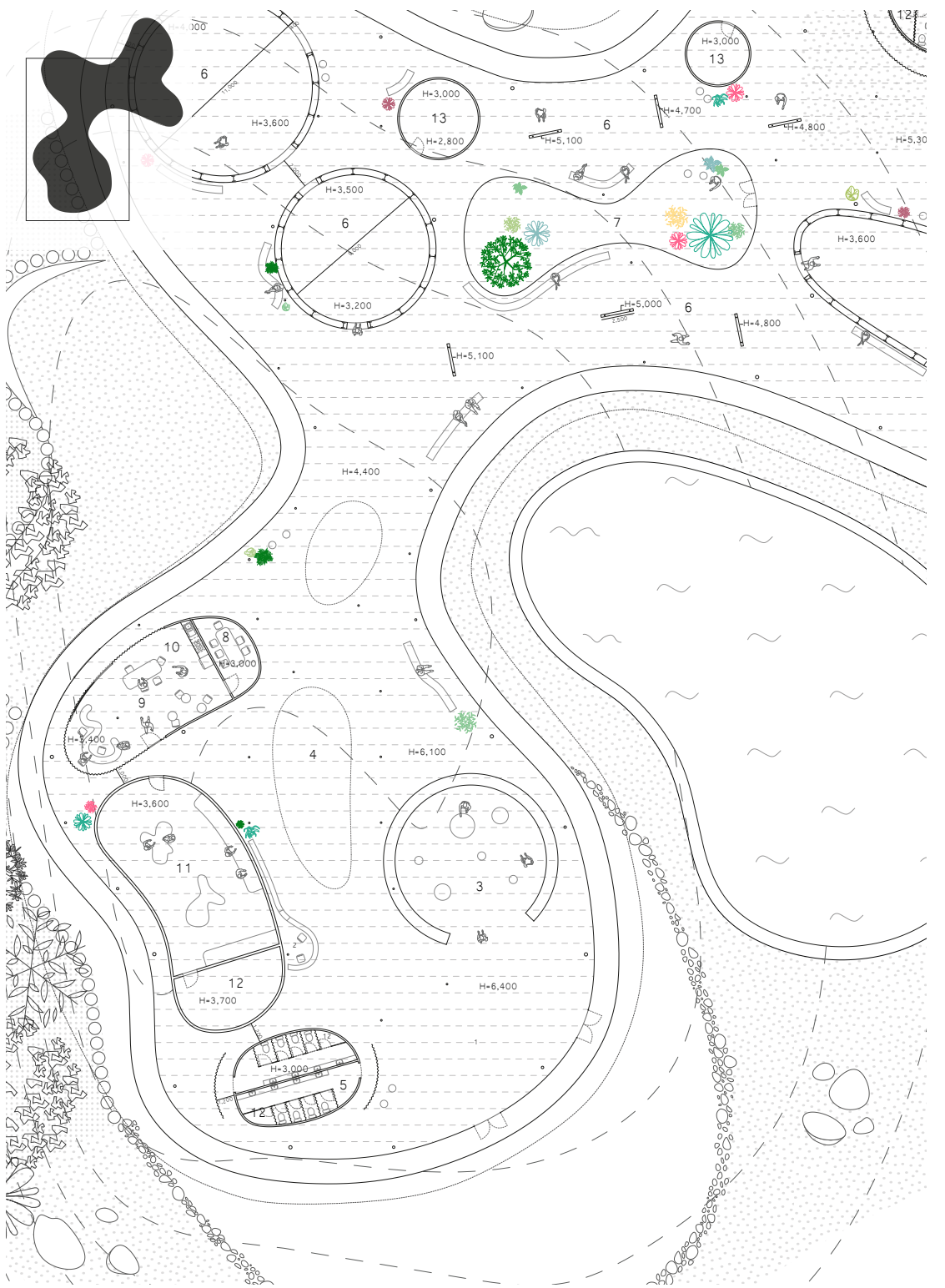

$\wedge$ 235. Zoom southern part of gallery $1: 500$

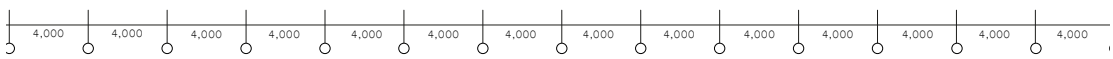




\section{Community Centre}

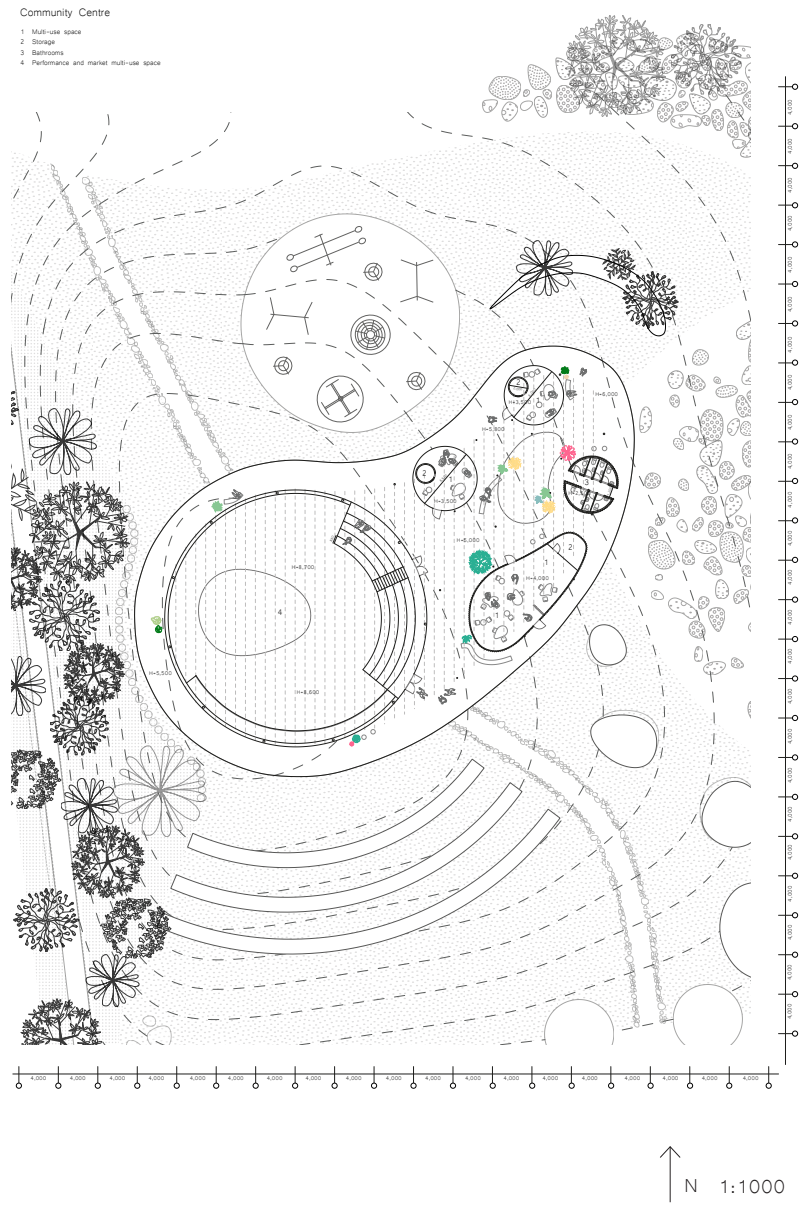




\section{Community Centre}

1 Multi-use space

2 Storage

3 Bathrooms

4 Performance and market multi-use space
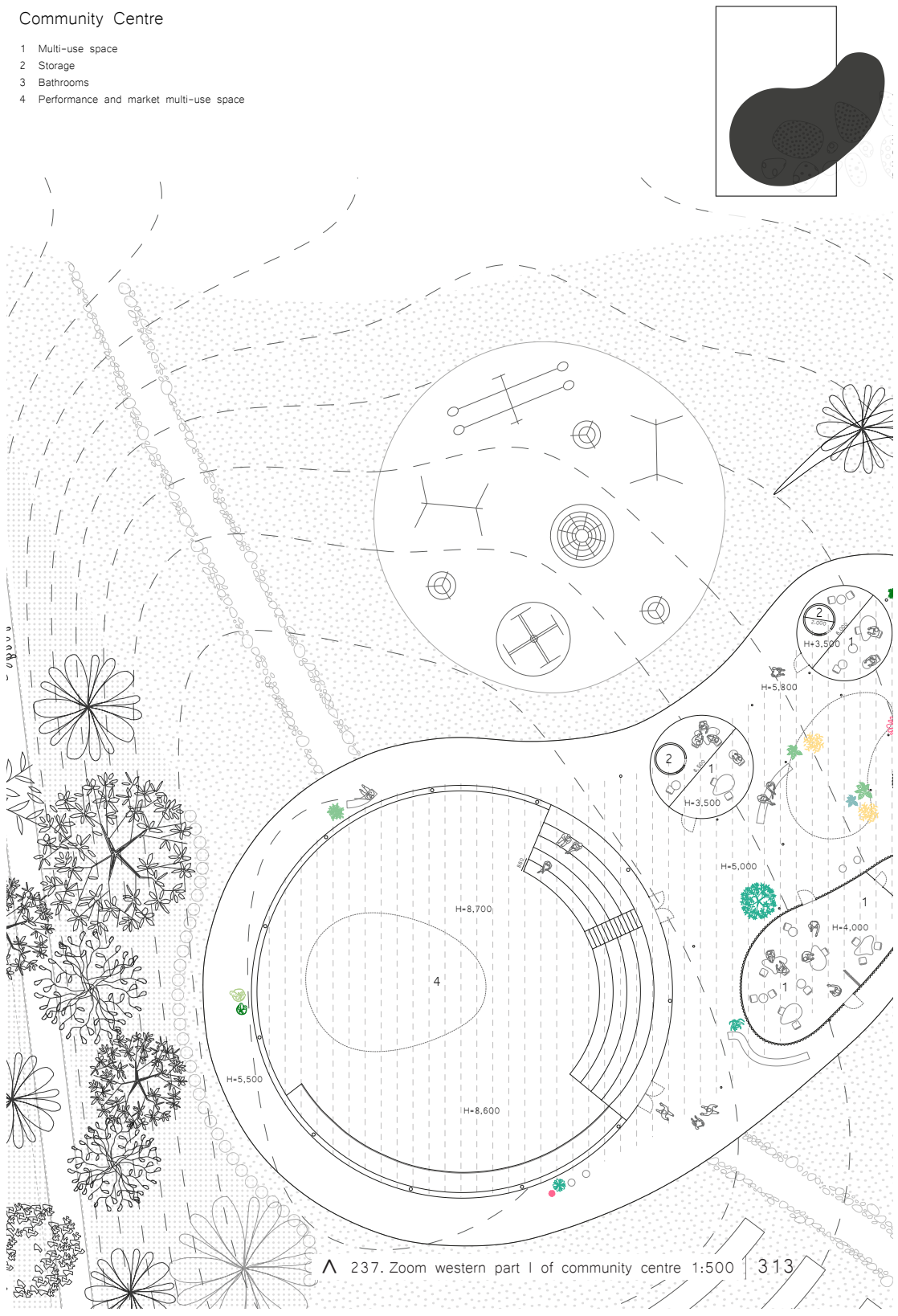

a $\rightarrow$

8000 

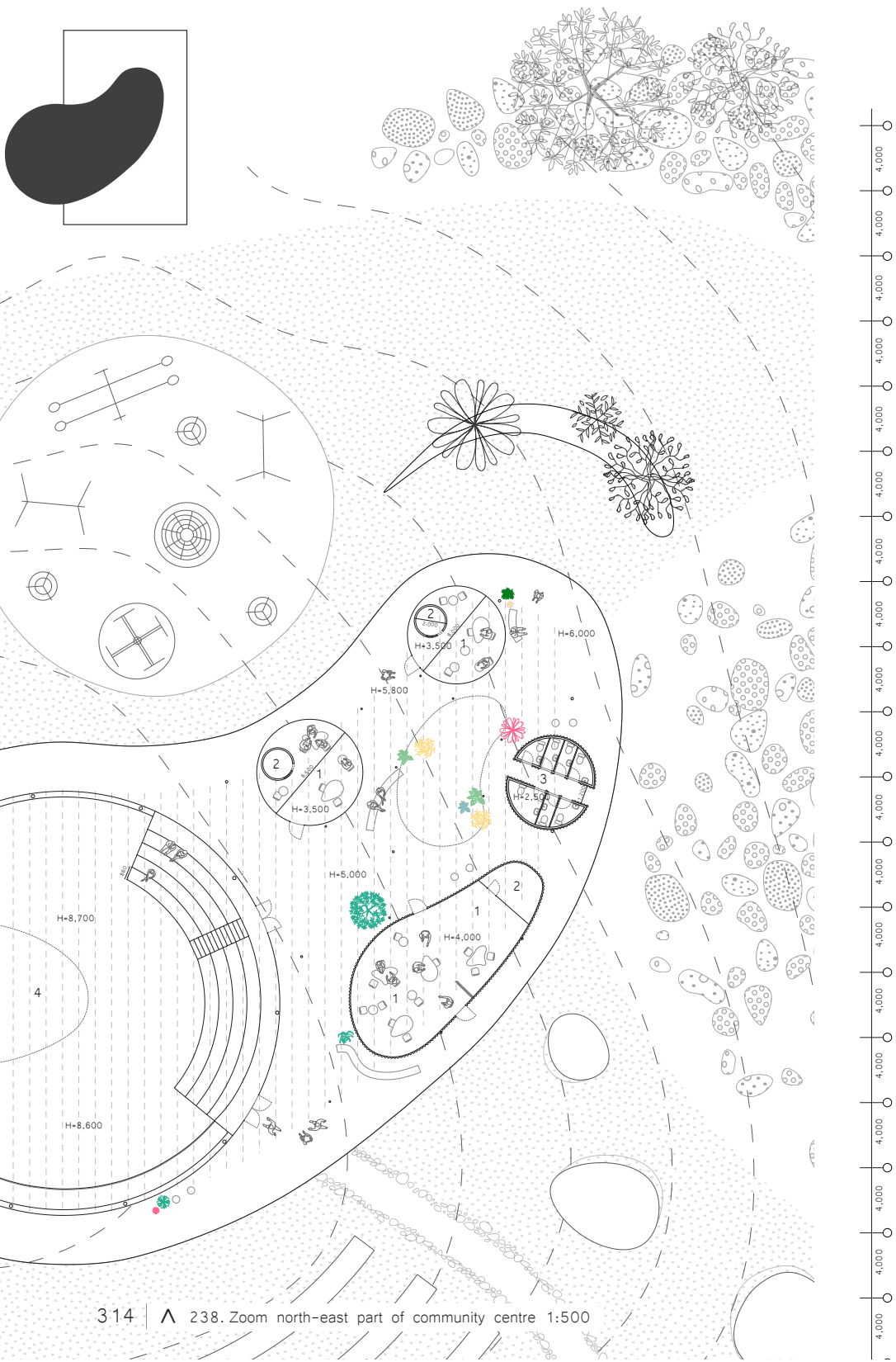

314 ^ 238. Zoom north-east part of community centre 1:500 


\section{Details}

The design considers the proposition from the parkscape down to the furniture. To ensure this, the architectural design responds to pragmatics with the design intent in mind. Services such as climate control were accounted for as each interior room has enough space in either the roof or walls to run the required services for the specific programme. For example the closed gallery spaces have double walls to ensure adequate space. The gallery building is enclosed and as a result has two service rooms with large underground service pits rather than traditionally placing the services in/on the roof. Smaller details such as toilet-wall connections were analysed in relation to SANAA' built projects to ensure the outcome was achievable.

\section{Scale}

The awareness of scale and delicacy is accentuated through contrast. The vast roof plane and its thickness highlight delicacy, as it appears to float over the landscape. The tapering structural fins and large eaves enhance this. The scalar contrast is also accentuated between the vast roof canopy and the intimate spaces below. The design attempts to explore the proposition from the whole right down to the detail, to ensure coherency at every scale, from landscape, to building, to furniture to a detail connection.

\section{Materiality}

The selection of materials and smooth finishes create seamless edges that appear continuous, allowing one space to blend into another. Slender supports were considered for their best strength-to-weight ratio. Having a multitude of thin was more successful rather than a set of huge columns. Another key aspect in evoking the perception of delicacy through the material was reconsidering standard connections. I developed details that make the connections appear seamless and effortless in favour of the delicate. 

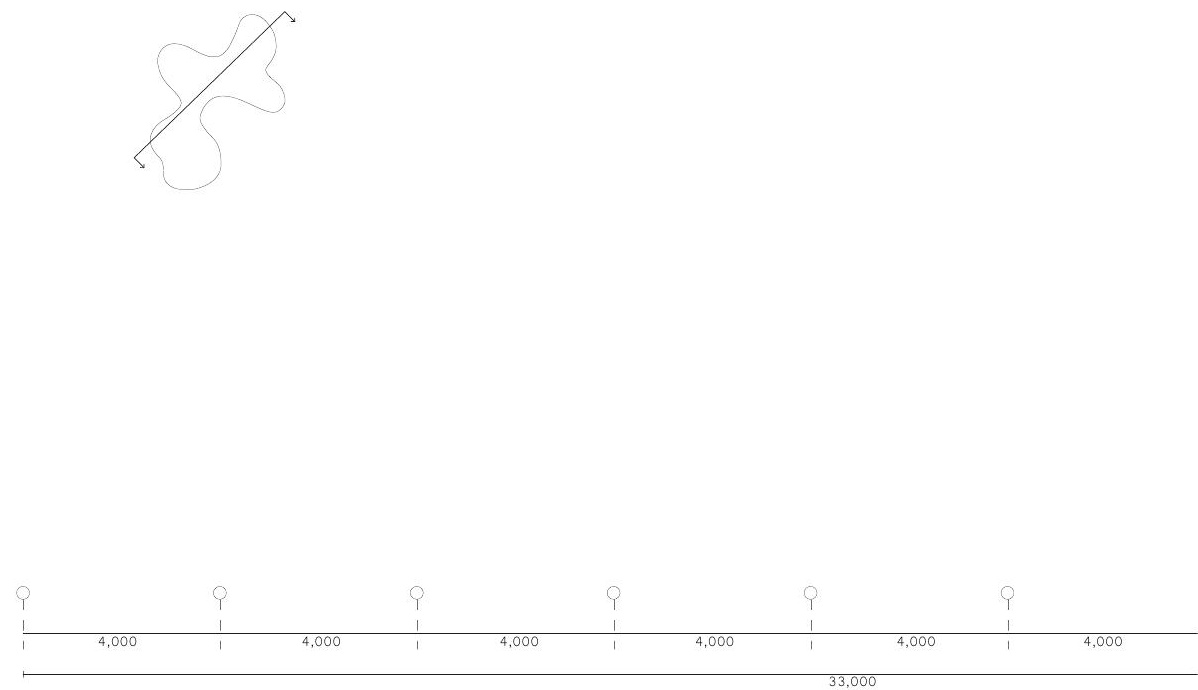

$\frac{1}{A 1}$

$\left(\frac{1}{A 2}\right.$

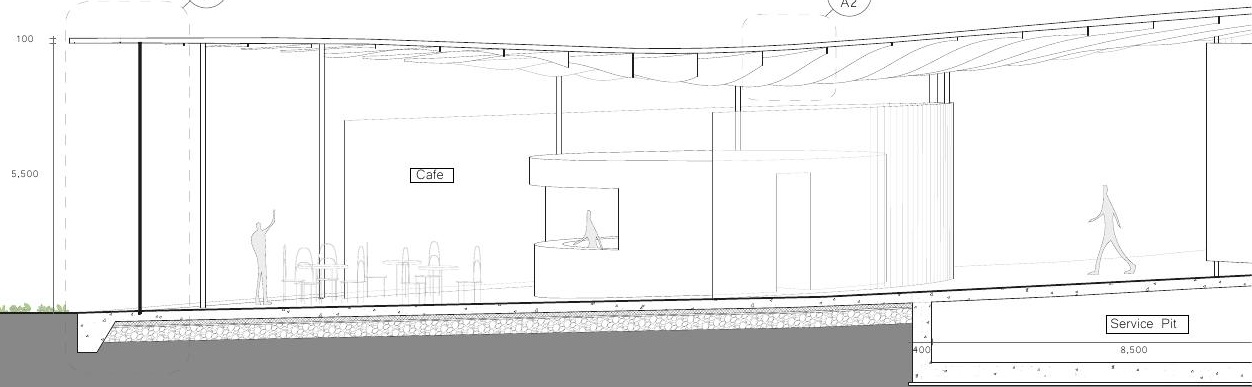



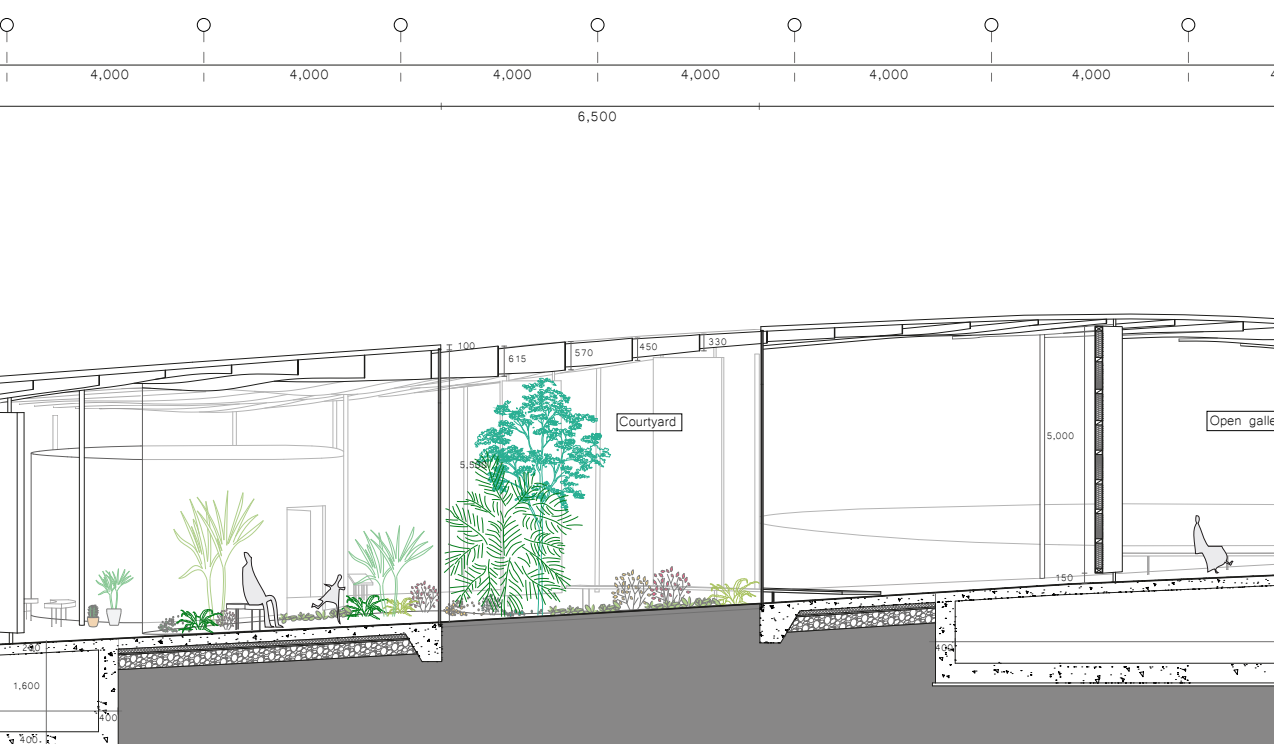


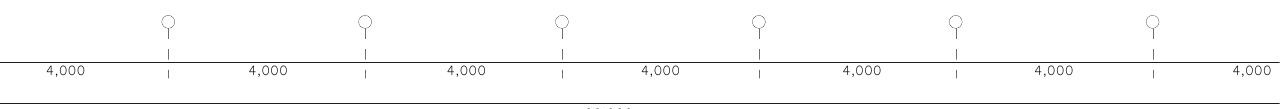

29,000

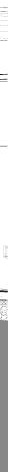



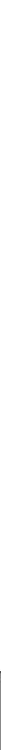

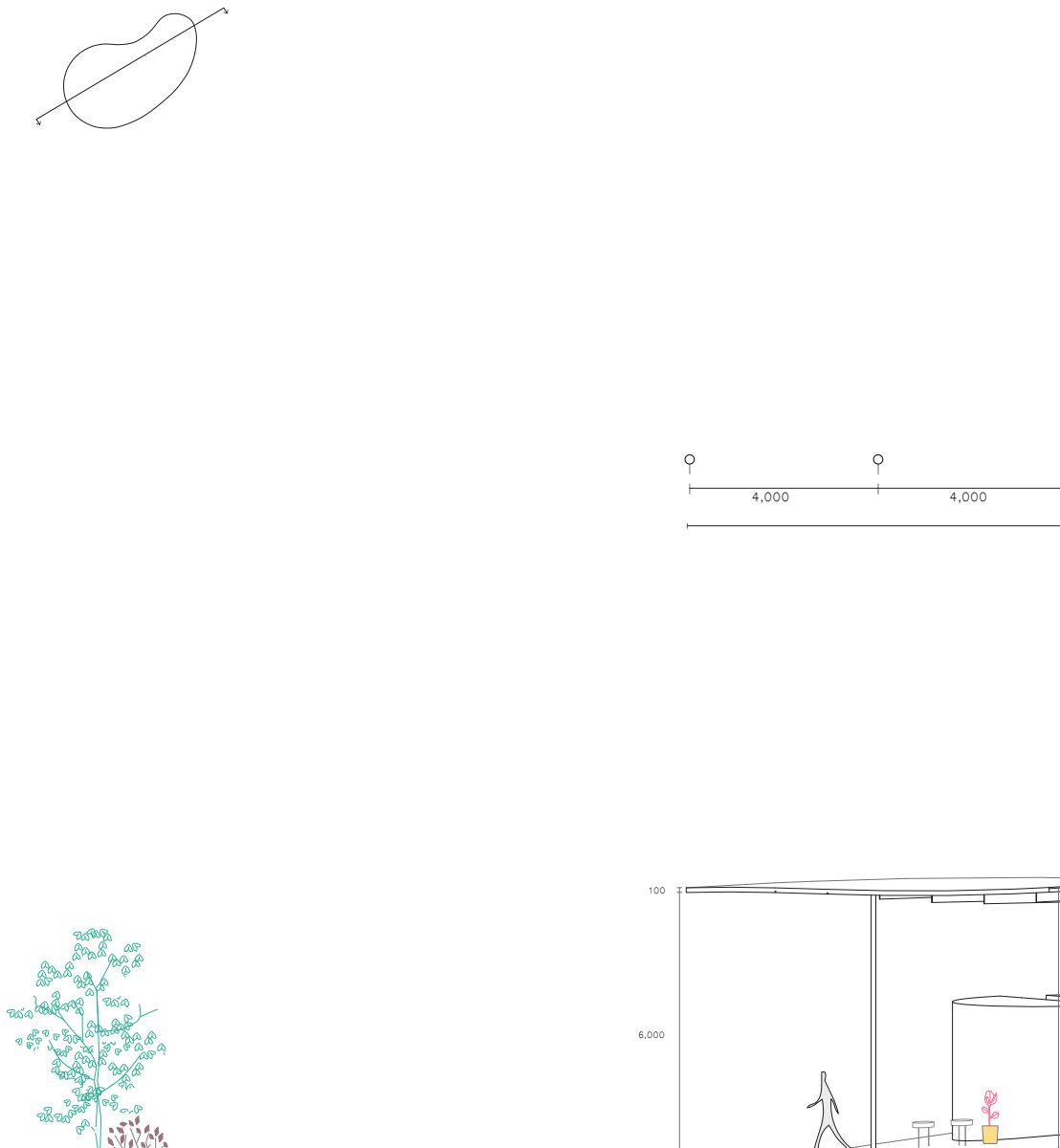

ing

100

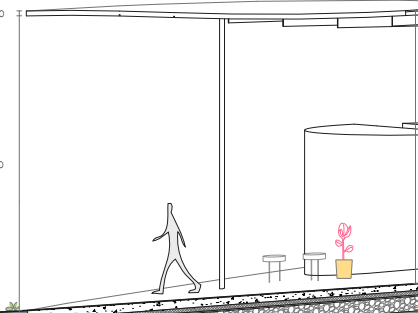
- $12=0$

ingerater 


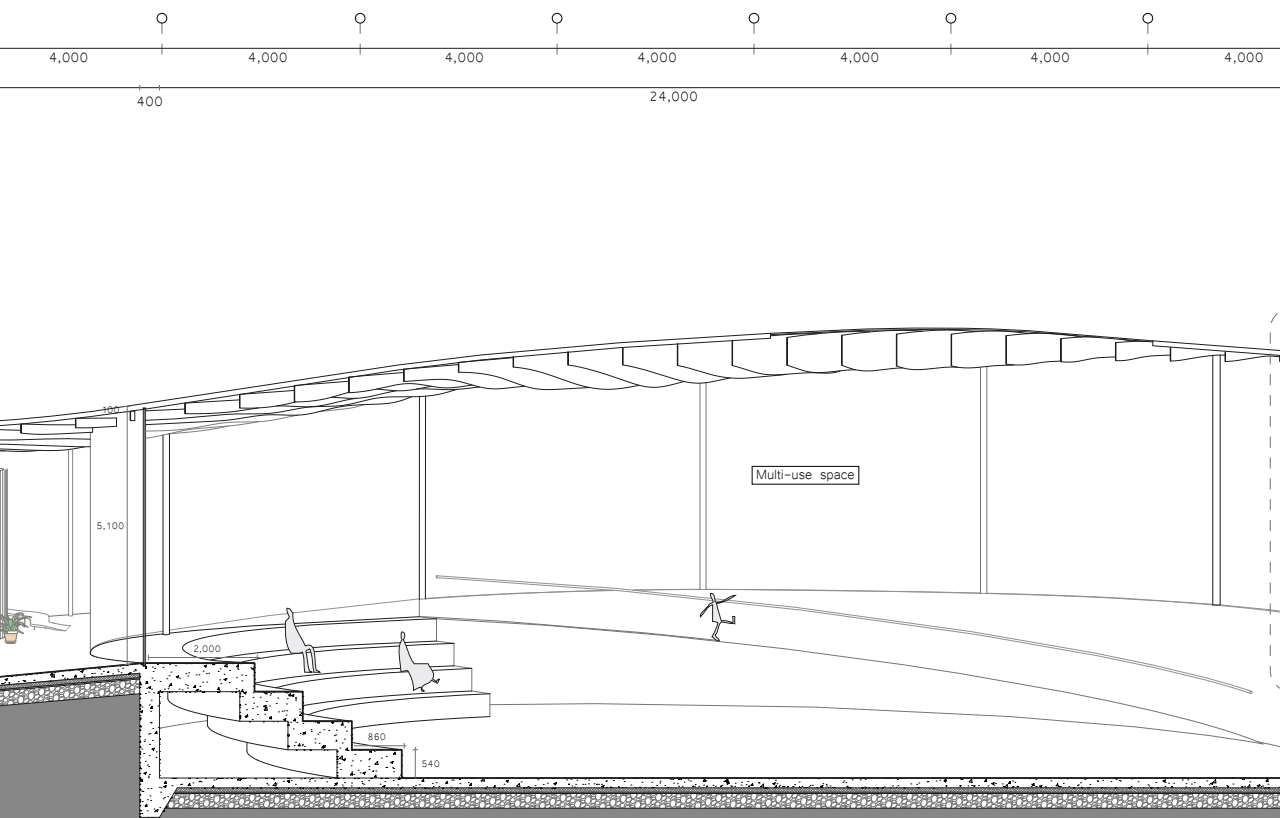

$322 \wedge$ 242. Community centre section part II 

Glazing floor to roof detail

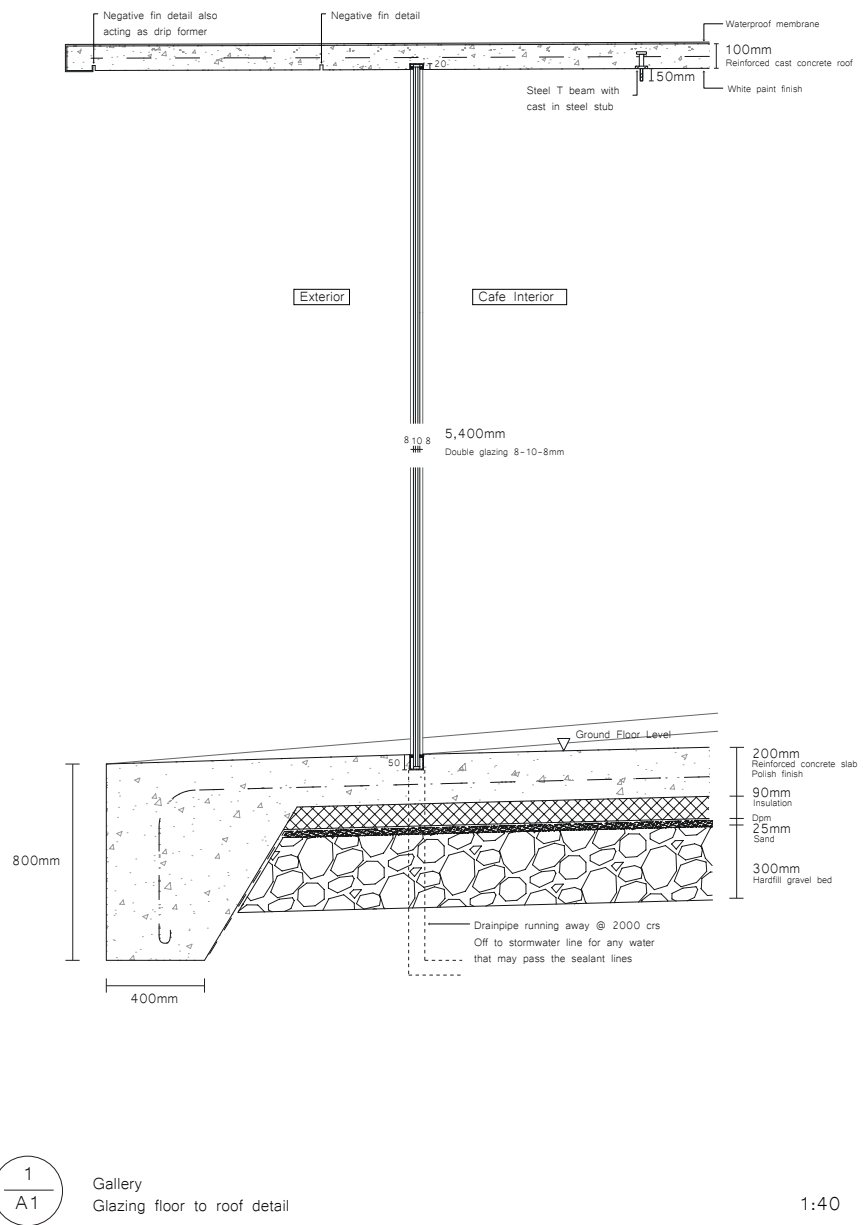

$324 \wedge$ 243. Detail one 


\section{Structural fin to roof detail}
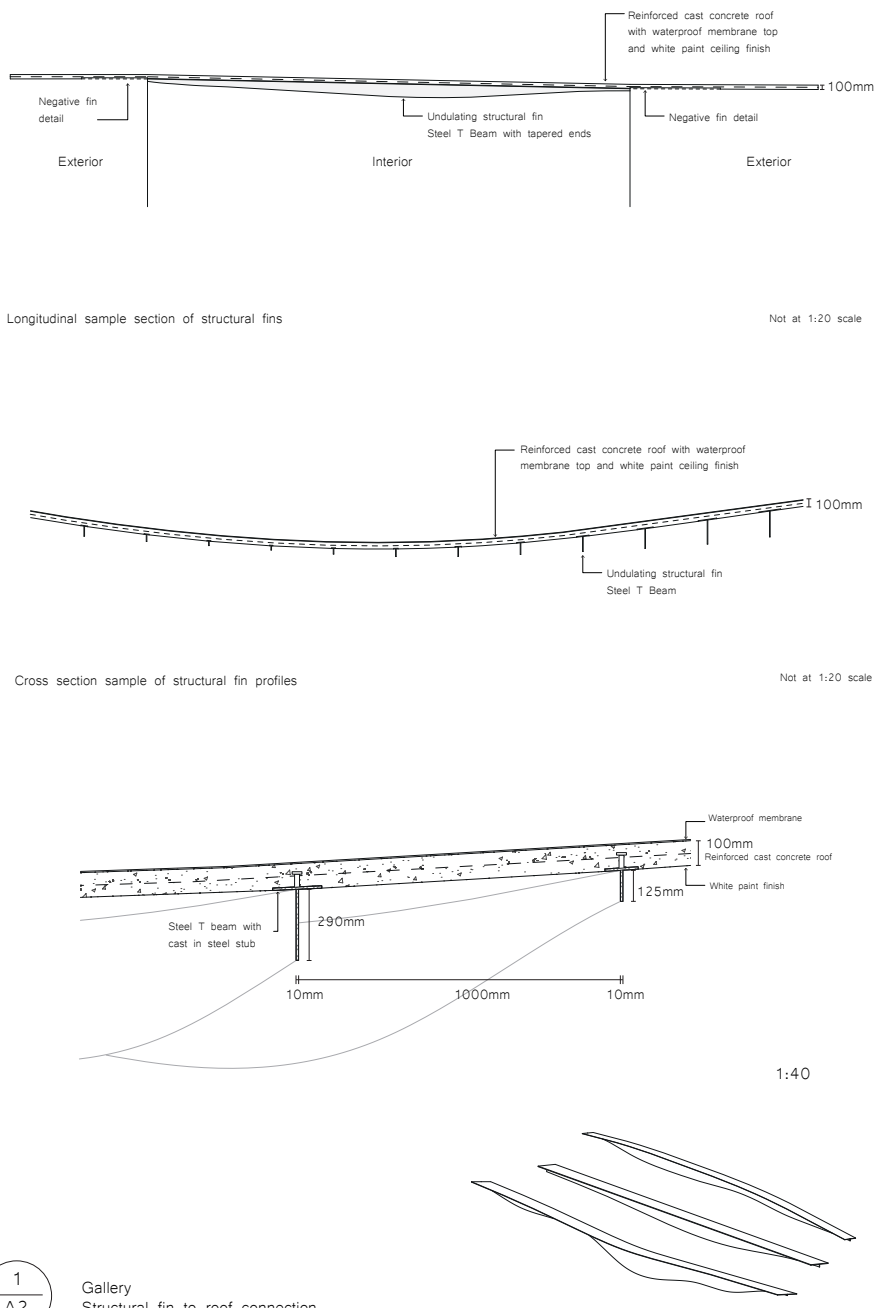
Column roof to floor detail
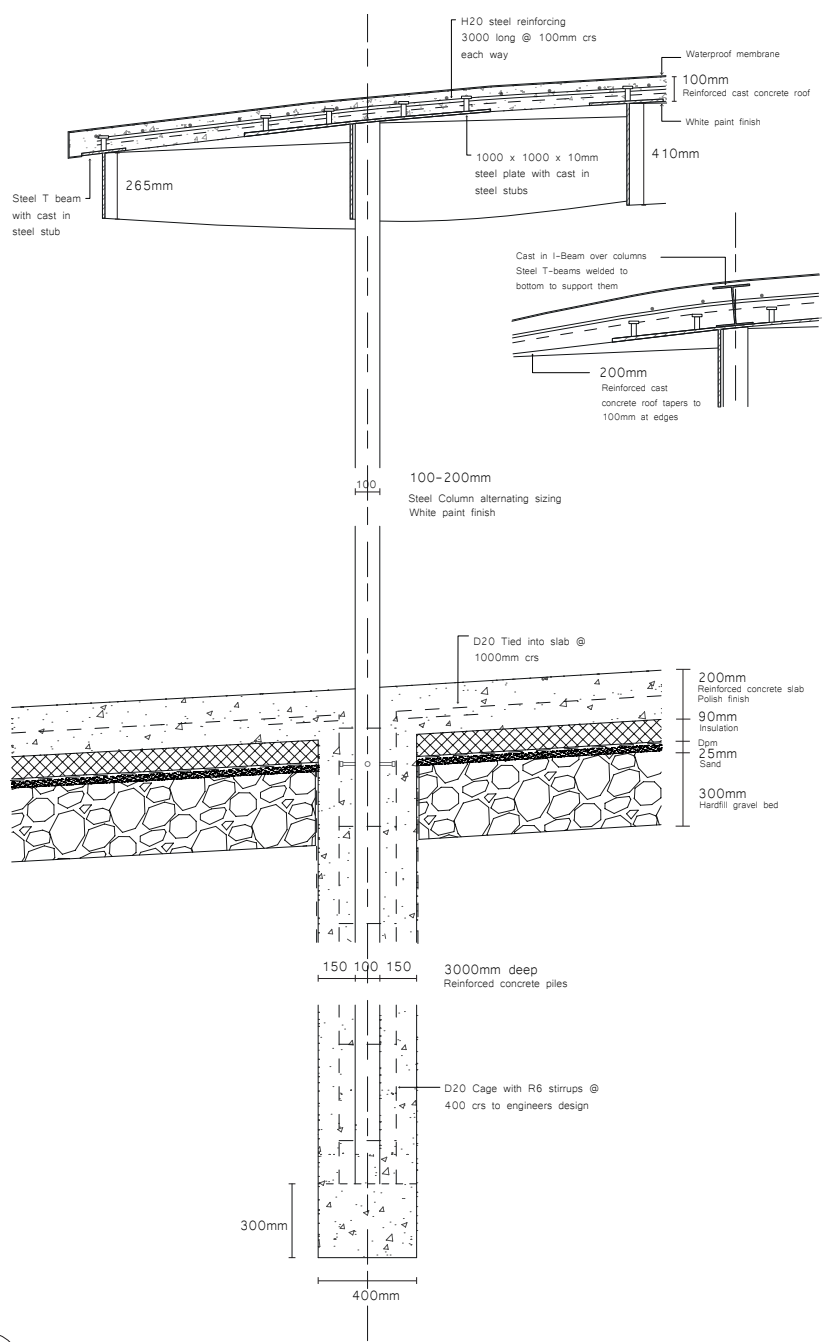

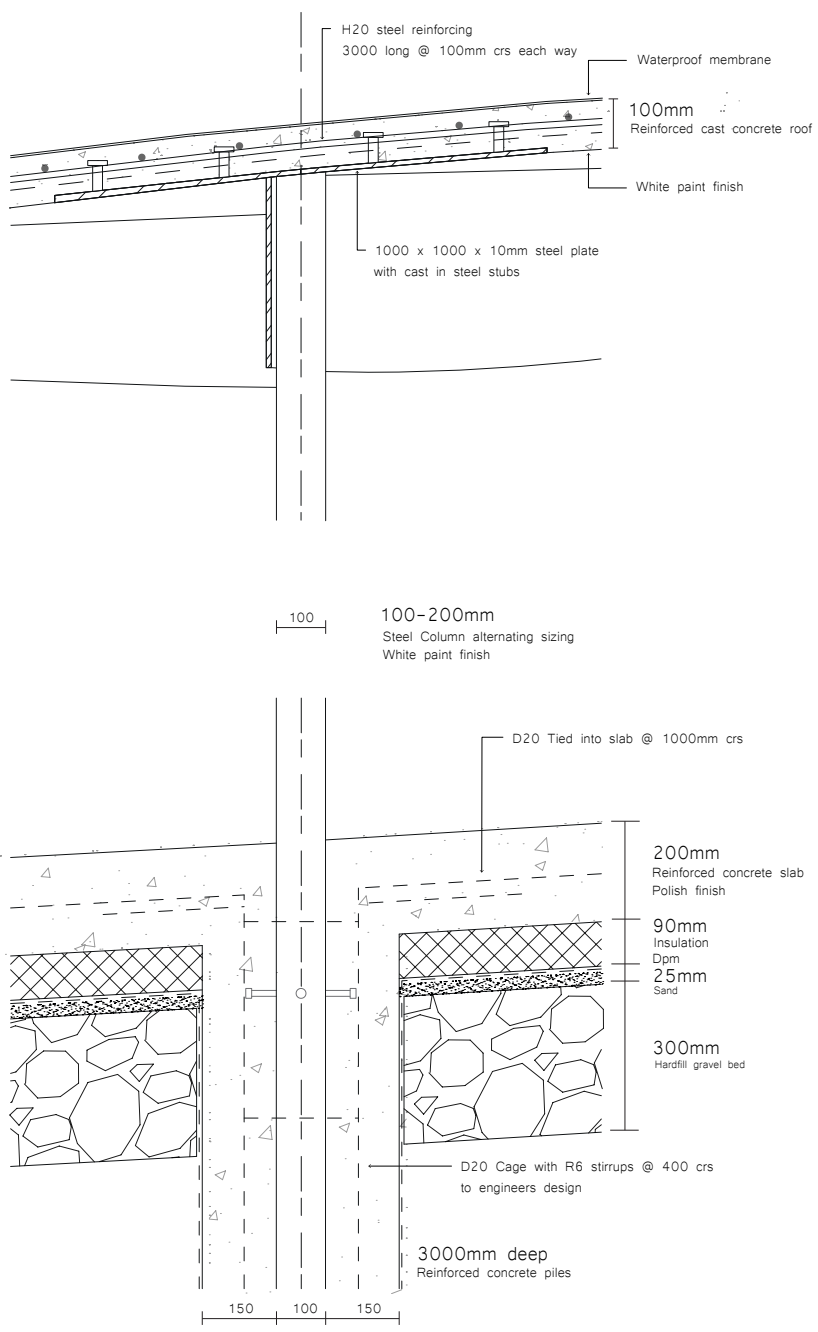
Community centre glazing floor to roof detail
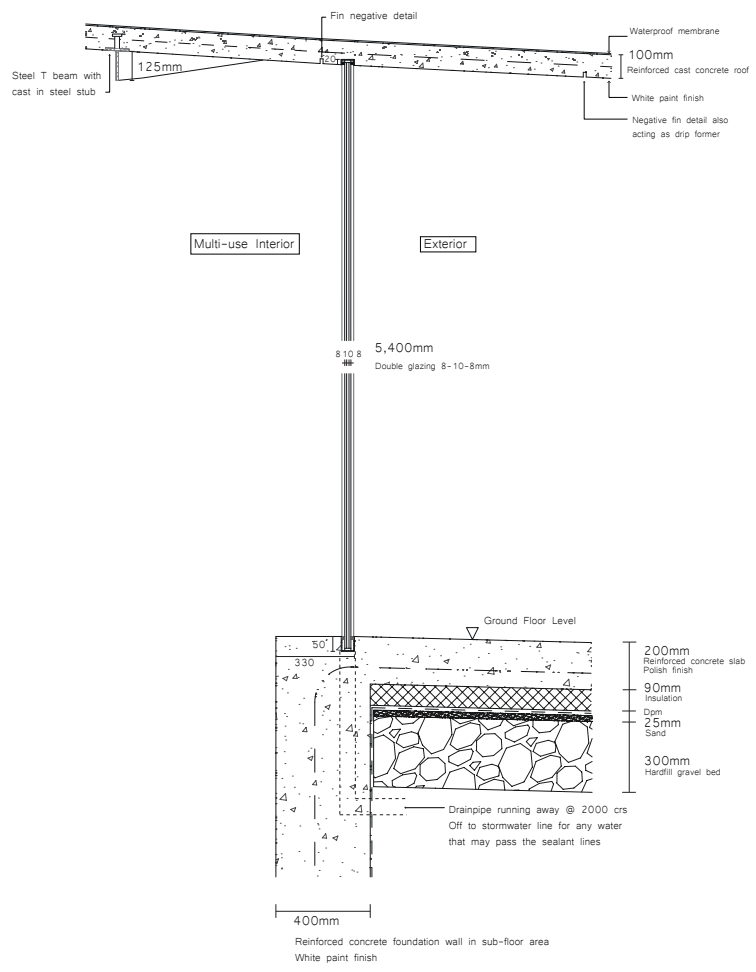

Community Centre

Glazing floor to roof detail

$1: 40$ 

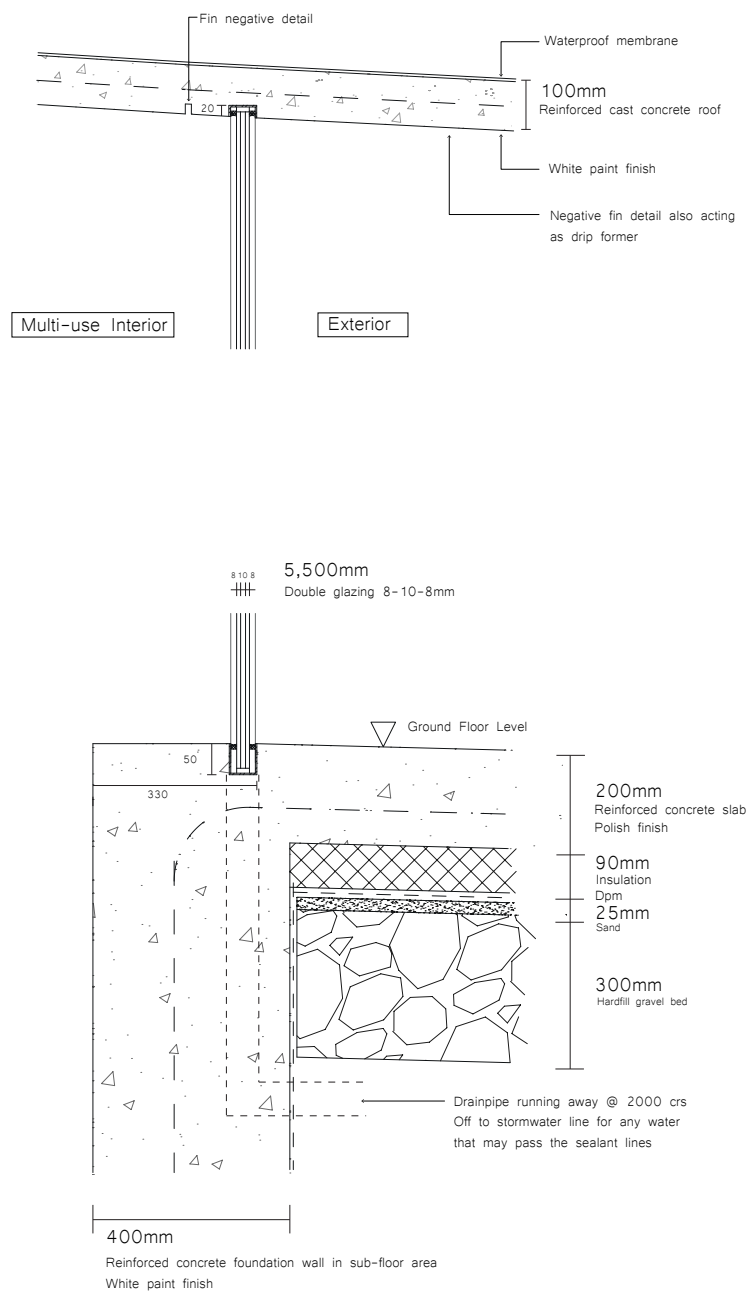
2. Nined

4.-

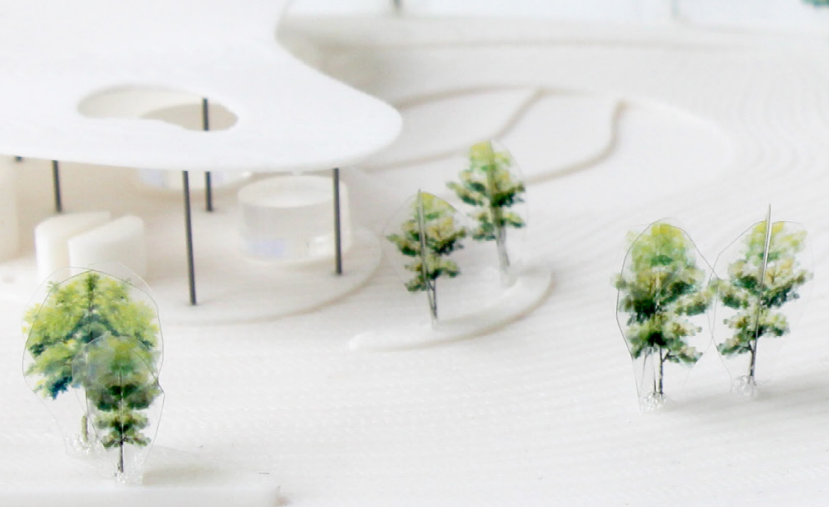



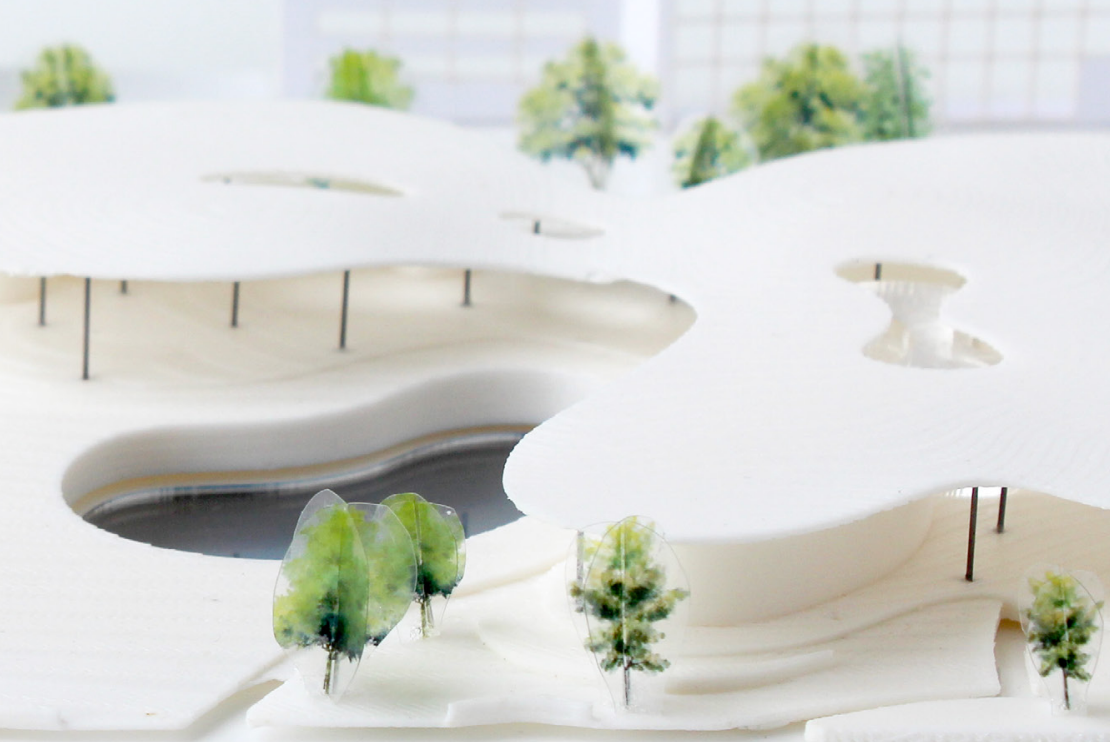

$\bigwedge$ 249. Contextual overview 


\section{Colour + Whiteness}

Whiteness was key to create open spaces with a reduced hierarchy (Twose \& Smitheram, 2009, p. 58; Moreno \& Grinda, 2004, p. 24). The reduced material palette allows the spaces and structure to feel incredible light and open. Alongside the building's smoothness, the use of white creates a soft blurring effect. However, within this ethereal environment moments of entry, intrigue and intimacy are highlighted through the use of warm timber tones.

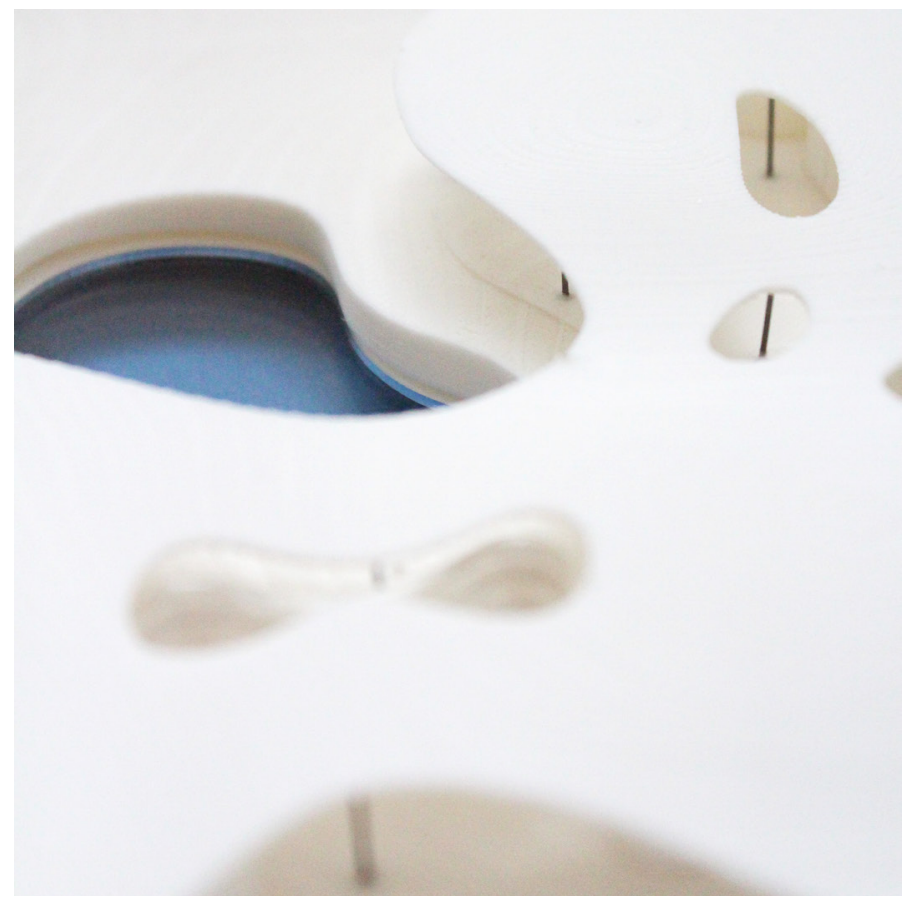

$\wedge$ 250. Material palette 

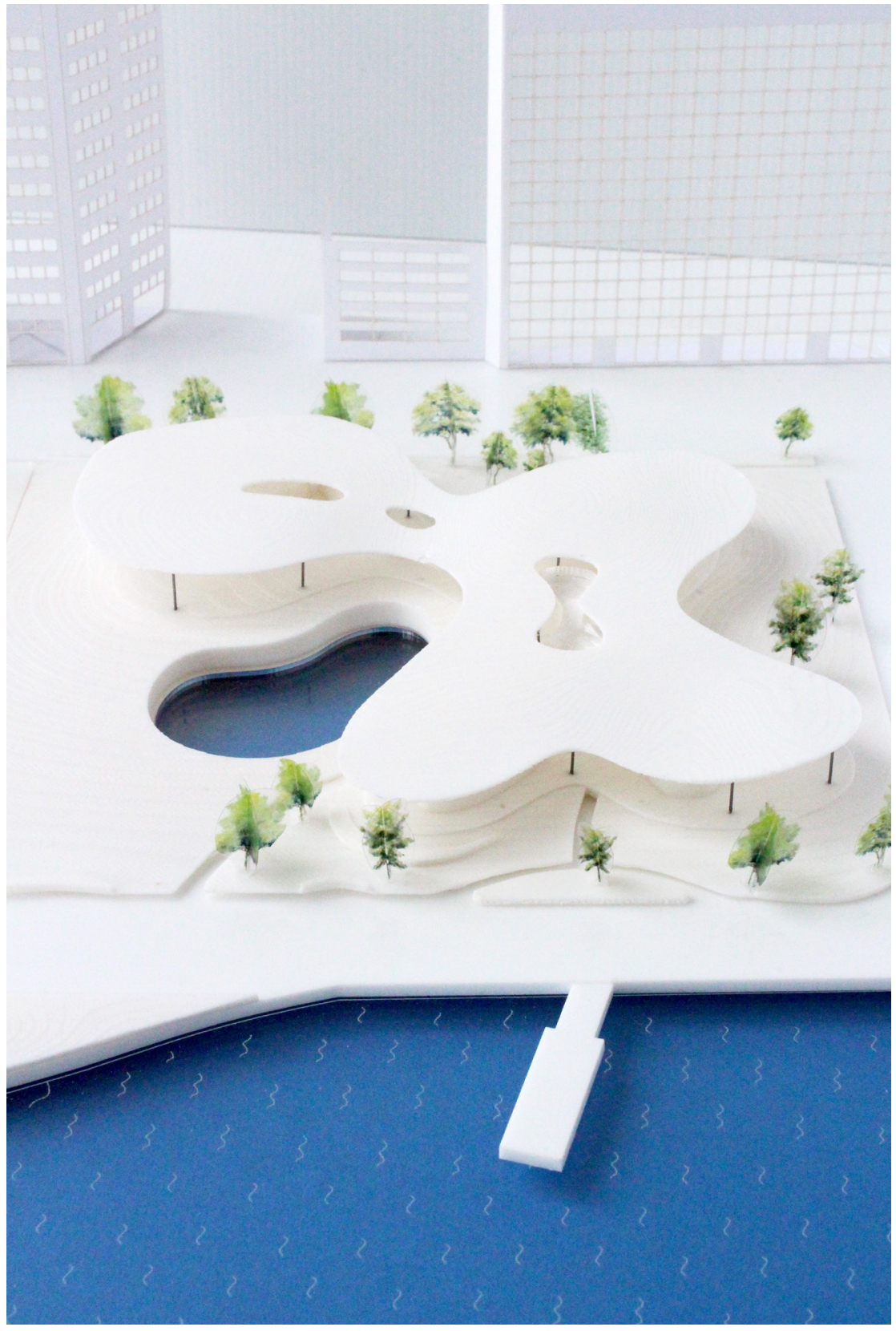


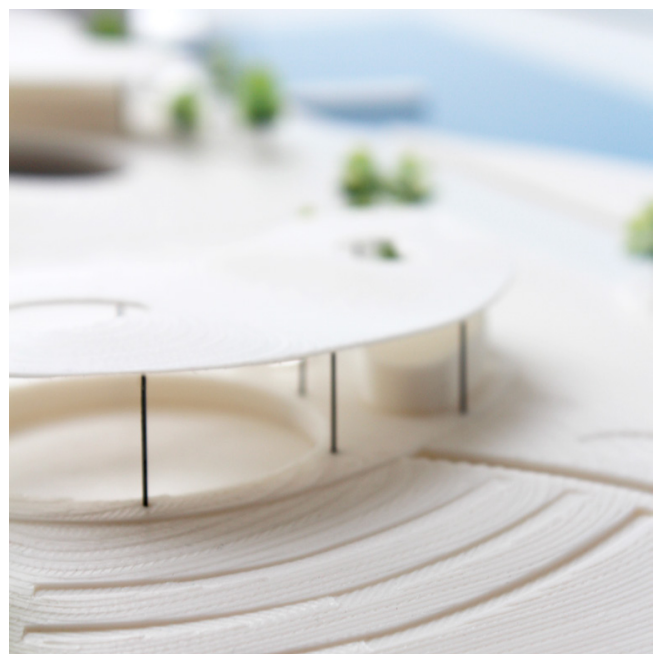

$\wedge$ 252. Community centre overview

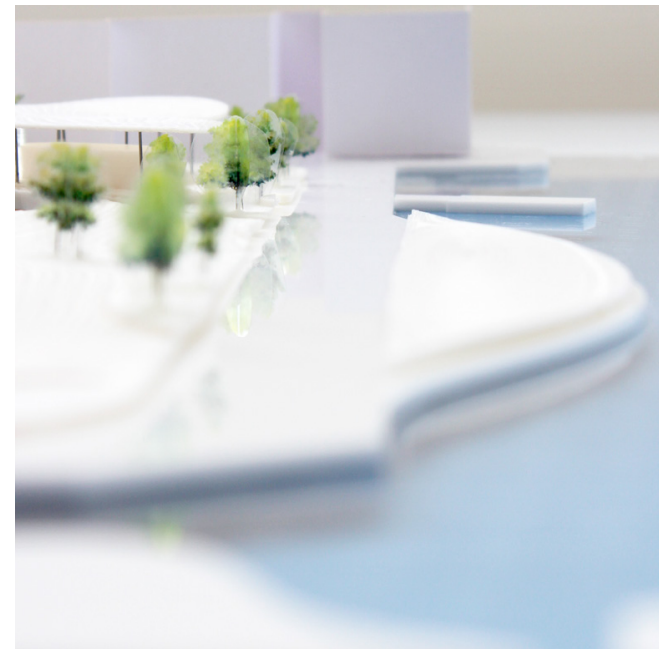

$\wedge$ 253. Waterfront promenade 


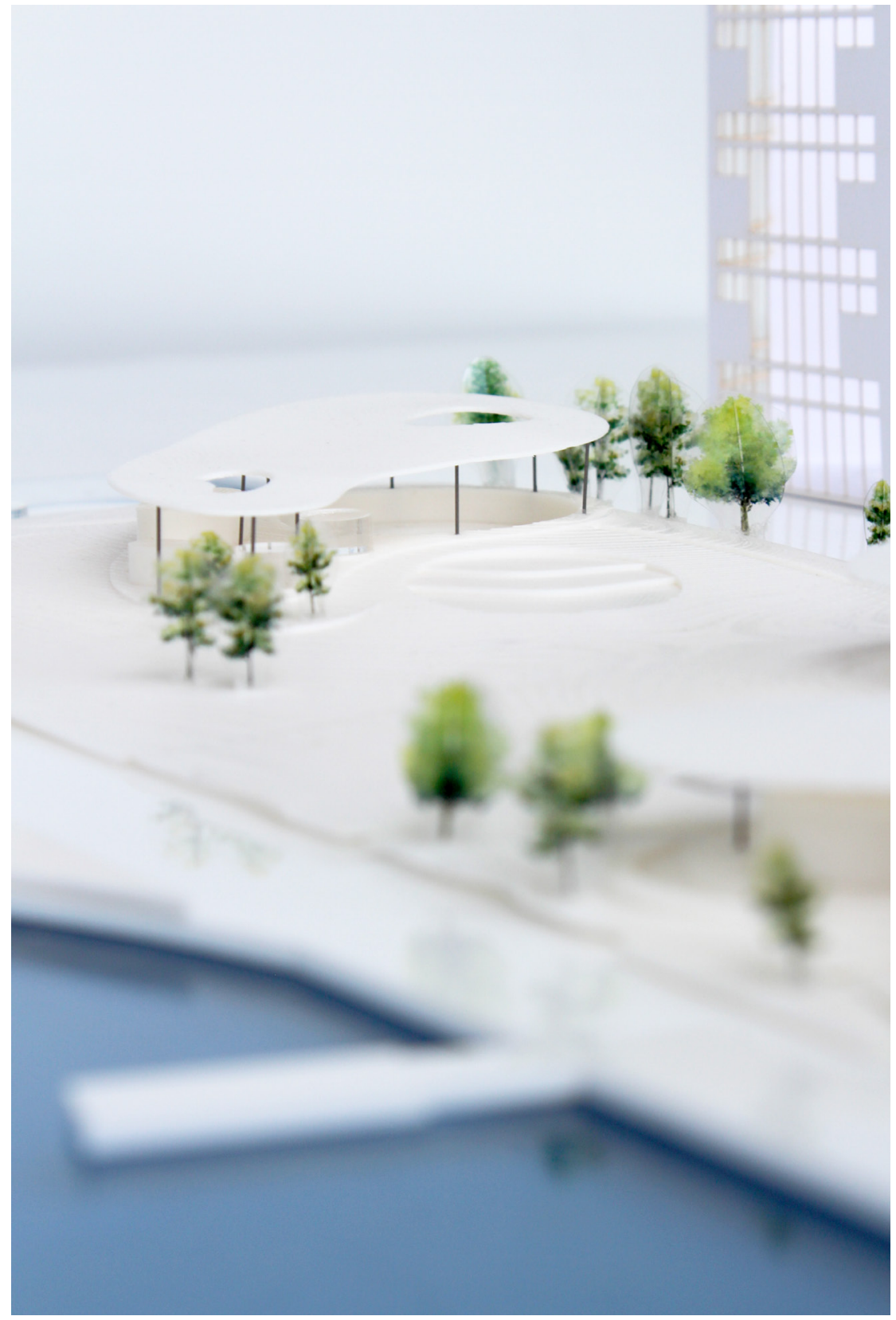




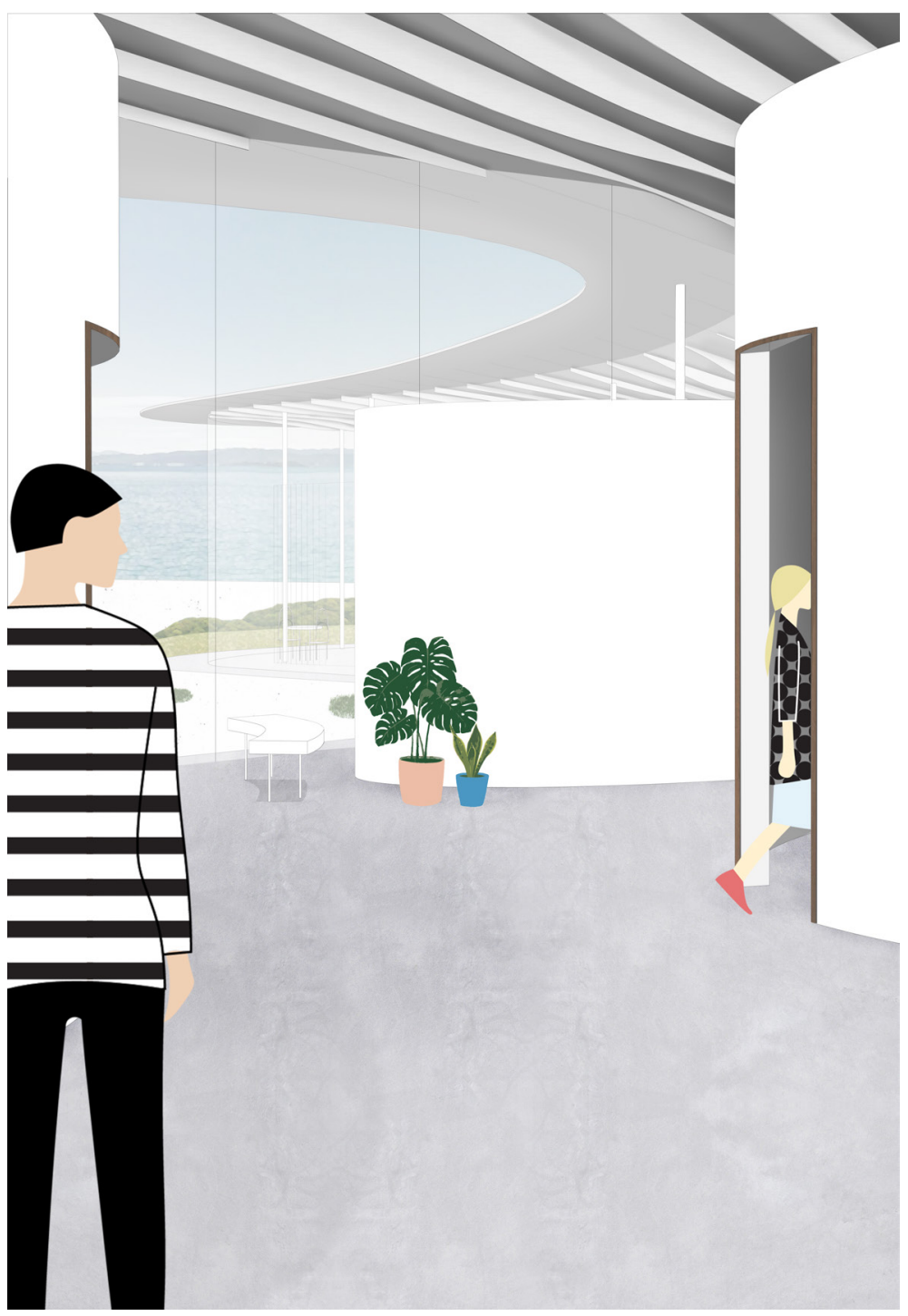

$336 \wedge$ 255. Gallery entry 


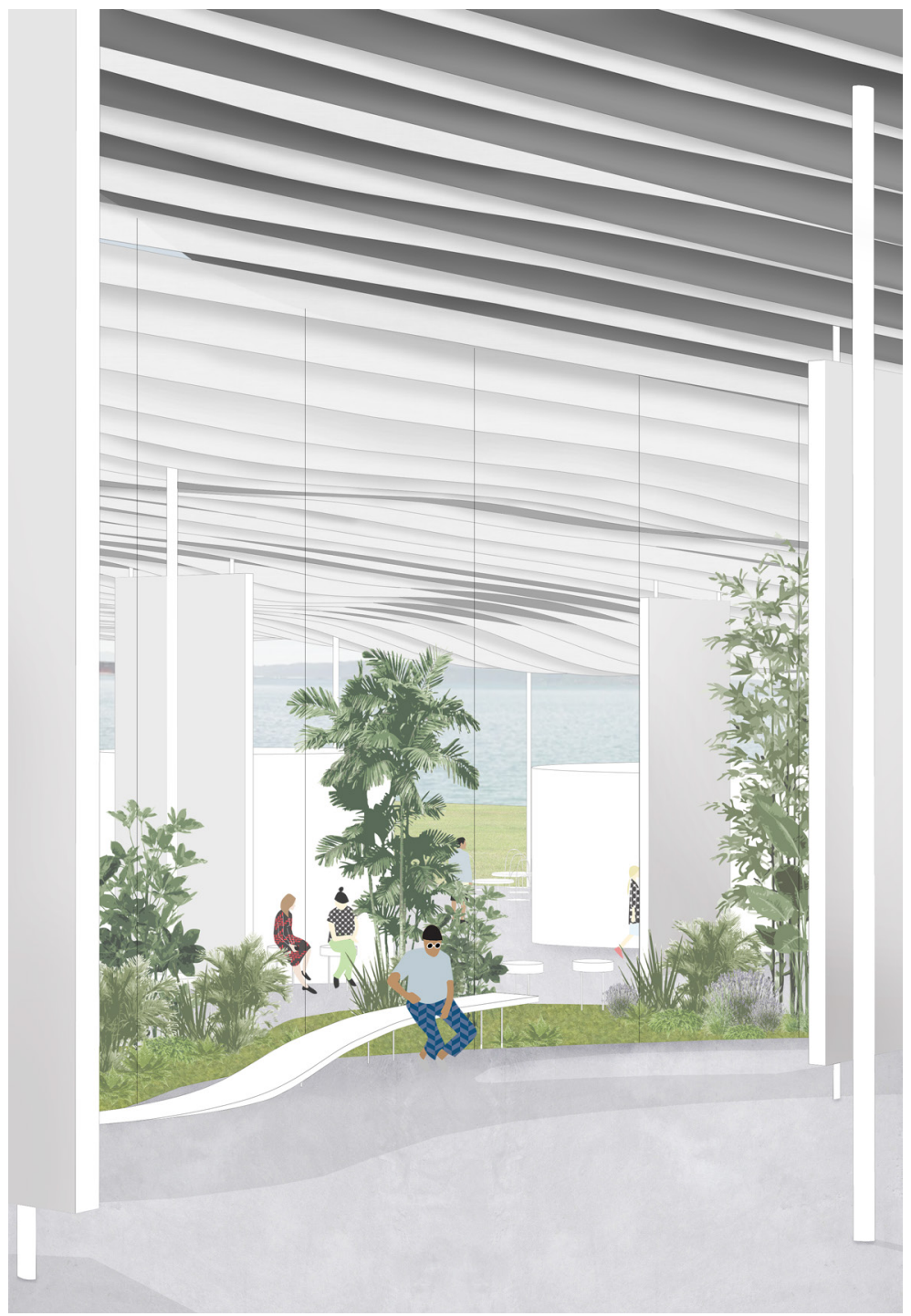

$\wedge$ 256. Open gallery and courtyard 


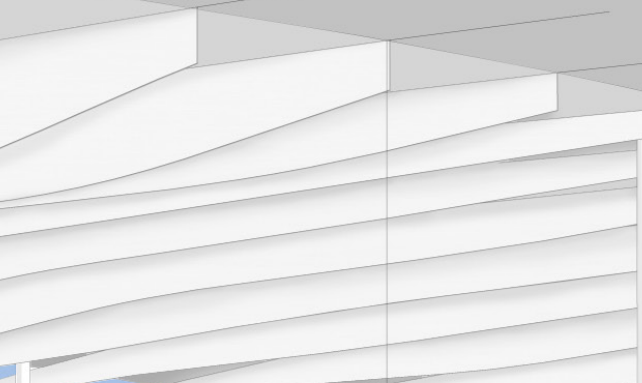

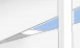
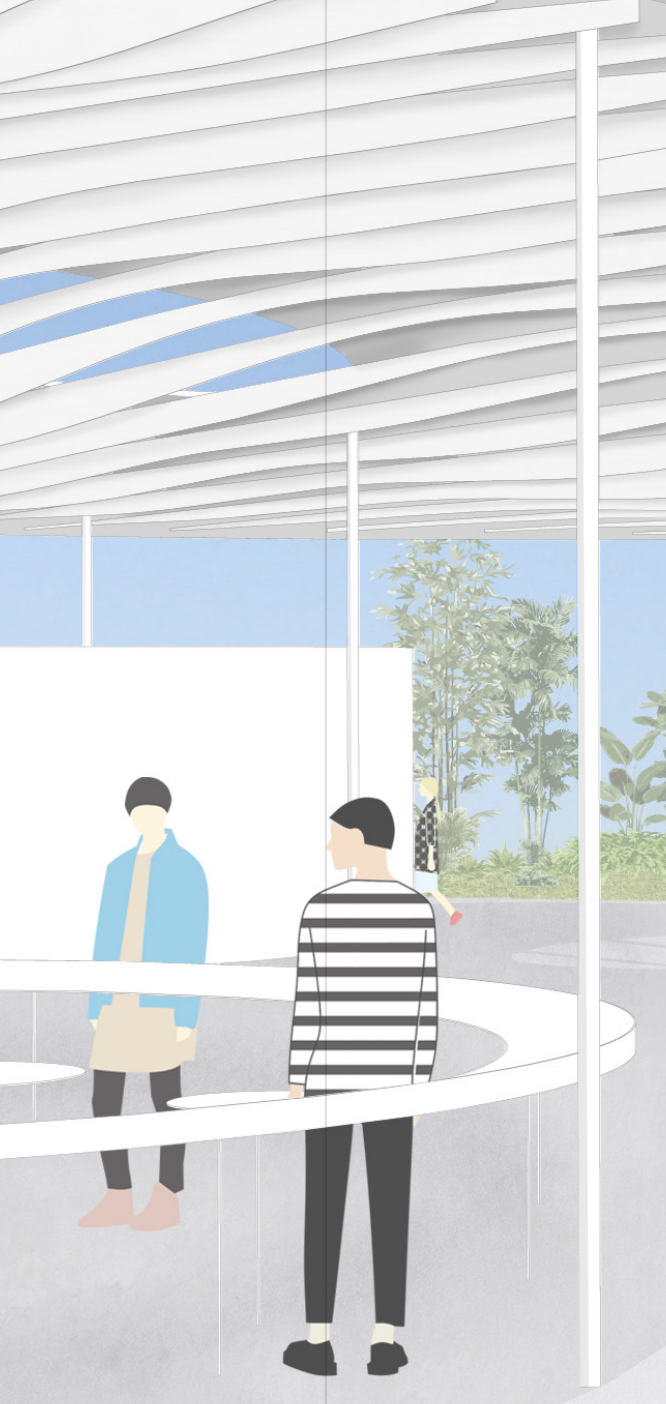

$\wedge$ 257. The pinch point
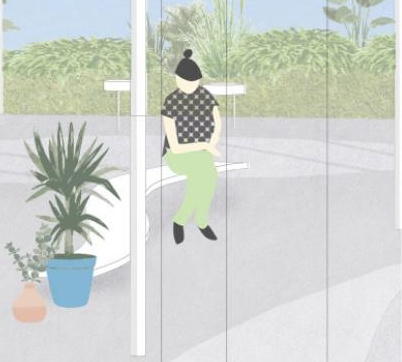

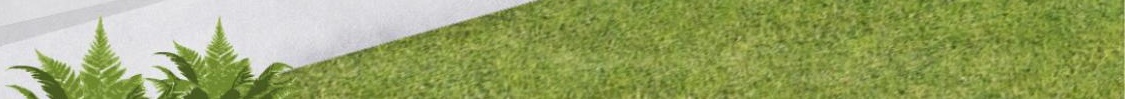




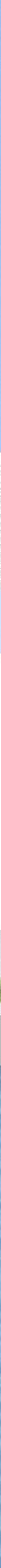




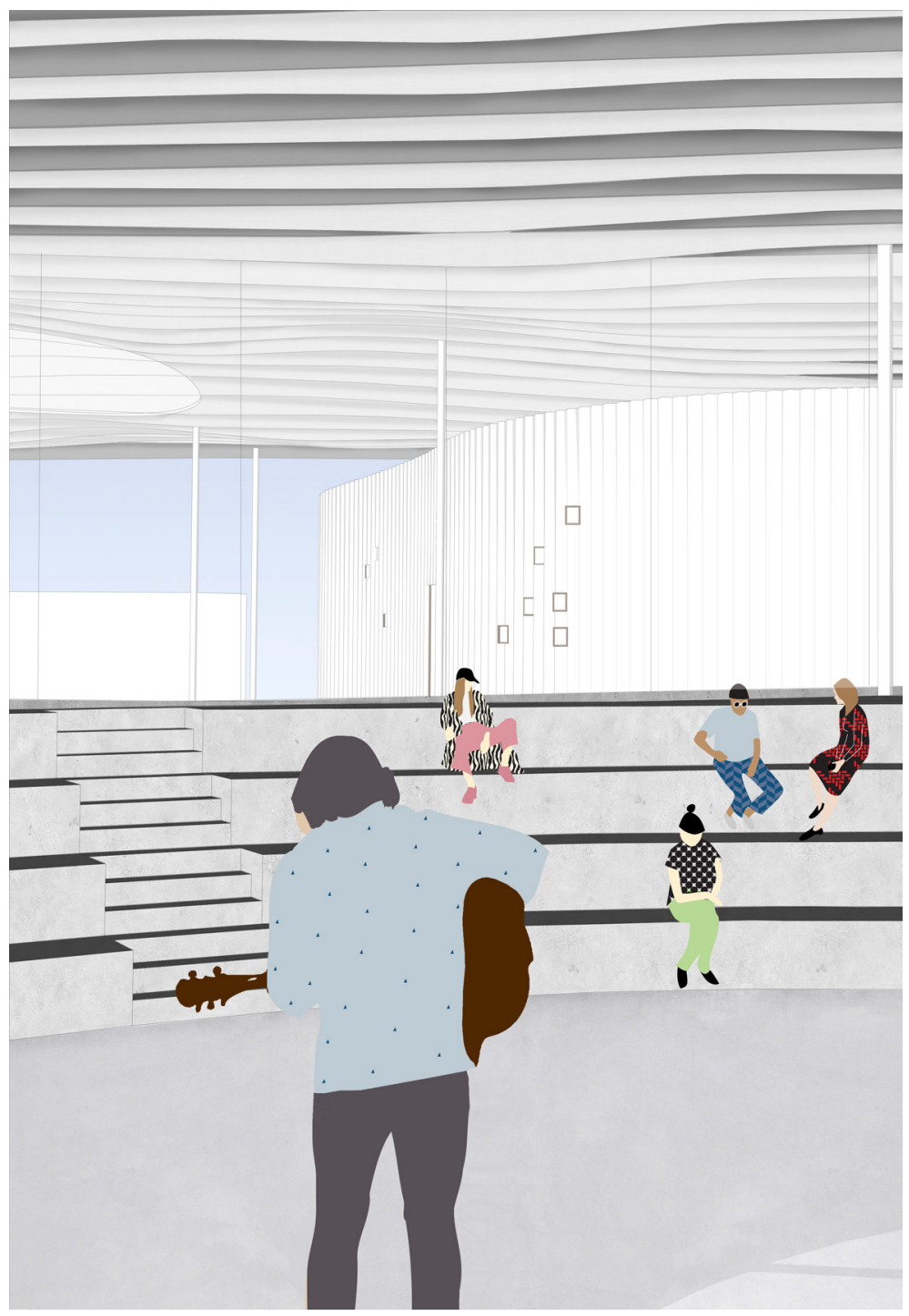

$340 \wedge$ 258. Community performance space 


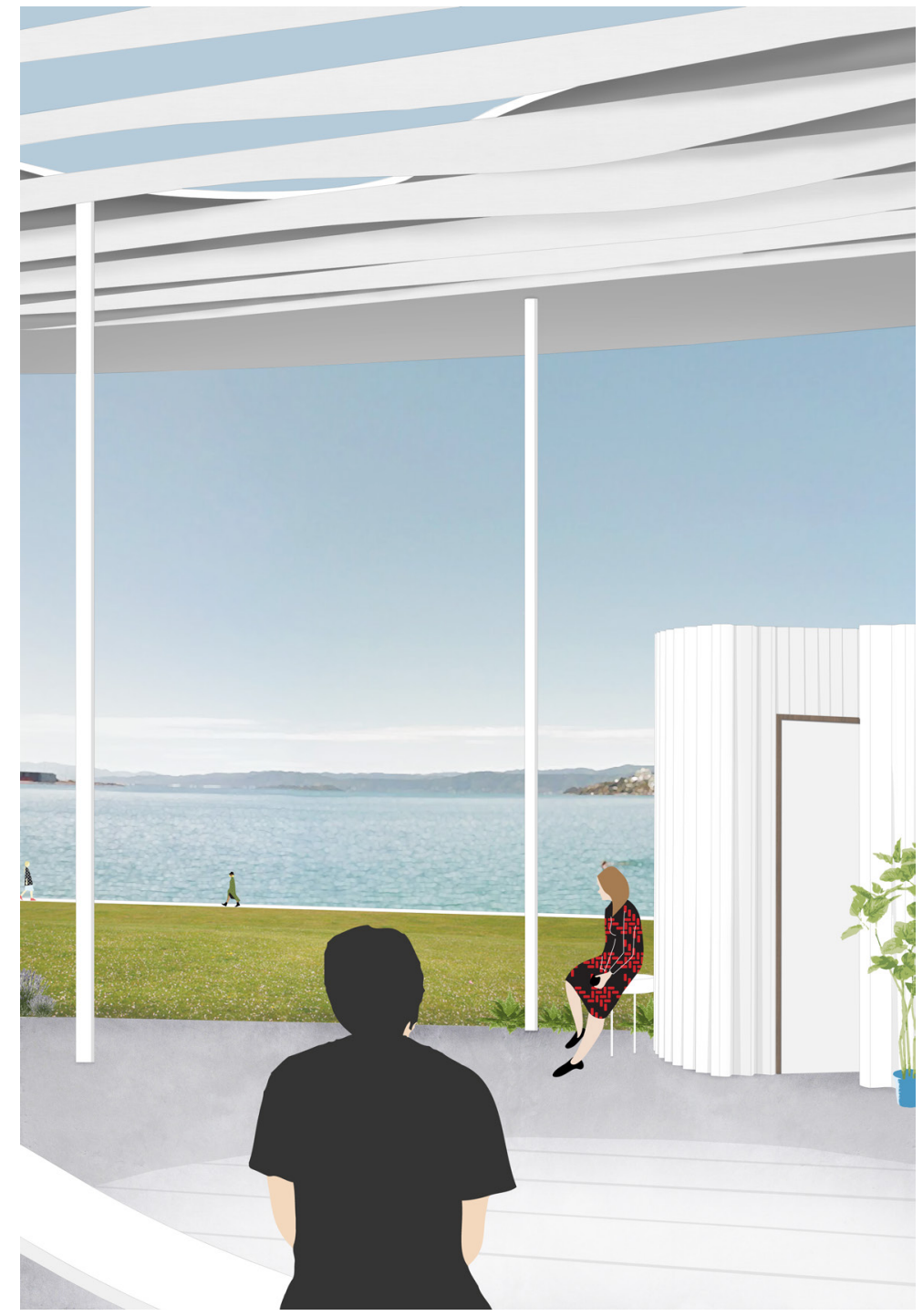

$\wedge$ 259. Community interior exterior 
November Review

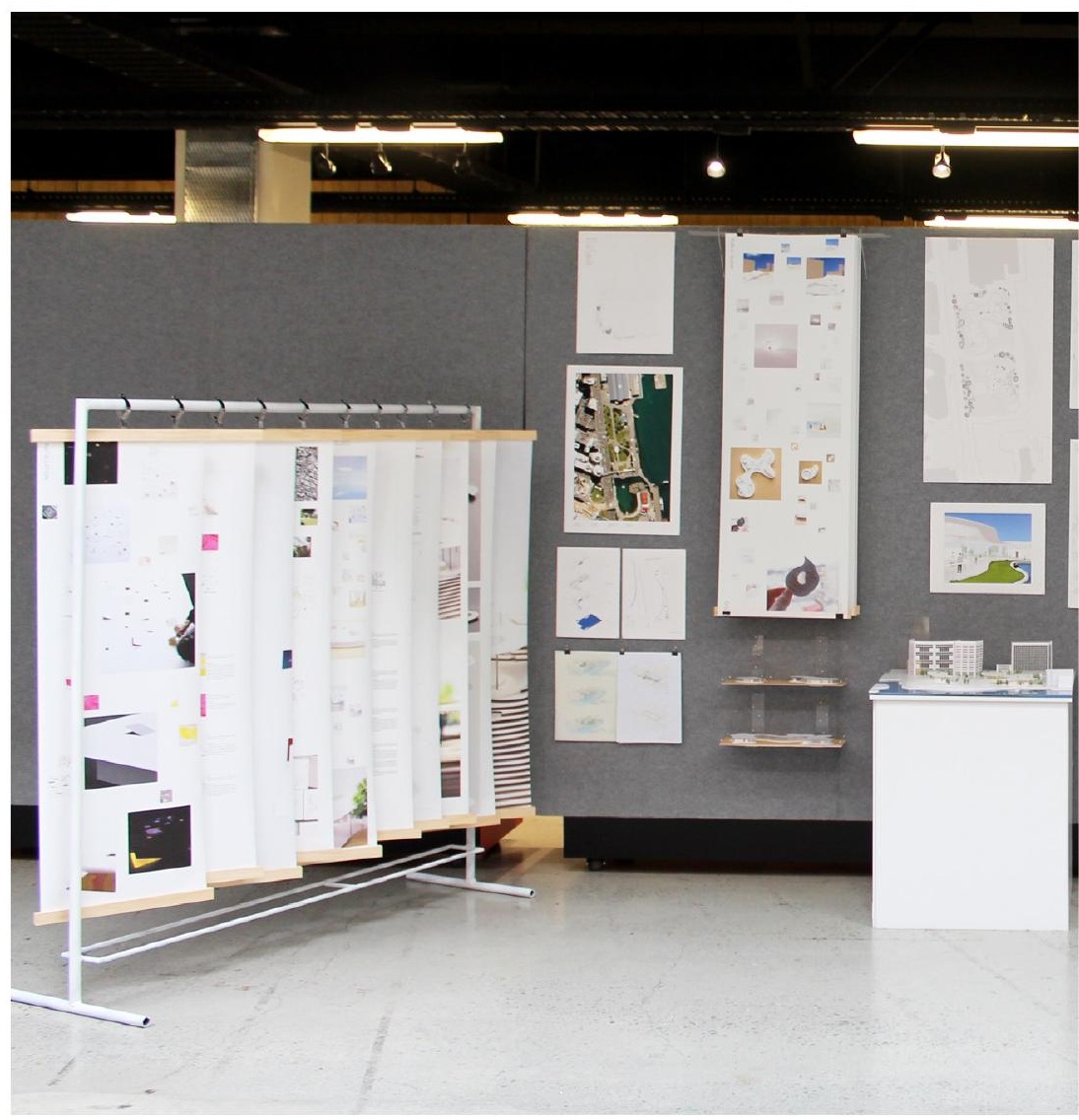

$\wedge$ 260. Final presentation pin-up 
November Review

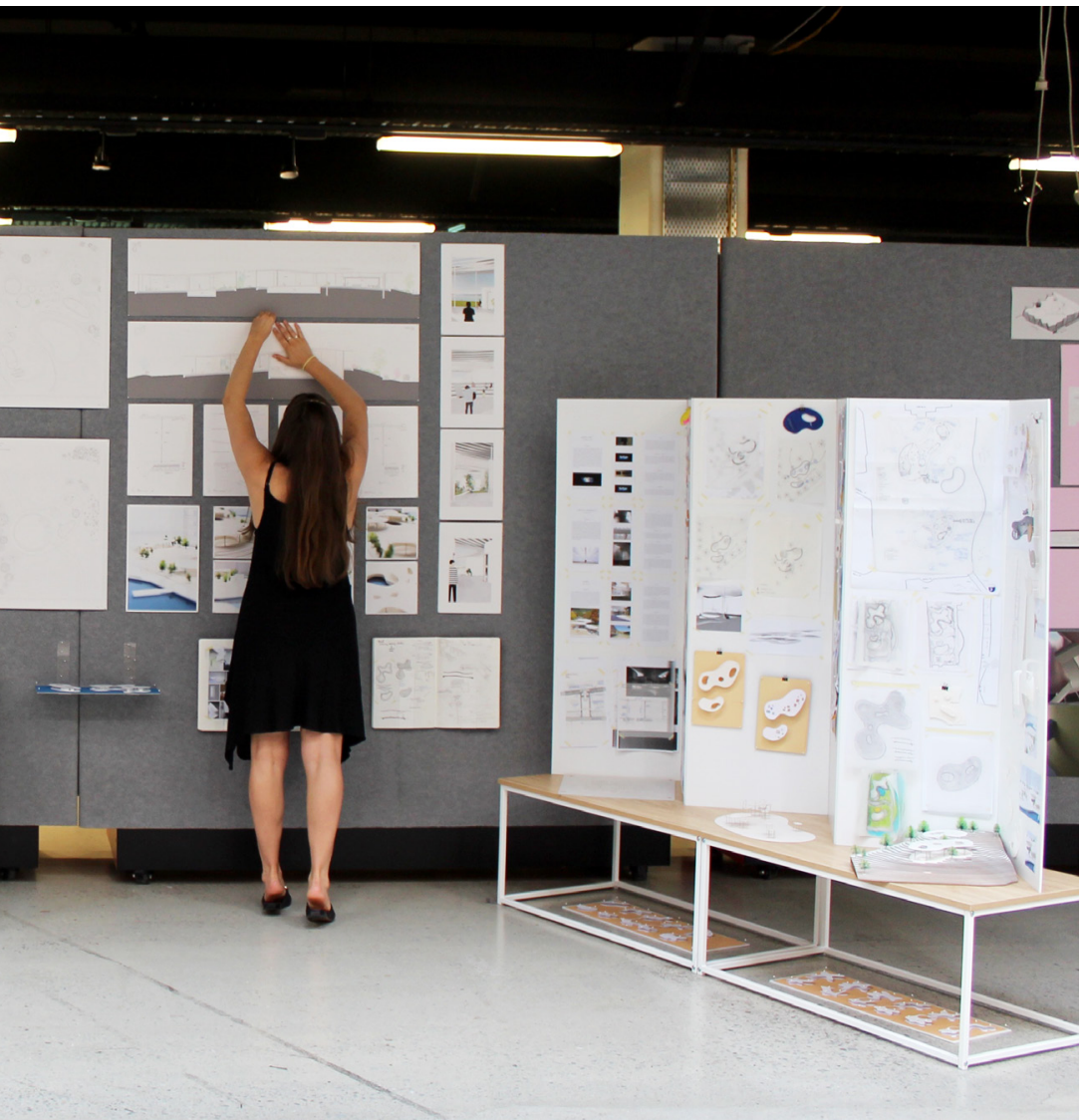




\section{Reflection}

The final design investigates the notion of delicacy through multiple scales and attempts to design architecture that evokes the perception of delicacy.

Developing the typology from the mid-scale successfully allowed the envelope to react to external factors such as slope, site, programme, and circulation. Upon reflection, the typology is delicate in the sense that the design reacts to the external context rather than imposes on it. It was discovered that the typology has a malleable resilience where it takes on all these impositions while still maintaining its overarching curvilinear typology. This strengthened the argument surrounding the form. A weakness regarding the roof that floats above the typology is its cantilever, which could have been extended even further. The larger the eaves the less reflection on the glass below and the interior spaces would appear far more intimate below the giant canopy. This intention is evident in the final design, however it could have been pushed to its physical limits.

It became clear through the public-scale process that the argument was more about the perception and appearance of delicacy rather than actually designing a delicate and fragile building. As connections and details are hidden, structural members are reduced and the smoothness of each space blends into one another, the building creates an appearance of effortlessness where the complexities are hidden. This aligns with the common link between minimalism and delicacy. The argument is structured around buildings that look deceptively simple with new forms of complexity. As my design followed a similar minimal aesthetic, it was vital to develop the details and structural realisation of the building, working out those complexities. 
I found that considering the design proposition at every scale, from the big picture right down to the detail, was successful in developing and communicating my ideas. The plans and sections, which were weak at the August review were continually built up with information about the building's legibility, but also about how it can convey effortlessness, delicacy and intimacy through elements such as structure, materials and furniture. The overall coherency of the design comes from a consideration of every scale.

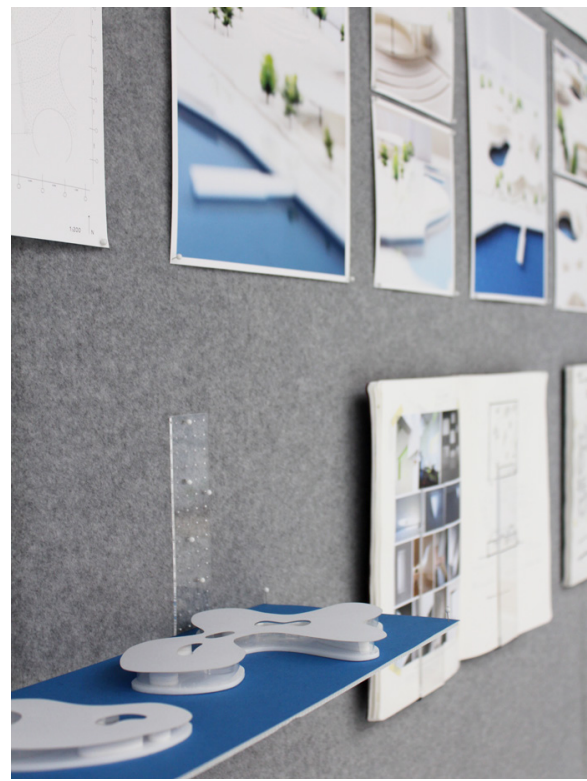

$\wedge$ 261. Final presentation zoom 


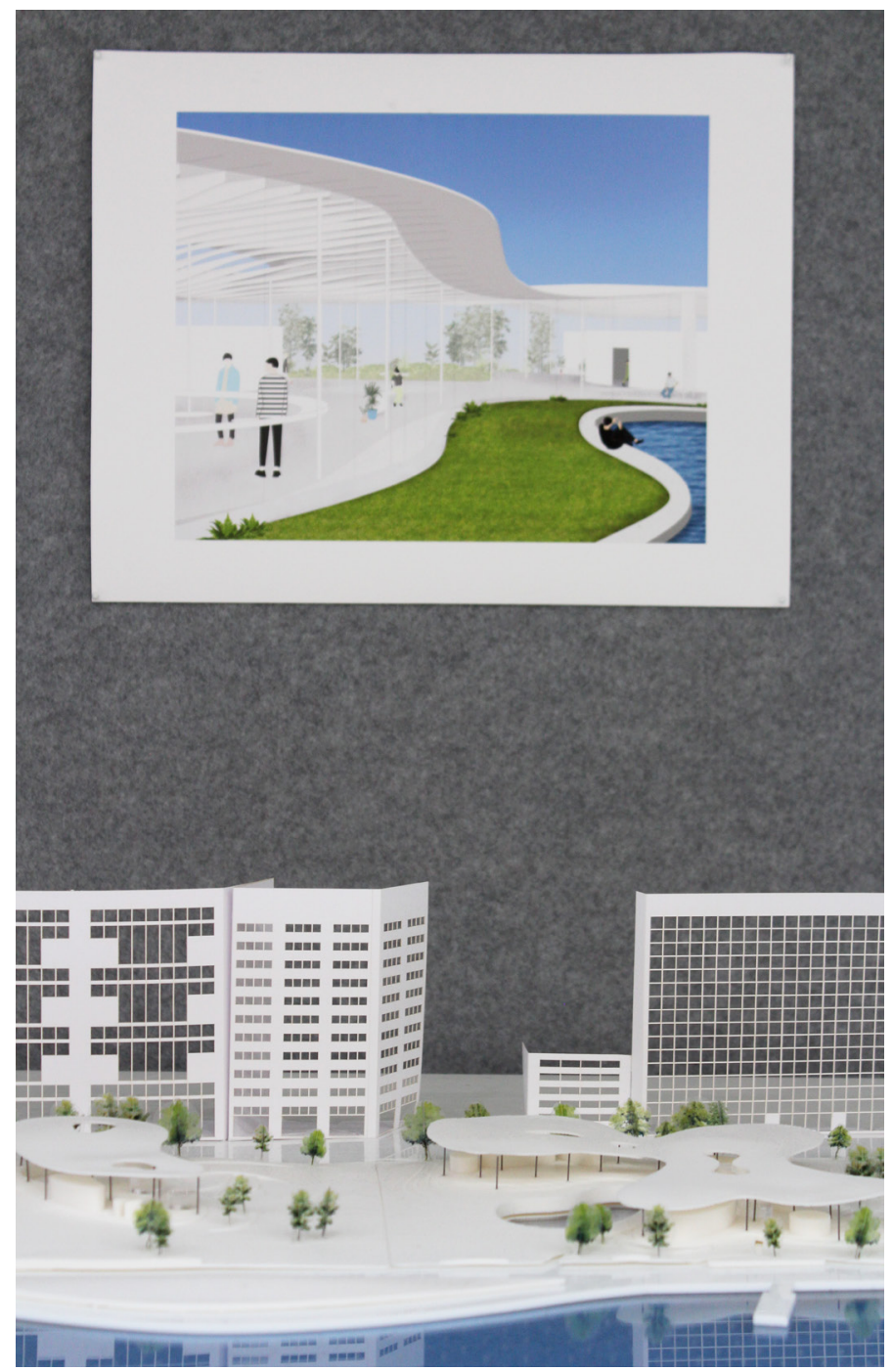


07

CONCLUSION 


\section{Summary}

This research questioned the notion of delicacy within architecture through three design tests that increase in scale and complexity. Approaching this research with a 'design-led research' methodology a defined area of interest was immediately investigated through design. Through this process, the proposition evolved and shifted from investigating the beautiful sublime to the notion of delicacy.

The literature context and case studies fed into the design process, further refining the proposition as it shifted. The literature review provided a historical understanding of aesthetics and beauty, the relationship between delicacy and minimalism with key figures, and developed a framework to evaluate delicacy. This evaluative framework was used to analyse three case studies relative to each design test scale as the proposition evolved. The analysis and evaluation of scale, materiality, and whiteness and colour continued throughout the design process.

The first design experiment was an installation that experimented with shifting scales. It investigated the beautiful sublime through focusing on the vast and the intimate scale. This was the initial defined area of interest. Working at a 1:1 scale the installation highlighted the importance of detailing, construction, materiality and the awareness of the human scale.

The second design experiment developed upon learning and successes from the installation into an architectural solution in the form of a café pavilion. The ideas regarding the vast and intimate scale were translated 
into an architectural outcome that dealt with complexities such as site, form and material. Each iteration and test was evaluated. These critical evaluations led to key explorations that investigated scaling up the installation, evaluating the importance of the roof, and investigating how to shape space with light, colour and material. Upon critical reflection at the end of this stage, the direction of the vast and the intimate scale was not as clear as exploring the notion of delicacy. The ideas behind the vast and the intimate scale, plus a discussion around the beautiful sublime were far too large, it lacked specificity. This was a pivotal shift in my research. I refined my proposition to question the notion of delicacy within architecture. In result, the scope was narrowed and shifted direction slightly.

The final experiment investigated delicacy through the design of a gallery and community centre. The previous design tests were still relevant to the body of research and were developed upon in relation to the proposition. Upon critical evaluation at each design test, key explorations were investigated; scaling up the mid-scale, generating a malleable and reactive typology, and exploring details in relation to delicacy. The final architectural outcome focused on the exploration of delicacy through scale, materiality, and colour and whiteness. Rather than investigating how to design delicate buildings, the research developed towards designing for the appearance of delicacy, with an emphasis on detail. In pursuit of 'effortlessness' the design attempted to capture the perception of delicacy. 


\section{Critical Reflection}

The designs and process are critically evaluated in relation to the scope of the research and disciplinary body of research through five key themes: general, scale, materials, details, and colour and whiteness.

\section{General}

By conducting this research through a design-led research methodology there were many discoveries made. The evident success of this methodology was the proposition refinement in an unexpected yet positive shift in direction. It was through the process of design and continual critical reflection that led to clarifying the proposition. However, through this non-linear methodology it became difficult to provide a clear explanation and overview of the entire research in a linear format. As the research continually oscillated between designs and ideas, it developed and shifted direction. The location and review of design precedents and literature review was essential as it provided direction and grounded the research within a wider body of knowledge.

The evaluative framework was successful in narrowing the research's scope and keeping the evaluations focused. Because of this, further critical reflections about the designs will be evaluated through the three key themes; scale, materiality, and colour and whiteness.

\section{Scale}

The three different design tests were successful in accelerating the design process in relation to the scope of the research. The forceful 'jump' in scale continually added complexities shifting from the installation to a final public-scale architectural outcome. These shifts also ensured that throughout the process the consideration of the human scale was maintained, even as the tests grew in considerable size. This became essential to my research. For example, the public-scale building was the 
final conclusive design, and despite its large scale, the details of furniture, connections and door-frames were still considered, as they were essential to the overall design. Despite the successes the method of jumping scales did limit the developed design at the mid-scale stage. Due to the pace at which each design experiment needed to be finished the café pavilion would have benefitted from more development. Rather than a final conclusive design, the café pavilion became part of the development towards the final public-scale design.

\section{Materiality}

SANAA was a key figure through the research, however their projects have a different focus. SANAA places a huge emphasis on atmosphere and using materials as optical intensifiers. Although this is an interesting inquiry, my research was investigating material properties for the effects of smoothness and lightness rather than the direction of atmospheric qualities through reflection and refraction. A weakness of this reflection would reveal that SANAA has a more extensive exploration with materials and their effects than what I managed to explore.

\section{Details}

Within exploring the appearance of delicacy through materials, a major discovery was how the research revealed opportunities for reconsidering details and standard connections in favour of the delicate. After thorough analysis of SANAA's details I evaluated their ability to create "architecture without visible joints" (Wigley, 2015, p. 29). SANAA succeeds in creating deceptively seamless connections, linking back to the relationship between delicacy and minimalism where they combine architectural complexities with deceptively simple solutions. Applying and developing what I learnt from SANAA, the details I developed attempted to create a delicate architectural solution with an appearance of lightness and effortlessness. These details I believe were successful at communicating the proposition at another scale. 


\section{Colour + Whiteness}

As the research developed in the direction of delicacy there was more emphasis on materiality and whiteness. Whiteness became increasingly successful throughout each design scale. The bright ephemeral quality of colour evident in the installation however, was slowly lost. The installation was the most successful design outcome that explores colour, it was favourable and charming. A weakness of this is perhaps the forceful nature as I tried to integrate colour in every scale when it never reached the same success as the installation. Colour transitioned from an artificial application to the natural. The intimate engagement with colour was integrated with the honest expression of materials. Despite the interest and discovery in highlighting colour embedded in materials, a weakness would be its lack of visibility in the final building. Through representational drawings, material colour expression other than white is rarely evident.

This shift from the artificial to the natural, however did lead to discovery of highlighting the context to colour the building. Or, acknowledging that architecture is intended to be occupied, therefore it is the people who colour buildings. This shift occurred through unsuccessful executions with artificial colour and the arguments made in Mattie's book (2015). Mattie brings together architects who discuss colour both artificial and natural. The natural aspect lead to considering the external environment and its diurnal and seasonal shifts effecting the perception on the building's material and colour. White for example Richard Meier argues, "is the ephemeral emblem of perpetual movement, the white is always present but never the same" (cited in Jong, 2015, p. 11). The colour continually shifts with elements such as light and layers. 


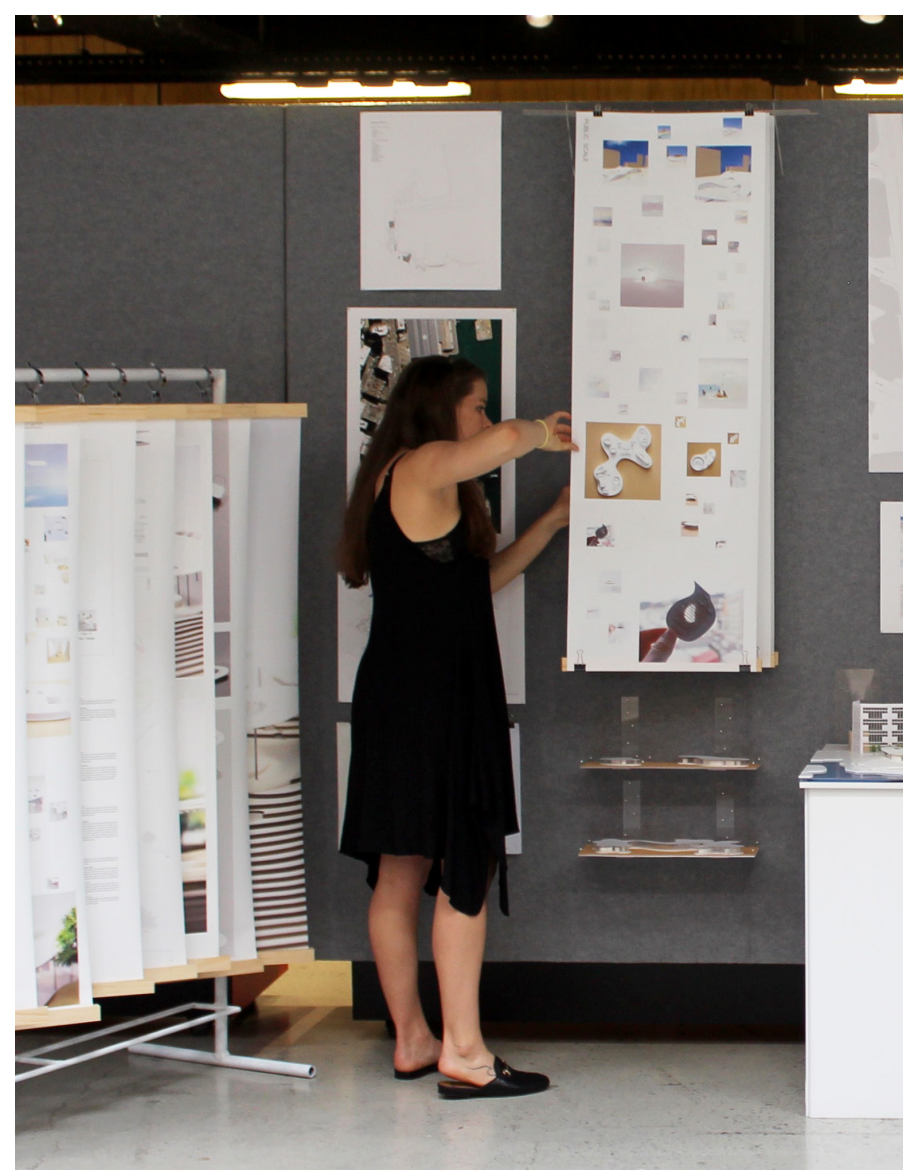

$\wedge$ 263. Final presentation layering of design process 


\section{Future Direction}

Throughout the mid-scale and public-scale design tests, my choice of materials were fairly consistent which I found successful in the final outcome. However, a future direction for this research would be to expand upon this further. Timber, for example, is a popular material in the New Zealand building industry, and can be argued to be delicate and light, therefore in relation to my proposition it begs the expression of delicacy. Foster + Partners have recently completed a visitor centre for Apple which clearly tests material properties in relation to delicate extremities. Apple is a key contemporary figure in slender technology now has a building that reflects this. The carbon fibre roof, lined with timber "sails over its transparent walls" creating "delicate pavilion" (Howarth , 2017, p. np). Thus a future development would be accentuating the materiality through expansive explorations with material advancements. Neri\&Hu architects for example explore delicacy with brass in their design of the Sulwhasoo Flagship Store. The design highlights fragility and contrast. Neri\&Hu consider "the journey is a constant contradiction between two counterparts: enclosed to open, dark to light, delicate to massive" (cited in Griffiths, 2016, np). The direction of latticework and extreme interior spatial contrasts could have been another approach that this research could have investigated. 


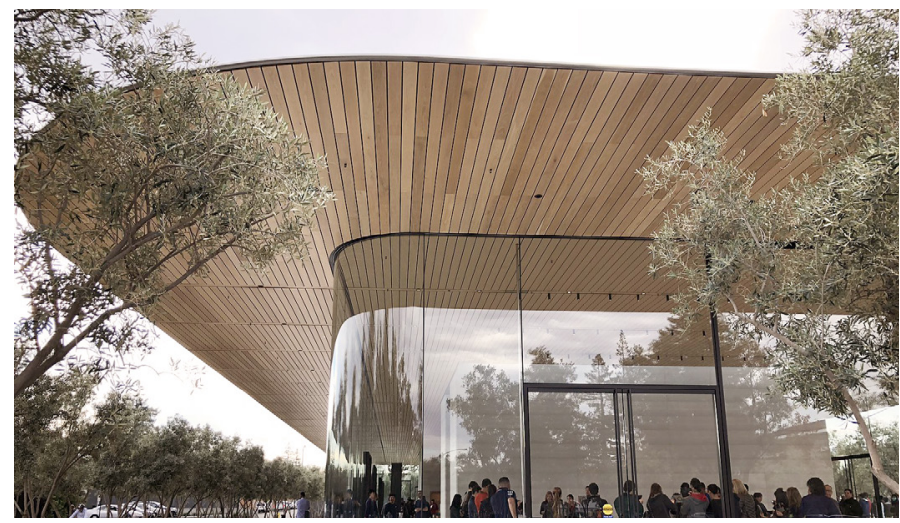

^ 264. Foster + Partners, Apple Park Visitor Centre (Ez7b4q, 2017)

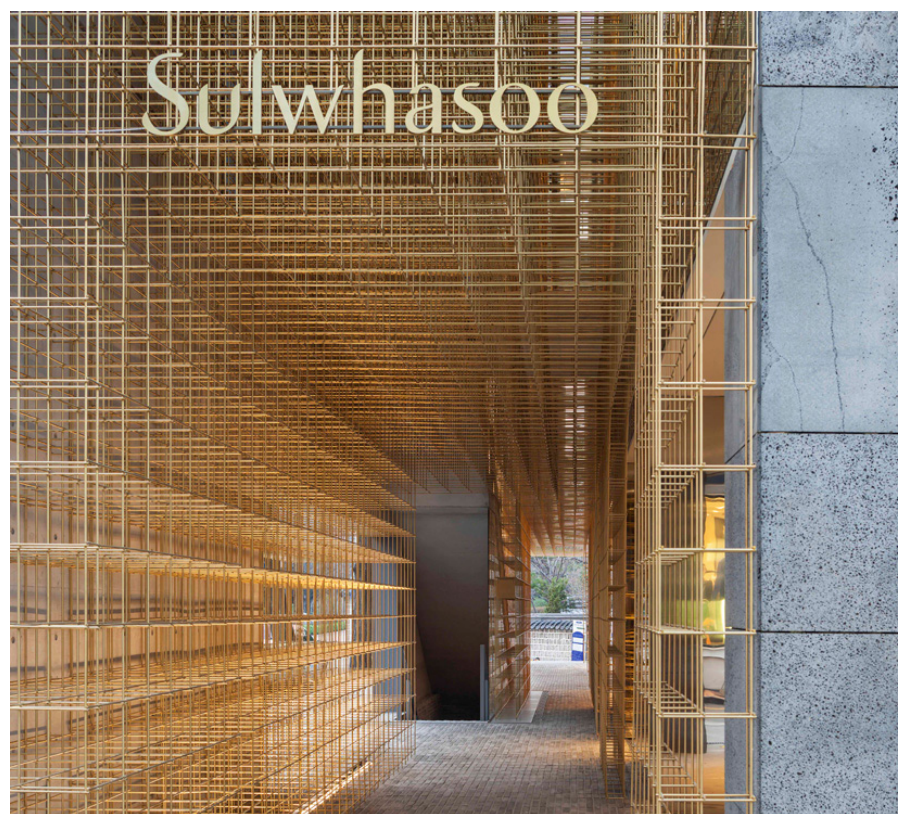

$\bigwedge$ 265. Neri \& Hu, Sulwhasoo Flagship Store (Pegenaute, 2016) 


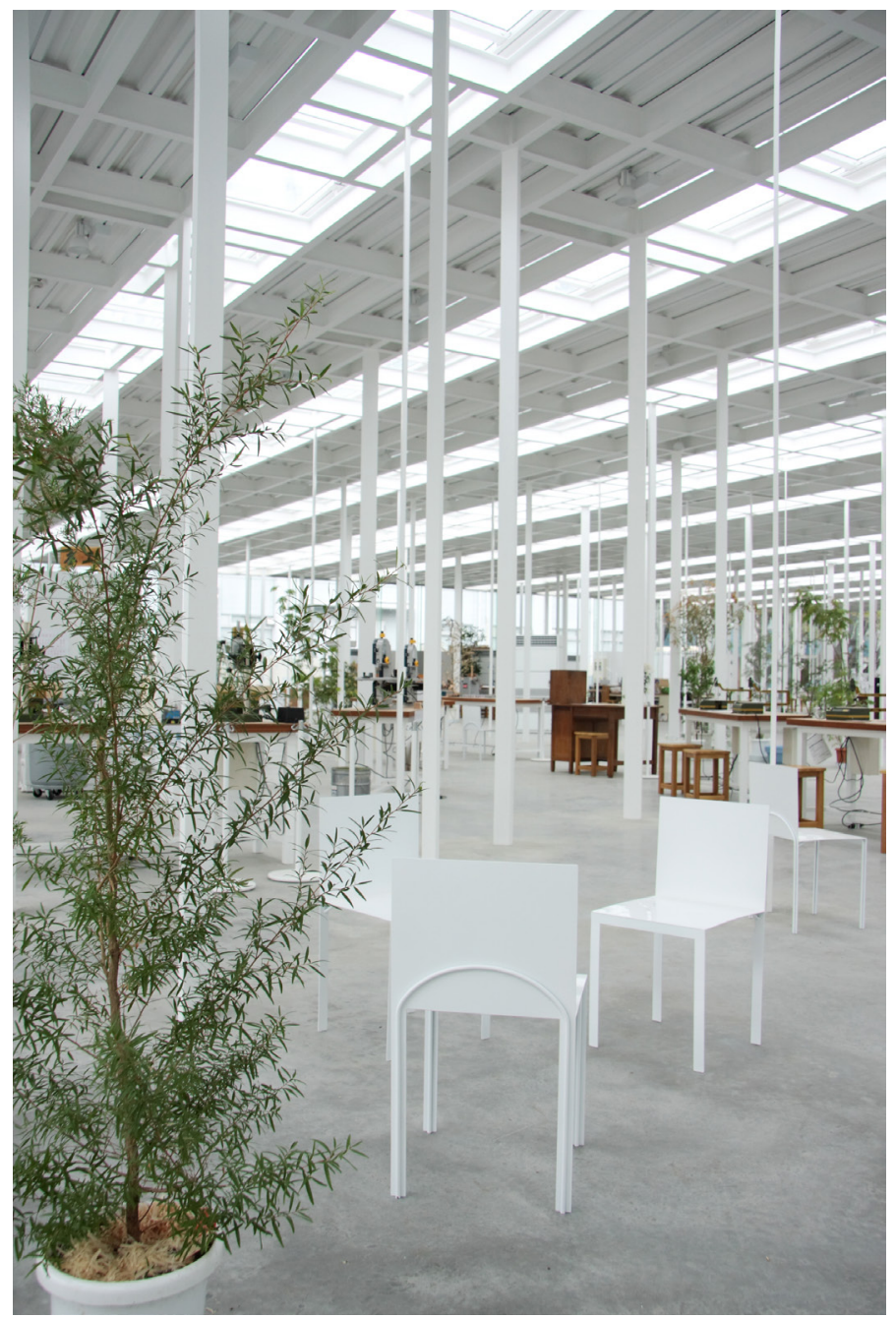

$\wedge$ 266. Junya Ishigami, Kanagawa Institute of Technology (Fujii, 2008) 
Technological advancements in the area of making is another future direction for this research. Although the research's proposition was not focused on the methods of making and production, it was experimented with to produce physical models. Routers and 3-d printers for example, have the capacity to create extremely delicate and precise objects and the future potential is extremely positive.

There is also potential for further research in this subject of delicacy in relation to structure to positively inform and enrich architecture's aesthetic possibilities. Clark and Pause argue, structure "becomes inextricably linked to the very elements which create architecture, its quality and excitement" (cited in Charleson, 2015, p. 1). Structure, materials and details are part of the essential elements that create architecture. Encouraging and highlighting the beauty of details adds immense value to the building. For example Ishigami's 'Kanagawa Institute of Technology' is composed of a dense structural framework of a multitude of slender columns. This architectural environment "suggest[s] they are working within a forest" (Charleson, 2015, p. 93). Charleson argues there are many possibilities to interpret Ishigami's interior structural environment such as "informality, unpredictability, lightness and delicacy" (2015, p. 94). Ishigami is part of the young contemporary architects that explore lightness and delicacy with a focus on structural, material, detail and aesthetic expression. 


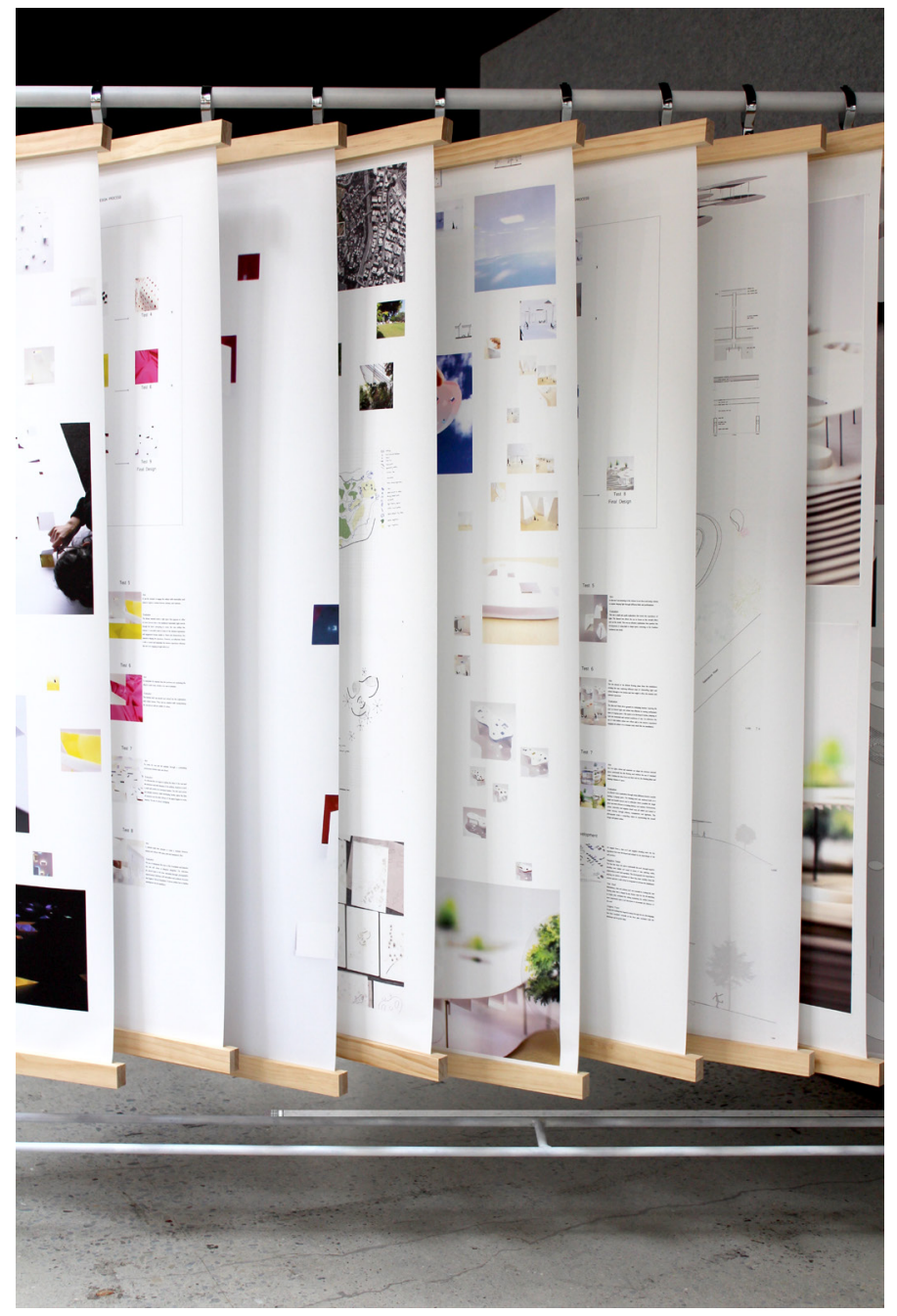

$358 \wedge 267$. Final presentation installation and mid-scale 


\section{Conclusion}

The concluding critical reflection on the designs in relation to the scope of the research and the disciplinary body of knowledge is considering the proposition consistently at every scale of the design. The coherency of the designs develops from acknowledging the overall, down to the detail. This is evident by working across three different scales that increase in size, learning the complexities and how to make the proposition clear with each scale jump. However, this is also evident throughout the three design tests as they explored overarching forms and envelopes but also investigated the furniture and material details.

To conclude, through my proposition I have investigated the notion of delicacy through multiple scales and through the final design explored how to design a seemingly effortless building, one that evokes the perception of delicacy. As connections and details are hidden, structural members are minimalised and the smoothness of each space blends into one another, and the building creates an appearance of effortlessness where the complexities are hidden. 


\section{BIBLIOGRAPHY}

Adler, G. (2012). Introduction. In G. Adler, T. Brittain-Catlin, and G. FontanaGiusti (Eds.), Scale: Imagination, Perception and Practice in Architecture (pp. 1-10). Oxon: Routledge.

Allen, S. (2010). SANAA's Dirty Realism. In F. Idenburg (Ed.), The $S A N A A$ studios 2006-2008 : learning from Japan: single story urbanism / School of Architecture, Princeton University. (pp. 58-67). Baden: Lars Muller.

Austin, J. L. (1956-1957). A Plea for Excuses: The Presidential Address. Proceedings of the Aristotelian Society, New Series, 57, 1-30.

Bertoni, F. (2002). Minimalist Architecture. Basel, Boston, Berlin: Birkhauser.

Brownell, B. (2011). Matter in the Floating World: Conversations with leading Japanese Architects and Designers. New York: Princeton Architectural Press.

Burke, E. ([1773]1958). A Philosophical Enquiry into the Orgin of our ideas of the Sublime and Beautiful. (J. T. Boulton, Ed.) London: Routledge and Kegan Paul Limited.

Charleson, A. (2015). Structure as architecture: a source book for architects and structural engineers. New York: Routledge.

Colomina, B. (2015). Unclear Visions. El Croquis 20112015 SANAA (179/180), 391-397.

Colquhoun, A. (2002). Modern Architecture. Oxford: Oxford University Press.

Frampton, K. (1980). Modern Architecture: A Critical History. London: Thames and Hudson Ltd. 
Fraser, M. (2013). Introduction. In P. Downton, and M. Fraser (Ed.), Design Research in Architecture: an overview (pp. 1-14). Surrey: Ashgate Publishing Ltd.

Fraser, M. (2013). Introduction. In P. Downton, and M. Fraser (Ed.), Design Research in Architecture: an overview (pp. 1-14). Surrey: Ashgate Publishing Ltd.

Goodwin, K. (2013, November 11). Meet the architects: Grafton sensing spaces. Retrieved April 17, 2017 from: https://www.royalacademy.org.uk/ article/meet-the-architects-grafton

Griffiths, A. (2016, May 24). Delicate brass framework divides spaces inside Nerie $H_{u}$ 's Sulwhasoo flagship store. Retrieved December 7, 2017: https://www.dezeen. com/2016/05/24/neri-hu-sulwhasoo-flagship-store-seoul-south-koreabrass-framework-lattice/

Griffiths, A. (2017, February 25). Kubota Architect Atelier combines delicately tapered surfaces with sturdy concrete walls for FU House. Retrieved from July 30, 2017: https://www.dezeen.com/2017/02/25/kubota-architect-ateliers-fuhouse-delicate-sturdy-concrete-walls-architecture-shunan-japan/

Grinda, E. G., and Moreno, C. D. (2004, Summer). Ocean of Air. El Croquis: Sanaa : Kazuyo Sejima, Ryue Nishizawa, 1998-2004, pp. 27-39.

Hartt, M. (2008). Retrieved March 25, 2017 from: http://mairinhartt.com/ section/261968_Miniature_Sublime.html

Holl, S. (2000). Parallax: Steven Holl. New York: Princeton Architectural Press.

Holt, M., and Looby, M. (2010 12-December). Junya Ishigami: Architecture as Air. Retrieved December 2, 2017 from: https://www.domusweb.it/en/ architecture/2010/12/12/junya-ishigami-architecture-as-air.html

Howarth , D. (2017, November 21). Foster + Partners' Apple Park Visitor Center opens to the public. Retrieved December 12, 2017 from: https://www.dezeen. com/2017/11/21/foster-partners-apple-park-visitor-center-opens-tothe-public/ 
Jong, C. W. (2015). Introduction. In E. Mattie (Ed.), The Colours of... :Frank O. Gehry, Jean Nouvel, Wang Shu and Other Architects (pp. 7-19). Basel: Birkhauser.

Kant, I., and Meredith, J. C. (1911). Kant's Critique of Aesthetic Judgement. Oxford: Clarendon Press.

Kazuyo Sejima and Ryue Nishizawa 2010 Laureates: Jury Citation. (n.d.). Retrieved August 1, 2017 from: http://www.pritzkerprize.com/2010/jury

Kirk, J. (2012). Re-reading Japan: SANAA's Relational Architecture: A reflection on the EPFL Learning Centre, Lausanne. (Dissertation) University of Westminster, Architecture.

Kirk, P. J. (2007). The infinite and the intimate: notes for an architecture of meditative bliss. Shelley: Friend Books.

Krohn, C. (2014). Mies van der Robe-The Built Work . Basel: Birkhauser.

Kulper, P. (2012, August 5). Drawing Architecture - Conversation with Perry Kulper. Retrieved May 2, 2017 from: http://archinect.com/news/ article/54767042/drawing-architecture-conversation-with-perry-kulper

Marques, B. (2017). 2017 Research Portfolio Outline ARCI/INTA/LAND 593. Wellington.

Mattick, P. (2003). Art in its Time: Theories and practices of modern aesthetics. London: Routledge.

Mattie, E. (2015). Colour in Perspective. In E. Mattie (Ed.), The Colours of... :Frank O. Gehry, Jean Nouvel, Wang Shu and Other Architects (pp. 224-235). Basel: Birkhauser.

Meyer, E. K. (2008). Sustaining beauty: The performance of appearance. A manifesto in three parts. Landscape Architecture, 3(1), 6-23. 
Moreno, C. D., and Grinda, E. G. (2004). Liquid Playgrounds. El Croquis: Ocean of Air: SANAA Kazuyo Sejima Ryue Nishizawa 1998-2004(121/122), 9-25.

Mosco, V. P. (2012). Naked Architecture. Milan: Skira Editore.

Mostafavi, M. (2010). A Conversation with Kazuyo Sejima and Ryue Nishizawa. El Croquis: SANAA 2008-2011, 6-16.

Mostafavi, M. (2011). Inorganic Architecture. El Croquis: SANAA 2008-2011, 245-251.

Ngai, S. (2005). The Cuteness of the Avant Garde. Critical Enquiry, 31(4), 811847.

Ngai, S. (2015). Our aesthetic categories : zany, cute, interesting. Harvard University Press.

Nickelsen, A. (2010 Jan-Feb). White: a delicate explosion of color: render the elusive, subtle colors present in white objects, using colored pencil. The Artist's Magazine, 34-35.

Obrist, H. U. (2012). SANAA Kazuyo Sejima and Ryue Nishizawa: The Conversation Series 26. Cologne: Verlag der Buchhandlung Walther Konig.

O’Byrne, C. (2016). Evaluating the Influence of Governance on the Built Form: The redevelopment of Wellington, New Zealand's waterfront precinct. Wellington: Victoria University of Wellington.

O’Gorman, R., \& Werry, M. (2012). On Failure (On Pedagogy): Editorial Introduction. Performance Research, 17(1), 1-8.

Okayama University. (2015, February). The Opening Ceremony at the Junko Fukutake Terrace. Retrieved May 20, 2017 from: http://www.okayama-u.ac.jp/user/ kouhou/ebulletin/news/vol10/news_002.html

O'Sullivan, S. (2001). The Aesthetics of Affect: Thinking art beyond representation. Angelaki, 6(3), 125-135. 
Reisner, Y., and Watson, F. (2010). Architecture and Beauty: Conversations with architects about a troubled relationship. Sussex: John Wiley and Sons Ltd.

Rendell, J. (2013). A Way with Words. In M. Fraser (Ed.), Design Research in Architecture: an overview (pp. 117-136). Surrey: Ashgate Publishing Ltd.

Ruby, I., Ruby, A., Sachs, A., \& Ursprung, P. (2003). Minimal Architecture. Munich, Berlin, London, New York: Prestel.

Safont-Tria, J., Kwinter, S., and Holl, S. (2012). Steven Holl: Colour Light Time. Zurich: Lars Muller Publishers.

Scruton, R. (1979). The Aesthetics of Architecture. London: Methuen and Co Ltd.

Spector, T. (2006/2007 Fall/Winter). The Morals of Modernist Minimalist. Harvard Design Magazine, 84-90.

Stevens, P. (2015, September 11). SANAA sets okayama university café beneath sinuous steel canopy. Retrieved May 22, 2017 from https://www. designboom.com/architecture/sanaa-junko-fukutake-terrace-okayamauniversity-09-10-2015/

Sudjic, D. (2006). The lightness of being. In K. Feireiss (Ed.), Kazuyo Sejima + Ryue Nishizawa SANAA : The Zollverein School of Management and Design Essen, Germany (pp. 44-59). Munich, London, New York: Prestel.

Twose, S., and Smitheram, J. (2009). The Paper Life of Building: Performative intra-action. Interstices: Journal of Architecture and Related Arts(11), 49-61.

Vasilski, D. (2015). Minimalism in Architecture as a cultural symbol of the times. (PhD Thesis) University Union, Faculty of Construction Management, Serbia.

Wellington Regional Economic Development Agency. (n.d.). Wellington Waterfront. Retrieved June 2017, from Wellington NZ: https://www.wellingtonnz. com/discover/sights-activities/wellington-waterfront/

Wigley, M. (1995). White Walls, Designer Dresses. Cambridge, Mass: The MIT Press. 
Wigley, M. (2015). How thin is thin? El Croquis: SANAA Kazuyo Sejima, Ryue Nishirawa, 2011-2015(179/180), 27-39.

Wilkinson, C. (2001). Lightness and Delicacy. In C. Wilkinson, and J. Eyre, Bridging Art \& Science (pp. 32-43). London: Booth-Clibborn Editions.

Wybe, K. (2015). Borrowing scenery and the landscape that lends- the final chapter Yuanye. Journal of Landscape Architecture, 10(2), 32-43.

Yaneva, A. (2005, December). Scaling Up and Down: Extraction Trials in Architectural Design. Social Studies of Science, 35(6), 867-894. 


\section{FIGURES LIST}

Unattributed figures belong to the author

05. lietz.photo. (2011, January 28). Neue Nationalgalerie, Berlin. Retrieved November 24, 2017 from https://www.flickr.com/photos/joe_leads/5455613489

06. Teer, M. (2010, October 21). The New Museum, SANAA, New York.

Retrieved October, 132017 from https://www.flickr.com/photos/ marcteer/ 5459831348

07. Lanoo, J. (2012, December 12). SANAA - Louvre Lens Museum.

Retrieved October 13, 2017 from https://www.flickr.com/photos/ eager/10780996675

08. Hartt, M. (2012). Installation View 1. Retrieved March 25, 2017 from http:// mairinhartt.com/artwork/2609109_Installation_View_1_Miniature_ Sublime.html

09. The Miniature Sublime Series:

-Hartt, M. (2012). tefilvaercos. Retrieved March 25, 2017 from: http:/ / mairinhartt. com/artwork/2609084_tefilvaercos.html

-Hartt, M. (2012). nasvtess. Retrieved March 25, 2017 from http://mairinhartt. com/artwork/2609104_nasvtess.html

- Hartt, M. (2012). avitpiron. Retrieved March 25, 2017 from http://mairinhartt. com/artwork/2609082_avitpiron.html

-Hartt, M. (2012). ertero. Retrieved March 25, 2017 from http://mairinhartt.com/ artwork/2609105_ertero.html

10. Hartt, M. (2012). Installation View 3. Retrieved March 25, 2017 from http:// mairinhartt.com/artwork/2609086_Installation_View_3_Miniature_ Sublime.html 
11. Harris, J. (2014). Grafton Architects, Sensing Spaces installation. Retrieved April 12, 2017 from https://www.royalacademy.org.uk/exhibition/sensing-spaces

12. De Arriba, L. (2014, February 3). Sensing Spaces. Retrieved April 12, 2017 from https://aglaeas.wordpress.com/2014/02/03/sensing-spaces/

13. Carl Court/Getty Images. (2014). Sensing Spaces: Architecture Reimagined -review. Retrieved April 17, 2017 from https://www.theguardian.com/ artanddesign/2014/jan/26/sensing-spaces-royal-academy-review

14. Japanese architecture matrix:

-Alves, D. (2013, June 25). Sou Fujimoto Pavilion, Serpentine Gallery. Retrieved September 5, 2017 from https://www.flickr.com/photos/ dominicspics/9127854121/in/photostream/

-Alves, D. (2013, June 25). Sou Fujimoto Pavilion, Serpentine Gallery. Retrieved September 5, 2017 from https://www.flickr.com/photos/ dominicspics/9127854121/in/photostream/

-Fujii, N. (2008, April 12). Facility of Kanagawa Institute of Technology. Retrieved September 5, 2017 from https://www.flickr.com/photos/ naoyafujii/2409782486/in/photostream/

-Kurihara, K. (2013). Aichi Sangyo University College of Language and Information. Retrieved September 5, 2017 from http://www.studiovelocity.jp/ works/030-2013-ASU/works-ASU.html

-Wiiii. (2007, September 25). Tama Art University Library, at Hacbiouji, Tokyo, Japan, designed by Toyo Ito in 2007. Retrieved from https://commons.wikimedia. org/wiki/File:Tama_Art_University_Library2.JPG

15. Okayama University. (2015). Sanaa: junko fukutake terrace . okayama. Retrieved June 1, 2017 from http://afasiaarchzine.com/2015/09/sanaa-30/

16. Okayama University. (2015). Sanaa: junko fukutake terrace . okayama. Retrieved June 1, 2017 from http://afasiaarchzine.com/2015/09/sanaa-30/

17. Okayama University. (2015). Sanaa: junko fukutake terrace . okayama. Retrieved June 1, 2017 from http://afasiaarchzine.com/2015/09/sanaa-30/ 
67. Google. (2017). Map Data: Wellington City. Retrieved April 20, 2017 from https://www.google.co.nz/maps/place/Wellington/@$41.284014,174.7681083,982 \mathrm{~m} / \mathrm{data}=! 3 \mathrm{~m} 1 ! 1 \mathrm{e} 3 ! 4 \mathrm{~m} 5 ! 3 \mathrm{~m} 4 ! 1 \mathrm{~s} 0 \times 6 \mathrm{~d} 38 \mathrm{~b} 1 \mathrm{fc} 49$ e974cb:0xa00ef63a213b470!8m2!3d-41.2864603!4d174.776236

80. Warchol, P. (1992). D.E. SHAW \& CO. OFFICES. Retrieved April 29, 2017 from http://www.stevenholl.com/projects/de-shaw-offices

81. Titz, T. (2016). Glenn Murcutt: Architecture of Faith. Retrieved April 30, 2017 from https://www.ngv.vic.gov.au/exhibition/glenn-murcutt/. Website: http://tobiastitz.de

82. Koji Fujii / Nacasa and Partners. (2015). Rainbow Chapel / Kubo Tsushima Architects. Retrieved April 24, 2017 from https://www.archdaily. com/771396/rainbow-chapel-kubo-tsushima-architects/55c23c93e58ece fd9200018a-rainbow-chapel-kubo-tsushima-architects-photo

127. Google. (2017). Map Data: Wellington City. Retrieved June 19, 2017 from https://www.google.co.nz/maps/place/Wellington/@$41.284014,174.7681083,982 \mathrm{~m} /$ data $=! 3 \mathrm{~m} 1 ! 1 \mathrm{e} 3 ! 4 \mathrm{~m} 5 ! 3 \mathrm{~m} 4 ! 1 \mathrm{~s} 0 \times 6 \mathrm{~d} 38 \mathrm{~b} 1 \mathrm{fc} 49$ e974cb:0xa00ef63a213b470!8m2!3d-41.2864603!4d174.776236

170. Masunaga, K. (2017). FU House by Kubota Architect Atelier. Retrieved July 30, 2017 from https://www.dailyicon.net/2017/03/fu-house-by-kubotaarchitect-atelier/

264. Ez7b4q. (2017, November 15). Apple Park Visitor Center. Retrieved from https://commons.wikimedia.org/wiki/File:Apple_Park___Visitor_ Center_-_Side_view_-_November_2017.jpg

265. Pegenaute, P. (2016). neri \& bu inserts delicate brass frame into sulwhasoo flagship in seoul. Retrieved December 7, 2017 from https://www.designboom. $\mathrm{com} /$ architecture/neri-hu-sulwhasoo-skincare-flagship-store-gangnamseoul-05-24-2016/

266. Fujii, N. (2008, April 12). Facility of Kanagawa Institute of Technology. Retrieved from November 21, 2017 https://www.flickr.com/photos/ naoyafujii/2408949625/in/photostream/ 
Illustration people that appear in images: 142. 143. 144. 145. 146. 147. 148. 150. 152. 155. 156. 157. 159. 160. 161. are sourced from: Pugsley, Kate. (n.d). Illustrations. Retrieved July 10, 2017 from https://www.katepugsley.com/

Illustration people that appear in images: 255. 256. 257. 258. 259. are sourced from: A:LOG. (n.d) Drawings: Scalies. Retrieved October 19, 2017 from https://www.projectalog.com/drawings/?category=Scalies 